\title{
PROBABILIDADE DE ATENDIMENTO NATURAL DAS NECESSIDADES HIDRICAS DOS CITROS NO ESTADO DE SAO PAULO
}

\author{
ELISEO LECLERC SEQUEIRA SAMPAIO \\ Engenhei ro Agrónomo
}

Orientador: Dr. ALIINO ALDO ORTOLANI

Dissertação apresentada à Escola Superior de Agrlcultura "Luiz de Queiroz". da Úniversidade de São Paulo, para obtenção do titulo de Mestre em Agronomia, Área de concentração: Agrometeorologia.

P I R A C I C A B A

Estado de Sao Paulo - Brasil

Outubro - 1990 
Ficha catalográfica preparada pela Seção de Livros da Divisão de Biblioteca e Documentação - PCAP/USP

Sequeira Sampaio, Eliseo Leclerc

S479p Probabilidade de atendimento natural das necessi dades hídricas dos citros no Estado de São Paulo. Piracicaba, 1990.

$147 \mathrm{p}$.

Diss. (Mestre) - ESALQ

Bibliografia.

1. Fruta citrica - Balanço hídrico - São Paulo (Estado) I. Escola Superior de Agricultura Luiz de Queiroz, Piracicaba

CDD 634.3 
PROBABILIDADE DE ATENDIMENTO NATURAL DAS NECESSIDADES HIDRICAS DOS CITROS NO ESTADO DE SAO PAULO

Aprovada em: 21.11 .1990 . in:

Comissaão julgadora:

Dr. Altino Aldo Ortolani IAC.

Prof. Dr. Nilison Augusto Vijia Nova ESALQVUSP

Dr. Mario Jose Pedro Jumior IAC. 


\section{Dedico}

A minha mãe, Catharina,

$$
\text { por ter me dado a vida }
$$

A meus sogros, Ruben e Alba, por seu constante apóio, dedicação e sacrificio

A minha esposa, Amalia, e meus filhos Enrique, Jorge e Alejandro, por seu constante apoio, e pelo seu sacrificio, às vezes maior do que o meu, suportado durante 29 longos meses de separaçăo 


\section{Agradeci mentos.}

Ao Dr. Altino Aldo Ortolani, pela amizade, estimulo e orientação em todas as fases deste trabalho.

Aos Profesores do Curso de Pós-Graduação em Agrometeorologia, pelos ensinamentos.

Aos Drs. P. Vidal e J. Quaggio, pelo fornecimento das informações requeridas.

Aos funcionarios do Departamento de Fisica e Meteorologia da Escola Superior de Agricultura "Luiz de Queiroz"/USP, e da Seção de Climatología Agrícola do Instituto Agronómico de Campinas, pela colaboração prestada.

Aos colegas do Curso de Pós-Graduação em Agrometeorologia, pela satisfação de te-los conhecido, trabal hado junto e desfrutado de sua amizade.

As familias Colafranceschi, Castiglioni, Doni e Olivera, por seu apoio e estimulo em todo momento.

A Escola Superior de Agricultura "Luiz de Queiroz"/USP e a Direção Nacional de Meteorologia do Uruguai, pela oportunidade concedida.

A Organização Meteorológica Mundial, pela conceção da bolsa de estudos.

Ao Instituto Agronómico de Campinas, pelo fornecimento dos dados e instal ações necessários.

A todos que direta ou indiretamente colaboraram para o bom desenvolvimento desta pesquisa. 
SUMARIO

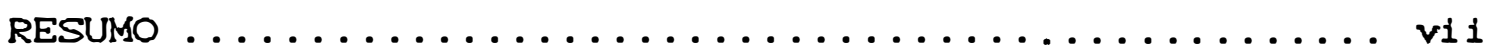

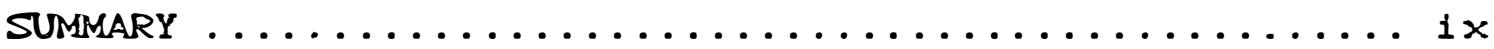

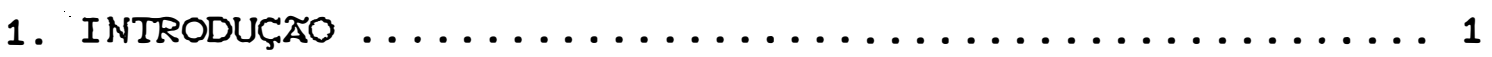

2. REVISATO DE LITERATURA ....................

2.1. Origem e propagação da cultura ............. 3

2.2. Areas de producão ..................... 3

2.3. Exigências climaticas ................... 4

2.4. Exigencias de solos ...................

2.5. Necessidades hídricas ..................8

2.6. Influencia dos porta-enxertos .............10

2.7. Caracterização da zona produtora paulista .....11

2.7.1. Distribuiçăo espacial .............11

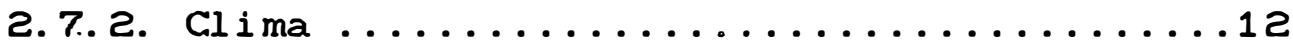

2.7.3. Solos .....................13

2.7.4. Variedades e porta-enxertos ...........15

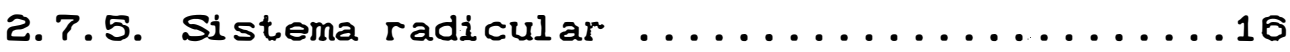

2.7.6. Disponibilidade de agua nos solos ......17

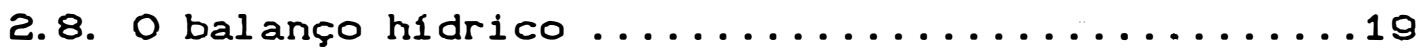

2.8.1. Precipitaçăo e irrigaçăo .............19

2.8.2. Deflúvio superficial e drenagem profunda .20

2.8.3. Evapotranspiração .................21

2.8. 4. Variação de armazenamento da água do solo 22

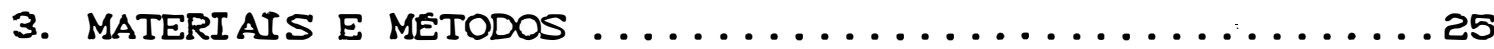

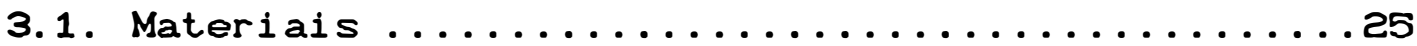

3.1.1. Dados meteorologicos ................25

3.1.2. Capacidade de armazenamento de água do

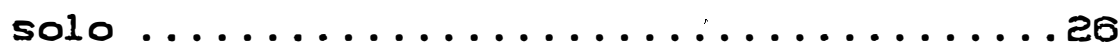

3.1.3. Equi pamento de computaçăo .. ...........27

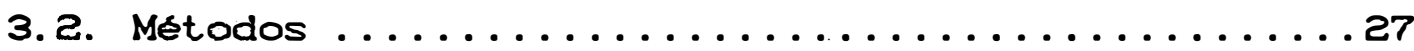

3.2.1. Estimativa da evapotranspiração ........27

3. 2. 2. Balanço hidrico ....................29 
3.2. 3. Análise estatistica .......................

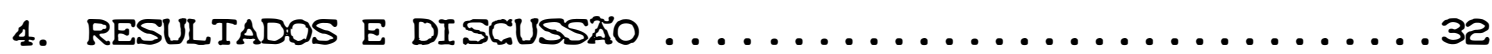

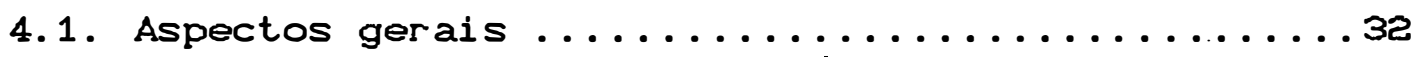

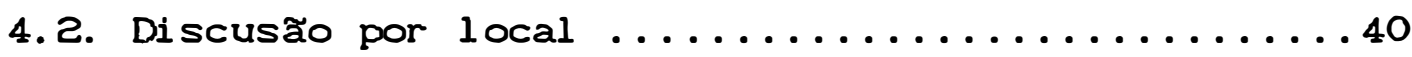

4.2.1. Campinas .......................40

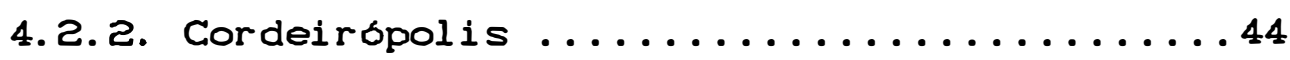

4.2.3. Jaú ........................... 48

4.2.4. Pindorama ....................51

4.2.5. Ribeirão Preto ...................55

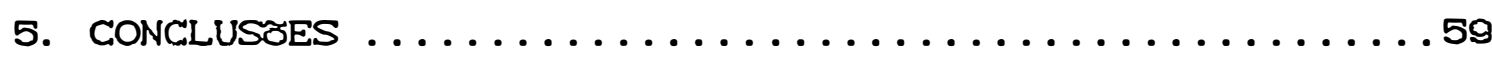

REFERENCIAS BIBLIOGRAFICAS . . . . . . . . . . . . . 61

ANEXO 1 (Tabelas de dados para calculos) ...........73

ANEXO 2 (Tabelas de resultados $\ldots \ldots \ldots \ldots \ldots \ldots . \ldots \ldots$ 


\section{PROBABILIDADE DE ATENDIMENTO NATURAL DAS NECESSIDADES HIDRICAS DOS CITROS NO ESTADO DE SAO PAULO}

Autor: ELISEO LECLERC SEQUEIRA SAMPAIO Orientador: DR. ALTINO ÁLDO ORTOLANI

RESUKO

A concentração da citricultura brasileira no Estado de São Paulo está fundamentada, além de fatores culturais e.tecnológicos, em condiçơes climáticas e edáficas favoráveis. Em cerca de $90 \%$ do território paulista predominam climas mesotérmicos úmidos tropicais de altitude, com verão úmido (outubro-março) e um inverno com temperaturas e precipitações pluviais mais reduzidas (abril-agosto). Os valores médios da evapotranspiração e de precipitação pluvial, quando confrontados, resultam em balanços hídricos favoráveis ao cultivo dos citros, quer no aspecto quantitativo como qualitativo. A citricultura da região paulista, compete no mercado mundial sem utilização da irrigação.

Em anos eventuais, dependendo da região, ou do sistema de produção, ocorrem reduções de produção condicionadas por irregularidades do regime pluviométrico que se reflete pelos episódios de seca, seja no periodo de repouso e maturação, ou mesmo na estação de crescimento em pleno verão úmido. Quando se decompãe os valores médios do balanço hidrico em periodos curtos, dificilmente se constata um equilibrio. O gráu de aptidão agroclimática para citros vai depender da probabilidade de atendimento natural da demanda hídrica.

Com o principal objetivo de calcular os 
niveis de probabilidade de atendimento natural das necessidades hídricas de pomares cltricos em cinco regižes do Estado de São Paulo, foram realizados balanços hidricos com dados decendiais de chuva e evapotranspiração máxima (ETm), para as localidades de Campinas, Cordeirópolis, Jaú, Pindorama e Ribeirão Preto.

A ETm foi estimada combinando a equação encontrada por Villa Nova e Ometto (1981) e os coeficientes do cultivo sugeridos por Vieira (1984), para pomares não irrigados.

- balanço hidrico foi calculado sequiencialmente para 30 anos consecutivos, para quatro níveis de disponibilidade hidrica $(30,40,50$ e $75 \mathrm{~mm}$ de água fácilmente disponivel - AFDJ, representativos para citros e para os principais tipos de solos dessas localidades. Em Pindorama, usou-se tambem o nivel de $100 \mathrm{~mm}$ de AFD.

Os resultados obtidos mostram que a area com maior desenvolvimento atual da citricultura no Estado (representada por Pindorama e Ribeirão Preto), em geral apresenta maiores probabilidades de ocorréncia de deficites de maior duração e intensidade durante a floração e inicio da frutificaçăo, com os respectivos riscos de queda da produção. Esses maiores riscos são compensados pela ocorréncia de plantaçơes de pomares citricos em solos com maiores niveis de AFD.

Um em cada trés anos, pode ocorrer deficite hidrico nos meses de abril a junho, que pode afetar o desenvolvimento final dos frutos.

Tambem foi constatada 50\% de probabilidade de ocorréncia de excedentes hidricos maiores que $10 \mathrm{~mm}$ por decendio no final do periodo de colheita (dezembro), que em condiçres especificas podem afetar a qualidade dos frutos ainda não colhidos. 
NATURAL SUPPLY PROBABILITY OF CITRUS WATER REQUIREMENTS IN SAO PAULO STATE - BRAZIL

\author{
Author: ELISEO LECLERG SEQUEIRA SAMPAIO \\ Adviser: ALTINO ALDO ORTOLANI
}

SUMACARY

Brazilian citrus production concentration in São Pablo State is based, beyond cultural and tecnological factors, in favorable climatic and edaphyc conditions. Almost in $90 \%$ of the extension of the state, prevail humid mesothermic climates of altitude, with humid summer (october - march) and a winter with lower temperatures and rainfall (april - august). When mean evapotranspiration and rainfall values are compared, they result in favorable water balance to qualitative and quantitative citros production. This region contend in world market without irrigation.

Some years, depending on region or crop production management, production fall occurs, conditioned by dry periods resulting of rainfall regime irregularity during rest and rippening season or during humid summer growing season. When mean values of that balance are separated in shorts periods, it is difficult to obtain water equilibrium. The extent of agroclimatic suitability for citrus depends on frequency and probability of hydric requirements natural supply.

With the principal objetive to compute the natural atendiment probability level of citrus orchards hydric requirements on five regions of São Pablo State, were calculated water balances using rainfall and maximum evapotranspiration (ETm) data on a ten day basis, for Campinas, Cordeirópolis, Jaú, Pindorama and Ribeirão Preto 
cities.

Estimates of ETm were done using Villa Nova \& Ometto (1981) equation with crop coeficients suggested by Vieira (1984) for non irrigated citrus orchards.

Water balance was made sequentially for 30 years data, for four levels (30,40,50 and $75 \mathrm{~mm}$ ) of easy available water (EAW), representative for citrus and principal kinds of soils in those places. In Pindorama it was also used $100 \mathrm{~mm}$ EAW level.

The results showed that the area of the State with greater actual development in citriculture (represented by Pindorama and Ribeirão Preto), generally presents greater probabilities of ocurrence of deficits with greater duration and intensity during flowering and begining of fructification, with respective fall production hazard level. These hazard is reduced by citrus ocurrence in soils with greater levels of EAW.

Final fruit development can be affected orie each three years with water deficits that could occur from April to June.

Also, at the end of harvesting season (December), it was found $50 \%$ probability of ocurrence of water surplus greater than $10 \mathrm{~mm}$ each decade, that can affect, in specifyc conditions, the quality of fruits still non harvested. 
1. INTRODUÇ.ZTO

Os citricos, Citrus spp., são, sob diversas formas o grupo de frutas de maior comercialização internacional. Sua comercialização in natura só perde para a banana em volume, sendo superior, entretanto, em valor.

A produção de citros, como outras culturas, - resultado da disponibilidade de tecnologia no sistema solo-planta-atmosfera e da possibilidade de sua aplicaça pelo homem. Dos elementos desse conjunto, em geral a atmosfera tem sido menos estudada, embora se verifique atualmente um numero crescente de trabalhos nessa area. Estes trabalhos são de diversos graus de especialização, como regionalizaçб̄es agroclimaticas gerais e estudos mais complexos que modelam variáveis agrometeorológicas e produção.

A regionalização ou zoneamento agroclimático permite decidir o estabelecimento de uma dada cultura em dado local, e identificar seu potencial, os principais problemas meteorológicos e escalas respectivas de riscos.

Sao poucos os trabalhos sobre agrometeorología dos citricos no Brasil. O mais abrangente, publicado por CAMARGO et alii (1974), que trata de regionalização agroclimatica, não cita trabalhos do Brasil. Mais recentemente foram divulgadas as primeiras relaçőes sobre clima-produção por TUBELIS \& SALIBE (1986, 1989), uma revisão sobre ecofisiologia por RODRIGUES (1987). e uma 
revisão relacionando agrometeorología e o cultivo por ORTOLANI et alii (1990).

Um dos problemas de maior releváncia na produção é a disponibilidade de água, numa interação complexa que envolve todo o ciclo 'fenológico, suas fases construtivas e reprodutivas, nas quais a demanda hidrica da planta pode variar de forma significativa. Năo havendo outros fatores limitantes, essa disponibilidade hídrica ira. condicionar a absorção dos nutrientes necessarios para a planta expressar todo seu potencial de rendimento.

Quando não existe irrigação, a principal fonte de água para as culturas e a chuva. A disponibilidade hidrica efetiva é resultado de uma interação complexa, parcialmente conhecida, que envolve as caracteristicas risicas e hidricas do solo, a capacidade de demanda e absorção de água da combinação copa-cavalo $e$ as caracteristicas de intensidade e distribuiç̃o temporal da chuva.

Este trabalho, ainda que reconhecendo as dificuldades descritas, tem como objetivos principais:

a) calcular os niveis de probabilidade de atendimento natural, das necessidades hidricas de pomares citricos no Estado de São Paulo, a partir de dados agrometeorológicos das cidades de Campinas, Cordeirópolis, Jau, Pindorama e Ribeirão Preto;

b) estabelecer uma escala de riscos de disponibilidade hidrica no periodo critico que vai do florescimento ao inicio da frutificação. 
2. REVISAOO BIBLIOGRAFICA

2.1. Origem e propagação da cultura

WEBBER (1967) considera que a origem mais provável das especies cultivadas de citricos são as regiðes tropicais e subtropicais do sudeste da Asia e o arquipélago da Malasia. Sua propagação foi um processo lento, marcado pelas diferenças relativamente pequenas das variedades originais até a obtenção das atuais.

Segundo o mesmo autor, nenhuma especie do genero é originaria da America, e as primeiras sementes foram introduzidas por Cristovão Colombo em 1493 na ilha de Haiti. No Brasil, já no ano 1540 aparecem citaçðes da propagação e crescimento de numerosas árvores de cltricps.

2.2. Areas de produção

A produção mundial atingiu $61.153 \mathrm{mil}$ toneladas no ano 1988 (FAO, 1989a), equivalendo aproximadamente a U\$S 32 bilhöes ao preço do mercado internacional desse ano (FAO, 1989bj. A mesma fonte indica - Brasil como maior produtor do mundo, cerca de $27 \%$ do total. Segundo dados dó ANUARIO ESTATISTICOO DO ESTADO DE SAOO PAULO - 1988 (1989), nesse mesmo ano o Estado de São Paulo produziu o equivalente a $18 \%$ da produção mundial. ocupando o primeiro lugar em importancia economica nesse 
Estado.

O Estado de São Paulo possue a maior area de produção de citricos no mundo. Em 1988, sua produção atingiu 11.115 .144 ton, correspondendo a $91 \%$ de laranjas CANUARIO ESTATISTICO DO ESTADO DE SãO PAULO - 1988, 1989 . Esta polarização da citricultura brasileira ja começava a se definir em 1981, quando São Paulo superou a produço da Flórida (EUA), que até esse momento liderava a produção citricola do mundo (TEOFILO SOBRINHO et alii, 1982).

Para efeitos comparativos, na Tabela 1 CFAO. 1989a). se relacionam as produç̧̃es citricas de algumas areas do mundo.

Tabela 1 - Produção mundial de citros e comparativo por regi ðes.

\begin{tabular}{|lcr|}
\hline AREA & PRODUÇAO (ton) & PORCENTAGEM \\
\hline Mundo & 67.398 .000 & 100,0 \\
America do sul & 19.687 .000 & 29,2 \\
Brasil & 16.377 .000 & 24,3 \\
America central e norte & 16.336 .000 & 24,2 \\
EUA & 11.547 .000 & 17,1 \\
Europa $\because$. & 8.449 .000 & 12,5 \\
Asia & 16.650 .000 & 24,7 \\
Africa & 5.479 .000 & 8,1 \\
Oceania & 619.000 & 0,9 \\
\hline
\end{tabular}

\subsection{Exigéncias climaticas}

Um ponto de destaque é a grande diversidade de temperaturas medias, amplitudes diarias e regimes sazonals de temperaturas e chuvas entre as distintas zonas citrícolas do mundo (REUTHER, 1973).

Em relação às exigencias térmicas, segundo os dados citados por REUTHER (1973), as temperaturas btimas 
para a germinaço das sementes e crescimento das raizes, estariam entre $15^{\circ}$ e $35^{\circ} \mathrm{C}$ no solo. Para o crescimento vegetativo, a temperatura do ar mais favorável situa-se entre $14^{\circ}$ e $32^{\circ} \mathrm{C}$ e para a produção de polem viável, entre $15^{\circ}$ e $20^{\circ} \mathrm{C}$. Niveis termicos estressantes danificam e destroem os polens, prejudicam o tubo polinico causam atrofia rloral CORTOLANI et alii. 1990 . Temperaturas muito elevadas, baixo teor de umidade do ar e má disponibilidade hidrica no solo são ratores que condicionam a formação da camada de absisão na base do pedúnculo das flores, provocando sua queda.

Ainda para crescimento vegetativo, MENDEL (1969) especifica um minimo de $12,5^{\circ}$ a $13^{\circ} \mathrm{C}$, um ótimo entre $23^{\circ}$ e $34^{\circ} \mathrm{C}$ e um máximo de $37^{\circ}$ a $39^{\circ} \mathrm{C}$.

Temperaturas abaixo de $13^{\circ} \mathrm{C}$ ou acima de $39^{\circ} \mathrm{C}$ interrompem a atividade vegetativa (MONTENEGRO, 1980 ). Segundo REUTHER (1973), a taxa de crescimento de frutos ocorre entre $10^{\circ}$ e $30^{\circ} \mathrm{C}$, ou seja, com temperaturas inferiores às de crescimento vegetativo.

Quanto a produção de pigmentos, a de licopeno apresenta uma relaça diretamente proporcional com a temperatura, ao contrario da de caroteno, que apresenta. uma proporção inversa (MEREDITH \& YOUNG, 1989 ).

climas úmidos a com amplitudes termicas diarias a sazonais pequenas, tendem a produzir frutos citricos com glándulas de oleo menos proeminentes e formas mais oblongas que os climas mais secos e com amplitudes maiores, como os mediterránicos (REUTHER, 1973 ).

Quanto a composição do suco, temperaturas maiores dão menor conteúdo de ácido CREUTHER \& CASTANO 1969). No caso dos sólidos solúveis, a relação já não ta tao clara e existe uma grande influença da disponibilidade de água.

A floração a a maturação não apresentam 
relaçơes tão definidas com as temperaturas extremas; mas suas ocorrencias podem ser previstas usando o conceito de graus-dia CLOMAS et alii 1969; LOMAS \& BURD 1983 ).

REUTHER (1973) indica que a indução floral normalmente ocorre um mes antes de que seja discernivel a evidencia histologlca da diferenciação floral. A floração 6 estimulada por temperaturas baixas durante certo periodo, estimulo que tambem pode ser criado por condicóes de falta de água. Segundo DOORENBOS \& KASSAM (1979), esse déficite conseguido com aportes de agua iguais ou inferiores a 50-60 $\mathrm{mm}$ mensais durante dois meses. Não obstante, não foi encontrada na bibliografía informação precisa de ate quanto esse deficite que induz a floração pode ser prejudicial para o desenvol vimento normal da planta.

Varios autores, citados por REUTHER (1973). verificaram que a taxa de crescimento aumenta com a duraça do dia (até 16 horas). Segundo MENDEL (1969), a taxa de crescimento diminui com o aumento da intensidade da luz.

Na floraço, REUTHER (1973) assinala que alguns trabalhos consideram os citros como indeterminados em relação ao fotoperílodo. Contudo, LENZ (1969) encontrou que a floraça em laranja doce, podia ser controlada pelo fotoperiodo, quando se trabal hava com temperaturas de $24^{\circ} \mathrm{C}$ ao dia $19^{\circ} \mathrm{C}$ a noite.

Chuvas, umidade elevada, nevoeiro e temperaturas baixas, alem de dificultar a ação dos insetos polinizadores, prejudicam a abertura das anteras $\theta$ a própria polinização CORTOLANI et alii, 1990). Estas condições são comuns em periodos muito chuvosos. TUBELIS \& SALIBE (1989) observaram um efeito depressivo das chuvas de setembro na produção de laranja "Hamlin" no altiplano de Botucatu.

A chuva, como fator agroclimático, esta relacionada a disponibilidade de água no solo e a moderação 
do fluxo de energia. Este fluxo tambem é influenciado pela umidade relativa do ar e pelo vento. Salienta-se, ainda. que a umidade relativa influencia os ciclos biológicos de pragas e doenças, e vento pode provocar danos mecánicos nos frutos o outros orgãos da planta.

Recentemente, BEN MECHLIA E CARROLL (1989) propuseram uma integração dos fatores climáticos que influenciam os citros num modelo de simulação da evol ução de sua fenologia, crescimento e maturação dos frutos, quantidade e qualidade da produça.

CAMARGO et alii (1974), ná confeção da carta de aptidão climática para a citricultura paulista, usaram os seguintes parametros:

a) temperatura media anual de $17^{\circ} \mathrm{C}$, como $11 \mathrm{mite}$ acima do qual existe aptidão para a citricultura, exceto pomelo e mexerica;

b) temperatura media anual de $20^{\circ} \mathrm{C}$, como $11 \mathrm{mite}$ acima do qual existe aptidão para a citricultura, sem exeços;

c) deficiencias hidricas anuais nulas (podem corresponder a regibes com problemas fitossanitarios);

d) deficiencias hidricas anuais ate $60 \mathrm{~mm}$ como regizes aptas, e acima desse limite como regioes com restriçóes hídricas, porém próprias para cultivo comercial.

\section{4. Exigéncias de solos}

Segundo SALIBE (1969), os citricos apresentam um grande poder de adaptação a diferentes solos em função do uso de porta-enxertos adequados. Por isso, possivel seu cultivo em solos de alto teor de areia. assim como aqueles muito argilosos. No entanto, devem ser evitados solos pouco profundos ou que encharcam racilmente, devido a sua extrema sensibilidade aos excessos 
e deficites de água (ver ponto 2.5$)$.

As raizes, em condiçoses favoraveis chegam a 8 a $10 \mathrm{~m}$ a partir do tronco 5 a $6 \mathrm{~m}$ de profundidade (SALIBE, 1969). No entanto, nas estimativas de densidade de raizes segundo a absorção de água pela planta, os dados Indicam concentrafóes significativas ate 90 a $120 \mathrm{~cm}$ de profundidade, dependendo do tipo de solo CKOO, 1961 ; CAHOOM \& STOLZY, 1959; AVILAN, 1986 ).

O pH ideal esta em torno de 6,5, mas existem laranjais produzindo rentávelmente em solos com pH entre 4,5 (Brasil) 9.0 (Homestead, Florida) CSALIBE, 1969 .

OLIVEIRA (1990), citando varias fontes, acrescenta que os citros são sensivels à salinidade e a alcalinidade.

2. 5. Necessidades hidricas

Os citricos requerem entre 800 . $1300 \mathrm{~mm}$ anuais de água CGERBER et alii, 1973; SALIBE, 1969; DOOREMBOS \& KASSAM, 1979; MARSH, 1973; VIEIRA, 19902. Esta demarda varia entre e dentro das distintas localidades, pela variação espacial e temporal da radiaçăo solar recebida, da temperatura, do vento. da umidade relativa do ar, do conteúdo de umidade no solo, da sanidade das plantas, das diferenças de volume de solo explorado e capacidade de extração de água das distintas combinaçరes enxerto/porta-enxerto, das caracteristicas de retenção de água nos distintos solos, e dos aspectos culturais como espacamento entre plantas e conduçăo da cobertura vegetal.

No caso dos citricos, 6 extremamente i mportante uma adequada distribuição da agua. MARSH (1973) assinala que a saturação hidrica de solo e uma condiça perigosa para estas árvores, exceto por poucas horas. 
podendo causar maiores danos que uma deficiencia hidrica. A morte de ralzes novas está associada ao exceso de água (FORD, 1972 ).

A deficiencia de agua pode ocasionar um forte estresse, ainda que não se constatem sintomas evidentes de falta de água (MARSH, 1973). Atribue-se que o fluxo de seiva na planta estressada se reduz a uma taxa mator que a djferença do potencial de água entre o solo e a fol ha (COHEN et alii, 1983 ).

BEUTEL (1964) detectou um decréscimo de $17,4 \%$ no crescimento de 1 aranjas 'Navel', quando a tensão d'agua no solo passava de 100 a $200 \mathrm{HPa}$.

KOO \& MCCORNACK (1965), HILGEMAN \& SHARP (1970) C CRUSE et alii (1982), verificaram que o aumento de disponibilidade de água para as plantas provoca redução do total de solidos solúveis de ácidos em lararjas e tangerinas. No entanto, o comportamento da relação solidos solúveis/ácidos em relação à disponibilidade de água, diferente nos tres estudos citados. Isto é importante na hora de operar um sistema de irrigação, ou no acompanhamento da ocorrencla de chuvas, porquanto dois terços da produção citricola brasileira se destinam à indústria de suco (VIACAVA, 1987 ).

VIEIRA (1990) sugere a interrupção da irrigação quando o fruto atingir $25-30 \mathrm{~mm}$ de diametro. $\mathrm{k} \infty$ (1969) recomenda que entre inicio da floração e frutos com $2.5 \mathrm{~cm}$ de diametro, a agua no solo seja mantida acima de $55 \%$ a $65 \%$ do valor de capacidade de campo. 
2.6. Infiuencia dos porta-enxértos

Os porta-enxertos apresentam determinadas preferencias em relação aos solos. MONTENEGRO (1980) indica que o limoeiro rugoso da florida prefere solos arenosos, a laranjeira calpira os solos de textura média. e o poncirus trifoliata os úmidos.

Ainda, o mesmo autor indica como resistentes a seca o limoeiro-rugoso-da-Flórida, o limoeiro-cravo e o tangelelro Sampson, no entanto a laranjeira calplra seria susceptivel. Tambem encontrou uma marcante influência do enxerto sobre o sistema radicular, sendo que a variedade Hamlim produziria seu robustecimento.

Para uma mesma variedade, a seleção do porta-enxerto pode determinar 0 exito ou fracasso da produção tanto como o clima ou solo. WUTSCHER \& BISILINE (1988), trabalhando com laranjas 'Hamlim' em 30 porta-enxertos durante quatro anos, encontraram diferencas muito significativas entre eles, na sobrevivencla das árvores, grossura do tronco, rendimento por planta, peso, diámetro, conteúdo e composição do suco, espesura da pele e cor dos frutos.

Outro fator importante na selecão do porta-enxerto, es sua resistencia ao declinio. doença que evolue rapidamente em distintas regizes citricolas, e cujo único controle, por enquanto, tem sido felto com porta-enxertos resistentes CFEICHTENBERGER, 1985). Isto tambem importa muito na producão, visto que GARNSEY \& YOUNG (1975) comprovaram que o fluxo de água nas árvores afetadas por declinio, corresponde a apenas $23 \%$ do observado em árvores normais, portanto, como mostra BELL \& BARTHOLIC (1973), apresentam estrésse hidrico mais rápidamente que plantas sadias. 


\subsection{Caracterização da zona produtora Paulista}

\subsubsection{Distribuição espacial}

Segundo O ANUARIO ESTATISTICO DO ESTADO DE SATO PAULO - 1988 (1989), este Estado apresentava no ano 1988, 691070 ha de cltricos, das quais 93\% eram laranjas. Dentro do Estado, as Diviszes Regionats Agricolas Cver mapa na Figura 1$)$ que têm as maiores concentraçóes de areas, são Ribeirão Preto, São Jose do Rio Preto e Campinas, com $48 \%, 28 \%$ e $27 \%$ do total estadual, respecti vamente.

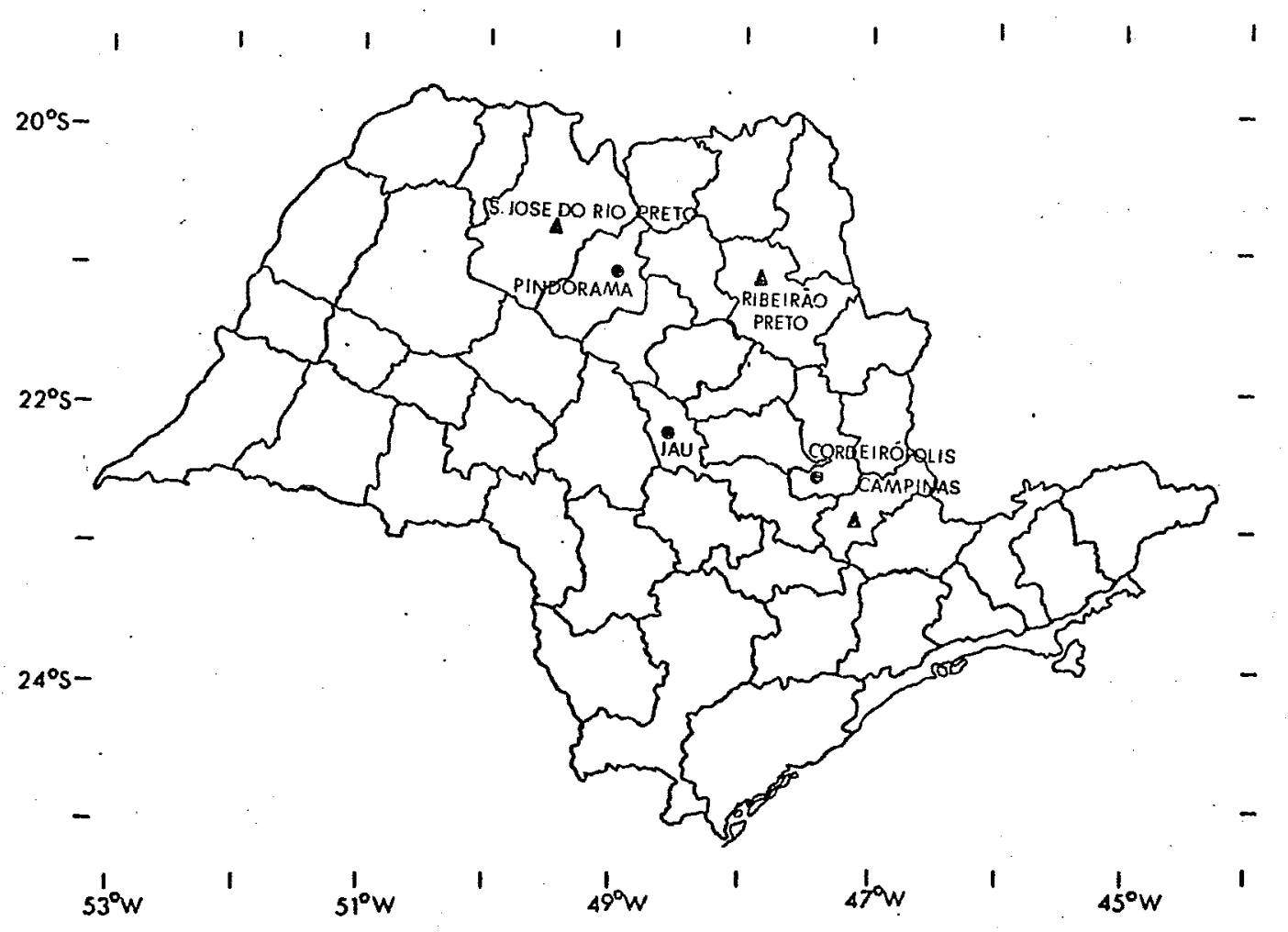

Figura 1 - Mapa do Estado de Săo Paulo, com localização de estaçбes meteorológicas e Divisరes Agricolas. 
E importante destacar o caso da Divisão de Sao Jose do Rio Preto, onde entre 1983 e 1985 cresceu em $40 \%$ o numero total de plantas citricas CCAMPOS et alii. 1983; SOUZA, 19852, e onde a citricultura esta em franca expansão.

\subsubsection{Clima}

SETZER (1966) analisou o clima do Estado segundo a metodologia de KOEPPEN, encontrando seis tipos climáticos distintos, todos eles correspondentes a climas úmidos, com mais de $1000 \mathrm{~mm}$ de chuva anual. Esses tipos são mostrados na Tabela 2 .

Tabela 2 - Tipos climáticos, segundo KOEPPEN, encontrados no Estado de Sa Paulo, e suas características.

\begin{tabular}{|c|c|c|c|}
\hline simb. & clima (úmido) & $\begin{array}{l}\text { Total } \\
\text { mes is chuva }\end{array}$ & $\begin{array}{l}\text { Temp. modia do } \\
\text { mes mante mos } \\
\text { quento } \\
\end{array}$ \\
\hline Af & $\begin{array}{l}\text { Tropical sêm } \\
\text { estação seca }\end{array}$ & $>$ de $60 \mathrm{~mm}$ & $F>22^{\circ} \mathrm{C} F>18^{\circ} \mathrm{C}$ \\
\hline $\begin{array}{l}\text { Aw } \\
\text { Ciwa } \\
\text { Ciwb }\end{array}$ & $\left.\begin{array}{l}\text { Tropical } \\
\text { Quente } \\
\text { Temperado }\end{array}\right]$ inverno & $f<30 \mathrm{~mm}$ & $t<18^{\circ} \mathrm{C}$ \\
\hline $\begin{array}{l}\text { Cfa } \\
\text { Cfb }\end{array}$ & $\begin{array}{l}\text { Quente } \\
\text { Temperado J } \\
\begin{array}{l}\text { estaçã } \\
\text { seca }\end{array}\end{array}$ & ] $>30 \mathrm{~mm}$ & $\begin{array}{l}>22^{\circ} \mathrm{C} \\
<22^{\circ} \mathrm{C}\end{array}$ \\
\hline
\end{tabular}

As areas de produção de mator importancia de citricos no Estado, considerando esta clasificação, são os tipos Aw (Tropical com inverno seco) abrangendo pomares ao norte de São José do Rio Preto, Ribeirão Preto e Barretos. - C Cwa (Quente com inverno seco), representativo dos pomares situados entre as regizes de Bebedouro. Araraquara, Limeira e Campinas. Ambos (Aw e Cwa apresentam caracteristicas de continentalidade. Plantios mais 
recentes, em antigas áreas interditadas, situam-se na região de Itapetininga, com predominancia do clima cfa, com inverno menos seco que os outros mencionados e temperaturas mais bai xas que o Aw.

o. zoneamento agroclimático de CAMARGO et alii (1974), identifica a citricultura paulista em zonas $A$ e B. cujas caracteristicas são:

- zona A: suriciencia térmica e hidrica, temperatura media anual maior que $17^{\circ} \mathrm{C}$, deficiencia hidrica media anual entre 0 e $60 \mathrm{~mm}$.

- zona B: apta com restriços, deficiencias hidricas sazonais, temperatura media anual maior que $17^{\circ} \mathrm{C}$. deficiencia hidrica média anual maior que $60 \mathrm{~mm}$.

A expansão atual do cultivo esta acontecendo principalmente na zona Aw da primeira classificaça e B da segunda.

\subsubsection{Solos}

O trabal ho do SERVIÇO NACI ONAL DE PESQUISAS AGRONOMICAS (1960) divide os solos do Estado de São Paulo em 26 grandes grupos e nove associaçoses, a maior parte correspondendo aos Podzólicos Vermelho-Amarelos, Latossolos e Solos Podzolizados.

OLIVEIRA et alii (1979), num mapeamento em menor escala e mais detalhado, que identifica 24 unidades taxonómicas e 54 unidades de mapeamento, ainda continua a dar aos grupos já mencionados comp os de maior extensão na área sob estudo. No entanto, a análise dos referidos trabalhos possibilita diferenciar as proporcōes das áreas ocupadas pelos distintos solos como mostrado na Tabela 3 . Alem desta discórdancia. nestes trabalhos fol impossivel identificar o uso dado a cada grupo de solo. 
Em relação a este ponto, so foram encontradas associaçరes. por certo muito superficiais entre pomares citricos e tipos de solos, nos trabalhos de RUBBO et alii (1983) e SUSANNA et alii (1983), e a nivel de estudos particulares, nos trabalhos de JORGE \& PRADO (1988) JORGE et alii (1988).

Tabela 3 - Comparativo de distribuiçăo de solos no Estado de São Paulo segundo os trabalhos do SERVIÇO NACIONAL DE PESQUISAS AGRONOMICAS (1960) OLIVEIRA et alii (1979).

\begin{tabular}{|c|c|c|c|c|}
\hline \multicolumn{2}{|l|}{1960} & \multicolumn{3}{|l|}{1979} \\
\hline Identificação solo & $\%$ & Identificaçăo & solo & $\%$ \\
\hline $\begin{array}{l}\mathrm{PV}+\mathrm{PVp}+\mathrm{PVIS} \\
\mathrm{PC}+\mathrm{Pln}+\mathrm{Pml} \\
\mathrm{LE} \\
\mathrm{LV}+\mathrm{LVr} \\
\mathrm{LR}\end{array}$ & $\begin{array}{r}36,8 \\
6,2 \\
12,7 \\
2,2 \\
25,1\end{array}$ & $\begin{array}{l}\text { PV-1 a } P V-6 \\
--- \\
L E-1 \text { a } L E-4 \\
L V-1 \text { a LV-4 } \\
\text { LRd + LRe }\end{array}$ & & $\begin{array}{r}32,4 \\
0,0 \\
17,2 \\
15,5 \\
9,9\end{array}$ \\
\hline
\end{tabular}

PV : Podzólicos Vermelho-Amarelos

$P$ : Solos Podzolizados

LE : Latossolos Vermelho-escuros

LR : Latossolos Roxos

LV : Latossolos Vermel ho-Amarelos

Isto motivou consulta a especialistas na area, para melhor esclarecimento do ponto. VIDAL 1 , baseado em analises de solos na região citricola do Estado Co mais recente em 26 trincheras de 18 localidades, previsto ro Projeto Produtividade da CITROSUCO PAULISTA S.A.J indica que no eixo Matao-Pindorama-São Jose do Rio Preto, a citricultura esta basicamente em solos Podzolicos Vermel ho-Amarelos eutroficos.

No eixo

1 VIDAL, P. CEscola Superior de Agricultura "Luiz de Quelroz" USP, Piracicaba, SP) Comunicaçăo pessoal, 1989. 
Jaboticabal-Bebedouro-Barretos ocorre un predominio de manchas de Latossolos Vermelho-escuro distroficos ou alicos. Na zona de Ribeirão Preto predominam os Latossolos Roxos. Mais para o sul, alem de Santa Rita do Passa Quatro, predominam os Latossolos de textura media (Vermelho-Amarelos e Vermelho-escuros tanto alicos como distroficos.

2.7.4. Variedades e porta-enxertos

A partir dos dados dos trabalhos de ASSUMPCYAO \& SOUZA (1985), BATIISTELLA et alii (1983). BENESI et alii (1985), CAMPOS et ali1 (1983), DOLCI \& PARO (1983), LEITE (1985), MATIA (1985), MIGLINSKI et alii (1985), MONTEIRO \& MURAKANI (1985), SANTINI (1985), SEGNINI 8. CHAINE (1985) e SOUZA (1985), e possivel comprovar que as variedades de laranjas Pera, Natal e Valencia são as principais, sendo respectivamente $54 \%, 27 \%$, $9 \%$ das copas existentes no Estado.

Segundo os mesmos autores, o principal porta-enxêrto (mais de $90 \%$ corresponde ao 1 imoeiro-cravo, embora se verifique um forte incremento de tangerina cleopatra nas mudas em preparaça dos viveros a partir de 1985. Esta mudarça fundamenta-se na susceptibilidade do limoeiro-cravo ao declínio, que em algumas areas produtoras do Estado mata 2 a $3 \%$ das plantas por ano.

Como plantas cultivadas comercialmente, os cltros podem ser agrupados em: laranjas doces, laranjas com acides, tangerinas, limas doces, limas acidas, limöes verdadeiros e pomelos, alem de outros grupos de menor importancia no Brasil, como laranjas azedas, cidras, toronjas e cumquates CDE NEGRI \& PIZA, 1988 ).

De acordo com a epoca de maturação dos 
frutos, as variedades de laranjas são divididas em precoces CLima Piralima e Hamlim), meia-estação (Baia, Baianinha) e tardias (Pera, Natal, Valencia). Estas ultimas são predominantes na citricultura brasileira, e como ja foi citado, na citricultura paulista. Săo variedades quase exclusivas para a indústria de sucos, e apresentam altos teores de acúcares e acidos e um longo periodo de colhelta, que vai de julho a dezembro (SILVA et alii, 1986). As colheitas são dispersas durante esses meses, sendo mais significativas as de outubro a dezembro.

A floração da-se em geral no més de setembro o inicio da frutificaçăo em outubro.

\subsubsection{Sistema radicular}

MONTENEGRO (1960); trabalhando nas Estaços
Experimentals de Limeira e Tiete, concluiu que a maior
porcentagem de raizes, independente da combinaça
copa/cavalo, encontra-se nos primeiros $60 \mathrm{~cm}$ de solo em plantas jovens e. $90 \mathrm{~cm}$ em plantas de mais de 20 anos.

MOREIRA (1983) encontrou aproximadamente $50 \%$ das radicelas nos primeiros $15 \mathrm{~cm}$ do perfil, $60 \%$ nos primeiros $30 \mathrm{~cm}$, trabalhando num solo transição Latossolo Vermel ho-Amarelo a Latossolo Roxo.

A profundidade efetiva do sistema radicular do citros tem sido relacionada com as caracteristicas químicas do perfil dos solos. QUAGGIO 2 , após o estudo de cerca de 15 trincheiras, em vários tipos de solo observou que em solos alicos csaturação de $\mathrm{Al}^{+3}$ maior a $50 \%$ no

2 QUAGgio, J.A. CInstituto Agronómico de Campinas, Campinas, SP3 Comuni cação pessoal. 1989. 
horizonte B), as ralzes são superficiais e geralmente não ultrapassam $0,6 \mathrm{~m}$. Em solos eutroficos (saturação por bases maior a 50\% no horizonte B3, elas alcancam cerca de $1,5 \mathrm{~m}$ de profundidade. Nos solos distróficos, a profundidade de enraizamento seria intermediaria Caproximadamente $1 \mathrm{~m}$. A distribulção do sistema radicular depende ainda do grau de compactação dos solos.

\subsubsection{Disponibilidade de agua nos solos}

E um parámetro de grande importáncia para calculo do balanço hidrico: pode ser fixado na forma tradicional para um ou distintos niveis de armazenamento; pode ser medido para cada solo, ou ser estimado a partir de dados existentes na bibliograria.

Dos trés métodos, a medição do nivel em cada solo 6 mais recomendavel, mas escaparia as finalidades deste trabalho.

- método com niveis rixos de armazenamento, tem sido usado no Estado de São Paulo por ALFONSI et alii (1989), gerando uma informação de grande valor para a agricultura de sequeiro.

A opção de uso dos dados existentes na bibliografia mostra-se, em principio, como de precisão intermediaria. Foram encontrados os trabal hos de GROHMANN \& MEDINA (1962), SOUZA (1966), MARCOS (1968, 1971) e LIBARDI \& REICHARDT (1973), cujos dados reanalizados såo resumidos a seguir:

a) GROHMANN \& MEDINA (1962); água entre $100 \mathrm{hPa} e$ 15000 hPa; Podzol Vermelho-Amarelo, 10\%; Latossolo Roxo, $15,3 \%$;

b) SOUZA (1968); água entre $333 \mathrm{hPa}$ e $15000 \mathrm{hPa}$; Podzols Vermelho-Amarelos, entre 15,2\% e 18,9\%, média de 
16,5\%; Latossolos Vermelho-escuros, entre $8,6 \%$ e $14,1 \%$, media de 10,6\%;

c) MARCOS $(1968,1971)$; agua entre $333 \mathrm{hPa}$ e $15000 \mathrm{hPa}$; Latossolos Roxos, entre $7 \%$ e $10 \%$;

d) LIBARDI \& REICHARDT (1973); agua entre $333 \mathrm{hPa} e$ 15000 hPaPodzol Vermelho-Amarelo, 12.5\%; Solo Podzolizado de Lins e Marilia Variação Marilia, 5,4\%.

ARRUDA et alii (1987), para valores de CC a $300 \mathrm{hPa}$ e de PMP a $15000 \mathrm{hPa}$, estimaram a agua disponível a partir dos valores de teor de argila mais silte $(X)$ e densidade aparente (da), desenvol vendo as equaços $1 \mathrm{e}$. Combinando os dados obtidos com o uso da equação 3 , obtem-se porcentagem de agua disponivel (AD) em volume.

$$
\begin{aligned}
& C C=\left(3,074+0,629 x-0,0034 x^{2}\right) . d a \\
& P M P=[398,889 x-(1308,09+x)] . d a \\
& A D=C C-P M P
\end{aligned}
$$

Aplicadas estas equaços aos dados de alguns dos perris fornecidos por VIDAL 1; foram obtidos os valores da Tabela 4.

Tabela 4 - Porcentagem de agua disponivel, em volume, para distintos solos do Estado de São Paulo. aplicando as equaçöes de ARRUDA et alii (1987). aos dados de VIDAL ${ }^{1}$.

\begin{tabular}{|l|l|l|}
\hline Municipio & Tipo de solo & $A D C \%$ \\
\hline Agulha & PV, endoeutrofico & 16,1 \\
Bebedouro & LE, distrofico & 14,5 \\
Bebedouro & LE, endoalico & 15,4 \\
Jaboticabal & LE, endoalico & 15,9 \\
Limeira & LV, distrofico & 16,0 \\
Pirassununga & LE, endoalico & 15,9 \\
Santa Rita do Passa Quatro & LV, endoálico & 14,2 \\
Sao Jose do Rio Preto & PV, eutrofico & 16,1 \\
Tabapuã & PV, eutrofico & 16,1 \\
\hline
\end{tabular}


2.8. O balanco hidrico

OMETTO (1981) apresenta o balanço hidrico como a contabilidade entre a entrada e a saida de água no solo. Aplicada a lei de conservação da massa num vol ume de solo com vegetaç̃o, o balanço hidrico e nulo e responde à equação 4.

$$
P+I+E t+\Delta M+F+D=0
$$

onde:

$$
\begin{aligned}
& P=\text { Precipitação }(\mathrm{mm}) \\
& I=\text { Irrigação }(\mathrm{mm} \\
& E t=\text { Evapotranspiração } \mathrm{Cmm} \\
& \Delta M=\text { Variação de armazenamento da agua do solo } \mathrm{cmm} \\
& F=\text { Derlưio superficial } \mathrm{Cmm} \\
& D=\text { Drenagem profunda }(\mathrm{mm})
\end{aligned}
$$

A equação 46 geral, as diferenças vão surgir segundo os criterios aplicados na definição de cada um dos seus parametros.

\subsubsection{Precipitação e irrigação}

São os parametros que correspondem à entrada de agua no solo. No caso das culturas de sequeiro, a irrigação zero.

A contabilidade da precipitaçăo pode variar. A via mais simples é a usada por OMETTO (1981), onde considerado o somatório dos valores lidos do pluviómetro no periodo considerado.

Já outros autores, como VIEIRA (1985), se associam a escola das chamadas chuvas efetivas. Despreza os valores díarios menores a determinado limite inferior, e os excessos diários acima de dado limite superior. Esse autor 
exemplifica o assunto com a aplicação de um segundo criterio, referente ao conceito de chuva efetiva. Neste exemplo usa uma tabela elaborada pelo Departamento de Agricultura dos Estados Unidos, onde se entra com a precipitação pluvial e a evapotranspiração media mensal.

Alem da quantidade, tambem pode-se considerar a intensidade da chuva. MANFRINATO (1970) encontrou diferenças significativas nos teores de umidade do solo ao considerar chuvas de diferentes intensidades.

\subsubsection{Deflúvio superficial e drenagem profunda}

São dois termos de saída de agua do sistema. De certa forma, no caso de uma cultura que cubra bem o solo, minimizando a evaporaçă, formariam as saldas de água não produtivas.

Aqui tambem podem ser citadas duas tendéncias principais.

Uma, como descreve OMETTO (1981), despreza o deflúvio superficial e considera que todas as perdas por excesso saem por drenagem profunda.

Outra e como a sugerida por MOTA (1979), onde o criterio usado e que chuvas de intensidade superior a velocidade de infiltração no solo, dão perdas por deflúvio superficial independendo do conteúdo de umidade do solo. Com chuvas de intensidade inferior a velocidade de infiltração, mas superiores em volume a parcela de água faltante no solo até chegar a capactiade de campo, as perdas seriam por drenagem profunda. Como a velocidade de infiltração depende da cobertura vegetal, do estado da superficie, tipo e umidade do solo, do grau de compactacão de alguma camada intermediaria $e$ da altura do nivel freatico, normalmente é fixado um valor diário máximo, 
acima do qual a chuva e considerada como excedente.

Ainda neste ponto, deve ser indicado que

estes dois termos, além do sinal negativo Csalda do sistemal, podem apresentar sinal positivo, o que complica mais o bal anco a nivel de parcela.

No caso do deflúvio superficial. o sinal

positivo pode aparecer em parcelas situadas no meio ou na parte baixa das encostas, como resultado dos excessos ocorridos nas partes altas.

No caso da drenagem profunda, o sinal positivo pode aparecer nos solos secos, como resultado de um maior potencial da solução do solo nas partes mais profundas do perfil.

\subsubsection{Evapotranspiração}

E o terceiro termo de saída de água do solo. A evapotranspiração de uma cultura. especialmente do tipo arboreo, $e$ um parametro dificil de ser medido, sendo portanto comum a utilização de valores esti mados.

Estas estimativas geralmente se referem ao valor de evapotranspiração de referencia (ETO), e os metodos de uso mals difundidos são os de THORNTHWAITE, citado por ORTOLANI et al1i (1970) e os de BLANEY-CRIDDLE, da Radiação, do Tanque de Evaporação Classe A e de PENMAN, citados por DOORENBOS \& PRUIT (1984).

- valor obtido, ajustado para cada cultura através do chamado "coeficiente da cultura" (KC), do qual DOORENBOS \& KASSAM (1979) \& DOORENBOS \& PRUITI (1984) fizeram uma sintese para diferentes especies, condiçós de cultivo e estádio de desenvolvimento. o valor obtido a evapotranspiração máxima da cultura (ETm. No caso 
especifico dos citricos (Tabela 5) tambem foram incluidos os coeficientes citados por VIEIRA $(1984,1990)$ se referem a pomares com solo livre de outras plantas e com $70 \%$ de cobertura.

Tabela 5 - Coeficientes de cultura (Ko) para citros.

\begin{tabular}{|lllllllllllll|}
\hline & $J$ & $F$ & $M$ & $A$ & $M$ & $J$ & $J$ & $A$ & $S$ & 0 & $N$ & $D$ \\
\hline$A(1)$ & .65 & .65 & .55 & .70 & .70 & .70 & .75 & .75 & .70 & .70 & .70 & .65 \\
$B(1)$ & .50 & .50 & .55 & .55 & .55 & .60 & .60 & .60 & .60 & .60 & .55 & .55 \\
C ( 2$)$ & .85 & .85 & .85 & .85 & .80 & .80 & .75 & .75 & .80 & .80 & .80 & .80 \\
\hline
\end{tabular}

A: DOORENBOS \& PRUIT (1984)

B: VIEIRA (1984) C: VIEIRA (1990)

(1) sem irrigaç̃o (2) com 1rrigação

A equaçăo para a estimativa de ETo, val depender do grau de ajuste requerido $\theta$ da informação agrometeorológica disponivel no local em estudo. Das já cltadas, a de PENMAN \& recomendada como padrão CFAO/IAEA OMM, citados por VILLA NOVA et alii, 1968), visto que considera tanto a energia radiante como a advectiva. Como poucas vezes se dispöe de todas as informaçסes necessarias para seu calculo, distintos investigadores tem proposto vias alternativas de estimativas das variávels do balanço de energía CSTANHILL, 1962; LINACRE, 1977 e VILLA NOVA \& OMETTO, 1981 ).

2.8. 4. Variação de armazenamento da água do solo

Dos termos da equaç̃o, $\&$ o que mais fácilmente varia de sinal segundo o aumento ou a diminuição do conteúdo de água do solo. Este conteúdo pade variar entre um minimo de zero, e um máximo que é atingido quando toda a porosidade do solo fica cheia de água. Para os 
cultivos, a disponibilidade de agua da-se entre um minimo no "ponto de murcha permenente". (PMP) e um máximo na "capacidade de campo" CCCS, que tradicionalmente tom sido derinidos respectivamente como constantes para as tensöes de retenç̃o da água no solo de $15000 \mathrm{hPa}$ C15 atm e $333 \mathrm{hPa}$ (1/3 atm CREICHARDT, 1985). O mesmo autor analisa a diferença entre estas constantes e a realidade, que $e$ muito mais dinamica e variável.

o valor de "capacidade de campo" e "a quantidade de água retida pelo solo após a drenagem do seu excesso, quando a velocidade do movimento descendente praticamente cessa", e apresenta no terreno valores entre 60 - $400 \mathrm{hPa}$. Isto porque a capacidade de armazenamento de agua de um solo esta relacionada ao tempo, composiç̃o textural e química do solo, sequencia de camadas no perfil, umidade inicial e praticas culturais Cincluido tipo de cultivos.

- conceito de "ponto de murcha permanente" foi primeiro introduzido por BRIGGS \& SHANTS (1912), citado por MOTA (1979) como "a umidade no solo quando a planta entra em murcha permanente", o que nem sempre acontece aos $15000 \mathrm{hPa}$.

Al ém desta variabilidade, REICHARDT (1985) assinala pelo menos trés criterios que tentam explicar como - a disponibilidade da agua entre esses dois extremos. Nenhum deles se apoia em base teórica bem fundamentada, dado que na absorç̃o da água pela planta intervem ratores do solo, da planta e da atmosfera, que atuam tanto em forma isolada como interagindo entre eles.

Seguindo um dos tres criterios mencionados

anteriormente, DOORENBOS \& KASSAM (1979) introduziram - conceito de fração de água disponivel no solo cou água fácllmente disponivels, como a parte da água disponivel que pode se esgotar sem que a evapotranspiração real seja 
inferior a maxima. Para citros, esses autores consideram os valores de fração de esgotamento da água do solo (p) segundo a evapotranspiração máxima (ETm), que figuram na Tabela 8 .

Tabela 6 - Valores de $p$ segundo os valores de ETm $(\mathrm{mm}$.

\begin{tabular}{|llllllllll|}
\hline $\operatorname{ETm}$ & 2 & 3 & 4 & 5 & 6 & 7 & 8 & 9 & 10 \\
$\mathrm{p}$ & .8 & .7 & .6 & .5 & .45 & .425 & .375 & .35 & .3 \\
\hline
\end{tabular}


3. MATERIAIS E METODOS

3.1: Materiais

3.1.1. Dados meteoralógicos

Foram usadas series de dados de 30 anos (1960 - 1989 das Estaç̄es Agrometeorológicas do Instituto Agronómico de Campinas cuja localização figura na Tabela 7 .

Tabela 7 - Localização geografica das Estaçoses Meteorologicas onde foram registrados os dados meteorologicos.

\begin{tabular}{|l|c|c|c|}
\hline & LATI TUDEC S & LONGI TUDEC W & ALII TUDEC 3 \\
\hline Campinas & $22^{\circ} 05^{\prime}$ & $47^{\circ} 05^{\prime}$ & 669 \\
Jau & $22^{\circ} 17^{\prime}$ & $48^{\circ} 34^{\prime}$ & 580 \\
Cordeiropolis & $22^{\circ} 3^{\prime}$ & $47^{\circ} 27^{\circ}$ & 639 \\
Pindorama & $21^{\circ} 13^{\prime}$ & $48^{\circ} 56^{\prime}$ & 562 \\
Ribeirão Preto & $21^{\circ} 11^{\prime}$ & $47^{\circ} 48^{\prime}$ & 621 \\
\hline
\end{tabular}

Os seguintes dados foram usados: temperatura média do ar. em ${ }^{\circ} \mathrm{C}$ e evaporaçăo de Piché, em mm, medidas no abrigo meteorologico a $1,70 \mathrm{~m}$ de altura do nivel do solo; número de horas de brilho solar, registrado em heliografo Campbell-Stokes; chuva, em $\mathrm{mm}$, medida com pluvismetro convencional. 


\subsubsection{Capacidade de armazenamento de água do solo}

Dos criterios de disponibilidade de agua no solop fol adotado o de água fácilmente disponivel CAFDS, considerando-se que ate o esgotamento desta. a evapotranspiração real CETrJ $\Leftrightarrow 1$ gual a ETm, $\theta$ a partir desse ponto começarla a ocorrencla de dericites.

Dado que a fração p depende da ETm, e esta varia dia a dia, verificaram-se casos de periodos com alta ETm precedidos de periodos de baixa ETm, com valores negativos de disponibilidade de agua no solo. Por este motivo, roi adotado um valor constante de AFD igual a $50 \%$ da $A D$.

Ainda que conhecidos os dados de. solos predominantes em cada região a existencia de estimativas das profundidades de enraizamento citens 2.7.5. e 2.7.6.), a grande variabilidade destes parametros, e a influencia de numerosos outros fatores na disponibilidade efetiva de agua para as plantas, foram considerados quatro níveis de armazenamento. Cada um desses niveis fol considerado nas cinco localidades em estudo. Estes for am obtidos por diferentes combinaç̧es solo-profundidade de enraizamento, sendo dificil associar cada combinação a um nivel de armazenamento dado, pela variabilidade já citada. Os quatro nivels fixados foram os de $30,40,50$ e $75 \mathrm{~mm}$ de AFD, e estimou-se que estes niveis são representativos de mals de $80 \%$ dos pomares existentes nas areas consideradas neste trabalho. Para a localidade de Pindorama, foi adicionado o nivel de $100 \mathrm{~mm}$ de AFD, devido a existéncia de solos eutróficos na sua área de influência.

Para exemplificar, considerando um valor de $A D$ de $10 \%$, significa 150,100 e $60 \mathrm{~mm}$ de água para as profundidades de enralzamento de 150,100 e $60 \mathrm{~cm}$, mencionadas para solos eutroficos, distroficos $e$ alicos 
respectivamente. Estes valores correspondem a $75,50=30$ $\mathrm{mm}$ de AFD.

\subsubsection{Equi pamento de computação}

Os equipamentos de computação usados foram um Monydata Nyda 200 Plus existente no Departamento de Física e Meteorologia da Escola Superior de Agricultura "Lujz de Queiroz", e um Amdek System 286 A da Seção de Climatologia Agricola do Instituto Agronómico de Campinas.

Para os calculos a a elabor ação dos quadros, fol usada a planilha eletrónica LoTUS 1-2-3. Os textos foram preparados com processadores de texto Wordstar e Chiwriter.

3.2. Metodos

\subsubsection{Estimativa da evapotranspiração}

A equação 5 a original de PENMAN (1948), citada por VILLA NOVA \& OMETTO (1981).

$$
E=\frac{\Delta}{\Delta+\gamma} \cdot H+\frac{\gamma}{\Delta+\gamma} \cdot E a
$$

onde:

$$
\begin{aligned}
H= & \text { energia radiante disponivel (mm evaporação } \\
& \text { equivalente) } \\
\mathrm{Ea}= & \text { poder evaporante do ar }(\mathrm{mm}) \\
\Delta= & \text { tangente a curva de tensão de saturaçã no ponto } \\
& \text { de temperatura de ar considerado }\left(\mathrm{mm} \mathrm{Hg} /{ }^{\circ} \mathrm{C}\right. \\
\gamma= & \text { constante psicrometrica }\left(\mathrm{mm} \mathrm{Hg} /{ }^{\circ} \mathrm{C}\right)
\end{aligned}
$$

Nesta equação, o primeiro termo representa a evaporação devida a radiação e o segundo, a devida ao poder evaporante do ar em função do vento. 
As equaç̧es 8 e 7 são as de estimativa de $H$ - Ea propostas por PENMAN (1948).

$H=00\left(a+b \cdot \frac{n}{N}(1-R)-\alpha T^{4}(0,56-0,092 . \sqrt{\operatorname{Ved}})(0,1+\right.$

(6)

$E_{2}=0,35(1+0,54$ U C Cs - ed)

onde:

Qo = constante solar (mm ev. eq./dia CTabela 1 , do Apêndice 1. OMETTO, 1981J

$a, b=$ constantes que dependem do local

$n=$ horas de brilho sol ar no dia considerado

$N=$ máximo possivel de horas de brilho solar no dia considerado (Tabela 5. do Apendice 1, LIST, 1951)

$R=$ albedo

$I=$ temperatura média do ar $C^{\circ} \mathrm{K}$

ed = tensão atual de vapor d'água atmosférico ( $\mathrm{mm} \mathrm{Hg})$

$U=$ velocidade do vento a $2 \mathrm{~m}$ de altura $(\mathrm{m} / \mathrm{s})$

es = tensão de saturação do vapor d'água atmosférico à temperatura media do ar $(\mathrm{mm} \mathrm{Hg}$

$\sigma=$ constante de Stefan-Boltzman

Como já foi indicado no item 2.3.3., esta equação apresenta dificultades de aplicação pela inexistencia muitas vezes de um ou mais dos parametros necesários. Portanto, neste trabalho, para estimar. a ETo. foi usada a equação de PENMAN modificada por VILLA NOVA \& OMETTO (1981), devido à disponibilidade de dados existente. A equação é do tipo:

ETo $=\alpha H+\Omega E p i$

(8)

onde:

$$
\begin{aligned}
& \text { ETo = evapotranspiraçäo potencial de referencia } \\
& \text { ( } \mathrm{mm} \text { /decendio) } \\
& \alpha=\text { coeficiente de correç̃o (tabela } 2 \text {, do Apéndice } \\
& \text { 1. VILLA NOVA, } 1967) \\
& H=\text { termo energetico }=\infty \quad\left(a^{\prime}+b^{\prime} \cdot n / N\right) \text { (á } e b^{\prime} \text {, } \\
& \text { tabela 3, do Apendice } 1 \text {, VILLA NOVA \& OMETTO, } \\
& 1981) \\
& \Omega \text {. = coeficiente de alteração da evaporação do Piché }
\end{aligned}
$$


Ctabela 4, do Apendice 1, VILLA NOVA \& OMETTO, $1981)$

Ep1 : evaporação do evaporimetro (Piche) ( $\mathrm{mm} /$ decendio)

Para a adaptaçáo da ETo para a cultura obtenção da ETm. for am usados os valores de coericiente de cultura (KC) adotados por VIEIRA (1984), num trabalho relativo ao Estado de São Paulo, para pomares não irrigados.

\subsection{Balanço hídrico}

A metodologia para a execução do balanço, fol a sugerida pela FAO, com adaptacão do metodo de calculo da evapotranspiraça citem 3.2.1.) o nivel de armazenamento (1tem 3.1.2.).

- balanço foi felto sequencialmente para os 30 anos considerados, usando para cada decendio os valores reais de chuva e de ETm estimada.

A periodicidade selecionada fol a decendial, que possibilita uma identificação adequada da disponibilidade hidrica, para o caso dos citros.

- roteiro do balanço fol separado em duas partes, sendo a primelra a estimativa da ETm e a segunda o balanco propriamente dito.

\section{ROTEIRO I}

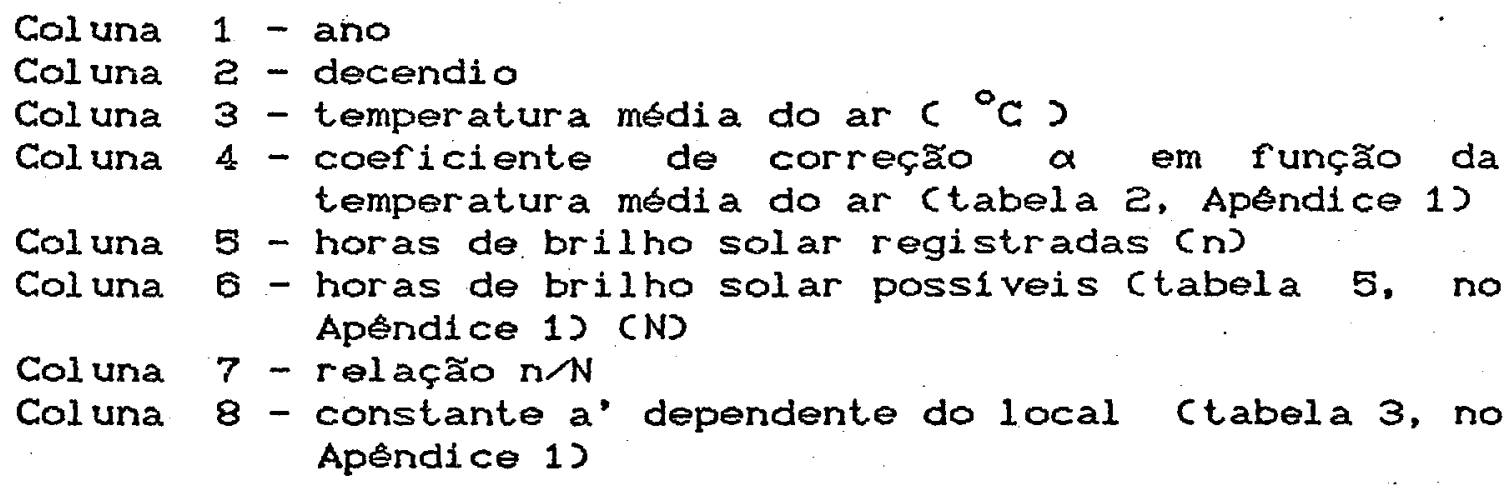
temperatura media do ar (tabela 2 , Apendice 1 )

Coluna 5 - horas de brilho solar registradas $(n)$

Coluna 6 - horas de britho solar possiveis Ctabela 5 , no Apendice 1 ) (N)

Coluna 7 - relação $n / N$

Coluna 8 - constante a' dependente do local Ctabela 3 , no Apendice 1) 
Coluna 9 - constante b' dependente do local ctabela 3 , Apéndice 13

Coluna 10 - 0 , dependente da latitude epoca do ano (tabela 1, Apéndice 1)

Coluna 11 - coeficiente de correção $\Omega$ em funça da epoca do ano (tabela 4, Apendice 1 )

Col una 12 - evaporação do evaporimetro de piche

Coluna 13 - evapotranspiraça potencial de referencia (ETo) estimada com base aos dados das colunas 4,7 , 8, $9,10,11 \odot 12$

Coluna 14 - coericiente da cultura (KC)

Coluna 15 - evapotranspiração potencial máxima (ETm)

\section{ROTEIRO II}

Coluna 1 - ano

Coluna 2 - decendio

Coluna 3 - precipitação pluvial

Coluna 4 - evapotranspiração potencial máxima (ETm)

Coluna 5 - armazenamento, obtido pelo resultado entre a soma das colunas 3 do periodo e a 5 do periodo anterior, menos a coluna 4 do periodo em questão; quando a diferença da um valor negativo, ocorre um deficite (ver coluna b) e nesta coluna coloca-se o valor zero; quando o valor obtido é maior ao de AFD, ocorre um exceso (ver col una 7 ) nesta col una colocado - valor de AFD

Coluna 8. - dericites obtidos com os valores absolutos dos valores negativos resultantes do procesamento da coluna 5

Coluna 7 - excedentes hídricos obtidos como a diferença entre os valores superiores a AFD resultantes do procesamento da coluna 5 e a própria AFD

3.2.3. Análise estatistica

Na literatura, são citados diferentes tipos de distribuiçőes para cada variável considerada, seja chuva, ETm, água disponivel no solo, deficites e excessos (YEVJEVI CH, 1972$).$

No caso da chuva, para algumas localidades do Estado de Sao Paulo, os trabalhos de ARRUDA E PINTO 
(1980) FRIZZONE (1985) entre outros,mostram que para periodos de 10 dias, fol obtido um bom ajuste com a função de distribuiça gama. FRIZZONE (1885), ainda que para apenas uma localidade, não encontrou ajuste aceitável quando o pertodo de trabalho se reduz a cinco dias.

CAMARGO et alii (1985), compararam a probabilidade de atendimento hidrico durante o ciclo do trigo, para diferentes regiós paulistas, usando a distribuição gama-reduzida.

ALFONSI et alii (1989b), usando a função de distribuição gama, calcularam os niveis de probabilidade de ocorrencias de decendios secos, o nivel de deficiencia hidrica e de armazenamento de agua no solo para 21 localidades paulistas. Tambem ALFONSI et alii (1989a), usando a mesma funçåo de distribuiça de probabilidade, calcularam a probabilidade de atendimento hídrico em cada fase das culturas de soja, milho e arroz de sequeiro no Estado de São Paulo.

Em testes preliminares, a ETo apresentou ajuste aceitável a distribuição normal. 0 uso da distribuição gama em trabalhos a nivel local, mostrou ser promissor nesse tipo de estudo. Entretanto, os outros parametros só se ajustavam a distribuiçăo gama quando eliminados os valores de AFD máximos e os zeros. Em todos os casos de decendios com elevadas quantidades de valores máximos e/ou zeros, torna-se dificil o uso de uma das distribulçós teóricas convencionais. Portanto, optou-se pelo uso do conceito de "decis" (SPIEGEL, 1978 ). Esta metodologia dispensa estudo previo do grau de ajuste, por estar baseada na distribuiça real, processada a nível de classes de $10 \%$ de probabilidade acumulada. Nas tabelas apresentadas, o valor minimo representa o limite inferior do primeiro decil. e o valor em cada coluna. o limite superior de cada decil ou "classe". 


\section{Resultados e discussão}

\subsection{Aspectos gerais}

As distribuiçốs dos totais de chuva e ETo. são apresentadas em tabelas por estação meteorologica, para cada decendio. So no caso das tabelas de ETo, foram corrigidos os valores do tercelro decendio de fevereiro dos anos bissestos, pelo coeficiente $8 / 9$, para que não al torassem a distribuição.

O conteúdo de agua no solo, os deficites e os excedentes hidricos, sao apresentados em tabelas por estação meteorologica e nível de AFD para cada decendio.

As tabelas de probabilidade se encontram no presente capitulo, e no Apendice 2 , constam 73 tabelas de dados, em mm, dispostos em ordem crescente.

Nas tabelas que constam no Apéndice 2 ,

um dado na coluna do decil 4 significa que: a)

existe $40 \%$ de probabilidade de ocorrer esse valor ou um valor menor; b) existe 60\% de probabilidade de ocorréncia de um valor maior que aquele da coluna 4. Cada classe de $10 \%$ de amplitude (decil), encontra-se limitada pelos valores de duas colunas consecutivas, na mesma linha. Nos casos das tabelas de água fácilmente disponivel, quando o nivel de AFD considerado e alcançado, ele se mantém nas colunas seguintes. Isto não significa que sua probabilidade de ocorrencia varie a partir daquele limite. Por exemplo, observe o primeiro decendio de janeiro, na Tabela 3 
CApéndice 2$)$, o nivel de AFD (30 mm) é alcançado no terceiro decil, significando que em $70 \%$ dos anos considerados, o solo atingiu o seu nivel maximo de AFD.

Tabela 8 - Valores médios decendiais de ETo (mm), para cinco localidades do Estado de Sa Paulo.

\begin{tabular}{|c|c|c|c|c|c|}
\hline & & ESTAGRO & TEOROLOK & & \\
\hline Decendio & Campinas & Cordeir. & Jau & Pindorama & R.Preto \\
\hline jan. $1-10$ & 59,3 & 51,6 & 55,0 & 53,7 & 55,8 \\
\hline $11-20$ & 59,5 & 53,1 & 58.5 & 54,7 & 56.6 \\
\hline $21-31$ & 65,1 & 58,1 & 81.0 & 59,0 & 60,6 \\
\hline fev. $1-10$ & 59,4 & 53.6 & 57.3 & 53,0 & 55.8 \\
\hline $11-20$ & 57,6 & 53,4 & 55,6 & 53,5 & 54,9 \\
\hline $21-28$ & 43,3 & 40.6 & 43.3 & 40,0 & 41,0 \\
\hline $\operatorname{mar} .1-10$ & 54,9 & 49,5 & 53,2 & 49,1 & 51,3 \\
\hline $11-20$ & 54,8 & 48.7 & 53,1 & 49,0 & 51,3 \\
\hline $21-31$ & 58,8 & 51,4 & 57.9 & 53,4 & 57,0 \\
\hline abr $\cdot 1-10$ & 44,7 & 37,6 & 43,8 & 40,4 & 42,3 \\
\hline $11-20$ & 43,1 & 36,3 & 42,6 & 38,4 & 40,8 \\
\hline $21-30$ & 40,9 & 34,1 & 40,4 & 37,0 & 39,0 \\
\hline $\operatorname{mat} .1-10$ & 36,2 & 31,4 & 36,1 & 33,5 & 35,4 \\
\hline $11-20$ & 35,2 & 29.9 & 35,0 & 32,4 & 34,0 \\
\hline $21-31$ & 37.5 & 32,4 & 37,6 & 33,8 & 36,2 \\
\hline jun. $1-10$ & 32,7 & 29,3 & 33,2 & 30,5 & 32,4 \\
\hline $11-20$ & 31,4 & 27,5 & 31,6 & 29,5 & 31,7 \\
\hline $21-30$ & 33,8 & 29,0 & 34,2 & 31,8 & 33,3 \\
\hline jul. 1-10 & 35,7 & 30,5 & 35,8 & 33,4 & 35,0 \\
\hline $11-\mathrm{eO}$ & 37,5 & 32,1 & 37,3 & 35,4 & 36,8 \\
\hline $21-31$ & 43,5 & 36.5 & 43,3 & 40,6 & 42,2 \\
\hline ago. $1-10$ & 41,4 & 36,2 & 41,1 & 38,7 & 41,1 \\
\hline $11-20$ & 43,0 & 37,2 & 42,4 & 40,1 & 43,6 \\
\hline $21-31$ & 50,1 & 43,7 & 49,7 & 47,9 & 51,6 \\
\hline set. $1-10$ & 46,9 & 40,2 & 46,9 & 44,1 & 47,4 \\
\hline $11-20$ & 49,3 & 42,9 & 48,9 & 46,8 & 51,2 \\
\hline $21-30$ & 48,7 & 43,0 & 48.1 & 47,3 & 50,3 \\
\hline out. $1-10$ & 59,6 & 53,6 & 57.5 & 56,3 & 58.7 \\
\hline $11-20$ & 61,8 & 55,8 & 60,4 & 57,9 & 61,2 \\
\hline $21-31$ & 67,4 & 80,2 & 65.7 & 63,8 & 66,4 \\
\hline nov. $1-10$ & 63,6 & 57.1 & 62,6 & 60,0 & 62,1 \\
\hline $11-20$ & 83,7 & 57.0 & 61.6 & 58,1 & 59.7 \\
\hline $21-30$ & 63,7 & 57.1 & 62,1 & 59,9 & 60,7 \\
\hline $\operatorname{dez} \cdot 1-10$ & 61.1 & 53,8 & 58,6 & 55,9 & 58.1 \\
\hline $11-20$ & 60,1 & 52,1 & 57.7 & 54,1 & 56.2 \\
\hline $21-31$ & 62.8 & 54,1 & 59,8 & 58,2 & 59,3 \\
\hline
\end{tabular}


Tabela 9 - Valores medios decendiais de chuva $(\mathrm{mm})$, para cinco localidades do Estado de São Paulo.

\begin{tabular}{|c|c|c|c|c|c|}
\hline \multirow[b]{2}{*}{ Decendio } & \multicolumn{5}{|c|}{ ESTACXO METEOROLOGICA } \\
\hline & Campinas & Cordeir. & Jau & Pindorarna & R.Preto \\
\hline jan. $1-10$ & 79,3 & 75,0 & 82,0 & 82,5 & 80,8 \\
\hline $11-20$ & 78,5 & 90,1 & 76.5 & 95,4 & 87,6 \\
\hline $21-31$ & 80,8 & 71,8 & 72,0 & 84,0 & 95,0 \\
\hline fev. $1-10$ & 72,9 & 62,9 & 75,5 & 83,2 & 84.7 \\
\hline $11-20$ & 74,3 & 64,7 & 78,7 & 73.7 & 74,9 \\
\hline $21-28$ & 52,8 & 60,6 & 62,3 & 61.0 & 66,6 \\
\hline $\operatorname{mar} .1-10$ & 55,5 & 64,0 & 48,1 & 64,4 & 62,8 \\
\hline $11-20$ & 53,0 & 64,6 & 64,4 & 57,7 & 58,9 \\
\hline $21-31$ & 39,6 & 33,1 & 38,4 & 44,6 & 38,4 \\
\hline abr. $1-10$ & 32,9 & 30,1 & 36,0 & 31,5 & 35,0 \\
\hline $11-20$ & 27,3 & 21,7 & 24,8 & 22,8 & 26,1 \\
\hline $21-30$ & 15,7 & 13,6 & 20,4 & 20,2 & 24,8 \\
\hline $\operatorname{mai} .1-10$ & 20,6 & 23,3 & 22,5 & 26,2 & 20,3 \\
\hline $11-20$ & 23,4 & 22,9 & 23,0 & 16,0 & 14,3 \\
\hline $21-31$ & 33.3 & 29,6 & 35,2 & 24,5 & 25,7 \\
\hline jun. 1-10 & 23,3 & $18 ; 6$ & 19,4 & 14,2 & 14,3 \\
\hline $11-20$ & 21,1 & 17.1 & 21.1 & 16.0 & 15,2 \\
\hline $21-30$ & 14.7 & 18.5 & 18,6 & 10,5 & 10,0 \\
\hline jul. $1-10$ & 18,5 & 17,4 & 13,5 & 8,4 & 13,3 \\
\hline $11-20$ & 11,4 & 11,3 & 11.7 & 9.4 & 11,1 \\
\hline $21-31$ & 18,2 & 13,4 & 15.1 & 11,2 & 9.5 \\
\hline ago. $1-10$ & 11,0 & 8,7 & 6.9 & 9.8 & 8,1 \\
\hline $11-20$ & 10.9 & 10,2 & 10,6 & 0,5 & 0,1 \\
\hline $21-31$ & 17.8 & 16,9 & 15,0 & 12,3 & 15,6 \\
\hline set. $1-10$ & 21,4 & 22,4 & 19,5 & 14,1 & 15,2 \\
\hline $11-20$ & 18,1 & 18,0 & 16.5 & 24,5 & 20,0 \\
\hline $21-30$ & 25,9 & 27,2 & 29.7 & 26,6 & 24,5 \\
\hline out. $1-10$ & 37.0 & 41,2 & 37,6 & 37,1 & 40,2 \\
\hline $11-20$ & 38,3 & 40,2 & 43,9 & 43,8 & 42,8 \\
\hline $21-31$ & 50,6 & 47.0 & 44,1 & 40,7 & 55,2 \\
\hline nov. $1-10$ & 38,3 & 42,9 & 51,3 & 48,7 & 53.6 \\
\hline $11-20$ & 46,7 & 50,4 & 55.2 & 53,3 & 62,8 \\
\hline $21-30$ & 51,4 & 54.7 & 59.2 & 51.4 & 70.2 \\
\hline dez. $1-10$ & 73,8 & 75,5 & 81,1 & 63,5 & 89,5 \\
\hline $11-20$ & 77,1 & 75,1 & 78,5 & 67,9 & 97,4 \\
\hline $21-31$ & 81,8 & 92,7 & 101.0 & 103,3 & 131.5 \\
\hline
\end{tabular}

Como pode-se observar a partir dos dados das Tabelas 8 e 9 , em todas as localidades aparece o periodo de 
março a novembro, com valores medios de chuva inferiores aos de ETO. Do ponto de vista agrícola, esse periodo sera maior ou menor dependendo dos valores de $\mathrm{Kc}$ usados para estimar a ETm relativa ao cultivo considerado. Neste caso, com citros e valores de Kc entre $0,5 \bullet 0,6$, esse periodo se reduz em aproximadamente tres meses, flcando de abril a setembro com ETm menores que a chuva.

Quando considera-se a disponibilidade de água para os cultivos, o inicio da deficiencia hidrica acontecera com o esgotamento da água do solo, fato que se da numa data posterior aquela onde a chuva se torna. inferior a ETm.

Neste caso, pode-se observar que para um dado nivel de probabilidade, em dado decendio, a duracăo e a intensidade dos deficites são iguais ou menores e a àgua disponivel no solo igual ou maior, quanto maior seja o nivel de AFD rixado. Como exemplo, na Figura 2 observa-se que quanto major 6 o nivel de AFD considerado. para um mesmo nivel de probabilidade de ocorrencia, os deficites são de menor duração e seu inicio e mais tardia. A partir de meados de setembro, verifica-se uma redução de periodos com deficite hídrico, as diferenças são pouco significativas entre os varios AFD, exceto para $30 \mathrm{~mm}$.

Ao longo do ano, para cada decendio 1 solado e para um dado nivel de probabilidade, quanto malor o nível de AFD fixado, menor a probabilidade de deficites hidricos. Dados os valores de água disponivel obtidos pelas equaçóses e pela revisão bibliografica, e evidente que o fator que mais influencia o nivel de AFD $e$ a profundidade de enraizamento. Para efeitos práticos, para solos alicos, recomenda-se o uso dos nivels inferiores (AFD 30 ou $40 \mathrm{~mm}$, para os distroficos, os intermediarios $(40$ ou $50 \mathrm{~mm}$, e para os eutroficos, os superiores (75 mm ou mais).

A probabilidade de ocorrencia de um decéndio 
com deficite hidrico e maior nos meses de julho e agosto. coincidente com o repouso ou pre-rlorescimento. Entretanto. ela existe praticamente ao longo do ano todo, com os menores níveis de probabilidade de ocorréncia nos meses de novembro a março.

A probabilidade de ocorréncia de urn decendlo com excedente hidrico e maior nos meses de dezembro a fevereiro, podendo existir no ano todo, com os menores níveis de probabilidade de ocorrencia nos meses de junho a setembro.

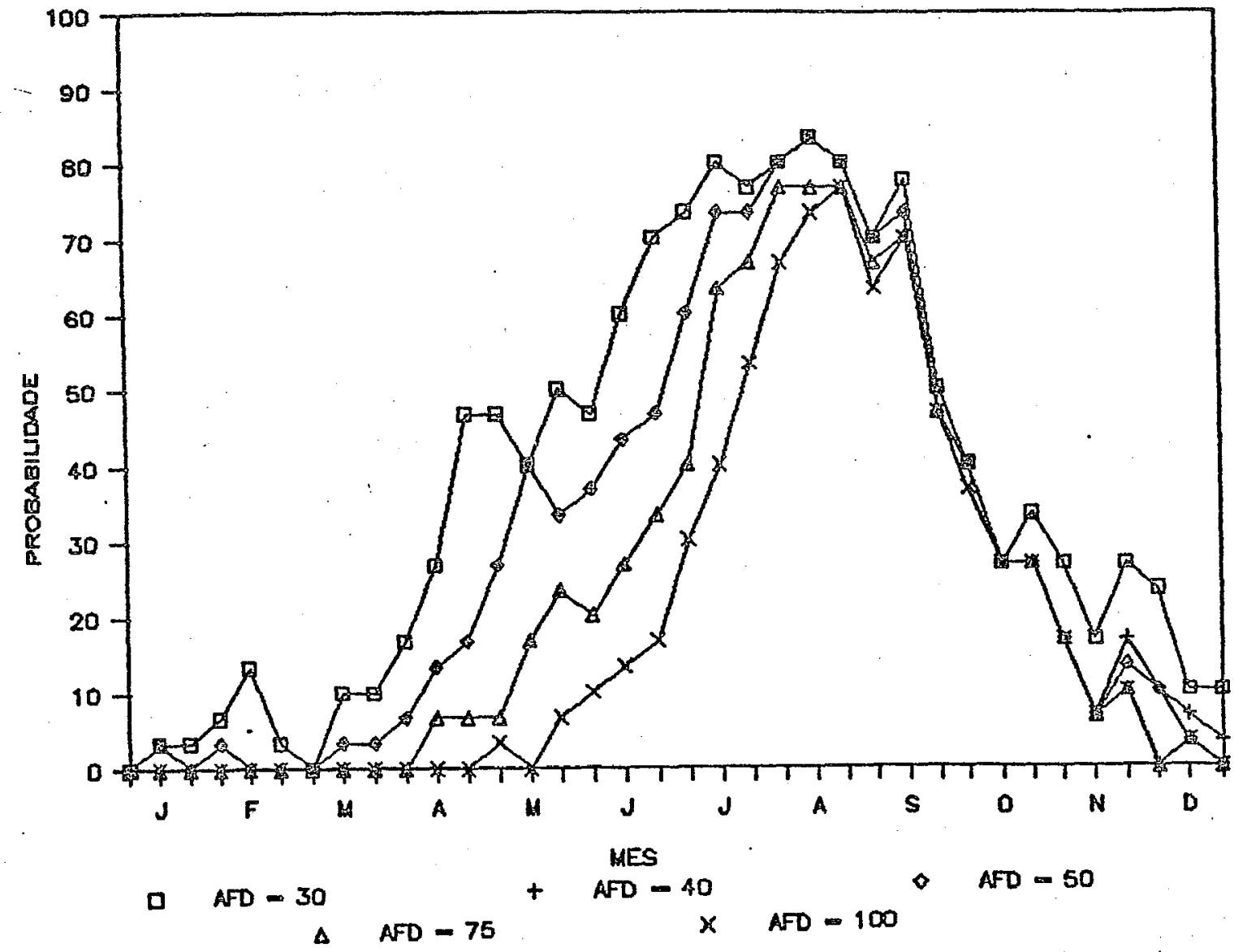

Figura 2 - Probabilidade que a AFD seja zero, para cinco níveis de armazenamento, na localidade de Pindorama - SP. 
Quanto ao comportamento por local, uma primeira analise permite separar dois grupos. Um deles, formado por Campinas Cordeirópolis, ainda que com uma forte tendencia de Campinas apresentar. para os mesmos níveis de probabilidade de ocorréncla e AFD, menor água disponivel no solo e malor quantidade e duraçăo do periodo com deflcites hidricos (Figura 3 ).

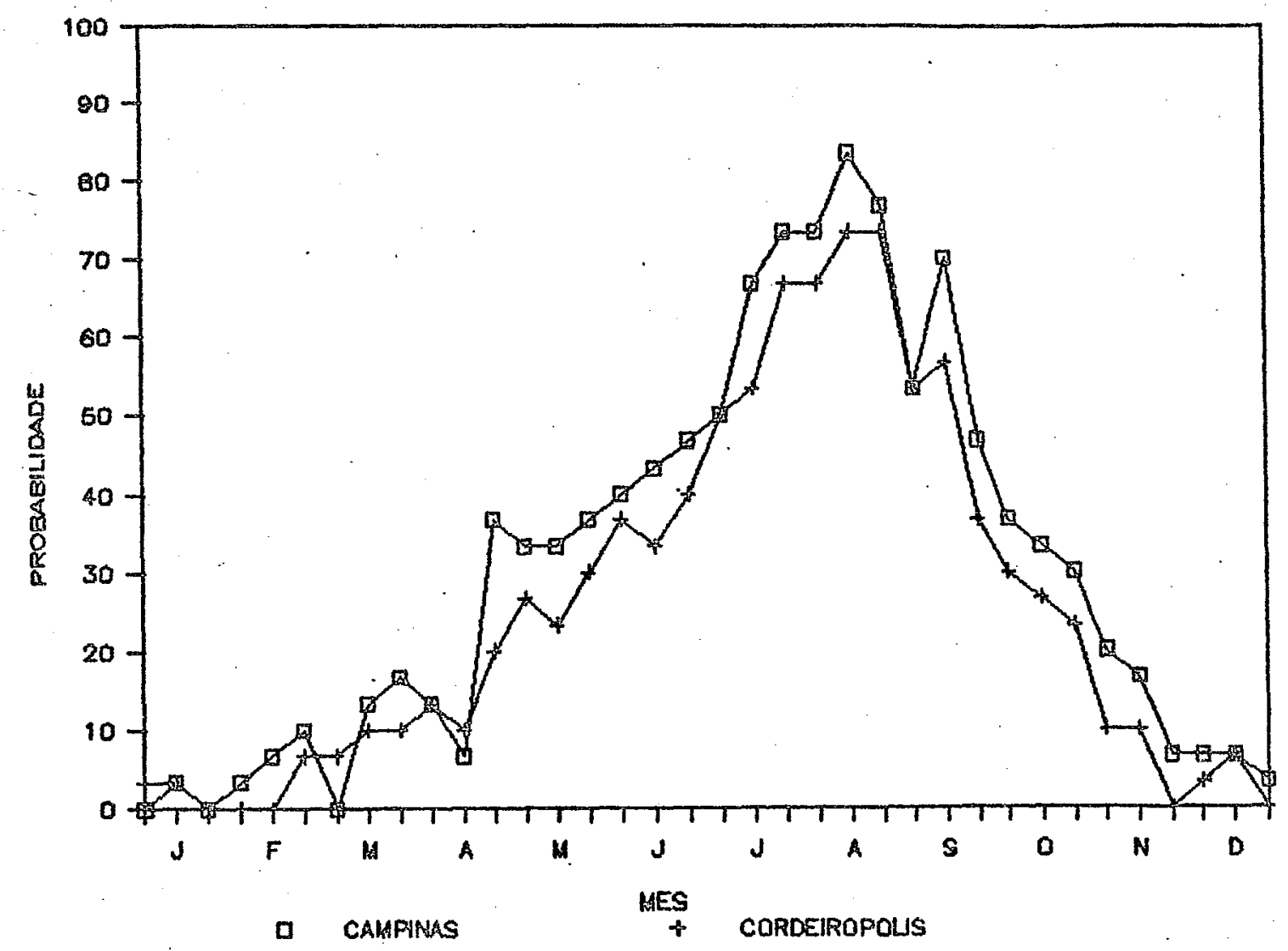

Figura 3 - Probabilidade que a AFD seja zero, para as localidades de Campinas e Cordeirópolis, para AFD C5O mm.

- outro grupo, formado por Jaú. Pindorama e Ribeirão Preto, quando comparado com o grupo anterior, 
apresenta maior quantidade de água disponivel e menores deficites no periodo de dezembro a maio. Porém, para niveis de mais de 30\% de probabilidade de ocorrencia, os deficites são de maior duraçăo que no outro grupo. $\mathrm{Na}$ figura 4 compara-se, como exemplo, o comportamento da localidade de Pindorama com a de Cordeirbpolis. Para AFD igual a zero. observa-se que no periodo maio-setembro, a probabilidade de ocorrencia do valor zero e sempre maior em Pindorama. 0 comportamento de Ribeirão Preto e Jaú, em relaç̃o a Cordefropolis, e similar.

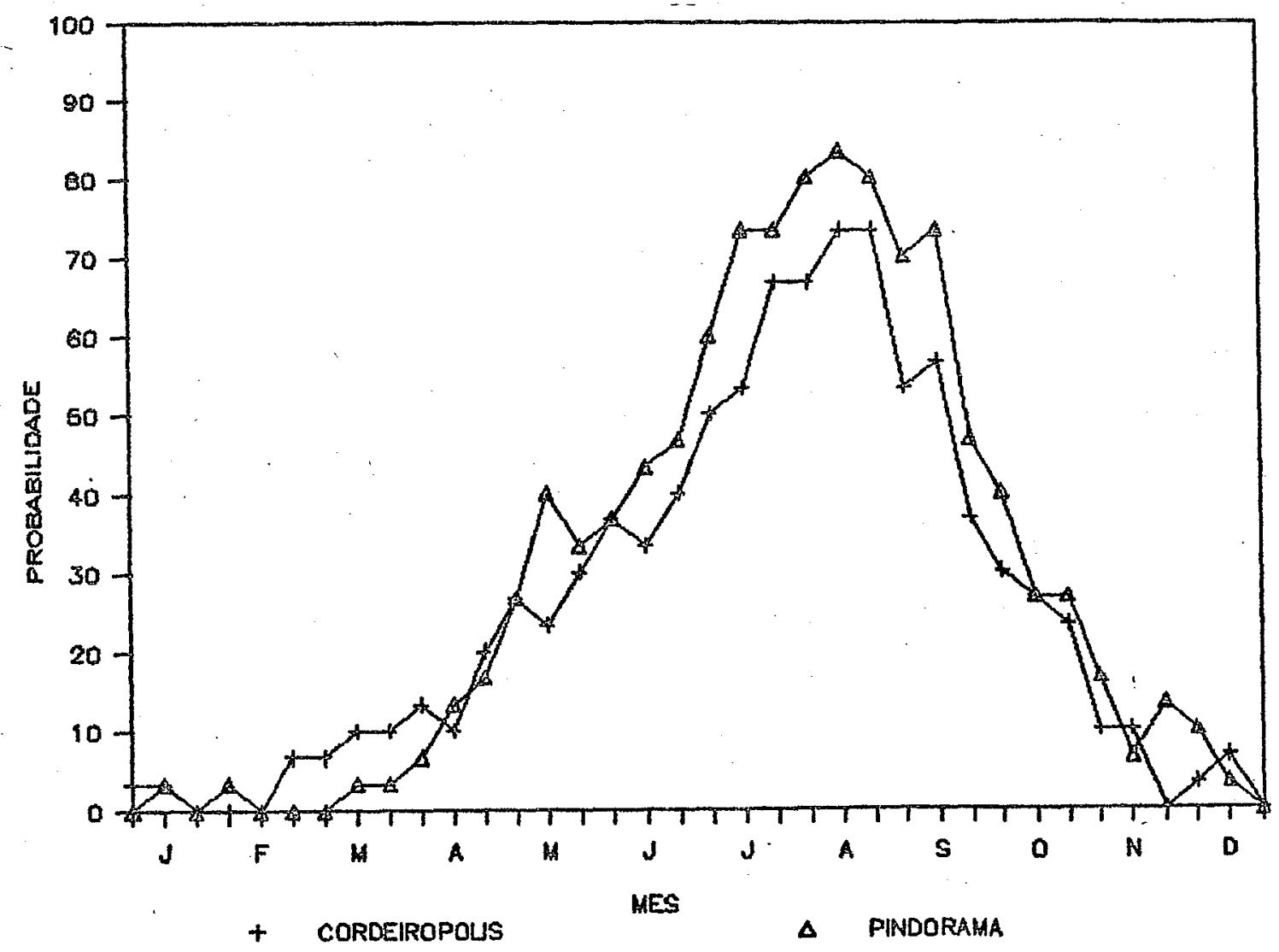

Figura 4 - Probabilidade que a AFD seja zero, para as localidades de Pindorama e Cordejrópolis, para AFD (50 mm). 
- estudo da relação entre o ciclo fenológico - o comportamento da planta com os $\mathrm{n}$ iveis da AFD, deve considerar as diferenças de duraçăo dos estádios fenológicos, que abrange desde uma floraça relativamente concentrada num mês; a uma maturação e colheita que se extende entre seis a 12 meses.Para efeitos de discussão, foram consideradas as seguintes relaçes tempo-estádio fenológico: a) junho-agósto, indução floral; b) setembro, floraço; c) outubro-novembro, crescimento inicial do fruto; C) dezembro-mato, crescimento do fruto; ds junho-dezembro, maturação e colheita.

Pelas Tabelas 10, 12, 14, 18 e 18 , verifica-se que, qualquer seja a localidade e o nível de AFD considerado, num periodo maior que dois meses, incluindo setembro (floraça), existe $50 \%$ ou mais de probabilidade que a AFD seja zero. Um ano de cada trés, o periodo de deficite hidrico mator que cinco meses e abrange outubro (inicio da frutiricação). Esta situação pode afetar a produção dos pomares, possivelmente provocando maior atrofia floral e malor queda de frutos pequenos. Aqui deve-se ressaltar, que está se relacionando água no solo (elemento do balanço hidrico) com floraça e inicio de frutificaçăo. Existem outros fatores que afetam a floração, como chuva, umidade do ar e temperaturas baixas CORTOLANI et alii 1990), todos relacionados com o balanço térmico do cultivo, os quais, além de dificultar a aç̃o dos insetos polinizadores, prejudicam a abertura das anteras e a própria polinização. Por isto, não se considerou que os resultados encontrados por TUBELIS \& SALIBE (1989), com a chuva de setembro prejudicando a safra do ano seguinte no caso de laranja 'Hamlim', afetem a interpretaça dos resultados encontrados neste trabalho.

o inicio do perlodo de deficite hidrico é comum nos meses de abril e maio (um ano de cada trés). 
sendo que nestes meses ainda existe crescimento dos frutos. Segundo a bibliografia CDOORENBOS \& KASSAM, 1979), no periodo de repouso e indução floral são necessarios pelo menos dois meses com deficites hidricos, para uniformidade e concentraço da florada principal. Tal condiçăo inclue o. ecossistema citricola do Planalto Paulista. Para todos os locals estudados, nos niveis de AFD de 30 e $40 \mathrm{~mm}$, existe a probabilidade que um em cada dez anos, exista agua no solo durante a maior parte do periodo de repouso e indução floral, e que um ano de cada cinco, os dericites apresentem uma duração de 20 dias ou menos. No caso do nivel AFD $75 \mathrm{~mm}$, os dericites hidricos podem ser menores que 30 dias, na relação de um para cada trés anos. Ressalte-se, entretanto, como ja rol indicado na revisão bibliografica, não $\Leftrightarrow$ claro o limite quantitativo e qualitativo para que os dericites induzan o florescimento, sem afetar a produção. E assim que GALLO et alii (1977) não encontraram correlação entre os dados dos balangos hidricos meteorológicos e a produçăo.

Dois em cada trés anos, ocorrem excedentes em dezembro, coincidindo com 0 final do periodo de colheita. Colheitas tardias, coincidentes com alta umidade neste periodo, podem reduzir substancialmente a qualidade dos frutos, principalmente os destinados a industria de sucos. Para a venda in natura, essa condição favorece o maior peso e volume dos frutos. Em todas as localidades, a duração do periodo, de dezembro a malo, com pleno atendimento hidrico, pouco influenciada pelo nivel de AFD considerado. 
4.2. Discussão por lacal

\section{2.1. Campinas}

Como pode ser observado na Figura 5, nesta localidade, a media de chuva e inferior a de ETm desde o último decéndio de junho ate 0 último de setembro, existindo um periodo com condiçæes similares no último decendio de abril.

Segundo o especificado no 1 tem 2.7.3., nesta area predominam solos alicos distroricos, que limitam o enraizamento, e portanto, a quantidade de AFD.

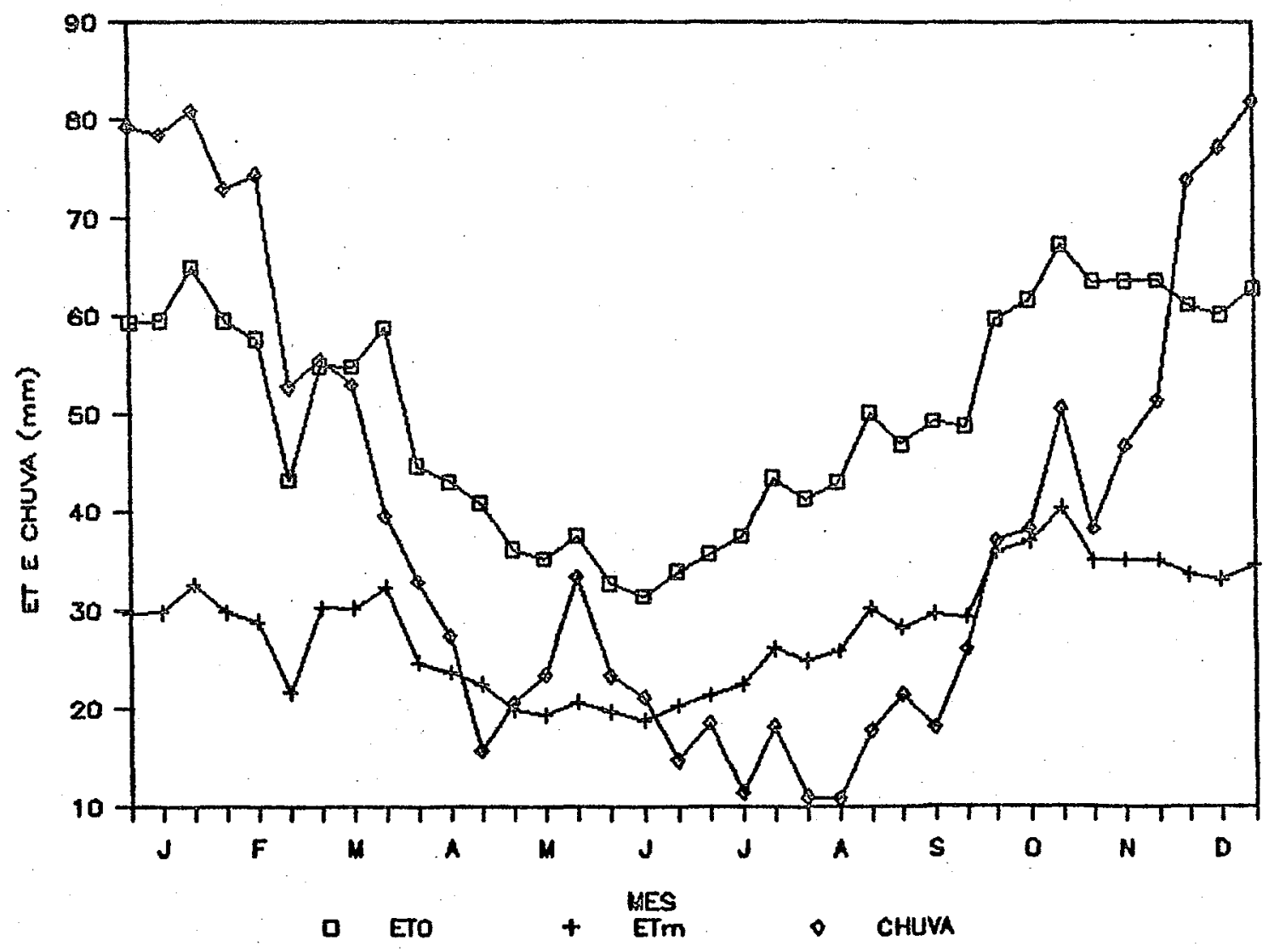

Figura 5 - Valores decendiais medios de chuva. ETo e ETm. para Campinas - SP. Periodo 1960 a 1989. 
Tabela 10 - Probabilidade, em porcentagem, de deficites hidricos e de que AFD seja zero para quatro niveis de AFD ( $30,40,50$ e $75 \mathrm{~mm}$, na local idade de Campinas - SP.

\begin{tabular}{|c|c|c|c|c|}
\hline & \multicolumn{4}{|c|}{ Ni vel de AFD considerado (mm) } \\
\hline Decendio & 30 & 40 & 50 & 75 \\
\hline $\begin{array}{r}\text { jan. } 1-10 \\
11-20 \\
21-31 \\
\text { fer. } 1-10 \\
11-20 \\
21-28 \\
\operatorname{mar} 11-10 \\
11-20 \\
21-31\end{array}$ & $\begin{array}{r}3,3 \\
10,0 \\
10,0 \\
6,7 \\
13,3 \\
13,3 \\
6,7 \\
33,3 \\
23,3\end{array}$ & $\begin{array}{r}3,3 \\
0,7 \\
6,7 \\
3,3 \\
6,7 \\
13,3 \\
3,3 \\
20,0 \\
23,3\end{array}$ & $\begin{array}{r}0,0 \\
3,3 \\
0,0 \\
3,3 \\
6,7 \\
10,0 \\
0,0 \\
13,3 \\
16,7\end{array}$ & $\begin{array}{l}0.0 \\
3,3 \\
0.0 \\
0.0 \\
0.0 \\
3,3 \\
0.0 \\
0,0 \\
3,3\end{array}$ \\
\hline $\begin{array}{r}\text { abr. } 1-10 \\
11-20 \\
21-30 \\
\text { mai. } 1-10 \\
11-20 \\
21-31 \\
\text { jun. } 1-10 \\
11-20 \\
21-30\end{array}$ & $\begin{array}{l}20,0 \\
26,7 \\
53,3 \\
40,0 \\
40,0 \\
46,7 \\
53,3 \\
53,3 \\
60,0\end{array}$ & $\begin{array}{l}16,7 \\
16,7 \\
53,3 \\
40,0 \\
38,7 \\
43,3 \\
43,3 \\
50,0 \\
53,3\end{array}$ & $\begin{array}{r}13,3 \\
6,7 \\
36,7 \\
33,3 \\
33,3 \\
36,7 \\
40,0 \\
43,3 \\
46,7\end{array}$ & $\begin{array}{r}10,0 \\
6,7 \\
10,0 \\
10,0 \\
30,0 \\
23,3 \\
23,3 \\
26,7 \\
33,3\end{array}$ \\
\hline $\begin{array}{r}\text { jul } 11-10 \\
11-20 \\
21-31 \\
\text { ago. } 1-10 \\
11-20 \\
21-31 \\
\text { set. } 1-10 \\
11-20 \\
21-30\end{array}$ & $\begin{array}{l}53,3 \\
80,0 \\
83,3 \\
73,3 \\
86,7 \\
76,7 \\
60,0 \\
73,3 \\
50,0\end{array}$ & $\begin{array}{l}53,3 \\
80,0 \\
80,0 \\
73,3 \\
83,3 \\
76,7 \\
53,3 \\
70,0 \\
46,7\end{array}$ & $\begin{array}{l}50,0 \\
66,7 \\
73,3 \\
73,3 \\
83,3 \\
76,7 \\
53,3 \\
70,0 \\
46,7\end{array}$ & $\begin{array}{l}36,7 \\
56,7 \\
60,0 \\
63,3 \\
76,7 \\
66,7 \\
53,3 \\
60,0 \\
46,7\end{array}$ \\
\hline $\begin{array}{r}\text { out. } 1-10 \\
11-20 \\
21-31 \\
\text { nov. } 1-10 \\
11-20 \\
21-30 \\
\text { dez. } 1-10 \\
11-20 \\
21-31\end{array}$ & $\begin{array}{l}46,7 \\
36,7 \\
36,7 \\
33,3 \\
23,3 \\
20,0 \\
13,3 \\
13,3 \\
10,0\end{array}$ & $\begin{array}{r}40,0 \\
33,3 \\
33,3 \\
30,0 \\
16,7 \\
13,3 \\
10,0 \\
6,7 \\
3,3\end{array}$ & $\begin{array}{r}36,7 \\
33,3 \\
30,0 \\
20,0 \\
16,7 \\
6,7 \\
6,7 \\
6,7 \\
3,3\end{array}$ & $\begin{array}{r}36,7 \\
30,0 \\
26,7 \\
20,0 \\
16.7 \\
6,7 \\
6,7 \\
8,7 \\
3,3\end{array}$ \\
\hline
\end{tabular}


Tabela 11 - Probabilidade $\% \%$ de excedentes hidricos para quatro niveis de AFD ( $30,40,50$ e $75 \mathrm{~mm}$, na local idade de Campinas - SP.

\begin{tabular}{|c|c|c|c|c|}
\hline \multirow{2}{*}{ Decendio } & \multicolumn{3}{|c|}{ Nivel de AFD considerado } & \multirow[b]{2}{*}{75} \\
\hline & 30 & 40 & 50 & \\
\hline jan. 1-10 & 80,0 & 80,0 & 80.0 & 80.0 \\
\hline $11-20$ & 70,0 & 70.0 & 70,0 & 70,0 \\
\hline $21-31$ & 76.7 & 70,0 & 60,7 & 63,3 \\
\hline fev. $1-10$ & 70,0 & 70,0 & 70,0 & 70,0 \\
\hline $11-20$ & 63,3 & 63,3 & 83,3 & 63,3 \\
\hline $21-28$ & 66.7 & 66,7 & 66.7 & 66,7 \\
\hline $\operatorname{mar} .1-10$ & 50,0 & 46.7 & 46,7 & 43,3 \\
\hline $11-20$ & 46,7 & 40,0 & 40,0 & 40,0 \\
\hline $21-31$ & 40.0 & 38.7 & 33,3 & 33,3 \\
\hline abr. $1-10$ & 40,0 & 40,0 & 33,3 & 33,3 \\
\hline $11-20$ & 33,3 & 33,3 & 33,3 & 33,3 \\
\hline $21-30$ & 13,3 & 10,0 & 10,0 & 10,0 \\
\hline $\operatorname{mai} .1-10$ & 23,3 & 23,3 & 23.3 & 16.7 \\
\hline $11-20$ & 23,3 & 20.0 & 20,0 & 20,0 \\
\hline $21-31$ & 20,0 & 10,7 & 16,7 & 16,7 \\
\hline jun. 1-10 & 10,0 & 10,0 & 10,0 & 10,0 \\
\hline $11-20$ & 23,3 & 13,3 & 13,3 & 10.0 \\
\hline $21-30$ & 13,3 & 13,3 & 10,0 & 3,3 \\
\hline jul. 1-10 & 8,7 & 6,7 & 8,7 & 6,7 \\
\hline $11-20$ & 3,3 & 3,3 & 3,3 & 3.3 \\
\hline $21-31$ & 3,3 & 3,3 & 3,3 & 3,3 \\
\hline ago. $1-10$ & 3,3 & 3,3 & 3,3 & 3,3 \\
\hline $11-20$ & $6: 7$ & 6,7 & 3,3 & 3,3 \\
\hline $21-31$ & 10.0 & 10,0 & 10,0 & 6.7 \\
\hline set. $1-10$ & 16,7 & 13,3 & 10,0 & 3,3 \\
\hline $11-20$ & 16,7 & 16,7 & 13,3 & 10.0 \\
\hline $21-30$ & 20,0 & 16.7 & 10,0 & 6,7 \\
\hline out. $1-10$ & 40,0 & 33,3 & 26,7 & 16.7 \\
\hline $11-20$ & 23,3 & 23,3 & 20.0 & 16.7 \\
\hline $21-31$ & 36,7 & 38,7 & 33,3 & 23,3 \\
\hline nov. $1-10$ & 38,7 & 33,3 & 30,0 & 20.0 \\
\hline $11-20$ & 43,3 & 40,0 & 40,0 & 30,0 \\
\hline $21-30$ & 40,0 & 40,0 & 36,7 & 33,3 \\
\hline dez. $1-10$ & 70,0 & 66.7 & 66,7 & 63,3 \\
\hline $11-20$ & 76,7 & 70,0 & 70,0 & 70,0 \\
\hline $21-31$ & 80,0 & 80,0 & 80,0 & 80,0 \\
\hline
\end{tabular}

Comparando os dados da Tabela 10 com os correspondentes as outras localidades, observa-se que 
Campinas, para o nivel de AFD de $30 \mathrm{~mm}$, apresenta maiores probabilidades de deficites. Esta situação inverte-se nos casos dos niveis superiores de AFD. Para os dois níveis menores de AFD, um em cada dois anos, o deficite pode começar em junho. Conforme a bibliografia são necessarios só dois meses com dericite de água para provocar a indugão floral. Neste caso, teriamos um mes a mais, que pode afetar negativamente os frutos existentes na planta. A duração do deficite hidrico cria uma alta probabilidade de que em 50\% dos anos apareçam dericienclas hídricas na floração, e um ano de cada tres, em estadio avangado do desenvol vimento do fruto, independente do nivel de AFD considerado.

No inicio de novembro, em $50 \%$ dos anos ocorrem excedentes (ver Tabela 11), os quais são maiores que $10 \mathrm{~mm}$ por decendio a partir de dezembro. Os excedentes hidricos podem afetar negativamente a qualidade dos frutos na rase de maturação, especialmente em solos com drenagem insuficiente. Quando coincide com periodos longos com baixa radiaçăo solar, pode reduzir a taxa de crescimento da planta.

Finalmente, próximo ao inicio do periodo de maturação (março, abri1), em solos com niveis baixos de AFD C30 $\odot 40 \mathrm{~mm}$, tambem aparecem com alta frequiencia cum em cada tres anos, deficites hidricos que podem aretar o crescimento final e a relaça solidos solúveis totais e acldez total dos frutos.

\subsubsection{Cordeiropolis}

Como pode ser observado na Figura 6, nesta localidade os valores médios de chuva são inferiores aos de ETm desde o primeiro decéndio de julho até o segundo de setembro, existindo tambem um deficite no terceiro decéndio 
de abril.

Tabela 12 - Probabilidade, em porcentagem, de deficites hídrlcos e de que AFD seja zero para quatro niveis de $A F D(30,40,50 \bullet 75 \mathrm{~mm}$, na localidade de cordeiropolis - SP.

\begin{tabular}{|c|c|c|c|c|}
\hline & \multicolumn{4}{|c|}{ N1 vel de AFD considerado $(\mathrm{mm}$} \\
\hline Decendio & 30 & 40 & 50 & 75 \\
\hline $\begin{array}{r}\text { jar. } 1-10 \\
11-20 \\
21-31 \\
\text { fer. } 1-10 \\
11-20 \\
21-28 \\
\operatorname{mar} .1-10 \\
11-20 \\
21-31\end{array}$ & $\begin{array}{r}3,3 \\
3,3 \\
3,3 \\
13,3 \\
10,0 \\
10,0 \\
13,3 \\
26,7 \\
33,3\end{array}$ & $\begin{array}{r}3,3 \\
3,3 \\
0,0 \\
3,3 \\
3,3 \\
10,0 \\
6,7 \\
13,3 \\
13,3\end{array}$ & $\begin{array}{r}3,3 \\
3,3 \\
0,0 \\
0,0 \\
0,0 \\
0,7 \\
6,7 \\
10,0 \\
10,0\end{array}$ & $\begin{array}{l}3,3 \\
3,3 \\
0,0 \\
0,0 \\
0,0 \\
0,0 \\
6,7 \\
3,3 \\
3,3\end{array}$ \\
\hline $\begin{array}{r}\text { abr. } 1-10 \\
11-20 \\
21-30 \\
\text { mai. } 1-10 \\
11-20 \\
21-31 \\
\text { jun. } 1-10 \\
11-20 \\
21-30\end{array}$ & $\begin{array}{l}16,7 \\
23,3 \\
40,0 \\
33,3 \\
33,3 \\
43,3 \\
40,0 \\
43,3 \\
53,3\end{array}$ & $\begin{array}{l}16,7 \\
16,7 \\
30,0 \\
30,0 \\
20,7 \\
33,3 \\
36,7 \\
36,7 \\
50,0\end{array}$ & $\begin{array}{l}13,3 \\
10,0 \\
20,0 \\
26,7 \\
23,3 \\
30,0 \\
30,7 \\
33,3 \\
40,0\end{array}$ & $\begin{array}{r}3,3 \\
3,3 \\
6,7 \\
13,3 \\
10,0 \\
20,0 \\
23,3 \\
26,7 \\
26,7\end{array}$ \\
\hline $\begin{array}{r}\text { jul } .1-10 \\
11-20 \\
21-31 \\
\text { ago. } 1-10 \\
11-20 \\
21-31 \\
\text { set. } 1-10 \\
11-20 \\
21-30\end{array}$ & $\begin{array}{l}56,7 \\
76,7 \\
76,7 \\
73,3 \\
83,3 \\
73,3 \\
53,3 \\
56,7 \\
36,7\end{array}$ & $\begin{array}{l}53,3 \\
56,7 \\
66,7 \\
70,0 \\
80,0 \\
73,3 \\
53,3 \\
66,7 \\
36,7\end{array}$ & $\begin{array}{l}50,0 \\
53,3 \\
66,7 \\
66,7 \\
73,3 \\
73,3 \\
53,3 \\
56,7 \\
36,7\end{array}$ & $\begin{array}{l}36,7 \\
50,0 \\
50,0 \\
53,3 \\
70,0 \\
66,7 \\
50,0 \\
53,3 \\
36,7\end{array}$ \\
\hline $\begin{array}{r}\text { out. } 1-10 \\
11-20 \\
21-31 \\
\text { nov. } 1-10 \\
11-20 \\
21-30 \\
\text { dez. } 1-10 \\
11-20 \\
21-31\end{array}$ & $\begin{array}{r}33,3 \\
26,7 \\
26,7 \\
20,0 \\
20,0 \\
6,7 \\
13,3 \\
10,0 \\
3,3\end{array}$ & $\begin{array}{r}33,3 \\
26,7 \\
23,3 \\
10,0 \\
16,7 \\
0,0 \\
13,3 \\
6,7 \\
3,3\end{array}$ & $\begin{array}{r}30,0 \\
26,7 \\
23,3 \\
10,0 \\
10,0 \\
0,0 \\
3,3 \\
6,7 \\
0,0\end{array}$ & $\begin{array}{r}30,0 \\
26,7 \\
23,3 \\
10,0 \\
10,0 \\
0,0 \\
3,3 \\
3,3 \\
0,0\end{array}$ \\
\hline
\end{tabular}


Tabela 13 - Probabilidade $c \%$ de excedentes hidricos para quatro niveis de $A F D$ C $30,40,50$ e $75 \mathrm{~mm}$, na localidade de Cordeirópolis - SP.

\begin{tabular}{|c|c|c|c|c|}
\hline & \multicolumn{4}{|c|}{ Nivel de AFD considerado $\mathrm{cmm}$} \\
\hline Decendio & 30 & 40 & 50 & 75 \\
\hline $\begin{array}{r}\text { jan. } 1-10 \\
11-20 \\
21-31 \\
\text { fev. } 1-10 \\
11-20 \\
21-28 \\
\operatorname{mar} .1-10 \\
11-20 \\
21-31\end{array}$ & $\begin{array}{l}83,3 \\
73,3 \\
76,7 \\
76,7 \\
63,3 \\
60,0 \\
56,7 \\
50,0 \\
26,7\end{array}$ & $\begin{array}{l}83,3 \\
73,3 \\
78,7 \\
76,7 \\
63,3 \\
56,7 \\
56,7 \\
50,0 \\
23,3\end{array}$ & $\begin{array}{l}83,3 \\
73,3 \\
76,7 \\
76,7 \\
63,3 \\
56,7 \\
56,7 \\
50,0 \\
23,3\end{array}$ & $\begin{array}{l}83,3 \\
73,3 \\
76,7 \\
76,7 \\
63,3 \\
56,7 \\
56,7 \\
50,0 \\
23,3\end{array}$ \\
\hline $\begin{array}{r}\text { abr. } 1-10 \\
11-20 \\
21-30 \\
\text { mai. } 1-10 \\
11-20 \\
21-31 \\
\text { jun. } 1-10 \\
11-20 \\
21-30\end{array}$ & $\begin{array}{l}43,3 \\
26,7 \\
10,0 \\
23,3 \\
23,3 \\
16,7 \\
16,7 \\
13,3 \\
13,3\end{array}$ & $\begin{array}{r}40,0 \\
23,3 \\
6,7 \\
16,7 \\
20,0 \\
16,7 \\
13,3 \\
13,3 \\
13,3\end{array}$ & $\begin{array}{r}40,0 \\
23,3 \\
6,7 \\
18.7 \\
20,0 \\
18,7 \\
6,7 \\
10,0 \\
13,3\end{array}$ & $\begin{array}{r}40,0 \\
23,3 \\
6,7 \\
16,7 \\
20,0 \\
16,7 \\
6,7 \\
10,0 \\
13,3\end{array}$ \\
\hline $\begin{array}{r}\text { jul } .1-10 \\
11-20 \\
21-31 \\
\text { ago. } 1-10 \\
11-20 \\
21-31 \\
\text { set. } 1-10 \\
11-20 \\
21-30\end{array}$ & $\begin{array}{r}3,3 \\
10,0 \\
6,7 \\
3,3 \\
3,3 \\
10,0 \\
10,0 \\
13,3 \\
20,0\end{array}$ & $\begin{array}{r}3,3 \\
0,7 \\
6,7 \\
3,3 \\
3,3 \\
10,0 \\
6,7 \\
13,3 \\
20,0\end{array}$ & $\begin{array}{r}3,3 \\
6,7 \\
3,3 \\
3,3 \\
3,3 \\
6,7 \\
6,7 \\
13,3 \\
20,0\end{array}$ & $\begin{array}{r}3,3 \\
6,7 \\
0,0 \\
3,3 \\
3,3 \\
6,7 \\
3,3 \\
10,0 \\
13,3\end{array}$ \\
\hline $\begin{array}{r}\text { out. } 1-10 \\
11-20 \\
21-31 \\
\text { nov. } 1-10 \\
11-20 \\
21-30 \\
\text { dez. } 1-10 \\
11-20 \\
21-31\end{array}$ & $\begin{array}{l}40,0 \\
40,0 \\
43,3 \\
40,0 \\
63,3 \\
53,3 \\
70,0 \\
70,0 \\
90,0\end{array}$ & $\begin{array}{l}33,3 \\
36,7 \\
43,3 \\
36,7 \\
63,3 \\
53,3 \\
68,7 \\
70,0 \\
86,7\end{array}$ & $\begin{array}{l}30,0 \\
26,7 \\
40,0 \\
33,3 \\
60,0 \\
46,7 \\
66,7 \\
70,0 \\
86,7\end{array}$ & $\begin{array}{l}20,0 \\
23,3 \\
36,7 \\
26,7 \\
50,0 \\
40,0 \\
66,7 \\
70,0 \\
86,7\end{array}$ \\
\hline
\end{tabular}

Os solos desta area apresentam 
características similares aos de Campinas, em relação a AFD, sendo válidos os mesmos comentarios.

Comparando os dados da Tabela 12 com os correspondentes às outras localidades, verifica-se que Cordeiropolis $\Leftrightarrow$ o local com menor duração de deficites hidricos nos meses de abril a outubro. qualquer seja o nivel de AFD considerado. Para um mesmo nivel de AFD e de probabilidade de ocorrencia, neste local em geral os deficites hidricos ocorrem com atrazo de 20 a 40 dias em relação a Campinas, apresentam AFD em nivel igual ou superior.

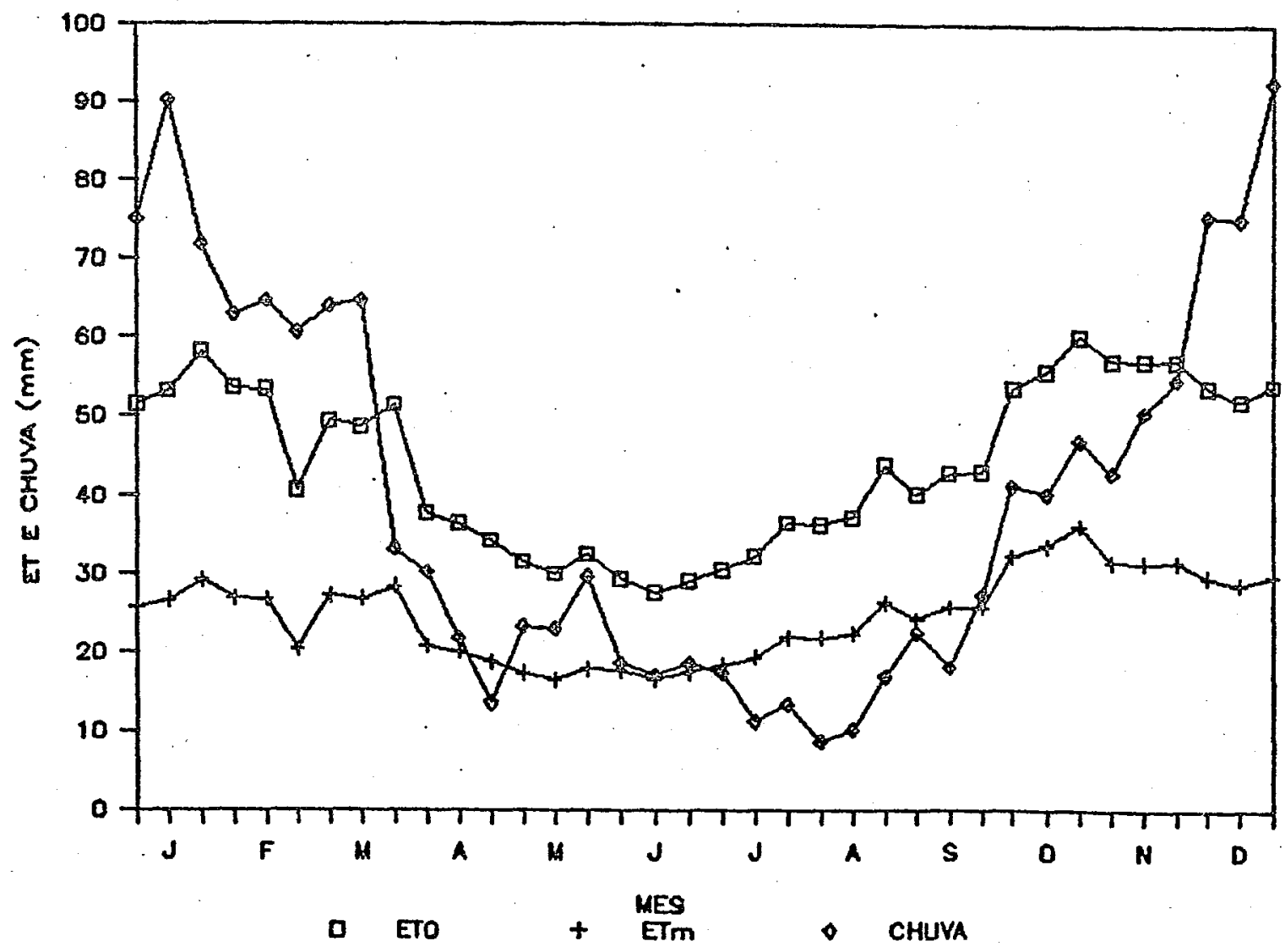

Figura 0 - Valores decendiais medios de chuva, ETo e ETm, para Cordeirópolis - SP. Periodo 1960 a 1989. 
Este atrazo no inicio dos deficites hidricos reduz sua duração, beneficiando a etapa de crescimento dos frutos sem afetar a de repouso e indução floral. No caso da floraça (setembro), na metade dos anos aparecem deficites hídricos. O desenvol vimento inicial do fruto coutubros, so 6 afetado um de cada trés anos.

Em relação aos excedentes hidricos CTabela $13)$ e aos deficites precoces (março, abril), são válidos os mesmos comentarios que para Campinas.

4. 2.3. Jaú

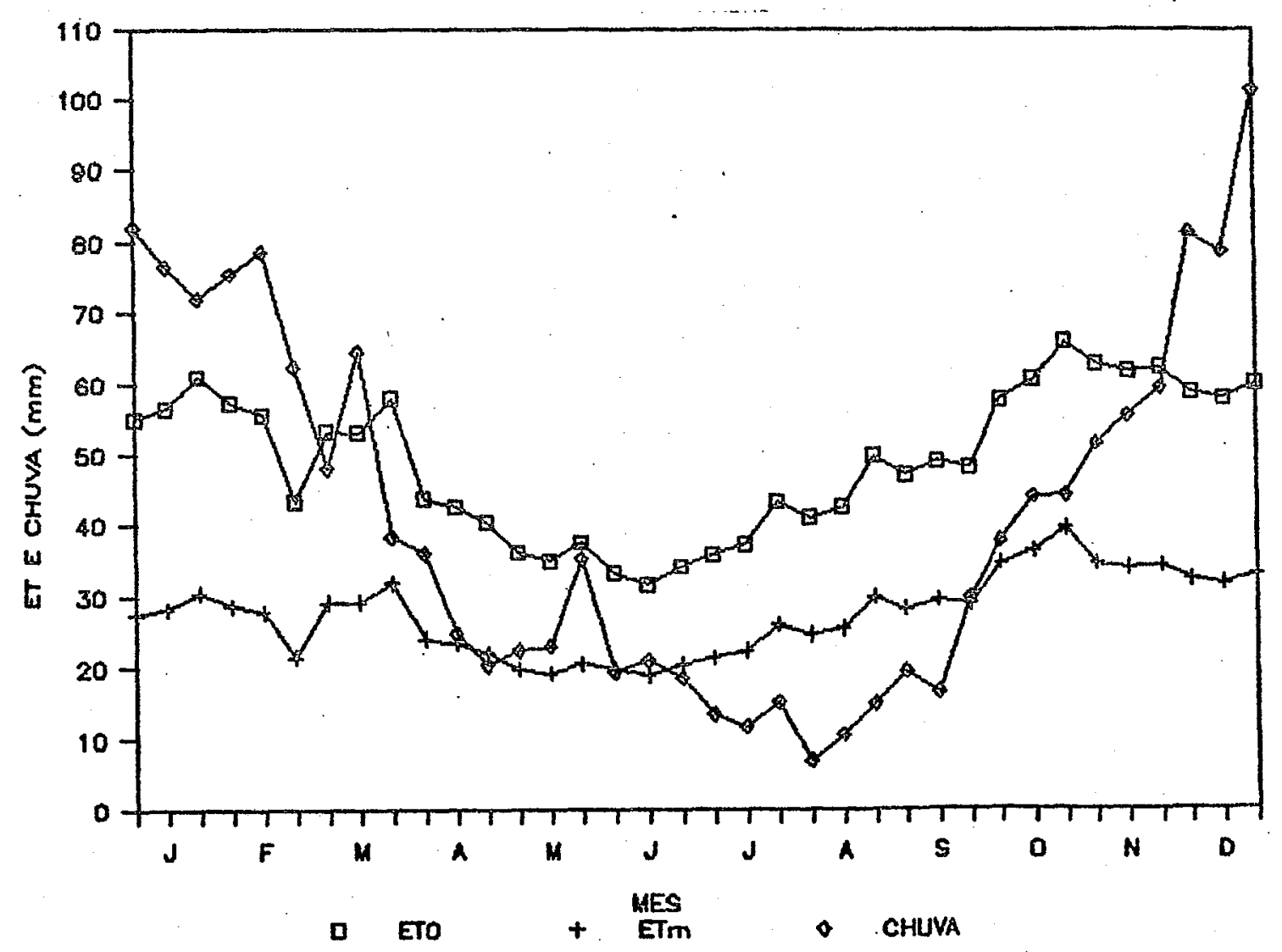

Figura 7 - Valores decendiais medios de chuva, ETo e ETm, para Jaú - SP. Periodo 1960 a 1989. 
Tabela 14 - Probabilidade, em porcentagem, de deficites hídricos a de que AFD seja zero para quatro niveis de AFD (30, 40, 50 e $75 \mathrm{~mm})$, na localidade de Jaú - SP.

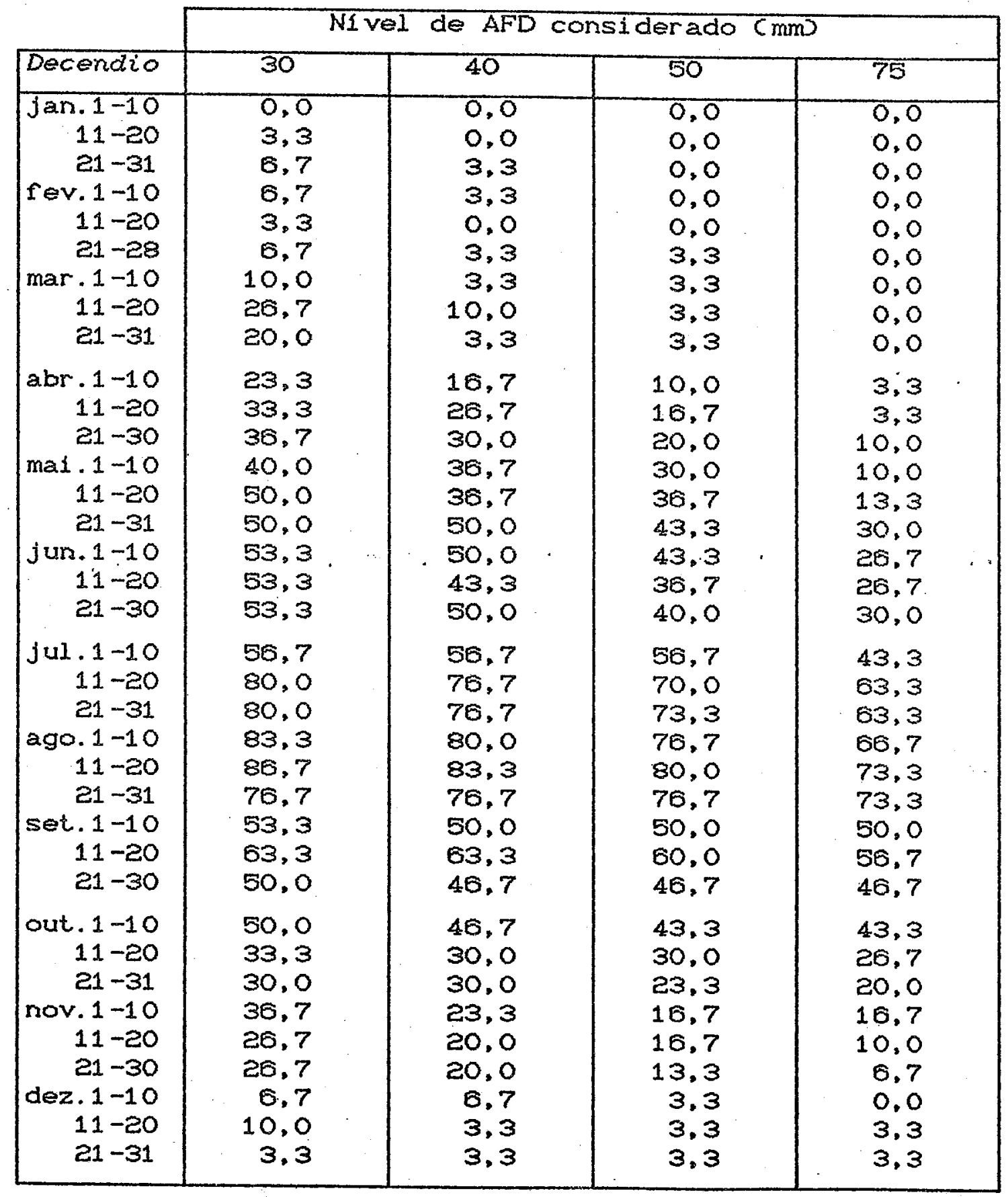


Tabela 15 - Probabilidade $(\%$ de excsientes hidricos para quatro nívels de AFD (30, 40,50 e $75 \mathrm{~mm}$, na localidade de Jaú - SP.

\begin{tabular}{|c|c|c|c|c|}
\hline . & \multicolumn{4}{|c|}{ N1 vel de AFD considerado $(\mathrm{mm})$} \\
\hline Decendio. & 30 & 40 & 50 & 75 \\
\hline $\begin{array}{r}\text { Jan. } 1-10 \\
11-20 \\
21-31 \\
\text { fev. } 1-10 \\
11-20 \\
21-28 \\
\operatorname{mar} .1-10 \\
11-20 \\
21-31\end{array}$ & $\begin{array}{l}86,7 \\
66,7 \\
73,3 \\
80,0 \\
70,0 \\
66,7 \\
46,7 \\
50,0 \\
30,0\end{array}$ & $\begin{array}{l}86,7 \\
60,7 \\
73,3 \\
80,0 \\
66,7 \\
60,7 \\
46,7 \\
46,7 \\
20,7\end{array}$ & $\begin{array}{l}83,3 \\
66,7 \\
73,3 \\
80,0 \\
66,7 \\
66,7 \\
43,3 \\
46,7 \\
26,7\end{array}$ & $\begin{array}{l}83,3 \\
66,7 \\
73,3 \\
80,0 \\
60,7 \\
66,7 \\
43,3 \\
46,7 \\
26,7\end{array}$ \\
\hline $\begin{array}{r}\text { abr. } 1-10 \\
11-20 \\
21-30 \\
\text { ma1. } 1-10 \\
11-20 \\
21-31 \\
\text { jun. } 1-10 \\
11-20 \\
21-30\end{array}$ & $\begin{array}{l}30,0 \\
26,7 \\
16,7 \\
16,7 \\
26,7 \\
23,3 \\
10,0 \\
20,0 \\
13,3\end{array}$ & $\begin{array}{l}30,0 \\
16,7 \\
10,7 \\
10,0 \\
20,7 \\
23,3 \\
10,0 \\
13,3 \\
10,0\end{array}$ & $\begin{array}{r}30,0 \\
16,7 \\
16,7 \\
10,0 \\
20,0 \\
20,0 \\
6,7 \\
6,7 \\
10,0\end{array}$ & $\begin{array}{r}30,0 \\
16,7 \\
16,7 \\
10,0 \\
20,0 \\
20,0 \\
6,7 \\
6,7 \\
10,0\end{array}$ \\
\hline $\begin{array}{r}\text { jul. } 1-10 \\
11-20 \\
21-31 \\
\text { ago. } 1-10 \\
11-20 \\
21-31 \\
\text { set. } 1-10 \\
11-20 \\
21-30\end{array}$ & $\begin{array}{r}10,0 \\
6,7 \\
6,7 \\
0,0 \\
6,7 \\
10,0 \\
16,7 \\
13,3 \\
20,0\end{array}$ & $\begin{array}{r}6,7 \\
0,7 \\
0,7 \\
0,0 \\
3,3 \\
6,7 \\
13,3 \\
10,0 \\
20,0\end{array}$ & $\begin{array}{r}8,7 \\
3,3 \\
0,7 \\
0,0 \\
3,3 \\
6,7 \\
10,0 \\
10,0 \\
10,7\end{array}$ & $\begin{array}{r}6,7 \\
3,3 \\
6,7 \\
0,0 \\
3,3 \\
3,3 \\
3,3 \\
6,7 \\
13,3\end{array}$ \\
\hline $\begin{array}{r}\text { out. } 1-10 \\
11-20 \\
21-31 \\
\text { nov. } 1-10 \\
11-20 \\
21-30 \\
\text { dez. } 1-10 \\
11-20 \\
21-31\end{array}$ & $\begin{array}{l}36,7 \\
30,0 \\
36,7 \\
36,7 \\
46,7 \\
33,3 \\
53,3 \\
80,0 \\
83,3\end{array}$ & $\begin{array}{l}36,7 \\
26,7 \\
33,3 \\
30,0 \\
43,3 \\
30,0 \\
53,3 \\
76,7 \\
83,3\end{array}$ & $\begin{array}{l}30,0 \\
23,3 \\
30,0 \\
30,0 \\
36,7 \\
30,0 \\
50,0 \\
70,0 \\
83,3\end{array}$ & $\begin{array}{l}23,3 \\
16,7 \\
30,0 \\
30,0 \\
33,3 \\
26,7 \\
50,0 \\
66,7 \\
80,0\end{array}$ \\
\hline
\end{tabular}

Nesta localidade, os valores medios de chuva são inferiores aos de ETm desde o último decendio de junho 
ate o segundo de setembro CFigura 7 .

Esta localidade apresenta pouca informação relativa a solos, por quanto fol selecionada mais do ponto de vista agrometeorológico que como area produtiva.

Comparada com as outras duas localidades do seu grupo (Pindorama e Ribeirão Preto), para igual nivel de AFD, $\Leftrightarrow$ a que apresenta menores deficites, em quantidade, para niveis de probabilidade de ocorrencia de $30 \%$ ou menos, não sendo tão clara esta tendêncla para niveis "de probabilidade superiores.

Para o nivel AFD $(30 \mathrm{~mm}$, um em cada dois anos, o deficite hidrico (ver Tabela 14 ) pode começar em maio e um de cada trés, em abril. Já para os niveis de AFD C40, 50 e $75 \mathrm{~mm}$. principalmente os dois superiores. 0 dericite hidrico só comesa em julho.

Como nas outras localidades, em $50 \%$ dos anos, o deficite hidrico pode aretar a floração e um em cada tres anos, o inicio da frutiricaça. As diferenças entre nuveis de AFD são bem significativas o comentario precedente é valido para os niveis de AFD de 50 e 75 mm. Para o nivel inferior $c 30 \mathrm{~mm}$, entretanto, os deficites hidricos afetam o inicio da frutificacão $650 \%$ de probabilidade de ocorrencia) e etapas avançadas desta (33\% de probabilidade de ocorrencial.

Os excedentes hídricos, nesta localidade se desenvol vem mais tardiamente CTabela 15). Valores maiores que $10 \mathrm{~mm}$ ocorrem a partir do segundo decéndio de dezembro Cpara probabilidade de ocorrencia de 50\%, sem interferir no final da colheita. 


\subsubsection{Pindorama}

Na Figura 8, verifica-se que os valores médios de chuva são inferiores aos de ETm desde o primeiro decendio de junho até o último de setembro.

Nesta regiao de Pindorama, a citricultura encontra-se em geral, em solos eutroficos, onde pela profundidade de enraizamento são obtidos altos niveis de AFD.

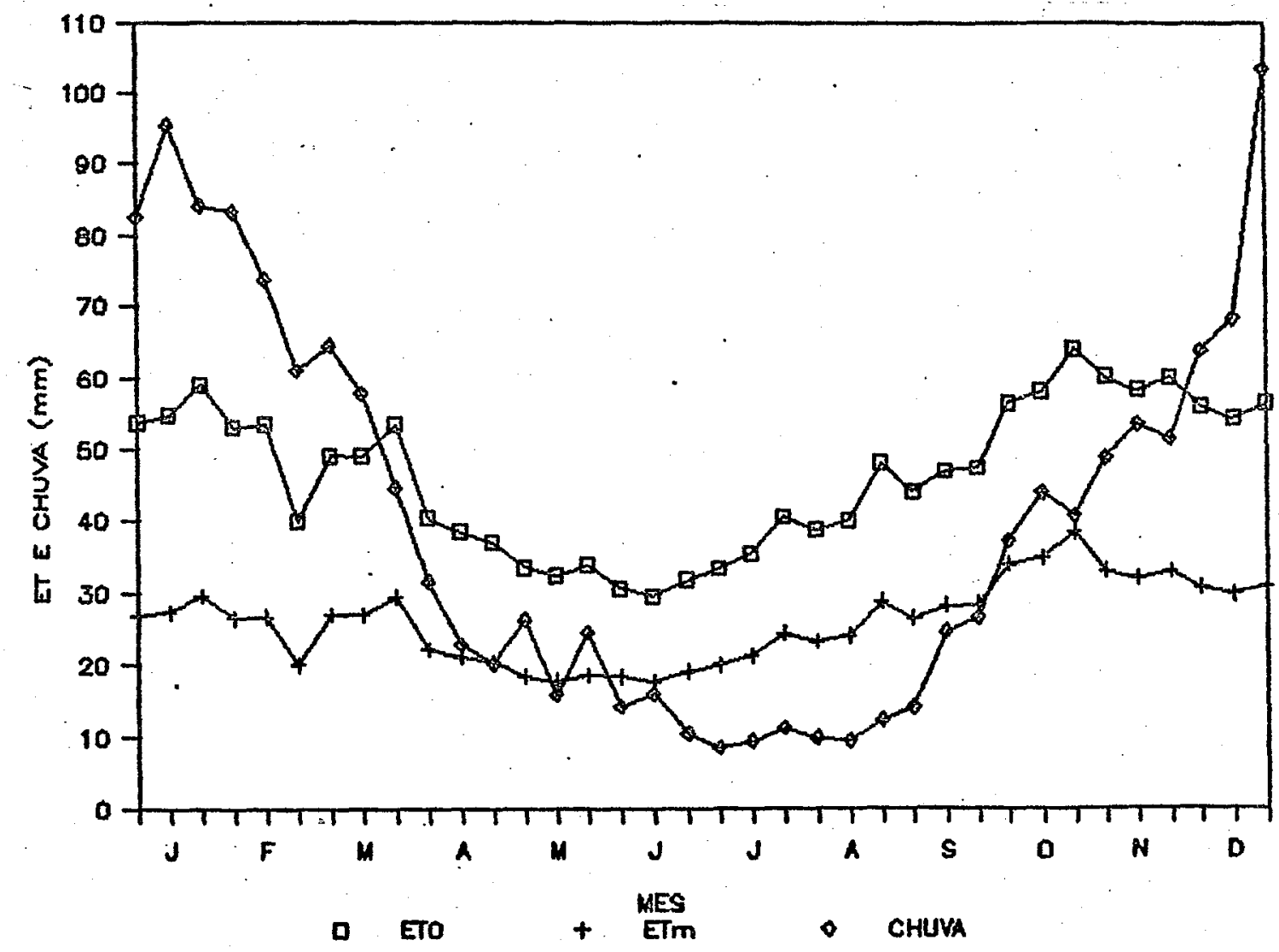

Figura 8 - Valores decendiais medios de chuva. ETo e ETm, para Pindorama - SP. Periodo 1960 a 1989.

- comportamento dos deficites, excedentes $\theta$ AFD desta localidade e similar ao de Ribeirão Preto. Em 
Tabela 16 - Probabilidade, em porcentagem, de deficites hidricos de que AFD seja zero para quatro niveis de AFD $(30,40,50$, $75 \mathrm{~mm}$, na local idade de Pindorama - SP.

\begin{tabular}{|c|c|c|c|c|c|}
\hline & \multicolumn{5}{|c|}{ Nivel de AFD considerado ( $\mathrm{mm}$} \\
\hline Decendio & 30 & 40 & 50 & 75 & 100 \\
\hline $\begin{array}{r}\text { jar. } 1-10 \\
11-20 \\
21-31 \\
\text { fer. } 1-10 \\
11-20 \\
21-28 \\
\operatorname{mar} .1-10 \\
11-20 \\
21-31\end{array}$ & $\begin{array}{r}0,0 \\
3,3 \\
3,3 \\
6,7 \\
13,3 \\
3,3 \\
0,0 \\
10,0 \\
10,0\end{array}$ & $\begin{array}{l}0,0 \\
3,3 \\
0,0 \\
3,3 \\
3,3 \\
0,0 \\
0,0 \\
0,7 \\
3,3\end{array}$ & $\begin{array}{l}0,0 \\
3,3 \\
0,0 \\
3,3 \\
0,0 \\
0,0 \\
0,0 \\
3,3 \\
3,3\end{array}$ & $\begin{array}{l}0,0 \\
0,0 \\
0,0 \\
0,0 \\
0,0 \\
0,0 \\
0,0 \\
0,0 \\
0,0\end{array}$ & $\begin{array}{l}0,0 \\
0,0 \\
0,0 \\
0,0 \\
0,0 \\
0,0 \\
0,0 \\
0,0 \\
0,0\end{array}$ \\
\hline $\begin{array}{r}\text { abr. } 1-10 \\
11-20 \\
21-30 \\
\operatorname{ma1} .1-10 \\
11-20 \\
21-31 \\
\text { jur. } 1-10 \\
11-20 \\
21-30\end{array}$ & $\begin{array}{l}16,7 \\
26,7 \\
46,7 \\
46,7 \\
40,0 \\
50,0 \\
46,7 \\
60,0 \\
70,0\end{array}$ & $\begin{array}{l}13,3 \\
16,7 \\
33,3 \\
36,7 \\
40,0 \\
36,7 \\
40,0 \\
53,3 \\
46,7\end{array}$ & $\begin{array}{l}0,7 \\
13,3 \\
16,7 \\
26,7 \\
40,0 \\
33,3 \\
36,7 \\
43,3 \\
46,7\end{array}$ & $\begin{array}{r}0,0 \\
6,7 \\
6,7 \\
6,7 \\
16,7 \\
23,3 \\
20,0 \\
26,7 \\
33,3\end{array}$ & $\begin{array}{r}0,0 \\
0,0 \\
0,0 \\
3,3 \\
0,0 \\
0,7 \\
10,0 \\
13,3 \\
16,7\end{array}$ \\
\hline $\begin{array}{r}\text { jul } .1-10 \\
11-20 \\
21-31 \\
\text { ago. } 1-10 \\
11-20 \\
21-31 \\
\text { set. } 1-10 \\
11-20 \\
21-30\end{array}$ & $\begin{array}{l}73,3 \\
80,0 \\
78,7 \\
80,0 \\
83,3 \\
80,0 \\
70,0 \\
78,7 \\
50,0\end{array}$ & $\begin{array}{l}70,0 \\
80,0 \\
76,7 \\
80,0 \\
83,3 \\
80,0 \\
70,0 \\
73,3 \\
46,7\end{array}$ & $\begin{array}{l}80,0 \\
73,3 \\
73,3 \\
80,0 \\
83,3 \\
80,0 \\
70,0 \\
73,3 \\
46,7\end{array}$ & $\begin{array}{l}40,0 \\
63,3 \\
66,7 \\
76,7 \\
76,7 \\
76,7 \\
68,7 \\
70,0 \\
46,7\end{array}$ & $\begin{array}{l}30,0 \\
40,0 \\
53,3 \\
66,7 \\
73,3 \\
76,7 \\
63,3 \\
70,0 \\
46,7\end{array}$ \\
\hline $\begin{array}{r}\text { out. } 1-10 \\
11-20 \\
21-31 \\
\text { nov. } 1-10 \\
11-20 \\
21-30 \\
\text { dez. } 1-10 \\
11-20 \\
21-31\end{array}$ & $\begin{array}{l}40,0 \\
26,7 \\
33,3 \\
26,7 \\
16,7 \\
26,7 \\
23,3 \\
10,0 \\
10,0\end{array}$ & $\begin{array}{r}40,0 \\
26,7 \\
30,0 \\
16,7 \\
6,7 \\
16,7 \\
10,0 \\
6,7 \\
3,3\end{array}$ & $\begin{array}{r}40,0 \\
26,7 \\
26,7 \\
16,7 \\
6,7 \\
13,3 \\
10,0 \\
3,3 \\
0,0\end{array}$ & $\begin{array}{r}40,0 \\
26,7 \\
26,7 \\
16,7 \\
6,7 \\
10,0 \\
0,0 \\
3,3 \\
0,0\end{array}$ & $\begin{array}{r}36,7 \\
26,7 \\
26,7 \\
16,7 \\
8,7 \\
10,0 \\
0,0 \\
3,3 \\
0,0\end{array}$ \\
\hline
\end{tabular}


Tabela 17 - Probabilidade $\%$ de excedentes hidricos para quatro nivels de $A F D C 30,40,50$ e $75 \mathrm{~mm}$, na localidade de Pindorama - SP.

\begin{tabular}{|c|c|c|c|c|c|}
\hline & \multicolumn{5}{|c|}{ Nível de AFD considerado $\mathrm{Cmm}$} \\
\hline Decendio & 30 & 40 & 50 & 75 & 100 \\
\hline $\begin{array}{r}\text { jan. } 1-10 \\
11-20 \\
21-31 \\
\text { fev. } 1-10 \\
11-20 \\
21-28 \\
\operatorname{mar} .1-10 \\
11-20 \\
21-31\end{array}$ & $\begin{array}{l}83,3 \\
80,0 \\
83,3 \\
73,3 \\
66,7 \\
83,3 \\
83,3 \\
56,7 \\
36,7\end{array}$ & $\begin{array}{l}83,3 \\
80,0 \\
83,3 \\
73,3 \\
66,7 \\
83,3 \\
80,0 \\
56,7 \\
36,7\end{array}$ & $\begin{array}{l}83,3 \\
80,0 \\
83,3 \\
73,3 \\
66,7 \\
83,3 \\
80,0 \\
56,7 \\
36,7\end{array}$ & $\begin{array}{l}83,3 \\
80,0 \\
83,3 \\
73,3 \\
68,7 \\
83,3 \\
80,0 \\
56,7 \\
36,7\end{array}$ & $\begin{array}{l}80,0 \\
80,0 \\
83,3 \\
73,3 \\
66,7 \\
83,3 \\
80,0 \\
56,7 \\
36,7\end{array}$ \\
\hline $\begin{array}{r}\text { abr. } 1-10 \\
11-20 \\
21-30 \\
\text { mai. } 1-10 \\
11-20 \\
21-31 \\
\text { jun. } 1-10 \\
11-20 \\
21-30\end{array}$ & $\begin{array}{r}36,7 \\
23,3 \\
6,7 \\
20,0 \\
10,0 \\
23,3 \\
20,0 \\
10,0 \\
0.7\end{array}$ & $\begin{array}{r}36,7 \\
20,0 \\
6,7 \\
13,3 \\
10,0 \\
16,7 \\
16,7 \\
10,0 \\
3,3\end{array}$ & $\begin{array}{r}36,7 \\
20,0 \\
6,7 \\
13,3 \\
10,0 \\
16,7 \\
13,3 \\
10,0 \\
0,0\end{array}$ & $\begin{array}{r}36,7 \\
20,0 \\
6,7 \\
13,3 \\
6,7 \\
16,7 \\
10,0 \\
6,7 \\
0,0\end{array}$ & $\begin{array}{r}36,7 \\
20,0 \\
6,7 \\
13,3 \\
3,3 \\
10,0 \\
6,7 \\
0,7 \\
0,0\end{array}$ \\
\hline $\begin{array}{r}\text { jul } 11-10 \\
11-20 \\
21-31 \\
\text { ago. } 1-10 \\
11-20 \\
21-31 \\
\text { set. } 1-10 \\
11-20 \\
21-30\end{array}$ & $\begin{array}{r}3,3 \\
6,7 \\
6,7 \\
6,7 \\
3,3 \\
10,0 \\
3,3 \\
20,0 \\
10,0\end{array}$ & $\begin{array}{r}3,3 \\
3,3 \\
3,3 \\
3,3 \\
3,3 \\
10,0 \\
3,3 \\
13,3 \\
6,7\end{array}$ & $\begin{array}{r}3,3 \\
3,3 \\
3,3 \\
3,3 \\
3,3 \\
3,3 \\
3,3 \\
13,3 \\
6,7\end{array}$ & $\begin{array}{r}3,3 \\
0,0 \\
0,0 \\
0,0 \\
3,3 \\
0,0 \\
0,0 \\
13,3 \\
3,3\end{array}$ & $\begin{array}{r}3,3 \\
0,0 \\
0,0 \\
0,0 \\
3,3 \\
0,0 \\
0,0 \\
10,0 \\
0,0\end{array}$ \\
\hline $\begin{array}{r}\text { out. } 1-10 \\
11-20 \\
21-31 \\
\text { nov. } 1-10 \\
11-20 \\
21-30 \\
\text { dez. } 1-10 \\
11-20 \\
21-31\end{array}$ & $\begin{array}{l}30,0 \\
30,0 \\
36,7 \\
46,7 \\
56,7 \\
46,7 \\
53,3 \\
66,7 \\
80,0\end{array}$ & $\begin{array}{l}26,7 \\
26,7 \\
30,0 \\
40,0 \\
53,3 \\
46,7 \\
53,3 \\
63,3 \\
70,7\end{array}$ & $\begin{array}{l}26,7 \\
26,7 \\
30,0 \\
36,7 \\
50,0 \\
46,7 \\
53,3 \\
63,3 \\
76,7\end{array}$ & $\begin{array}{l}13,3 \\
20,0 \\
20,0 \\
20,0 \\
36,7 \\
36,7 \\
50,0 \\
56,7 \\
76,7\end{array}$ & $\begin{array}{l}13,3 \\
20,0 \\
13,3 \\
13,3 \\
26,7 \\
30,0 \\
40,0 \\
56,7 \\
76,7\end{array}$ \\
\hline
\end{tabular}

comparação com as outras localidades, a duração do periodo com deficite e intermediaria para os niveis de AFD de 30 e 
$40 \mathrm{~mm}$. Entretanto, para os niveis mais altos (50 e $75 \mathrm{~mm}$. apresentam a maior duração que nas outras localidades.

Dependendo do nível de probabllidade considerado (um ano em cada dois ou trés anos), para o nivel inferior de AFD, os deficites (ver Tabela 16) iniciam no més de maio ou abril, configurando um periodo de duas vezes ao da duração necessaria para a induça floral. Ainda para niveis mais elevados de AFD, reduz-se o periodo de deficite. Este redução não \& tão marcante como em Jaú, o que resulta numa estação seca maior que a necessaria para a indução floral.

O final do periodo seco não e influenciado pelos niveis de AFD, podendo-se observar que em todos os casos a floraçăo, ou ate o inicio da frutificação podem ser afetados.

No caso dos excedentes (Tabela 17), corresponde a um dos locais com maior duraçăo. Para valores maiores a $10 \mathrm{~mm}$ por decendio, começam no inicio de dezembro - finalizam (um aro de cada dois) no primeiro decendio de março. A pesar dos riscos de perdas na produçáo cqualidade dos frutoss ou ainda, de morte de rafzes absorventes, por excedentes, reduz-se o risco de deficites hidricos neste periodo, com beneficio principalmente do final do crescimento dos frutos.

\subsubsection{Ribeirão Preto}

Nesta localidade, os valores médios de chuva são inferiores aos de ETm desde o segundo decéndio de maio ate o último de setembro, com excecão do último decéndio de maio (Figura 9 ).

Os comentarios para Pindorama, em geral, são válidos para esta localidade, exceto no referente a solos. 
Tabela 18 - Probabilidade, em porcentagem, de deficites hidricos e de que AFD seja zero para quatro niveis de AFD (30, 40, 50 e $75 \mathrm{~mm}$, na localidade de Ribeirão Preto - SP.

\begin{tabular}{|c|c|c|c|c|}
\hline & \multicolumn{4}{|c|}{ Nivel de AFD considerado ( $\mathrm{mm})$} \\
\hline Decendio & 30 & 40 & 50 & 75 \\
\hline $\begin{array}{r}\text { jan. } 1-10 \\
11-20 \\
21-31 \\
\text { fev. } 1-10 \\
11-20 \\
21-28 \\
\operatorname{mar} .1-10 \\
11-20 \\
21-31\end{array}$ & $\begin{array}{r}0.0 \\
6.7 \\
6.7 \\
6.7 \\
10.0 \\
6,7 \\
0.0 \\
20,0 \\
23.3\end{array}$ & $\begin{array}{r}0.0 \\
3,3 \\
0.0 \\
0.7 \\
3.3 \\
0.7 \\
0.0 \\
10.0 \\
6.7\end{array}$ & $\begin{array}{l}0,0 \\
3,3 \\
0,0 \\
3,3 \\
3,3 \\
6,7 \\
0,0 \\
6,7 \\
6,7\end{array}$ & $\begin{array}{l}0,0 \\
0,0 \\
0,0 \\
0,0 \\
0,0 \\
0,0 \\
0,0 \\
0,0 \\
0,7\end{array}$ \\
\hline $\begin{array}{r}\text { abr. } 1-10 \\
11-20 \\
21-30 \\
\text { mai. } 1-10 \\
11-20 \\
21-31 \\
\text { jun. } 1-10 \\
11-20 \\
21-30\end{array}$ & $\begin{array}{l}20,0 \\
26,7 \\
36,7 \\
40,0 \\
50,0 \\
46,7 \\
56,7 \\
63,3 \\
73,3\end{array}$ & $\begin{array}{l}10,0 \\
20,0 \\
26,7 \\
30,0 \\
43,3 \\
40,0 \\
43,3 \\
63,3 \\
63,3\end{array}$ & $\begin{array}{r}6,7 \\
13,3 \\
16,7 \\
23,3 \\
33,3 \\
40,0 \\
40,0 \\
50,0 \\
53,3\end{array}$ & $\begin{array}{r}3,3 \\
6,7 \\
13,3 \\
13,3 \\
10,0 \\
20,0 \\
26,7 \\
33,3 \\
36,7\end{array}$ \\
\hline $\begin{array}{r}\text { jul. } 1-10 \\
11-20 \\
21-31 \\
\text { ago. } 1-10 \\
11-20 \\
21-31 \\
\text { set. } 1-10 \\
11-20 \\
21-30\end{array}$ & $\begin{array}{l}66,7 \\
73,3 \\
76,7 \\
83,3 \\
90,0 \\
86,7 \\
70,0 \\
73,3 \\
60,0\end{array}$ & $\begin{array}{l}63,3 \\
73,3 \\
70,0 \\
83,3 \\
90,0 \\
83,3 \\
70,0 \\
70,0 \\
60,0\end{array}$ & $\begin{array}{l}60,0 \\
70,0 \\
66,7 \\
83,3 \\
90,0 \\
83,3 \\
70,0 \\
70,0 \\
60,0\end{array}$ & $\begin{array}{l}46,7 \\
60,0 \\
66,7 \\
63,3 \\
90,0 \\
83,3 \\
66,7 \\
66,7 \\
60,0\end{array}$ \\
\hline $\begin{array}{r}\text { out. } 1-10 \\
11-20 \\
21-31 \\
\text { nov. } 1-10 \\
11-20 \\
21-30 \\
\text { dez. } 1-10 \\
11-20 \\
21-31\end{array}$ & $\begin{array}{r}40,0 \\
36,7 \\
16,7 \\
16,7 \\
13,3 \\
16,7 \\
6,7 \\
10,0 \\
3,3\end{array}$ & $\begin{array}{r}40,0 \\
33,3 \\
10,0 \\
13,3 \\
3,3 \\
10,0 \\
0,0 \\
3,3 \\
3,3\end{array}$ & $\begin{array}{r}40,0 \\
33,3 \\
6,7 \\
10,0 \\
3,3 \\
0,0 \\
0,0 \\
0,0 \\
0,0\end{array}$ & $\begin{array}{r}40,0 \\
33,3 \\
6,7 \\
10,0 \\
3,3 \\
0,0 \\
0,0 \\
0,0 \\
0,0\end{array}$ \\
\hline
\end{tabular}


Tabela 19 - Probabilidade $\%$ de excedentes hidricos para quatro niveis de AFD (30, 40,50 e $75 \mathrm{~mm}$, na localidade de Ribeirão Preto - SP.

\begin{tabular}{|c|c|c|c|c|}
\hline & \multicolumn{4}{|c|}{ Nivel de AFD considerado $(\mathrm{mm}$} \\
\hline Decendio & 30 & 40 & 50 & 75 \\
\hline $\begin{array}{r}\operatorname{Jan} .1-10 \\
11-20 \\
21-31 \\
\text { fev. } 1-10 \\
11-20 \\
21-28 \\
\operatorname{mar} .1-10 \\
11-20 \\
21-31\end{array}$ & $\begin{array}{l}86,7 \\
80,0 \\
83,3 \\
76,7 \\
66,7 \\
66,7 \\
73,3 \\
56,7 \\
36,7\end{array}$ & $\begin{array}{l}86,7 \\
80,0 \\
83,3 \\
76,7 \\
66,7 \\
63,3 \\
73,3 \\
56,7 \\
36,7\end{array}$ & $\begin{array}{l}86,7 \\
80,0 \\
83,3 \\
76,7 \\
66,7 \\
63,3 \\
73,3 \\
56,7 \\
36,7\end{array}$ & $\begin{array}{l}86,7 \\
80,0 \\
83,3 \\
76,7 \\
66,7 \\
63,3 \\
73,3 \\
56,7 \\
36,7\end{array}$ \\
\hline $\begin{array}{r}\text { abr. } 1-10 \\
11-20 \\
21-30 \\
\text { mai. } 1-10 \\
11-20 \\
21-31 \\
\text { jun. } 1-10 \\
11-20 \\
21-30\end{array}$ & $\begin{array}{l}33,3 \\
20,0 \\
20,0 \\
16,7 \\
10,0 \\
20,0 \\
16,7 \\
10,0 \\
13,3\end{array}$ & $\begin{array}{l}33,3 \\
20,0 \\
20,0 \\
16,7 \\
10,0 \\
20,0 \\
13,3 \\
10,0 \\
6,7 .\end{array}$ & $\begin{array}{l}33,3 \\
20,0 \\
20,0 \\
16,7 \\
10,0 \\
16,7 \\
13,3 \\
3,3 \\
3,3\end{array}$ & $\begin{array}{l}33,3 \\
20,0 \\
20,0 \\
16,7 \\
10,0 \\
13,3 \\
8,7 \\
3,3 \\
0,0\end{array}$ \\
\hline $\begin{array}{r}\text { jul } 11-10 \\
11-20 \\
21-31 \\
\text { ago. } 1-10 \\
11-20 \\
21-31 \\
\text { set. } 1-10 \\
11-20 \\
21-30\end{array}$ & $\begin{array}{r}10,0 \\
3,3 \\
3,3 \\
3,3 \\
6,7 \\
3,3 \\
6,7 \\
13,3 \\
23,3\end{array}$ & $\begin{array}{r}6,7 \\
3,3 \\
3,3 \\
3,3 \\
3,3 \\
3,3 \\
6,7 \\
10,0 \\
13,3\end{array}$ & $\begin{array}{r}0,7 \\
3,3 \\
0,0 \\
3,3 \\
3,3 \\
3,3 \\
0,0 \\
10,0 \\
10,0\end{array}$ & $\begin{array}{r}3,3 \\
3,3 \\
0,0 \\
3,3 \\
3,3 \\
3,3 \\
0,0 \\
10,0 \\
6,7\end{array}$ \\
\hline $\begin{array}{r}\text { out. } 1-10 \\
11-20 \\
21-31 \\
\text { nov. } 1-10 \\
11-20 \\
21-30 \\
\text { dez. } 1-10 \\
11-20 \\
21-31\end{array}$ & $\begin{array}{l}43,3 \\
46,7 \\
43,3 \\
60,0 \\
53,3 \\
53,3 \\
66,7 \\
73,3 \\
93,3\end{array}$ & $\begin{array}{l}36,7 \\
43,3 \\
43,3 \\
56,7 \\
53,3 \\
53,3 \\
66,7 \\
73,3 \\
93,3\end{array}$ & $\begin{array}{l}26,7 \\
36,7 \\
36,7 \\
53,3 \\
53,3 \\
53,3 \\
66,7 \\
73,3 \\
93,3\end{array}$ & $\begin{array}{l}13,3 \\
26,7 \\
33,3 \\
43,3 \\
40,0 \\
50,0 \\
66,7 \\
73,3 \\
93,3\end{array}$ \\
\hline
\end{tabular}

Nos solos com citros desta localidade predominam os distróficos e álicos, portanto, com menor 
nivel de AFD, condicionantes de deficites hidricos CTabela $18)$.

Ainda que as duraçóes dos periodos com dericites hidricos sejam aproximadamente iguais para um dado nivel de AFD e de probabilidade de ocorrencia, os valores absolutos dos deficites são maiores. A razão disto $\Leftrightarrow$ que Ribeirão Preto apresenta maiores valores de ETo que Pindorama (ver Tabela 8 .

Os dados relativos aos excedentes hidricos aparecem na Tabela 19.

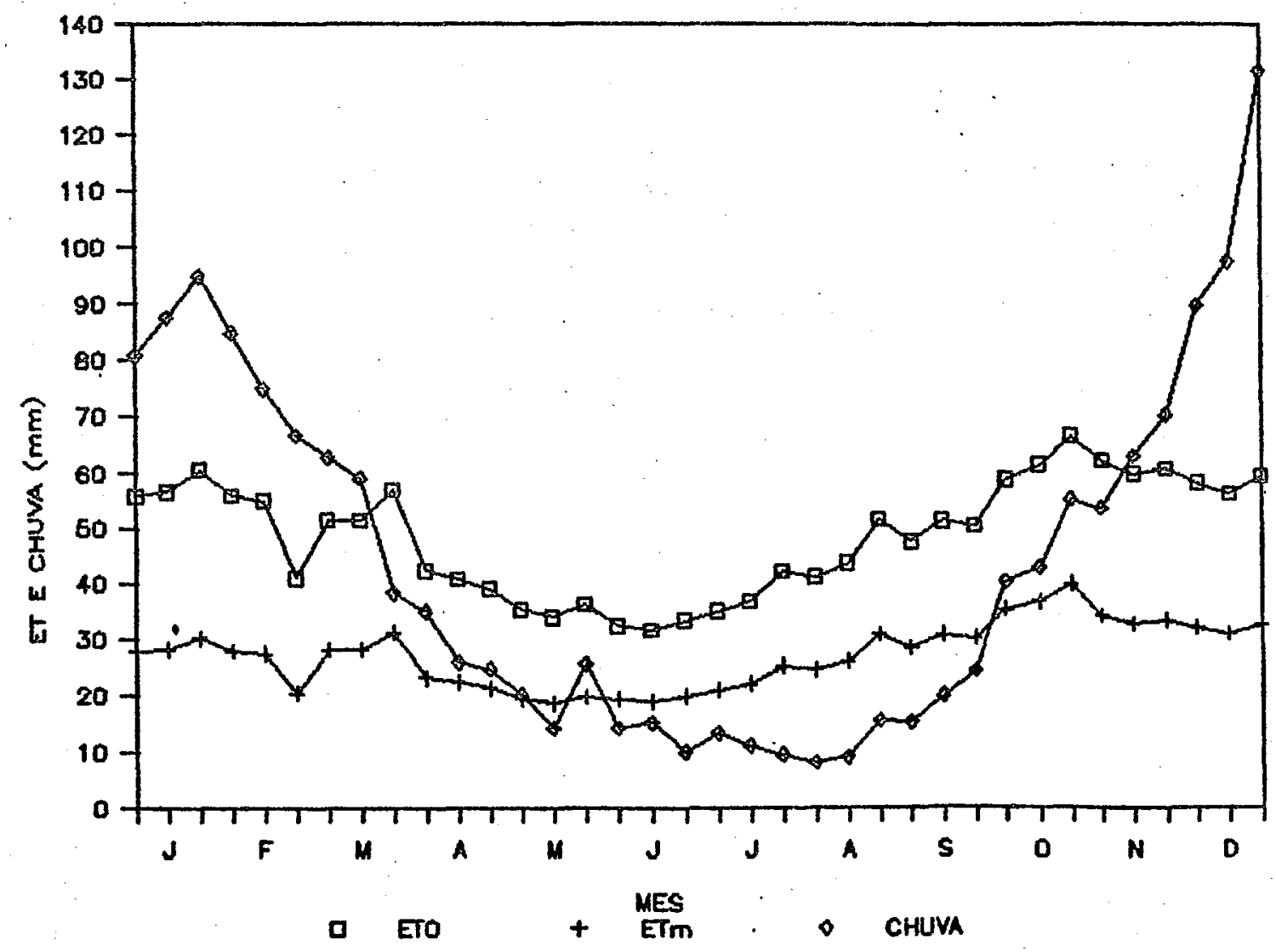

Figura 9 - Valores decendiais medios de chuva, ETo e ETm. para Ribelrão Preto - SP. Perlodo 1960 a 1989. 


\section{Concl usßres}

Considerando-se os resultados do presente trabalho e comparando-os aos conceitos disponiveis na literatura, conclui-se:

1) Mantendo fixos os outros fatores, quanto maior o nível de agua fácilmente disponível (AFD), menor e a duração e a probabilidade de ocorréncia de deficite hidrico para os citros nos locais em estudo.

2) Para um nivel de 50\% de probabilidade de ocorréncia e em solos allcos. CAFD $30 \mathrm{~mm}$, a duraç̃o do deficite hidrico no periodo abril - setembro o maior que 120 dias (exceto Cordeirópolis). Para o mesmo nivel de probabilidade de ocorréncia, a duração do deficite hidrico em solos eutroficos (AFD $75 \mathrm{~mm}$ é de 80 dias.

3) Os locals com maior duraçăo de deficite hidrico são Campinas e Jau, para os niveis de AFD de 30 e $40 \mathrm{~mm}$, e Pindorama e Ribelrăo Preto, para os niveis de 50 e $75 \mathrm{~mm}$.

4) Nas regizes de Pindorama e Ribeirão Preto foram constatadas maiores intensidades de deficite hidrico, qualquer seja o nivel de AFD considerado. para as cinco localidades estudadas.

5) A area com maior desenvolvimento atual da citricultura no Estado, representada por Pindorama $\theta$ Ribeirão Preto, em geral apresenta malores probabllidades de ocorrencia de dericites de malor duração e intensidade 
durante a floraç̃o e inicio de frutificaç̃o. Essa condição de estresse hidrico \& reduzida pela predominancia de solos distroficos eutroficos com AFD entre 50 e $100 \mathrm{~mm}$.

6) Foram constatados niveis de $20 \%$ de probabilidade de ccorrencia de deficites hidricos no outono (abril-maio), os quais podem afetar negativamente as etapas finais de crescimento dos frutos debilitar os pomares para a etapa de induçăo floral, especialmente com AFD igual ou inferior a $40 \mathrm{~mm}$.

73 A opção por solos de maior AFD na instal ação do pomar, aparece como uma opção válida, porquanto reduz a frequéncia de estresse hídrico e de modo geral, dispz̃em de boas condiçőes de drenagem.

8) Nos casos de solos com drenagem deficiente, a probabilidade de ocorrencia de excedentes hidricos no final do periodo de colheita (dezembro) poder fa reduzir a qualidade dos frutos, especialmente durante periodos longos. 
REFERENCI AS BI BLI OGRAFI CAS.

ALFONSI, R.R.; GAMARGO, M.B.P de; CHIAVEGATTO, O.M.D.P. ; PEDRO Jr. . M.J.; ORTOLANI, A. A. ; BRUNINI, O. : Si mul aça de epocas de plantio baseadas no atendimento da demanda hidrica para culturas de soja, milho e arroz de sequelro no Estado de São Paulo. In: CONGRESO BRASILEIRO DE AGROMETEOROLOGIA, 6. Maceió, 1989. Anais. Săo Jose dos Campos, INPE, $1989 a$. p. 34-8.

ALFONSI, R.R.; CAMARGO, M.B.P de; CHIAVEGATTO, O.M.D.P.; PEDRO Jr.. M.J.; ORTOLANI . A. A. ; BRUNINI, O. N1 veis de probabilidades de seca, como subsidio a irrigaçăo para o Estado de São Paulo. In: CONGRESO BRASILEIRO DE AGROMETEOROLOGIA, 6., Maceio, 1989. Anais. Săo Jose dos Campos, INPE, $1989 \mathrm{~b}$. p. 39-42.

ANUARIO ESTATISTICO DO ESTADO DE S3O PAULO - 1988, SZO Paulo, p. 487-9, 1989 .

ARRUDA, F.B.; ZULLO JR., J.; OLIVEIRA, J.B. de. Parametros de solo para o cáculo da agua disponivel com base na textura do solo. Revista Brasileira de Ciencia do Solo. Campinas, 11: 11-5, 1987 .

ARRUDA, H.V. de \& PINTO, H.S. A simplified gamma probability model for analysis of the frequency distribution of rainfall in the region of Campinas. SP. 
Brazil. Agricultural Meteorology, Amsterdan, 22: $101-8$, 1980.

ASSUMPCIAO, P. \& SOUZA, J.M.B.S. de. A citricultura paulista: Limeira. Laranja, Cordeiropolis, 6: 385-406, 1985.

AVILAN, L; LEAL, F.; MENESES, L.; SUCRE, R. ; GARCIA, M.L. Distribución del sistema radical de las citricas on algunos suelos de Venezuela. Fruits, Paris, 41 : $655-68,1988$.

BATISTELLA, C.; SANTOS, J.A. dos; SOUZA, J.M.B. de. Citricultura no Estado de São Paulo: Limeira. Laranja, Cordeiropolis, 4: 97-115, 1983 .

BELL, W.D. \& BARTHOLIC, J.F. Measure of water stress in citrus. Proceedings of the Florida State Horticultural Society, Lake Alfred, 86: 71-5, 1973.

BEN MECHLIA, N. \& CARROLL, J.J. Agroclimatic modeling for the simulation of phenology, yield and quality of crop production. II. Citrus model implementation and verification. International Journal of Biometeorolosy. Amsterdan, 33: 52-65, 1989.

BENESI, J.F.C.; BRITO, P.F de; PAULA, A.S. de. A citricultura paulista: Barretos. Laranja. Cordeirópolis, 6: $331-44,1985$.

BEUTEL, J.A. Soll moisture, weather and fruit growth. The California Citrograph, Los Angeles, 49: 372. 1964.

CAHOON, G.A. \& STOLZY, L.H. Estimating root density and 
distribution in citrus orchard by the neutron moderation method. Proceedings of the American Society for Horticultural Science, St. Joseph 74: 322-7, 1959.

CAMARGO, A.P. Contribuiç̃̃o para a determinação da evapotramspiraço potencial no Estado de Sáo Paulo. Piracicaba, 1961. 49p. CDoutorado - Escola Superior de Agricultura "Luiz de Queiroz" $/$ USP)

CAMARGO, A.P. de; PINTO, H.S.; PEDRO JR. , M.J.; BRUNINI, O.; ALFONSI, R.R.; ORTOLANI, A. A. Aptidao climatica de culturas agricolas. In: SAO PAULO (Estado). Secretaria da Agricultura do Estado de Săo Paulo. Zoneamento agricola do Estado de São Paulo. São Paulo, CATI. 1974. V.1, cap. 4, p. $109-49$.

CAMARGO, M. B.P. de; ARRUDA, H.V. de; PEDRO JR., M. J.; BRUNINI, O.; ALFONSI, R.R.. Melhores epocas de plantio do trigo no Estado de Sa paulo baseadas na probabilidade de atendimento hudrico. Bragantia, Campinas, 44(1): 255-61, 1985.

CAMPOS, A. S. ; BATISTA, O.C.; SOUZA, S.P. de. Citricultura no Estado de São Paulo: São Jose do Rio Preto. Laranja, Cordeiropolis, 4: 117-23, 1983.

COHEN, Y.; FUCHS, M. ; COHEN, S. Resistance to water uptake in mature citrus tree. Journal of Experimental Botany. Oxford. $34(141): 451-80,1983$.

CRUSE, R.R. ; WIEGAND, C.L.: SHANSON, W.A. The effects of rainfall and irrigation management on citrus juice quality in Texas. Journal of the American Society for Horticultural Science, St. Joseph, 107(5): 767-70. 1982. 
DE NEGRI, J.D. \&.PIZA JR., C. T. Manual shell sobre citricultura. s.1., Shell Brasil S.A., 1988. 10 2p.

DOLCI, A. \& PARO, R. Citricultura no Estado de São Paulo: Taquaritinga. Laranja, Cordeirópolis, 4: 125-46, 1983.

DOORENBOS, J. \& KASSAM A.H. Yieid response to water. Rome, FAO, 1979. 193p. CFAO. Irrigation and Drainage Paper, 33).

DOORENBOS, J. \& PRUIT W.O. Guidelines for predicting crop water requeriments. Rome, FAO, 1984. 144p. CFAO. Irrigation and Drainage Paper, 243.

FAO PRODUCTION YEARBOOK - 1988, ROME, 42: 214-7, 1989a.

FAO TRADE YEARBOOK - 1988, Rome, 42: 153-60, $1989 \mathrm{~b}$.

FEICHTENBERGER, E. Doenças dos citrus. In: SIMPOSIO SOBRE PRODUTIVIDADE DE CITROS, 1.. Jaboticabal. 1984. Jaboticabal, FUNEP, 1985. p. 57-81.

FORD, H.H. Eight years of root injury from water table fluctuations. Proceedings of the Florida state Horticultural Society, Lake Alfred, 85: 65-8, 1972.

FRIZZONE, J.A.; RETTORE, P.R.; PEREIRA, G.T. Anallse da distribulção das precipitaçß̄es em perlodos de 5 o 10 dias na região de Pereira Barreto (SP) utilizando a distribulção Gama incompleta. Irrigação e Tecnologia Moderna, Brasilia, 22: 2-4, 1985.

GALLO, J.R.; RODRIGUEZ, 0.; CAMARGO, A.P. de ; IGUE. T. 
Variaçōes anuais na produção de frutos e concentração de macronutrientes em folhas de citros, relacionadas ao bal anco hídrico meteorológico e adubação, no periodo de 1957 a 1975. Bragantia, Campinas, 36: 271-89, 1977.

GARNSEY S.M. \& YOUNG R.H. Water flow rates and starch reserves in roots from citrus tress affected by blight and tristeza. Proceedings of the florida state Horticultural Society, Lake Alfred, 88: 79-84, 1975.

GERBER, J.F.; KREZDORN, A.H.; BARTHOLIC. J.F.; CONNER, J.R. ; REITZ, H.J.; KOO, R.C.; HARRISON, D.S. ; SMERDON. E.T.; GEORG, J.G.; HARRIS, L.D. ; BRADLEY, J.T. Water needs of Florida citrus. Proceedings of the Florida State Horticultural Society. Lake Alfred 86: 61-4, 1973.

HILGEMAN, R.H. \& SHARP F.O. Response of 'Valencia" orange trees to four soil later schedules during 20 years. Journal of the American Society for Horticultural Science. St Joseph, 95(6): 739-45, 1970.

JORGE, J.A.; IGUE, T.; ALMEIDA, C.L.F. de. Propriedades hidricas e resistencia a penetração de quatro unidades de solo de Estado de São Paulo. Revista de Agricultura, Piracicaba, 63: 21-36, 1988.

JORGE, J.A. \& PRADO, H. do. Porosidade, consistencia e propriedades hidricas de tres podzolicos VermelhoAmarelos e uma Terra Roxa Estruturada. Revista Brasileira de Ciencia do Solo, Campinas, 12: 1-6. 1988.

KOO, R.C.J. The distribution and uptake of soll moisture in citrus groves. Proceedings of the florida state Horticultural Society, Lake Alfred, 74: 86-90, 1951. 
KOO, R.C.J. Evapotranspiration and soll moisture. determination as guides to citrus irrigation. In: INTERNATIONAL CITRUS SYMPOSIUM, 1., RIverside, 1968. Proceedings, edited by H.D. Chapman. Riverside. University of California, 1969. v.1, p.1725-30.

KOO, R.C.J. \& MCCORNACK. A.A. Erfects or irrigation and fertilization on production and quality of 'Dancy' tangerine. Proceedings of the florida state Horticultural Society, Lake Alfred, 78: 10-5, 1965.

LEITE, Z.N. A citricultura paulista: Sorocaba. Laranja, Cordeiropolis, 6: 419-24, 1985.

LENZ, F. Effects of day length and temperature on the vegetative and reproductive growth of 'Washington Navel' orange. In: INTERNATIONAL CITRUS SYMPOSIUM, 1., Riverside, 1808. Proceedings, edited by H. D. Chapman. Riverside, University of California, $1969 . \quad$ v.1. p. $333-8$.

LINACRE, E.T. A simple formula for estimating evaporation rates in various climates, using temperature data alone. Agricultural Meteorology, Amsterdan, 18: 409-24, 1977.

LIST, R.J. Smithsonian meteorological tables. B.ed. Hashington, Smithsonian Institution, $1951 . \quad$ 5e7p. (Smithsonian Miscellaneus Collections, 114).

LOMAS, J. \& BURD P. Prediction of the commencement and duration of the flowering period of citrus. Agricultural Meteorology, Amsterdan, 28: 387-96, 1983. 
LOMAS, J.; GAT Z.; SHIFRIN, B. Methods of forecasting the ripening dates of citrus fruit in various regions of Israel. Agricultural Meteorology, Amsterdan, 7: 321-7, 1970 .

MANFRINATO, H. A. A influencia da intensidade de chuva na disponibilidade da agua do solo às plantas. Piracicaba. 1970. 100p. CLivre-Docente - Escola Superior de Agricultura "Luiz de "Queiroz" $/$ USPS

MARSH, A.W. Irrigation. In: REUTHER, W., ed. The citrus industry. Riverside, Univ. of California, 1973. v. 3. cap. 8, p. $230-79$.

MATTA, J.P. A citricultura paulista: Bebedouro. Laranja. Cordeirópolis, 6: 345-58, 1985.

MENDEL, $K$. The influence of temperature and light on the vegetative development of citrus trees. In: INTERNATIONAL CITRUS SYMPOSIUM, 1., Riverside, 1968. Proceedings, edited by H. D. Chapman. Riverside, University of, California, 1969. v.1, p.259-65.

MEREDITH, F.I. \& YOUNG, R:H. Effect of temperature on pigment development in red blush grapefruit and $r u b y$ blood oranges. In: INTERNATIONAL CITRUS SYMPOSIUM. 1. . Riverside, 1968. Proceedings, edited by $H$. D. Chapman. Riverside, University of, California. $1969 . \quad v .1$. p. $271-6$.

MIGLINSKI, A. : SOUZA W. de; VIOTTI J. A citricultura paulista: Mogi-Mirim. Laranja, Cordeiropolis. 6: 407-12, 1985. 
MONTEIRO, J.A. \& MURAKANI, J.Y. A citricultura paulista: Taquaritinga. Laranja, Cordeiropolis, 6: 425-40, 1985.

MONTENEGRO, H.W.S. Contribuição ao estudo do sistema radicular das plantas citricas. Piracicaba, 1960. 147p. CCatedra - Escola Superior de Agricultura "Luiz de Queiroz" USPS

MONTENEGRO, H.W.S. Clima e solo. In: RODRIGUEZ, 0. \& VIEGAS, F.C.P., coord. Citricultura brasileira. 1.ed. Campinas, Fundagão Cargil1. 1980. v.1, cap. 9. p. $225-39$.

MOREIRA, C.S. Estudo da distribuição do sistema radicular da laranjeira 'Pera' (citrus sinensis, Osbeck) com diferentes manejos de solos. Piracicaba, 1983. 97p. CLivre Docencia - Escola Superior de Agricultura "Luiz de Queiroz" $/$ USPS

MOTA. F.S. da. Meteorologia agrícola. São Paulo, Nobel. 1979. 376p.

OLIVEIRA, J.B. de. Solos para citros. In: RODRIGUEZ, O. \& VIEGAS, F.C.P., coord. Citricultura brasileira. e.ed. Campinas, Fundação Gargi11, 1990. (No prelo)

OLIVEIRA, J.B. de; MENK, J.R.F.; ROTTA, C.L. Levantamento pedologico semidetalhado dos solos do Estado de São Paulo. quadricula de Campinas. Rio de Janeiro, IBGE, 1979. 172p.

OMETTO, J.C. Uma equação para a estimativa da ovapotranspiração potencial: sua aplicaçăo no calculo das necessidades hidricas $\theta$ do rendimento 
agro-industrial da cana-de-açúcar na regizo de Piracicaba (SP). Piracicaba, 1974. 129p. CLivre Docencia - Escola Superior de Agricultura "Luiz de Queiroz" USPS

OMETTO, J.C. Bioclimatologia vegetal. Sæo Paulo, Agron. Ceres, 1981 . 440p.

ORTOLANI, A. A.; PEDRO JUNIOR, M.J.; ALFONSI, R.R. Agrometeorologia e o cultivo dos citros. In: RODRIGUEZ, o. \& VIEGAS, F.C.P., coord. Citricultura brasileira. 2. ed. Campinas, Fundaç̃o Cargill, 1990. (No prelo)

ORTOLANI, A.A.; PINTO, H.S.; PEREIRA, A.R. ; ALFONSI, R. R. Parametros climáticos e a cafeicultura. s.1.. s.ed.. 1970. 27p.

REICHARDT, K. Processos de transferencia no sistema solo-planta-atmosfera. Campinas. Fundaça Cargill. 1985. 46Gp.

REUTHER, W. Climate and citrus behavior. In: REUTHER. W. ed. The citrus industry. Riverside, Univ. of California, 1973 . v. 3. cap. 9, p. 280-337.

REUTHER, W. \& CASTAFO, D.R. Comparison of growth maturation and composition of citrus fruits in subtropical California and tropical colombia. In: INTERNATIONAL CITRUS SYMPOSIUM, 1., RIverside. 1968. Proceedings, edited by $H$. D. Chapman. Riverside, University of California, 1969. v.1, p.277-300.

RODRIGUEZ, O. Ecofisiologia dos citros. In: CASTRO, P.R.C. ; FERREIRA, S.O.; YAMADA T. ed. Ecofisiologia da 
produção agricola. Piracicaba, POTAFOS, 1987. p. 149-64.

RUBBO, M.S.; VIOTTI, J.; FERREIRA, J.A.; SOUZA, $w$. de. Citricultura no Estado de São Paulo: Mogi Guaçú. Laranja, Cordeiropolis, 4: 85-95, 1983.

SALIBE, A.A. Curso de especialização em citricultura a nivel de pos-8raduação. Recife, s.ed., 1969. 175p.

SANTINI, J.A. A citricultura paulista: Casa Branca. Laranja, Cordeirópolis, 6: 359-84, 1985.

SEGNINI, I. \& CHAINE, R. A citricultura paulista: Araraquara. Laranja, Cordeiropolis, 6: 319-29, 1985.

SERVIÇO NACIONAL DE PESQUISAS AGRONOMICAS. COMISSz̃o de solos. Levantamenio de reconhecimento dos solos do Estado de São Paulo. Rio de Janeiro, SNPA, 1960. 634p. (Boletim, 12$)$

SETZER, J. Atlas ciimático e ecologico do Estado de Săo Paulo. São Paulo, Comissão Interestadual da Bacla Parana-Urugual, 1966. $61 \mathrm{p}$.

SILVA, G.L.S.P. da; VICENTE, J.R.; CASER, D.V. Efelto das condiçōes do tempo sobre a produtividade da laranja no Estado de Säo Paulo. Laranja, Cordeiropolis, 7: 423-38. 1986.

SoUZA, S.P.de. A citricultura paulista: Săo Jose do Rio Preto. Laranja. Cordeirópolis, 6: 413-8, 1985.

SPIEGEL, M.R. Probabilidade e estatistica. Trad. de A.A. 
de Faria. São Paulo, McGraw-Hill do Brasil, 1978. S27p.

STANHILL $G$. The use of the Plche evaporimeter in the calculation of evaporation. Quarterly Journal of the Royal Meteorological Society, London, 88(375): 80-2, 1962.

SUSANNA, A.A. ; SANTINI, J.A. J. ; D'ACARDIA, R.S. ; ANTONINI, A. C. Citricultura no Estado de São Paulo: Casa Branca. Laranja, Cordeirópolis, 4: 43-63, 1883.

TESFILO SOBRINHO, J.; CAETANO, A. A.; VIOLANTE NETTO, A. Flórida e São Paulo, os maiores polos citricolas do mundo. Laranja, Cordeiropolis, 3: 233-64, 1982.

TOLEDO FILHO, M. da R. Probabilidade de suprimento da demanda hidrica ideal da cultura de cana-de-acucar (Saccharum spp.) atraves da precipitação pluvial na zona canavieira do Estado de Alagoas. Piracicaba. 1988. 72p. CMestrado - Escola Superior de Agricultura "Luiz de Queiroz" $/$ USP3.

TUBELIS, A. Previsão de colheita de citros em fungão das chuvas. Laranja, Cordelrópolis, 7: 453-62, 1986.

TUBELIS, A. \& SALIBE, A. A. Estimativa de safra de laranja 'Hamlin' em cimco porta-enxertos. Laranja. Cordeiropolis, 10: $531-43,1989$.

VIACAVA, C. Mercado interno externo de suco cltrico. Laranja, Cordeirópolis, 8: $541-9,1987$.

VIEIRA, D.B. Controle da irrigação em citricultura. 
Laranja, Cordeiropolis, 5: 299-312, 1984.

VIEIRA, D.B. Irrigação de citros. In: RODRIGUEZ, 0. \& VIEGAS, F.C.P., coord. Citricultura brasileira. 2.ed. Campinas, Fundação Cargill, 1990. (No prelo)

VILLA NOVA. N.A. A estimativa da evaporaçá potencial no Estado de São Paulo. Piracicaba, 1967., 66p. CDoutorado - Escola Superior de Agricultura "Luiz de Queiroz" $/$ USP)

VILLA NOVA, N.A.; OMETTO, J.C. Adaptação simplificação do metodo de Penman às condiços cil máticas do Estado de São Paulo. In: SIMPOSTO BRASTLERIRO DE HIDROLOGIA E RECURSOS HIDRICOS, 4., Fortaleza, 1981 . Anais. Fortaleza, ABRH, 1981. v. 3., p. $281-99$.

VILLA NOVA, N.A.; REICHARDT, K. ; ORTOLANI, A. A. Principais métodos climáticos e de medida da perda de água de superficies naturais. Piracicaba, ESALODepto. de Fisica e Meteorologia, 1968. $57 \mathrm{p}$.

WEBBER, H.J. History and development of the citrus industry. In: REUTHER, W.; WEBBER, H.J.; BATCHELOR, L. D. ed. The citrus industry. Riverside, Univ. of California, 1967. v.1, cap. 1, p.1-39.

WUTSCHER, H.K. \& BISTLINE, F.W. Performance of 'Hamlin' orange on 30 citrus rootstocks in Southern Florida. Journal of the American Society for Horticultural Science, St. Joseph, 113(4): 493-7, 1988.

YEVJEVICH, V. Probability and statistics in hidrolosy. Fort Collins, Water Resources Publ., 1972. 302p. 
APENDICE 1 
Tabela 1 - Valores de 0 (OMETTO, 1981 ) em mm dia

\begin{tabular}{|l|rlllll|}
\hline Lat. & Jan. & Fev. & Mar. & Abr. & Mai. & Jun. \\
\hline 2o S & 17,3 & 16,5 & 15,0 & 13,0 & 11,0 & 10,0 \\
22 & 17,4 & 16,5 & 14,8 & 12,6 & 10,6 & 9,6 \\
24 & 17,5 & 16,5 & 14,6 & 12,3 & 10,2 & 9,1 \\
\hline Lat. & Jul. & Ago. & Set. & Out. & Nov. & Dez. \\
\hline $20 S$ & 10,4 & 12,0 & 13,9 & 15,8 & 17,0 & 17,4 \\
22 & 10,0 & 11,6 & 13,7 & 15,7 & 17,0 & 17,5 \\
24 & 9,5 & 11,2 & 13,4 & 15,6 & 17,1 & 17,7 \\
\hline
\end{tabular}

Tabela 2 - Valores de a (VILLA NOVA, 1967 )

\begin{tabular}{|cc|cc|cc|}
\hline Temp. & $\alpha$ & Temp. & $\alpha$ & Temp. & $\alpha$ \\
\hline 1 & 0.37 & 16 & 0.64 & 31 & 0.80 \\
2 & 0.44 & 17 & 0.64 & 32 & 0.81 \\
3 & 0.44 & 18 & 0.67 & 33 & 0.81 \\
4 & 0.44 & 19 & 0.67 & 34 & 0.81 \\
5 & 0.50 & 20 & 0.67 & 35 & 0.82 \\
6 & 0.50 & 21 & 0.69 & 36 & 0.84 \\
7 & 0.54 & 22 & 0.71 & 37 & 0.84 \\
8 & 0,54 & 23 & 0.72 & 38 & 0.84 \\
9 & 0.54 & 24 & 0.72 & 39 & 0.85 \\
10 & 0.54 & 25 & 0.74 & 40 & 0.85 \\
11 & 0,58 & 26 & 0.75 & & \\
12 & 0.58 & 27 & 0.76 & & \\
13 & 0.61 & 28 & 0.76 & & \\
14 & 0.61 & 29 & 0.78 & & \\
15 & 0.61 & 30 & 0.79 & & \\
\hline
\end{tabular}

temperatura em ${ }^{\circ} \mathrm{C}$ 
Tabela 3 - Valores de $a^{\prime} e b^{\prime}$ (VILLA NOVA \& OMETTO, 1981$)$

\begin{tabular}{|l|cc|cc|}
\hline Estaçăo & \multicolumn{2}{|c|}{ Prim. -Ver. C1) } & Out. - Inv. C2) \\
\cline { 2 - 5 } & $a^{\prime}$ & $b^{\prime}$ & $a^{\prime}$ & $b^{\prime}$ \\
\hline Campinas & 0,19 & 0,23 & 0,17 & 0,09 \\
Cordeirópolis & 0,19 & 0,24 & 0,17 & 0,10 \\
Jaú & 0,19 & 0,23 & 0,17 & 0,09 \\
Pindorama & 0,19 & 0,25 & 0,17 & 0,12 \\
R. Preto & 0,19 & 0,24 & 0,17 & 0,10 \\
\hline
\end{tabular}

(1) outubro - março

(2) abril -setembro

Tabela 4 - Valores de $\Omega$ (VILLA NOVA \& OMETTO, 1981 )

\begin{tabular}{|cc|cc|cc|}
\hline Més & $\Omega$ & Més & $\Omega$ & Més & $\Omega$ \\
\hline Jan. & 0,29 & Mai. & 0,27 & Set. & 0,28 \\
Fev. & 0,28 & Jun. & 0,28 & Out. & 0,29 \\
Mar. & 0,25 & Jul. & 0,29 & Nov. & 0,29 \\
Abr. & 0,29 & Ago. & 0,27 & Dez. & 0,29 \\
\hline
\end{tabular}

Tabela 5 - Valores de N (LIST, 1951 ) em horas e decimos

\begin{tabular}{|l|cc|cc|cc|}
\hline Dia & \multicolumn{2}{|c|}{5} & \multicolumn{2}{|c|}{15} & \multicolumn{2}{c|}{25} \\
\hline Latitude CS & $20^{\circ}$ & $25^{\circ}$ & $20^{\circ}$ & $25^{\circ}$ & $20^{\circ}$ & $25^{\circ}$ \\
\hline Mes & & & & & \\
Jan. & 13,2 & 13,6 & 13,2 & 13,6 & 13,1 & 13,4 \\
Fev. & 12,9 & 13,2 & 12,8 & 13,0 & 12,6 & 12,8 \\
Mar. & 12,4 & 12,6 & 12,2 & 12,3 & 12,1 & 12,1 \\
Abr. & 11,9 & 11,8 & 11,7 & 11,6 & 11,5 & 11,4 \\
Mai. & 11,4 & 11,1 & 11,2 & 10,9 & 11,1 & 10,8 \\
Jun. & 11,0 & 10,6 & 10,9 & 10,6 & 10,9 & 10,6 \\
Jul. & 11,0 & 10,6 & 11,1 & 10,8 & 11,2 & 10,9 \\
Ago. & 11,3 & 11,1 & 11,5 & 11,3 & 11,7 & 11,6 \\
Set. & 11,8 & 11,8 & 12,0 & 12,0 & 12,2 & 12,2 \\
Out. & 12,4 & 12,5 & 12,6 & 12,8 & 12,8 & 13,0 \\
Nov. & 12,9 & 13,2 & 13,1 & 13,4 & 13,2 & 13,5 \\
Dez. & 13,3 & 13,6 & 13,3 & 13,7 & 13,4 & 13,7 \\
\hline
\end{tabular}


APENDICE 2 
DECIL

\begin{tabular}{|c|c|c|c|c|c|c|c|c|c|c|c|}
\hline DECENDIO & MIN. & 1 & 2 & 3 & 4 & 5 & 6 & 7 & 8 & 9 & 10 \\
\hline jan.1-10 & 10.7 & 22.5 & 30.7 & 38.9 & 48.4 & 88.8 & 96.1 & 102.6 & 118.2 & 138.7 & 176.3 \\
\hline $11-20$ & 1.3 & 9 & 28.7 & 41.7 & 51.6 & 64.4 & 73.2 & 88.6 & 100.6 & 117 & 286.9 \\
\hline $21-31$ & 2.4 & 17.9 & 25.3 & 39.1 & 51.6 & 60.6 & 70.2 & 97.6 & 133.2 & 187.4 & 203.7 \\
\hline fev.1-10 & 0 & 6.6 & 17.9 & 42.8 & 48.3 & 59.9 & 71.7 & 109 & 122.8 & 155.7 & 167.5 \\
\hline $11-20$ & 0 & 5.9 & 16.7 & 39.7 & 42 & 52.7 & 57.8 & 72.4 & 84.7 & 114.3 & 331.5 \\
\hline $21-28$ & 1.7 & 2.4 & 9.2 & 13.9 & 27.5 & 39 & 59.9 & 65.4 & 84.9 & 95.8 & 181 \\
\hline $\operatorname{car}=1-10$ & 4.8 & 9.2 & 16.1 & 21.7 & 27.1 & 43 & 54.2 & 62.5 & 70.3 & 105.1 & 196.8 \\
\hline $11-20$ & 0 & 0 & 2.1 & 6.6 & 20.6 & 31.4 & 40.7 & 54.2 & 78.3 & 142.3 & 206.5 \\
\hline $21-31$ & 0 & 0 & 10.3 & 18.1 & $2 B$ & 35.3 & 41.8 & 51 & 58.6 & 75.8 & 116.2 \\
\hline abr. $1-10$ & 0 & 0 & 3.6 & 9.6 & 14.2 & 20.9 & 29.7 & 44.9 & 50.8 & 67.8 & 120 \\
\hline $11-20$ & 0 & 0 & 0.8 & 4.4 & 8.9 & 12.7 & 19.5 & 26.1 & 48.1 & 67.6 & 112 \\
\hline $21-30$ & 0 & 0 & 0.2 & 1 & 3.9 & 6.2 & 10.1 & 12.1 & 16.7 & 29.8 & 92.9 \\
\hline ตa. 1-10 & 0 & 0 & 0 & 1.8 & 10.8 & 13 & 14.8 & 18.6 & 26.9 & 64.3 & 76.3 \\
\hline $11-20$ & 0 & 0 & 0 & 0 & 1.3 & 8.9 & 15 & 24.3 & 42.3 & 57.1 & 108.9 \\
\hline $21-31$ & 0 & 0 & 0 & 0 & 1.7 & 5.8 & 19.5 & 23.6 & 29.7 & 59 & 227.2 \\
\hline jun. $1-10$ & 0 & 0 & 0 & 0 & 2.3 & 6.1 & 9.9 & 16 & 23.6 & 39.6 & 159.9 \\
\hline $11-20$ & 0 & 0 & 0 & 0 & 0.3 & 7.9 & 8.8 & 19.9 & 32 & 55.6 & 107.7 \\
\hline $21-30$ & 0 & 0 & 0 & 0 & 0 & 1.5 & 3.6 & 14.2 & 17.2 & 46.3 & 79.1 \\
\hline jul. $1-10$ & 0 & 0 & 0 & 0 & 0.3 & 2.4 & 3.8 & 7.7 & 23.2 & 28.1 & 138.1 \\
\hline $11-20$ & 0 & 0 & 0 & 0 & 0 & 0 & 1.4 & 6.6 & 14.8 & 17.1 & 85.8 \\
\hline $21-31$ & 0 & 0 & 0 & 0 & 2 & 2.7 & 4.7 & 10.2 & 17.3 & 24.2 & 139.1 \\
\hline $200.1-10$ & 0 & 0 & 0 & 0 & 0 & 1.4 & 3.3 & 5.6 & 14.7 & 34.7 & 61.4 \\
\hline $11-20$ & 0 & 0 & 0 & 0 & 0.3 & 1.9 & 5.7 & 11.8 & 13.7 & 16.2 & 70.5 \\
\hline $21-31$ & 0 & 0 & 0 & 0 & 0.1 & 1.9 & 9.4 & 15.8 & 21.2 & 37 & 110.6 \\
\hline set. $1-10$ & 0 & 0 & 0 & 0 & 4.8 & 8.1 & 15.7 & 25.9 & 38.8 & 56 & 86.2 \\
\hline $11-20$ & 0 & 0 & 0 & 0 & 1.3 & 2 & 5.8 & 13 & 24.9 & 47.4 & 104.7 \\
\hline $21-30$ & 0 & 0.2 & 2.2 & 5.1 & 11.7 & 20.4 & 29.6 & 35.3 & 47.4 & 63.2 & 70.2 \\
\hline out. $1-10$ & 0 & 0 & 1 & 3.7 & 19.5 & 29.9 & 51.5 & 62.2 & 64.8 & 74.8 & 99.1 \\
\hline $11-20$ & 0 & 2.1 & 10.4 & 20.2 & 24.2 & 30.8 & 42.1 & 53.7 & 62.4 & 71.5 & 104.2 \\
\hline $21-31$ & 0 & 5.9 & 15.6 & 22.6 & 28.2 & 36.4 & 44.9 & 65.7 & 96.7 & 97.5 & 143.1 \\
\hline nov. $1-10$ & 0 & 5.6 & 14 & 15.9 & 23.5 & 30.15 & 41.5 & 55.6 & 63.7 & 73.8 & 97.6 \\
\hline $11-20$ & 0 & 5.6 & 13.6 & 25.1 & 31.7 & 42.7 & 51.4 & 52.3 & 66.9 & 93.4 & 131.3 \\
\hline $21-30$ & 0 & 10.4 & 21.4 & 24.4 & 35.5 & 40.2 & 45.6 & 57.1 & 67.9 & 105 & 157.6 \\
\hline dez.1-10 & 0 & 10.4 & 36.4 & 43 & 63.8 & 68.8 & 77.4 & 98.5 & 103.1 & 137.1 & 172.8 \\
\hline $11-20$ & 5.5 & 9.3 & 32.6 & 40.9 & 48.6 & 57.2 & 72.5 & 80.2 & 102.3 & 132.4 & 266.4 \\
\hline $21-31$ & 2 & 7.2 & 38.98 & 50.5 & 63.1 & 76.3 & 93 & 99.8 & 118.6 & 161.5 & 189.3 \\
\hline
\end{tabular}


TABELA 02 - CAMPINAS: EVAPOTRAMSPIRACAD DE REFERENCIA

DECIL

\begin{tabular}{|c|c|c|c|c|c|c|c|c|c|c|c|}
\hline & & 1 & 2 & 3 & 4 & 5 & 6 & 7 & 8 & 9 & 10 \\
\hline an. 1-10 & 45.7 & 50.4 & 53.9 & 54.9 & 56.3 & 59.1 & 59.9 & 64.1 & 66.5 & 69.0 & 72.9 \\
\hline $11-20$ & 38.1 & 44.3 & 45.9 & 52.5 & 58.9 & 60.2 & 62.9 & 65.5 & 70.1 & 72.7 & 83.3 \\
\hline $21-31$ & 41.6 & 51.9 & 57.4 & 59.0 & 63.0 & 63.9 & 67.8 & 69.6 & 72.3 & 77.8 & 91.6 \\
\hline fev. $1-10$ & 39.7 & 46.6 & 50.9 & 53.6 & 57.9 & 59.7 & 64.0 & 65.9 & 69.0 & 70.7 & 75.8 \\
\hline $11-20$ & 37.2 & 42.8 & 47.0 & 52.5 & 55.1 & 58.4 & 62.7 & 64.0 & 67.5 & 70.6 & 75.4 \\
\hline $21-28$ & 28.3 & 32.8 & 36.0 & 40.7 & 43.0 & 43.8 & 44.7 & 46.7 & 51.7 & 52.8 & 55.9 \\
\hline tar. $1-10$ & 41.1 & 44.6 & 45.2 & 53.3 & 55.0 & 55.9 & 57.2 & 59.6 & 61.4 & 63.5 & 67.3 \\
\hline $11-20$ & 35.6 & 46.9 & 50.1 & 51.4 & 53.6 & 54.8 & 56.4 & 58.7 & 60.7 & 64.2 & 70.3 \\
\hline $21-31$ & 47.0 & 49.5 & 53.2 & 55.6 & 56.4 & 58.5 & 59.5 & 63.0 & 64.3 & 66.3 & 73.5 \\
\hline$a b r, 1-10$ & 35.0 & 39.8 & 40.7 & 41.0 & 42.1 & 43.7 & 46.0 & 47.5 & 50.6 & 51.3 & 54.6 \\
\hline $11-20$ & 34.7 & 36.1 & 38.6 & 39.6 & 42.0 & 43.2 & 45.1 & 46.5 & 47.9 & 49.5 & 50.6 \\
\hline $21-30$ & 32.6 & 35.5 & 37.3 & 38.5 & 40.0 & 41.2 & 41.8 & 43.5 & 44.3 & 45.2 & 49.7 \\
\hline 1.1.1-10 & 27.2 & 31.5 & 3.3 & 33.8 & 35.3 & 35.8 & 37.3 & 37.9 & 40.1 & 41.4 & 45.3 \\
\hline $11-20$ & 25.4 & 28.5 & 29.1 & 33.0 & 35.6 & 36.4 & 36.9 & 37.5 & 38.0 & 41.2 & 45.0 \\
\hline $21-31$ & 26.4 & 28.6 & 33.2 & 35.6 & 36.9 & 39.0 & 39.7 & 40.6 & 41.3 & 44.2 & 47.0 \\
\hline jun. $1-10$ & 17.5 & 27.4 & 28.7 & 29.5 & 33.1 & 34.7 & 35.8 & 36.2 & 36.9 & 38.3 & 41.1 \\
\hline $11-20$ & 17.1 & 26.3 & 27.8 & 29.3 & 31.0 & 31.9 & 33.5 & 34.9 & 36.2 & 37.5 & 39.4 \\
\hline $21-30$ & 23.0 & 27.1 & 30.1 & 33.0 & 34.3 & 34.7 & 75.8 & 37.1 & 37.5 & 39.4 & 40.4 \\
\hline jul.1-10 & 21.4 & 29.9 & 33.3 & 34.8 & 35.4 & 36.0 & 37.3 & 37.6 & 39.2 & 43.0 & 44.3 \\
\hline $11-20$ & 29.0 & 32.1 & 34.0 & 34.5 & 36.0 & 36.4 & 38.6 & 40.0 & 41.3 & 43.5 & 46.6 \\
\hline $21-31$ & 34.3 & 36.7 & 39.4 & 40.8 & 42.3 & 43.7 & 44.9 & 45.3 & 46.1 & 50.7 & 54.2 \\
\hline มุด. $1-10$ & 32.7 & 33.4 & 36.9 & 38.2 & 39.4 & 80.1 & 44.5 & 44.9 & 46.1 & 47.1 & 52.0 \\
\hline $11-20$ & 29.3 & 34.9 & 38.3 & 40.3 & 43.3 & 44.3 & 45.7 & 46.7 & 47.7 & 48.2 & 54.6 \\
\hline $21-31$ & 37.9 & 40.5 & 43.0 & 45.4 & 47.9 & 50.4 & 52.4 & 54.3 & 56.0 & 57.8 & 65.1 \\
\hline set.1-10 & 29.6 & 34.8 & 40.2 & 43.1 & 44.4 & 46.3 & 48.7 & 51.1 & 55.7 & 57.6 & 64.6 \\
\hline $11-20$ & 30.0 & 32.9 & 41.3 & 45.9 & 49.1 & 51.1 & 53.3 & 55.3 & 58.6 & 61.2 & 63.3 \\
\hline $21-30$ & 35.6 & 40.7 & 43.4 & 44.6 & 46.7 & 47.7 & 49.1 & 51.2 & 53.1 & 58.7 & 64.8 \\
\hline out. $1-10$ & 40.1 & 45.4 & 49.1 & 53.2 & 54.8 & 58.7 & 61.9 & 65.2 & 70.3 & 75.9 & 81.5 \\
\hline $11-20$ & 46.0 & 51.6 & 54.8 & 59.8 & 61.0 & 62.2 & 62.5 & 63.7 & 65.8 & 67.4 & 82.7 \\
\hline $21-31$ & 50.0 & 54.4 & 58.2 & 62.6 & 64.5 & 66.3 & 70.1 & 72.1 & 75.2 & 77.2 & 90.3 \\
\hline nov. $1-10$ & 52.1 & 53.1 & 57.6 & 59.2 & 61.5 & 64.6 & 64.9 & 67.6 & 69.6 & 74.1 & 75.6 \\
\hline $11-20$ & 41.0 & 48.2 & 54.8 & 57.0 & 59.8 & 62.5 & 64.3 & 68.2 & 71.0 & 73.7 & 99.8 \\
\hline $21-30$ & 44.5 & 51.4 & 57.8 & 59.3 & 62.8 & 64.5 & 66.5 & 69.1 & 71.5 & 74.1 & 79.5 \\
\hline dez. 1-10 & 41.3 & 46.0 & 54.2 & 54.8 & 56.7 & 58.2 & 60.4 & 65.0 & 73.1 & 78.3 & 84.2 \\
\hline $11-20$ & 36.7 & 46.4 & 51.6 & 54.8 & 57.7 & 58.6 & 60.6 & 67.6 & 71.1 & 73.3 & 83.0 \\
\hline $21-31$ & 48.0 & 49.8 & 54.9 & 55.8 & 56.8 & 61.4 & 64.3 & 67.0 & 69.0 & 72.2 & 91.8 \\
\hline
\end{tabular}


TABELA 03 - CAMPINAS: AGUA FACILHENTE DISPONIVEL (BALANCO COM AFD = 30 (1)

DECIL

\begin{tabular}{|c|c|c|c|c|c|c|c|c|c|c|c|}
\hline DECENDIO & KIH. & 1 & 2 & 3 & 4 & 5 & 6 & 7 & 8 & 9 & 10 \\
\hline jan.1-10 & $\therefore 0.0$ & 10.9 & 25.8 & 30.0 & 30.0 & 30.0 & 30.0 & 30.0 & 30.0 & 30.0 & 30.0 \\
\hline $11-20$ & 0.0 & 0.0 & 17.7 & 26.0 & 30.0 & 30.0 & 30.0 & 30.0 & 30.0 & 30.0 & 30.0 \\
\hline $21-31$ & 0.0 & 0.0 & 16.9 & 30.0 & 30.0 & 30.0 & 30.0 & 30.0 & 30.0 & 30.0 & 30.0 \\
\hline fev. $1-10$ & 0.0 & 1.2 & 13.1 & 22.7 & 30.0 & 30.0 & 30.0 & 30.0 & 30.0 & 30.0 & 30.0 \\
\hline $11-20$ & 0.0 & 0.0 & 3.7 & 21.8 & 30.0 & 30.0 & 30.0 & 30.0 & 30.0 & 30.0 & 30.0 \\
\hline $21-28$ & 0.0 & 0.0 & 5.3 & 11.9 & 30.0 & 30.0 & 30.0 & 30.0 & 30.0 & 30.0 & 30.0 \\
\hline ar. $1-10$ & 0.0 & 2.1 & 8.4 & 11.8 & 21.6 & 25.7 & 30.0 & 30.0 & 30.0 & 30.0 & 30.0 \\
\hline $11-20$ & 0.0 & 0.0 & 0.0 & 0.0 & 9.6 & 18.1 & 30.0 & 30.0 & 30.0 & 30.0 & 30.0 \\
\hline $21-31$ & 0.0 & 0.0 & 0.0 & 2.5 & 8.4 & 17.8 & 29.6 & 30.0 & 30.0 & 30.0 & 30.0 \\
\hline$a b r .1-10$ & 0.0 & 0.0 & 0.0 & 3.7 & 16.4 & 18.8 & 22.5 & 30.0 & 30.0 & 30.0 & 30.0 \\
\hline $11-20$ & 0.0 & 0.0 & 0.0 & 1.3 & 3.7 & 6.9 & 13.7 & 30.0 & 30.0 & 30.0 & 30.0 \\
\hline $21-30$ & 0.0 & 0.0 & 0.0 & 0.0 & 0.0 & 0.0 & 7.0 & 18.5 & 21.1 & 30.0 & 30.0 \\
\hline Gais $1-10$ & 0.0 & 0.0 & 0.0 & 0.0 & 0.0 & 1.1 & 7.3 & 15.9 & 30.0 & 30.0 & 30.0 \\
\hline$=11-20$ & 0.0 & 0.0 & 0.0 & 0.0 & 0.0 & 8.1 & 9.7 & 18.9 & 30.0 & 30.0 & 30.0 \\
\hline $21-31$ & 0.0 & 0.0 & 0.0 & 0.0 & 0.0 & 2.8 & 10.7 & 18.0 & 29.9 & 30.0 & 30.0 \\
\hline jun. $1-10$ & 0.0 & 0.0 & 0.0 & 0.0 & 0.0 & 0.0 & 4.3 & 15.2 & 18.1 & 25.2 & 30.0 \\
\hline $11-20$ & 0.0 & 0.0 & 0.0 & 0.0 & 0.0 & 0.0 & 10.1 & 15.9 & 30.0 & 30.0 & 30.0 \\
\hline $21-30$ & 0.0 & 0.0 & 0.0 & 0.0 & 0.0 & 0.0 & 0.0 & 8.2 & 9.9 & 30.0 & 30.0 \\
\hline jul.1-10 & 0.0 & 0.0 & 0.0 & 0.0 & 0.0 & 0.0 & 1.8 & 6.8 & 9.3 & 19.8 & 30.0 \\
\hline $11-20$ & 0.0 & 0.0 & 0.0 & 0.0 & 0.0 & 0.0 & 0.0 & 0.0 & 0.0 & 13.1 & 30.0 \\
\hline $21-31$ & 0.0 & 0.0 & 0.0 & 0.0 & 0.0 & 0.0 & 0.0 & 0.0 & 0.0 & 16.1 & 30.0 \\
\hline ago. $1-10$ & 0.0 & 0.0 & 0.0 & 0.0 & 0.0 & 0.0 & 0.0 & 0.0 & 6.5 & 12.4 & 30.0 \\
\hline $11-20$ & 0.0 & 0.0 & 0.0 & 0.0 & 0.0 & 0.0 & 0.0 & 0.0 & 0.0 & 7.9 & 30.0 \\
\hline $2\lfloor-31$ & 0.0 & 0.0 & 0.0 & 0.0 & 0.0 & 0.0 & 0.0 & 0.0 & 0.2 & 18.5 & 30.0 \\
\hline set. $1-10$ & 0.0 & 0.0 & 0.0 & 0.0 & 0.0 & 0.0 & 0.0 & 6.1 & 18.5 & 30.0 & 30.0 \\
\hline $11-20$ & 0.0 & 0.0 & 0.0 & 0.0 & 0.0 & 0.0 & 0.0 & 0.0 & 3.1 & 30.0 & 30.0 \\
\hline $21-30$ & 0.0 & 0.0 & 0.0 & 0.0 & 0.0 & 0.0 & 8.6 & 17.3 & 27.1 & 30.0 & 30.0 \\
\hline out. $1-10$ & 0.0 & 0.0 & 0.0 & 0.0 & 0.0 & 5.5 & 27.0 & 30.0 & 30.0 & 30.0 & 30.0 \\
\hline $11-20$ & 0.0 & 0.0 & 0.0 & 0.0 & 1.4 & 11.6 & 19.2 & 26.1 & 30.0 & 30.0 & 30.0 \\
\hline $21-31$ & 0.0 & 0.0 & 0.0 & 0.0 & 3.3 & 24.9 & 28.5 & 30.0 & 30.0 & 30.0 & 30.0 \\
\hline nov. $1-10$ & 0.0 & 0.0 & 0.0 & 0.0 & 15.2 & 22.3 & 27.7 & 30.0 & 30.0 & 30.0 & 30.0 \\
\hline $11-20$ & 0.0 & 0.0 & 0.0 & 5.7 & 15.5 & 21.9 & 30.0 & 30.0 & 30.0 & 30.0 & 30.0 \\
\hline $21-30$ & 0.0 & 0.0 & 0.0 & 10.1 & 16.1 & 19.7 & 28.7 & 30.0 & 30.0 & 30.0 & 30.0 \\
\hline dez.1-10 & 0.0 & 0.0 & 8.0 & 29.7 & 30.0 & 30.0 & 30.0 & 30.0 & 30.0 & 30.0 & 30.0 \\
\hline $11-20$ & 0.0 & 0.0 & 22.3 & 30.0 & 30.0 & 30.0 & 30.0 & 30.0 & 30.0 & 30.0 & 30.0 \\
\hline $21-31$ & 0.0 & 0.0 & 22.8 & 30.0 & 30.0 & 30.0 & 30.0 & 30.0 & 30.0 & 30.0 & 30.0 \\
\hline
\end{tabular}


TABELA O4 - CAMPINAS: DEFICITES (BALAMCO COM AFD = 30 a)

DECIL

\begin{tabular}{|c|c|c|c|c|c|c|c|c|c|c|c|}
\hline DECENDIO & MIN. & 1 & 2 & $\mathfrak{3}$ & 4 & 5 & 6 & 7 & 8 & 9 & 10 \\
\hline jan.1-10 & 0.0 & 0.0 & 0.0 & 0.0 & 0.0 & 0.0 & 0.0 & 0.0 & 0.0 & 0.0 & 8.1 \\
\hline $11-20$ & 0.0 & 0.0 & 0.0 & 0.0 & 0.0 & 0.0 & 0.0 & 0.0 & 0.0 & 0.0 & 22.3 \\
\hline $21-31$ & 0.0 & 0.0 & 0.0 & 0.0 & 0.0 & 0.0 & 0.0 & 0.0 & 0.0 & 0.0 & 15.6 \\
\hline fev. $1-10$ & 0.0 & 0.0 & 0.0 & 0.0 & 0.0 & 0.0 & 0.0 & 0.0 & 0.0 & 0.0 & 21.3 \\
\hline $11-20$ & 0.0 & 0.0 & 0.0 & 0.0 & 0.0 & 0.0 & 0.0 & 0.0 & 0.0 & 4.0 & 25.5 \\
\hline $21-28$ & 0.0 & 0.0 & 0.0 & 0.0 & 0.0 & 0.0 & 0.0 & 0.0 & 0.0 & 6.7 & 18.0 \\
\hline adr.1-10 & 0.0 & 0.0 & 0.0 & 0.0 & 0.0 & 0.0 & 0.0 & 0.0 & 0.0 & 0.0 & 13.1 \\
\hline $11-20$ & 0.0 & 0.0 & 0.0 & 0.0 & 0.0 & 0.0 & 0.0 & 2.3 & 5.3 & 17.2 & 23.2 \\
\hline $21-31$ & 0.0 & 0.0 & 0.0 & 0.0 & 0.0 & 0.0 & 0.0 & 0.0 & 10.4 & 18.3 & 29.7 \\
\hline $2 b r .1-10$ & 0.0 & 0.0 & 0.0 & 0.0 & 0.0 & 0.0 & 0.0 & 0.0 & 0.0 & 10.1 & 27.9 \\
\hline $11-20$ & 0.0 & 0.0 & 0.0 & 0.0 & 0.0 & 0.0 & 0.0 & 0.0 & 5.9 & 8.8 & 20.3 \\
\hline $21-30$ & 0.0 & 0.0 & 0.0 & 0.0 & 0.0 & 2.8 & 10.6 & 12.3 & 16.3 & 21.6 & 26.0 \\
\hline aj.1-10 & 0.0 & 0.0 & 0.0 & 0.0 & 0.0 & 0.0 & 0.0 & 7.7 & 11.4 & 20.8 & 24.9 \\
\hline$\therefore 11-20$ & 0.0 & 0.0 & 0.0 & 0.0 & 0.0 & 0.0 & 0.0 & 8.2 & 20.4 & 21.9 & 24.8 \\
\hline $21-31$ & 0.0 & 0.0 & 0.0 & 0.0 & 0.0 & 0.0 & 10.1 & 15.8 & 19.7 & 21.8 & 25.9 \\
\hline jun.1-10 & 0.0 & 0.0 & 0.0 & 0.0 & 0.0 & 0.7 & 2.6 & 14.2 & 16.7 & 21.7 & 24.2 \\
\hline $11-20$ & 0.0 & 0.0 & 0.0 & 0.0 & 0.0 & 3.4 & 8.5 & 11.0 & 17.5 & 21.0 & 23.5 \\
\hline $21-30$ & 0.0 & 0.0 & 0.0 & 0.0 & 0.0 & 2.8 & 6.4 & 20.6 & 22.3 & 23.0 & 24.3 \\
\hline jul. $1-10$ & 0.0 & 0.0 & 0.0 & 0.0 & 0.0 & 10.9 & 17.6 & 20.9 & 22.3 & 24.4 & 26.6 \\
\hline $11-20$ & 0.0 & 0.0 & 0.0 & 2.5 & 9.5 & 13.3 & 17.7 & 22.2 & 24.5 & 25.9 & 28.0 \\
\hline $21-31$ & 0.0 & 0.0 & 0.5 & 8.9 & 15.6 & 20.7 & 23.0 & 24.9 & 27.0 & 30.4 & 32.5 \\
\hline $290.1-10$ & 0.0 & 0.0 & 0.0 & 5.4 & 14.1 & 18.9 & 23.4 & 26.9 & 27.6 & 28.3 & 31.2 \\
\hline $11-20$ & 0.0 & 0.0 & 7.4 & 11.2 & 15.0 & 18.2 & 22.4 & 25.2 & 27.0 & 28.7 & 32.8 \\
\hline $21-31$ & 0.0 & 0.0 & 0.0 & 0.9 & 13.1 & 20.8 & 30.6 & 31.9 & 32.8 & 33.7 & 39.0 \\
\hline set. $1-10$ & 0.0 & 0.0 & 0.0 & 0.0 & 0.0 & 7.0 & 17.1 & 27.6 & 30.8 & 33.7 & 38.8 \\
\hline $11-20$ & 0.0 & 0.0 & 0.0 & 1.1 & 5.6 & 19.9 & 28.4 & 32.1 & 33.9 & 35.9 & 38.0 \\
\hline $21-30$ & 0.0 & 0.0 & 0.0 & 0.0 & 0.0 & 0.0 & 14.8 & 19.5 & 25.9 & 31.3 & 38.7 \\
\hline out.1-10 & 0.0 & 0.0 & 0.0 & 0.0 & 0.0 & 0.0 & 4.0 & 15.1 & 36.3 & 45.5 & 16.6 \\
\hline $11-20$ & 0.0 & 0.0 & 0.0 & 0.0 & 0.0 & 0.0 & 0.0 & 3.8 & 13.1 & 31.8 & 49.6 \\
\hline $21-31$ & 0.0 & 0.0 & 0.0 & 0.0 & 0.0 & 0.0 & 0.0 & 5.3 & 19.1 & 33.9 & 54.2 \\
\hline nov. $1-10$ & 0.0 & 0.0 & 0.0 & 0.0 & 0.0 & 0.0 & 0.0 & 0.0 & 11.2 & 19.7 & 35.0 \\
\hline $11-20$ & 0.0 & 0.0 & 0.0 & 0.0 & 0.0 & 0.0 & 0.0 & 0.0 & 2.7 & 10.8 & 42.0 \\
\hline $21-30$ & 0.0 & 0.0 & 0.0 & 0.0 & 0.0 & 0.0 & 0.0 & 0.0 & 0.0 & 13.7 & 27.6 \\
\hline dez.1-10 & 0.0 & 0.0 & 0.0 & 0.0 & 0.0 & 0.0 & 0.0 & 0.0 & 0.0 & 1.9 & 24.9 \\
\hline $11-20$ & 0.0 & 0.0 & 0.0 & 0.0 & 0.0 & 0.0 & 0.0 & 0.0 & 0.0 & 0.9 & 33.6 \\
\hline $21-31$ & 0.0 & 0.0 & 0.0 & 0.0 & 0.0 & 0.0 & 0.0 & 0.0 & 0.0 & 0.0 & 47.1 \\
\hline
\end{tabular}


TABELA O5 - CAMPINAS: EXCEDENTES HIDRICOS (BALANCO COH AFD = 30

DECIL

\begin{tabular}{|c|c|c|c|c|c|c|c|c|c|c|c|}
\hline & & 1 & 2 & 3 & 4 & 5 & 6 & 7 & $B$ & 9 & 10 \\
\hline jan. $1-10$ & 0.0 & 0.0 & 0.0 & 8.1 & 17.3 & 40.0 & 69.9 & 74.9 & 95.4 & 105.6 & 148.5 \\
\hline $11-20$ & 0.0 & 0.0 & 0.0 & 0.0 & 19.4 & 30.0 & 43.0 & 59.3 & 74.2 & 97.9 & 260.6 \\
\hline $21-31$ & 0.0 & 0.0 & 0.0 & 7.1 & 10.0 & 14.7 & 33.5 & 48.8 & 102.3 & 154.3 & 174.2 \\
\hline fev. $1-10$ & 0.0 & 0.0 & 0.0 & 0.0 & 16.5 & 21.4 & 35.5 & 78.8 & 93.6 & 123.8 & 142.6 \\
\hline $11-20$ & 0.0 & 0.0 & 0.0 & 0.0 & 1.8 & 14.2 & 25.3 & 42.2 & 57.6 & 87.9 & 312.6 \\
\hline $21-28$ & 0.0 & 0.0 & 0.0 & 0.0 & 5.1 & 13.9 & 24.5 & 36.5 & 59.4 & 72.3 & 163.0 \\
\hline ar. $1-10$ & 0.0 & 0.0 & 0.0 & 0.0 & 0.0 & 0.0 & 8.6 & 21.1 & 39.9 & 82.5 & 143.1 \\
\hline $11-20$ & 0.0 & 0.0 & 0.0 & 0.0 & 0.0 & 0.0 & 3.1 & 11.3 & 50.7 & 100.6 & 165.0 \\
\hline $21-31$ & 0.0 & 0.0 & 0.0 & 0.0 & 0.0 & 0.0 & 0.0 & 7.7 & 19.9 & 37.4 & 71.2 \\
\hline $2 b r .1-10$ & 0.0 & 0.0 & 0.0 & 0.0 & 0.0 & 0.0 & 0.0 & 6.3 & 10.2 & 21.4 & 75.1 \\
\hline $11-20$ & 0.0 & 0.0 & 0.0 & 0.0 & 0.0 & 0.0 & 0.0 & 3.0 & 19.6 & 31.2 & 64.0 \\
\hline $21-30$ & 0.0 & 0.0 & 0.0 & 0.0 & 0.0 & 0.0 & 0.0 & 0.0 & 0.0 & 1.2 & 58.7 \\
\hline tai. $1-10$ & 0.0 & 0.0 & 0.0 & 0.0 & 0.0 & 0.0 & 0.0 & 0.0 & 3.1 & 23.8 & 50.1 \\
\hline $11-20$ & 0.0 & 0.0 & 0.0 & 0.0 & 0.0 & 0.0 & 0.0 & 0.0 & 2.7 & 29.1 & 93.2 \\
\hline $21-31$ & 0.0 & 0.0 & 0.0 & 0.0 & 0.0 & 0.0 & 0.0 & 0.0 & 0.0 & 41.5 & 206.3 \\
\hline jun. $1-10$ & 0.0 & 0.0 & 0.0 & 0.0 & 0.0 & 0.0 & 0.0 & 0.0 & 0.0 & 0.0 & 148.4 \\
\hline $11-20$ & 0.0 & 0.0 & 0.0 & 0.0 & 0.0 & 0.0 & 0.0 & 0.0 & 1.5 & 26.3 & 67.4 \\
\hline $21-30$ & 0.0 & 0.0 & 0.0 & 0.0 & 0.0 & 0.0 & 0.0 & 0.0 & 0.0 & 16.4 & 65.3 \\
\hline jul.1-10 & 0.0 & 0.0 & 0.0 & 0.0 & 0.0 & 0.0 & 0.0 & 0.0 & 0.0 & 0.0 & 96.2 \\
\hline $11-20$ & 0.0 & 0.0 & 0.0 & 0.0 & 0.0 & 0.0 & 0.0 & 0.0 & 0.0 & 0.0 & 45.2 \\
\hline $21-31$ & 0.0 & 0.0 & 0.0 & 0.0 & 0.0 & 0.0 & 0.0 & 0.0 & 0.0 & 0.0 & 87.1 \\
\hline $290.1-10$ & 0.0 & 0.0 & 0.0 & 0.0 & 0.0 & 0.0 & 0.0 & 0.0 & 0.0 & 0.0 & 27.9 \\
\hline $11-20$ & 0.0 & 0.0 & 0.0 & 0.0 & 0.0 & 0.0 & 0.0 & 0.0 & 0.0 & 0.0 & 36.9 \\
\hline $21-31$ & 0.0 & 0.0 & 0.0 & 0.0 & 0.0 & 0.0 & 0.0 & 0.0 & 0.0 & 0.0 & 78.6 \\
\hline set. $1-10$ & 0.0 & 0.0 & 0.0 & 0.0 & 0.0 & 0.0 & 0.0 & 0.0 & 0.0 & 12.4 & 38.4 \\
\hline $11-20$ & 0.0 & 0.0 & 0.0 & 0.0 & 0.0 & 0.0 & 0.0 & 0.0 & 0.0 & 17.9 & 86.7 \\
\hline $21-30$ & 0.0 & 0.0 & 0.0 & 0.0 & 0.0 & 0.0 & 0.0 & 0.0 & 0.0 & 11.5 & 43.9 \\
\hline out.1-10 & 0.0 & 0.0 & 0.0 & 0.0 & 0.0 & 0.0 & 0.0 & 11.5 & 20.5 & 33.1 & 70.0 \\
\hline $11-20$ & 0.0 & 0.0 & 0.0 & 0.0 & 0.0 & 0.0 & 0.0 & 0.0 & 10.2 & 36.9 & 71.3 \\
\hline $21-31$ & 0.0 & 0.0 & 0.0 & 0.0 & 0.0 & 0.0 & 0.0 & 15.0 & 40.4 & 57.2 & 105.3 \\
\hline nov. $1-10$ & 0.0 & 0.0 & 0.0 & 0.0 & 0.0 & 0.0 & 0.0 & 5.7 & 12.5 & 32.1 & 40.7 \\
\hline $11-20$ & 0.0 & 0.0 & 0.0 & 0.0 & 0.0 & 0.0 & 1.4 & 8.1 & 34.0 & 52.8 & 97.7 \\
\hline $21-30$ & 0.0 & 0.0 & 0.0 & 0.0 & 0.0 & 0.0 & 0.0 & 14.1 & 27.6 & 63.1 & 132.7 \\
\hline $\operatorname{dez} .1-10$ & 0.0 & 0.0 & 0.0 & 0.0 & 13.8 & 30.8 & 35.9 & 41.1 & 66.6 & 95.5 & 115.7 \\
\hline $11-20$ & 0.0 & 0.0 & 0.0 & 4.1 & 6.3 & 18.7 & 37.1 & 47.4 & 70.2 & 100.9 & 206.3 \\
\hline $21-31$ & 0.0 & 0.0 & 0.0 & 5.2 & 28.3 & 32.4 & 54.2 & 67.3 & 88.1 & 129.1 & 162.9 \\
\hline
\end{tabular}


TABELA Ob - CAMPINAS: AGUA FACILFENTE DISPONIVEL (BALAHCO COM AFD $=40$ )

DECIL

\begin{tabular}{|c|c|c|c|c|c|c|c|c|c|c|c|}
\hline DECEHDIO & MIN. & 1 & 2 & 3 & 4 & 5 & 6 & 7 & 8 & 9 & 10 \\
\hline jan.1-10 & 0.0 & 10.9 & 35.8 & 40.0 & 40.0 & 40.0 & 40.0 & 40.0 & 40.0 & 40.0 & 40.0 \\
\hline $11-20$ & 0.0 & 5.3 & 21.0 & 36.0 & 40.0 & 40.0 & 40.0 & 40.0 & 40.0 & 40.0 & 40.0 \\
\hline $21-31$ & 0.0 & 2.2 & 26.9 & 39.4 & 40.0 & $\$ 0.0$ & 40.0 & 40.0 & 40.0 & 40.0 & 40.0 \\
\hline fev. $1-10$ & 0.0 & 11.2 & 15.2 & 32.7 & 40.0 & 40.0 & 40.0 & 40.0 & 40.0 & 40.0 & 40.0 \\
\hline $11-20$ & 0.0 & 2.3 & 11.8 & 28.2 & 40.0 & 40.0 & 40.0 & 40.0 & 40.0 & 40.0 & 40.0 \\
\hline $21-28$ & 0.0 & 0.0 & 15.3 & 21.9 & 40.0 & 40.0 & 40.0 & 40.0 & 40.0 & 40.0 & 40.0 \\
\hline tar. $1-10$ & 0.0 & 9.2 & 18.1 & 21.8 & 27.8 & 32.3 & 40.0 & 40.0 & 40.0 & 40.0 & 40.0 \\
\hline $11-20$ & 0.0 & 0.0 & 0.0 & 7.4 & 19.6 & 28.1 & 39.5 & 40.0 & 40.0 & 40.0 & 40.0 \\
\hline $21-31$ & 0.0 & 0.0 & 0.0 & 8.1 & 17.8 & 24.7 & 39.5 & 40.0 & 40.0 & 40.0 & 40.0 \\
\hline abr. $1-10$ & 0.0 & 0.0 & 1.1 & 12.0 & 19.9 & 28.2 & 32.0 & 40.0 & 80.0 & 40.0 & 40.0 \\
\hline $11-20$ & 0.0 & 0.0 & 1.2 & 4.1 & 13.2 & 16.9 & 23.6 & 40.0 & 40.0 & 40.0 & 40.0 \\
\hline $21-30$ & 0.0 & 0.0 & 0.0 & 0.0 & 0.0 & 0.0 & 17.0 & 28.5 & 31.1 & 36.4 & 40.0 \\
\hline ai. $1-10$ & 0.0 & 0.0 & 0.0 & 0.0 & 0.0 & 7.3 & 11.1 & 25.9 & 40.0 & 40.0 & 40.0 \\
\hline$\therefore 11-20$ & 0.0 & 0.0 & 0.0 & 0.0 & 2.2 & 18.1 & 19.7 & 29.2 & 38.2 & 40.0 & 40.0 \\
\hline $21-31$ & 0.0 & 0.0 & 0.0 & 0.0 & 0.0 & 4.6 & 18.5 & 26.5 & 30.6 & 40.0 & 40.0 \\
\hline jun. $1-10$ & 0.0 & 0.0 & 0.0 & 0.0 & 0.0 & 1.6 & 7.6 & 18.2 & 21.9 & 35.2 & 40.0 \\
\hline $11-20$ & 0.0 & 0.0 & 0.0 & 0.0 & 0.0 & 0.0 & 16.3 & 21.7 & 31.5 & 10.0 & 40.0 \\
\hline $21-30$ & 0.0 & 0.0 & 0.0 & 0.0 & 0.0 & 0.0 & 7.2 & 12.0 & 19.8 & 40.0 & 40.0 \\
\hline jul. $1-10$ & 0.0 & 0.0 & 0.0 & 0.0 & 0.0 & 0.0 & 5.3 & 11.8 & 18.8 & 26.6 & 40.0 \\
\hline $11-20$ & 0.0 & 0.0 & 0.0 & 0.0 & 0.0 & 0.0 & 0.0 & 0.0 & 0.0 & 19.7 & 40.0 \\
\hline $2|-3|$ & 0.0 & 0.0 & 0.0 & 0.0 & 0.0 & 0.0 & 0.0 & 0.0 & 0.0 & 20.3 & 40.0 \\
\hline ago.1-10 & 0.0 & 0.0 & 0.0 & 0.0 & 0.0 & 0.0 & 0.0 & 0.0 & 9.3 & 14.2 & 40.0 \\
\hline $11-20$ & 0.0 & 0.0 & 0.0 & 0.0 & 0.0 & 0.0 & 0.0 & 0.0 & 0.0 & 17.9 & 40.0 \\
\hline $21-31$ & 0.0 & 0.0 & 0.0 & 0.0 & 0.0 & 0.0 & 0.0 & 0.0 & 6.0 & 28.5 & 40.0 \\
\hline set. $1-10$ & 0.0 & 0.0 & 0.0 & 0.0 & 0.0 & 0.0 & 3.6 & 11.5 & 22.9 & 40.0 & 40.0 \\
\hline $11-20$ & 0.0 & 0.0 & 0.0 & 0.0 & 0.0 & 0.0 & 0.0 & 0.0 & 8.8 & 40.0 & 40.0 \\
\hline $21-30$ & 0.0 & 0.0 & 0.0 & 0.0 & 0.0 & 0.6 & 8.6 & 20.1 & 32.5 & 40.0 & 40.0 \\
\hline out. $1-10$ & 0.0 & 0.0 & 0.0 & 0.0 & 0.0 & 6.4 & 27.0 & 40.0 & 40.0 & 40.0 & 40.0 \\
\hline $11-20$ & 0.0 & 0.0 & 0.0 & 0.0 & 6.2 & 19.2 & 22.4 & 32.1 & 40.0 & 40.0 & 40.0 \\
\hline $21-31$ & 0.0 & 0.0 & 0.0 & 0.0 & 13.3 & 28.5 & 36.7 & 40.0 & 40.0 & 10.0 & 40.0 \\
\hline nov. $1-10$ & 0.0 & 0.0 & 0.0 & 0.0 & 21.8 & 28.0 & 32.3 & 40.0 & 40.0 & 40.0 & 40.0 \\
\hline $11-20$ & 0.0 & 0.0 & 2.9 & 11.2 & 17.7 & 31.5 & 39.6 & 40.0 & 40.0 & 40.0 & 40.0 \\
\hline $21-30$ & 0.0 & 0.0 & 2.7 & 10.1 & 22.4 & 29.2 & 38.7 & 40.0 & 40.0 & 40.0 & 40.0 \\
\hline dez. $1-10$ & 0.0 & 0.0 & 8.8 & 37.1 & 40.0 & 40.0 & 40.0 & 40.0 & 40.0 & 40.0 & 40.0 \\
\hline $11-20$ & 0.0 & 0.7 & 32.3 & 37.5 & 40.0 & 40.0 & 40.0 & 40.0 & 40.0 & 40.0 & 40.0 \\
\hline $21-31$ & 0.0 & 6.7 & 32.8 & 40.0 & 40.0 & 40.0 & 40.0 & 40.0 & 40.0 & 10.0 & 40.0 \\
\hline
\end{tabular}


TABELA 07 - CAMPINAS: DEFICITES (BALANCO COH AFD = 40 an)

DECIL

\begin{tabular}{|c|c|c|c|c|c|c|c|c|c|c|c|}
\hline DECENDIO & MIN. & 1 & 2 & 3 & 4 & 5 & 6 & 7 & 8 & 9 & 10 \\
\hline jan.1-10 & 0.0 & 0.0 & 0.0 & 0.0 & 0.0 & 0.0 & 0.0 & 0.0 & 0.0 & 0.0 & 7.4 \\
\hline $11-20$ & 0.0 & 0.0 & 0.0 & 0.0 & 0.0 & 0.0 & 0.0 & 0.0 & 0.0 & 0.0 & 22.3 \\
\hline $21-31$ & 0.0 & 0.0 & 0.0 & 0.0 & 0.0 & 0.0 & 0.0 & 0.0 & 0.0 & 0.0 & 5.6 \\
\hline fev. $1-10$ & 0.0 & 0.0 & 0.0 & 0.0 & 0.0 & 0.0 & 0.0 & 0.0 & 0.0 & 0.0 & 21.3 \\
\hline $11-20$ & 0.0 & 0.0 & 0.0 & 0.0 & 0.0 & 0.0 & 0.0 & 0.0 & 0.0 & 0.0 & 15.5 \\
\hline $21-28$ & 0.0 & 0.0 & 0.0 & 0.0 & 0.0 & 0.0 & 0.0 & 0.0 & 0.0 & 4.7 & 12.0 \\
\hline $\operatorname{lar}=1-10$ & 0.0 & 0.0 & 0.0 & 0.0 & 0.0 & 0.0 & 0.0 & 0.0 & 0.0 & 0.0 & 3.1 \\
\hline $11-20$ & 0.0 & 0.0 & 0.0 & 0.0 & 0.0 & 0.0 & 0.0 & 0.0 & 0.0 & 9.0 & 17.9 \\
\hline $21-31$ & 0.0 & 0.0 & 0.0 & 0.0 & 0.0 & 0.0 & 0.0 & 0.0 & 0.4 & 11.0 & 25.1 \\
\hline$a b r .1-20$ & 0.0 & 0.0 & 0.0 & 0.0 & 0.0 & 0.0 & 0.0 & 0.0 & 0.0 & 10.1 & 27.9 \\
\hline $11-20$ & 0.0 & 0.0 & 0.0 & 0.0 & 0.0 & 0.0 & 0.0 & 0.0 & 0.0 & 2.6 & 20.3 \\
\hline $21-30$ & 0.0 & 0.0 & 0.0 & 0.0 & 0.0 & 0.2 & 4.8 & 7.6 & 12.0 & 15.7 & 26.0 \\
\hline ai. $1-10$ & 0.0 & 0.0 & 0.0 & 0.0 & 0.0 & 0.0 & 0.0 & 5.8 & 8.7 & 20.8 & 24.9 \\
\hline $11-20$ & 0.0 & 0.0 & 0.0 & 0.0 & 0.0 & 0.0 & 0.0 & 6.1 & 20.4 & 21.9 & 24.8 \\
\hline $21-31$ & 0.0 & 0.0 & 0.0 & 0.0 & 0.0 & 0.0 & 0.1 & 11.9 & 19.7 & 21.8 & 25.9 \\
\hline jun. $1-10$ & 0.0 & 0.0 & 0.0 & 0.0 & 0.0 & 0.0 & 0.7 & 5.4 & 16.7 & 21.7 & 24.2 \\
\hline $11-20$ & 0.0 & 0.0 & 0.0 & 0.0 & 0.0 & 0.0 & 5.1 & 10.4 & 13.7 & 21.0 & 23.5 \\
\hline $21-30$ & 0.0 & 0.0 & 0.0 & 0.0 & 0.0 & 1.1 & 5.6 & 16.8 & 21.8 & 23.0 & 24.3 \\
\hline jul. $1-10$ & 0.0 & 0.0 & 0.0 & 0.0 & 0.0 & 4.0 & 16.4 & 18.6 & 21.1 & 24.2 & 26.1 \\
\hline $11-20$ & 0.0 & 0.0 & 0.0 & 2.4 & 3.1 & 9.5 & 13.3 & 22.0 & 24.5 & 25.9 & 28.0 \\
\hline $21-31$ & 0.0 & 0.0 & 0.0 & 1.6 & 14.5 & 20.7 & 23.0 & 24.9 & 27.0 & 30.1 & 32.5 \\
\hline ago. $1-10$ & 0.0 & 0.0 & 0.0 & 5.4 & 13.9 & .18 .9 & 23.4 & 26.9 & 27.6 & 28.3 & 31.2 \\
\hline $11-20$ & 0.0 & 0.0 & $\$ .1$ & 11.2 & 12.7 & 16.7 & 19.5 & 25.2 & 27.0 & 28.7 & 32.8 \\
\hline $21-31$ & 0.0 & 0.0 & 0.0 & 0.9 & 13.1 & 20.8 & 30.8 & 31.9 & 32.8 & 33.7 & 39.0 \\
\hline set. $1-10$ & 0.0 & 0.0 & 0.0 & 0.0 & 0.0 & 7.0 & 17.1 & 27.6 & 30.8 & 33.7 & 38.8 \\
\hline $11-20$ & 0.0 & 0.0 & 0.0 & 0.0 & 5.6 & 17.9 & 27.9 & 31.6 & 33.7 & 35.9 & 38.0 \\
\hline $21-30$ & 0.0 & 0.0 & 0.0 & 0.0 & 0.0 & 0.0 & 14.8 & 19.5 & 25.9 & 31.3 & 38.7 \\
\hline out. $1-10$ & 0.0 & 0.0 & 0.0 & 0.0 & 0.0 & 0.0 & 0.0 & 15.1 & 33.5 & 45.5 & 46.6 \\
\hline $11-20$ & 0.0 & 0.0 & 0.0 & 0.0 & 0.0 & 0.0 & 0.0 & 0.8 & 13.1 & 31.8 & 19.6 \\
\hline $21-31$ & 0.0 & 0.0 & 0.0 & 0.0 & 0.0 & 0.0 & 0.0 & 5.3 & 19.1 & 33.9 & 54.2 \\
\hline noy. $1-10$ & 0.0 & 0.0 & 0.0 & 0.0 & 0.0 & 0.0 & 0.0 & 0.0 & 2.2 & 19.7 & 35.0 \\
\hline $11-20$ & 0.0 & 0.0 & 0.0 & 0.0 & 0.0 & 0.0 & 0.0 & 0.0 & 0.0 & 10.8 & 42.0 \\
\hline $21-30$ & 0.0 & 0.0 & 0.0 & 0.0 & 0.0 & 0.0 & 0.0 & 0.0 & 0.0 & 3.7 & 27.6 \\
\hline dez.1-10 & 0.0 & 0.0 & 0.0 & 0.0 & 0.0 & 0.0 & 0.0 & 0.0 & 0.0 & 0.0 & 16.9 \\
\hline $11-20$ & 0.0 & 0.0 & 0.0 & 0.0 & 0.0 & 0.0 & 0.0 & 0.0 & 0.0 & 0.0 & 32.1 \\
\hline $21-31$ & 0.0 & 0.0 & 0.0 & 0.0 & 0.0 & 0.0 & 0.0 & 0.0 & 0.0 & 0.0 & 38.0 \\
\hline
\end{tabular}


TABELA OB - CAMPINAS: EXCEDENTES HIDRICOS (BALAKCO COH AFD = 40 -

DECIL

\begin{tabular}{|c|c|c|c|c|c|c|c|c|c|c|c|}
\hline DECENDIO & MIII. & 1 & 2 & 3 & 4 & 5 & 6 & 7 & 8 & 9 & 10 \\
\hline jan.1-10 & 0.0 & 0.0 & 0.0 & 8.1 & 17.3 & 40.0 & 69.9 & 74.9 & 95.4 & 105.6 & 148.5 \\
\hline $11-20$ & 0.0 & 0.0 & 0.0 & 0.0 & 19.4 & 30.0 & 43.0 & 59.3 & 74.2 & 97.9 & 260.6 \\
\hline $21-31$ & 0.0 & 0.0 & 0.0 & 0.0 & 7.3 & 14.7 & 23.5 & 48.8 & 102.3 & 154.3 & 174.2 \\
\hline fev. $1-10$ & 0.0 & 0.0 & 0.0 & 0.0 & 16.5 & 21.4 & 35.5 & 78.8 & 93.6 & 123.8 & 142.6 \\
\hline $11-20$ & 0.0 & 0.0 & 0.0 & 0.0 & 1.8 & 14.2 & 25.3 & 42.2 & 57.6 & 87.9 & 312.6 \\
\hline $21-28$ & 0.0 & 0.0 & 0.0 & 0.0 & 1.6 & 13.9 & 24.5 & 36.5 & 59.4 & 64.5 & 163.0 \\
\hline ar. $1-10$ & 0.0 & 0.0 & 0.0 & 0.0 & 0.0 & 0.0 & 8.6 & 21.1 & 39.6 & 82.5 & 143.1 \\
\hline $11-20$ & 0.0 & 0.0 & 0.0 & 0.0 & 0.0 & 0.0 & 0.0 & 11.3 & 50.7 & 100.6 & 165.0 \\
\hline $21-31$ & 0.0 & 0.0 & 0.0 & 0.0 & 0.0 & 0.0 & 0.0 & 6.2 & 12.6 & 37.4 & 70.9 \\
\hline abr. $1-10$ & 0.0 & 0.0 & 0.0 & 0.0 & 0.0 & 0.0 & 0.0 & 5.9 & 0.7 & 21.4 & 75.1 \\
\hline $11-20$ & 0.0 & 0.0 & 0.0 & 0.0 & 0.0 & 0.0 & 0.0 & 3.0 & 19.6 & 31.2 & 63.8 \\
\hline $21-30$ & 0.0 & 0.0 & 0.0 & 0.0 & 0.0 & 0.0 & 0.0 & 0.0 & 0.0 & 0.0 & 58.7 \\
\hline ai. $1-10$ & 0.0 & 0.0 & 0.0 & 0.0 & 0.0 & 0.0 & 0.0 & 0.0 & 3.1 & 13.8 & 50.1 \\
\hline $11-20$ & 0.0 & 0.0 & 0.0 & 0.0 & 0.0 & 0.0 & 0.0 & 0.0 & 0.0 & 29.1 & 93.2 \\
\hline $21-31$ & 0.0 & 0.0 & 0.0 & 0.0 & 0.0 & 0.0 & 0.0 & 0.0 & 0.0 & 41.5 & 206.3 \\
\hline jun. $1-10$ & 0.0 & 0.0 & 0.0 & 0.0 & 0.0 & 0.0 & 0.0 & 0.0 & 0.0 & 0.0 & 148.4 \\
\hline $11-20$ & 0.0 & 0.0 & 0.0 & 0.0 & 0.0 & 0.0 & 0.0 & 0.0 & 0.0 & 19.1 & 58.8 \\
\hline $21-30$ & 0.0 & 0.0 & 0.0 & 0.0 & 0.0 & 0.0 & 0.0 & 0.0 & 0.0 & 8.6 & 65.3 \\
\hline jul.1-10 & 0.0 & 0.0 & 0.0 & 0.0 & 0.0 & 0.0 & 0.0 & 0.0 & 0.0 & 0.0 & 96.2 \\
\hline $11-20$ & 0.0 & 0.0 & 0.0 & 0.0 & 0.0 & 0.0 & 0.0 & 0.0 & 0.0 & 0.0 & 35.2 \\
\hline $21-31$ & 0.0 & 0.0 & 0.0 & 0.0 & 0.0 & 0.0 & 0.0 & 0.0 & 0.0 & 0.0 & 77.1 \\
\hline ago.1-10 & 0.0 & 0.0 & 0.0 & 0.0 & 0.0 & 0.0 & 0.0 & 0.0 & 0.0 & 0.0 & 27.9 \\
\hline $11-20$ & 0.0 & 0.0 & 0.0 & 0.0 & 0.0 & 0.0 & 0.0 & 0.0 & 0.0 & 0.0 & 26.9 \\
\hline $21-31$ & 0.0 & 0.0 & 0.0 & 0.0 & 0.0 & 0.0 & 0.0 & 0.0 & 0.0 & 0.0 & 68.6 \\
\hline set. $1-10$ & 0.0 & 0.0 & 0.0 & 0.0 & 0.0 & 0.0 & 0.0 & 0.0 & 0.0 & 2.5 & 28.4 \\
\hline $11-20$ & 0.0 & 0.0 & 0.0 & 0.0 & 0.0 & 0.0 & 0.0 & 0.0 & 0.0 & 12.1 & 86.7 \\
\hline $21-30$ & 0.0 & 0.0 & 0.0 & 0.0 & 0.0 & 0.0 & 0.0 & 0.0 & 0.0 & 6.5 & 43.9 \\
\hline out. $1-10$ & 0.0 & 0.0 & 0.0 & 0.0 & 0.0 & 0.0 & 0.0 & 1.5 & 19.8 & 33.1 & 70.0 \\
\hline $11-20$ & 0.0 & 0.0 & 0.0 & 0.0 & 0.0 & 0.0 & 0.0 & 0.0 & 9.1 & 36.9 & 67.5 \\
\hline $21-31$ & 0.0 & 0.0 & 0.0 & 0.0 & 0.0 & 0.0 & 0.0 & 9.6 & 30.4 & 57.2 & 105.3 \\
\hline nov. $1-10$ & 0.0 & 0.0 & 0.0 & 0.0 & 0.0 & 0.0 & 0.0 & 2.5 & 7.7 & 26.5 & 34.5 \\
\hline $11-20$ & 0.0 & 0.0 & 0.0 & 0.0 & 0.0 & 0.0 & 0.0 & 8.1 & 26.9 & 52.8 & 97.7 \\
\hline $21-30$ & 0.0 & 0.0 & 0.0 & 0.0 & 0.0 & 0.0 & 0.0 & 13.3 & 26.2 & 61.1 & 132.7 \\
\hline de2.1-10 & 0.0 & 0.0 & 0.0 & 0.0 & 13.8 & 20.9 & 35.9 & 41.1 & 66.6 & 99.5 & 115.7 \\
\hline $11-20$ & 0.0 & 0.0 & 0.0 & 0.0 & 8.3 & 18.7 & 37.1 & 47.4 & 68.0 & 100.9 & 196.3 \\
\hline $21-31$ & 0.0 & 0.0 & 0.0 & 5.2 & 28.3 & 32.4 & 54.2 & 61.4 & 88.1 & 129.1 & 162.9 \\
\hline
\end{tabular}


TABELA O9 - CAMPIHAS: AGUA FACILMENTE DISPONIVEL (BALAHCO COM AFD $=50$ a)

DECIL

\begin{tabular}{|c|c|c|c|c|c|c|c|c|c|c|c|}
\hline DECENDID & HIN. & 1 & 2 & 3 & 4 & 5 & 6 & 7 & 8 & 9 & 10 \\
\hline jan. $1-10$ & 2.6 & 10.9 & 45.8 & 50.0 & 50.0 & 50.0 & 50.0 & 50.0 & 50.0 & 50.0 & 50.0 \\
\hline $11-20$ & 0.0 & 15.3 & 23.4 & 46.0 & 50.0 & 50.0 & 50.0 & 50.0 & 50.0 & 50.0 & 50.0 \\
\hline $21-31$ & 4.4 & 12.2 & 36.9 & 45.4 & 50.0 & 50.0 & 50.0 & 50.0 & 50.0 & 50.0 & 50.0 \\
\hline fev. $1-10$ & 0.0 & 21.2 & 25.2 & 42.7 & 50.0 & 50.0 & 50.0 & 50.0 & 50.0 & 50.0 & 50.0 \\
\hline $11-20$ & 0.0 & 12.3 & 21.8 & 38.2 & 50.0 & 50.0 & 50.0 & 50.0 & 50.0 & 50.0 & 50.0 \\
\hline $21-28$ & 0.0 & 0.0 & 25.3 & 31.9 & 50.0 & $\$ 0.0$ & 50.0 & 50.0 & 50.0 & 50.0 & 50.0 \\
\hline ar. $1-10$ & 6.9 & 18.3 & 28.1 & 29.1 & 37.4 & 41.8 & 50.0 & 50.0 & 50.0 & 50.0 & 50.0 \\
\hline $11-20$ & 0.0 & 0.0 & 4.0 & 17.4 & 29.6 & 38.1 & 49.5 & 50.0 & 50.0 & 50.0 & 50.0 \\
\hline $21-31$ & 0.0 & 0.0 & 1.7 & 12.1 & 23.7 & 34.7 & 49.5 & 50.0 & 50.0 & 50.0 & 50.0 \\
\hline $\mathrm{abr} .1-10$ & 0.0 & 0.0 & 5.7 & 21.6 & 27.8 & 38.2 & 40.2 & 50.0 & 50.0 & 50.0 & 50.0 \\
\hline $11-20$ & 0.0 & 1.3 & 7.4 & 12.5 & 19.6 & 23.3 & 33.6 & 50.0 & 50.0 & 50.0 & 50.0 \\
\hline $21-30$ & 0.0 & 0.0 & 0.0 & 0.0 & 0.1 & 5.2 & 27.0 & 38.5 & 41.1 & 46.4 & 50.0 \\
\hline (1.1-10 & 0.0 & 0.0 & 0.0 & 0.0 & 4.2 & 12.4 & 21.1 & 35.9 & 50.0 & 50.0 & 50.0 \\
\hline$\therefore 11-20$ & 0.0 & 0.0 & 0.0 & 0.0 & 4.9 & 18.9 & 29.7 & 36.3 & 48.2 & 50.0 & 50.0 \\
\hline $21-31$ & 0.0 & 0.0 & 0.0 & 0.0 & 2.8 & 14.6 & 26.5 & 30.6 & 38.4 & 50.0 & 50.0 \\
\hline jun. $1-10$ & 0.0 & 0.0 & 0.0 & 0.0 & 0.0 & 4.6 & 17.4 & 18.2 & 28.5 & 45.2 & 50.0 \\
\hline $11-20$ & 0.0 & 0.0 & 0.0 & 0.0 & 0.0 & 9.0 & 16.3 & 31.5 & 33.1 & 50.0 & 50.0 \\
\hline $21-30$ & 0.0 & 0.0 & 0.0 & 0.0 & 0.0 & 1.1 & 12.0 & 20.9 & 29.6 & 48.6 & 50.0 \\
\hline jul. $1-10$ & 0.0 & 0.0 & 0.0 & 0.0 & 0.0 & 0.0 & 6.0 & 12.5 & 27.7 & 30.3 & 50.0 \\
\hline $11-20$ & 0.0 & 0.0 & 0.0 & 0.0 & 0.0 & 0.0 & 0.0 & 0.8 & 7.6 & 29.6 & 50.0 \\
\hline $21-31$ & 0.0 & 0.0 & 0.0 & 0.0 & 0.0 & 0.0 & 0.0 & 0.0 & 4.4 & 20.3 & 50.0 \\
\hline $2 g 0.1-10$ & 0.0 & 0.0 & 0.0 & 0.0 & 0.0 & 0.0 & 0.0 & 0.0 & 9.3 & 18.6 & 50.0 \\
\hline $11-20$ & 0.0 & 0.0 & 0.0 & 0.0 & 0.0 & 0.0 & 0.0 & 0.0 & 0.0 & 23.8 & 50.0 \\
\hline $21-31$ & 0.0 & 0.0 & 0.0 & 0.0 & 0.0 & 0.0 & 0.0 & 0.0 & 6.0 & 32.1 & 50.0 \\
\hline set. $1-10$ & 0.0 & 0.0 & 0.0 & 0.0 & 0.0 & 0.0 & 6.1 & 13.6 & 22.9 & 42.5 & 50.0 \\
\hline $11-20$ & 0.0 & 0.0 & 0.0 & 0.0 & 0.0 & 0.0 & 0.0 & 0.0 & 9.3 & 50.0 & 50.0 \\
\hline $21-30$ & 0.0 & 0.0 & 0.0 & 0.0 & 0.0 & 0.6 & 8.6 & 20.1 & 38.6 & 47.1 & 50.0 \\
\hline out.1-10 & 0.0 & 0.0 & 0.0 & 0.0 & 5.5 & 12.3 & 27.0 & 41.5 & 50.0 & 50.0 & 50.0 \\
\hline $11-20$ & 0.0 & 0.0 & 0.0 & 0.0 & 10.4 & 23.9 & 31.6 & 42.1 & 49.1 & 50.0 & 50.0 \\
\hline $21-31$ & 0.0 & 0.0 & 0.0 & 0.0 & 23.3 & 28.5 & 45.0 & 50.0 & 50.0 & 50.0 & 50.0 \\
\hline nov. $1-10$ & 0.0 & 0.0 & 0.0 & 9.3 & 28.0 & 35.2 & 42.3 & 47.7 & 50.0 & 50.0 & 50.0 \\
\hline $11-20$ & 0.0 & 0.0 & 11.2 & 20.0 & 21.9 & 41.5 & 49.6 & 50.0 & 50.0 & 50.0 & 50.0 \\
\hline $21-30$ & 0.0 & 2.7 & 10.1 & 14.8 & 32.4 & 39.2 & 48.5 & 50.0 & 50.0 & 50.0 & 50.0 \\
\hline$d e z .1-10$ & 0.0 & 5.3 & 18.8 & 47.1 & 50.0 & 50.0 & 50.0 & 50.0 & 50.0 & 50.0 & 50.0 \\
\hline $11-20$ & 0.0 & 10.7 & 34.1 & 47.5 & 50.0 & 50.0 & 50.0 & 50.0 & 50.0 & 50.0 & 50.0 \\
\hline $21-31$ & 0.0 & 16.7 & 42.8 & 50.0 & 50.0 & 50.0 & 50.0 & 50.0 & 50.0 & 50.0 & 50.0 \\
\hline
\end{tabular}


TABELA 10 - CAMPINAS: DEFICITES (BALANCO COH AFD = 50 nÂI)

DECIL

\begin{tabular}{|c|c|c|c|c|c|c|c|c|c|c|c|}
\hline DECEHDIO & HIN. & 1 & 2 & 3 & 4 & 5 & 6 & 7 & 8 & 9 & 10 \\
\hline jan.1-10 & 0.0 & 0.0 & 0.0 & 0.0 & 0.0 & 0.0 & 0.0 & 0.0 & 0.0 & 0.0 & 0.0 \\
\hline $11-20$ & 0.0 & 0.0 & 0.0 & 0.0 & 0.0 & 0.0 & 0.0 & 0.0 & 0.0 & 0.0 & 22.3 \\
\hline $21-31$ & 0.0 & 0.0 & 0.0 & 0.0 & 0.0 & 0.0 & 0.0 & 0.0 & 0.0 & 0.0 & 0.0 \\
\hline fev. $1-10$ & 0.0 & 0.0 & 0.0 & 0.0 & 0.0 & 0.0 & 0.0 & 0.0 & 0.0 & 0.0 & 16.9 \\
\hline $11-20$ & 0.0 & 0.0 & 0.0 & 0.0 & 0.0 & 0.0 & 0.0 & 0.0 & 0.0 & 0.0 & 8.0 \\
\hline $21-28$ & 0.0 & 0.0 & 0.0 & 0.0 & 0.0 & 0.0 & 0.0 & 0.0 & 0.0 & 0.0 & 10.8 \\
\hline ar. $1-10$ & 0.0 & 0.0 & 0.0 & 0.0 & 0.0 & 0.0 & 0.0 & 0.0 & 0.0 & 0.0 & 0.0 \\
\hline $11-20$ & 0.0 & 0.0 & 0.0 & 0.0 & 0.0 & 0.0 & 0.0 & 0.0 & 0.0 & 0.9 & 17.9 \\
\hline $21-31$ & 0.0 & 0.0 & 0.0 & 0.0 & 0.0 & 0.0 & 0.0 & 0.0 & 0.0 & 5.6 & 15.1 \\
\hline$a b r .1-10$ & 0.0 & 0.0 & 0.0 & 0.0 & 0.0 & 0.0 & 0.0 & 0.0 & 0.0 & 6.1 & 27.9 \\
\hline $11-20$ & 0.0 & 0.0 & 0.0 & 0.0 & 0.0 & 0.0 & 0.0 & 0.0 & 0.0 & 0.0 & 20.3 \\
\hline $21-30$ & 0.0 & 0.0 & 0.0 & 0.0 & 0.0 & 0.0 & 0.0 & 2.0 & 4.9 & 11.4 & 26.0 \\
\hline ad. $1-10$ & 0.0 & 0.0 & 0.0 & 0.0 & 0.0 & 0.0 & 0.0 & 2.9 & 7.7 & 20.8 & 24.9 \\
\hline$\quad 11-20$ & 0.0 & 0.0 & 0.0 & 0.0 & 0.0 & 0.0 & 0.0 & 1.8 & 20.4 & 21.9 & 24.8 \\
\hline $21-31$ & 0.0 & 0.0 & 0.0 & 0.0 & 0.0 & 0.0 & 0.0 & 9.5 & 15.8 & 20.3 & 25.9 \\
\hline jun. $1-10$ & 0.0 & 0.0 & 0.0 & 0.0 & 0.0 & 0.0 & 0.0 & 2.3 & 13.1 & 18.1 & 24.2 \\
\hline $11-20$ & 0.0 & 0.0 & 0.0 & 0.0 & 0.0 & 0.0 & 2.7 & 9.1 & 13.7 & 21.0 & 23.5 \\
\hline $21-30$ & 0.0 & 0.0 & 0.0 & 0.0 & 0.0 & 0.0 & 3.5 & 6.8 & 21.3 & 23.0 & 24.3 \\
\hline jul. $1-10$ & 0.0 & 0.0 & 0.0 & 0.0 & 0.0 & 0.0 & 8.6 & 17.6 & 20.9 & 24.2 & 28.1 \\
\hline $11-20$ & 0.0 & 0.0 & 0.0 & 0.0 & 1.6 & 2.9 & 13.3 & 22.0 & 24.5 & 25.9 & 28.0 \\
\hline $21-31$ & 0.0 & 0.0 & 0.0 & 0.7 & 14.5 & 17.9 & 20.7 & 24.2 & 27.0 & 30.4 & 32.5 \\
\hline ago. $1-10$ & 0.0 & 0.0 & 0.0 & 3.4 & 13.9 & 18.9 & 23.4 & 26.9 & 27.6 & 28.3 & 31.2 \\
\hline $11-20$ & 0.0 & 0.0 & 2.4 & 8.7 & 12.7 & 16.7 & 19.5 & 25.2 & 27.0 & 28.7 & 32.8 \\
\hline $21-31$ & 0.0 & 0.0 & 0.0 & 0.9 & 12.2 & 20.8 & 30.8 & 31.9 & 32.8 & 33.7 & 39.0 \\
\hline set. $1-10$ & 0.0 & 0.0 & 0.0 & 0.0 & 0.0 & 7.0 & 17.1 & 27.6 & 30.8 & 33.7 & 38.8 \\
\hline $11-20$ & 0.0 & 0.0 & 0.0 & 0.0 & 5.6 & 8.9 & 27.9 & 31.6 & 33.7 & 35.9 & 38.0 \\
\hline $21-30$ & 0.0 & 0.0 & 0.0 & 0.0 & 0.0 & 0.0 & 14.8 & 19.5 & 25.9 & 31.3 & 38.7 \\
\hline out. $1-10$ & 0.0 & 0.0 & 0.0 & 0.0 & 0.0 & 0.0 & 0.0 & 15.1 & 31.6 & 45.5 & 46.6 \\
\hline $11-20$ & 0.0 & 0.0 & 0.0 & 0.0 & 0.0 & 0.0 & 0.0 & 0.8 & 10.9 & 31.8 & 49.6 \\
\hline $21-3 \mid$ & 0.0 & 0.0 & 0.0 & 0.0 & 0.0 & 0.0 & 0.0 & 0.0 & 19.1 & 33.9 & 54.2 \\
\hline nov. $1-10$ & 0.0 & 0.0 & 0.0 & 0.0 & 0.0 & 0.0 & 0.0 & 0.0 & 0.0 & 19.7 & 35.0 \\
\hline $11-20$ & 0.0 & 0.0 & 0.0 & 0.0 & 0.0 & 0.0 & 0.0 & 0.0 & 0.0 & 2.9 & $\$ 2.0$ \\
\hline $21-30$ & 0.0 & 0.0 & 0.0 & 0.0 & 0.0 & 0.0 & 0.0 & 0.0 & 0.0 & 0.0 & 27.6 \\
\hline dez. $1-10$ & 0.0 & 0.0 & 0.0 & 0.0 & 0.0 & 0.0 & 0.0 & 0.0 & 0.0 & 0.0 & 1.9 \\
\hline $11-20$ & 0.0 & 0.0 & 0.0 & 0.0 & 0.0 & 0.0 & 0.0 & 0.0 & 0.0 & 0.0 & 22.1 \\
\hline $21-31$ & 0.0 & 0.0 & 0.0 & 0.0 & 0.0 & 0.0 & 0.0 & 0.0 & 0.0 & 0.0 & 28.0 \\
\hline
\end{tabular}


TABELA 11 - CAMPINAS: EXCEDENTES HIDRICOS (BALANCO COM AFD = 50 as)

DECIL

\begin{tabular}{|c|c|c|c|c|c|c|c|c|c|c|c|}
\hline DECENDIO & HIN. & 1 & 2 & 3 & 4 & 5 & 6 & 7 & 8 & 9 & 10 \\
\hline jan.1-10 & 0.0 & 0.0 & 0.0 & 8.1 & 17.3 & 40.0 & 69.9 & 74.9 & 95.4 & 105.6 & 148.5 \\
\hline $11-20$ & 0.0 & 0.0 & 0.0 & 0.0 & 19.4 & 30.0 & 43.0 & 59.3 & 74.2 & 97.9 & 260.6 \\
\hline $21-31$ & 0.0 & 0.0 & 0.0 & 0.0 & 7.3 & 14.1 & 23.0 & 49.8 & 102.3 & 154.3 & 174.2 \\
\hline fev. $1-10$ & 0.0 & 0.0 & 0.0 & 0.0 & 16.5 & 21.4 & 34.5 & 78.8 & 93.6 & 119.2 & 142.6 \\
\hline $11-20$ & 0.0 & 0.0 & 0.0 & 0.0 & 1.8 & 14.2 & 25.3 & 42.2 & 57.6 & 87.9 & 312.6 \\
\hline $21-28$ & 0.0 & 0.0 & 0.0 & 0.0 & 1.6 & 13.9 & 24.5 & 36.5 & 59.4 & 64.5 & 163.0 \\
\hline lar. $1-10$ & 0.0 & 0.0 & 0.0 & 0.0 & 0.0 & 0.0 & 8.6 & 20.6 & 39.6 & 82.5 & 143.1 \\
\hline $11-20$ & 0.0 & 0.0 & 0.0 & 0.0 & 0.0 & 0.0 & 0.0 & 11.3 & 50.7 & 100.6 & 165.0 \\
\hline $21-31$ & 0.0 & 0.0 & 0.0 & 0.0 & 0.0 & 0.0 & 0.0 & 6.2 & 10.4 & 37.4 & 70.9 \\
\hline $2 b r .1-10$ & 0.0 & 0.0 & 0.0 & 0.0 & 0.0 & 0.0 & 0.0 & 3.2 & 7.7 & 21.4 & 75.1 \\
\hline $11-20$ & 0.0 & 0.0 & 0.0 & 0.0 & 0.0 & 0.0 & 0.0 & 3.0 & 19.6 & 25.4 & 63.8 \\
\hline $21-30$ & 0.0 & 0.0 & 0.0 & 0.0 & 0.0 & 0.0 & 0.0 & 0.0 & 0.0 & 0.0 & 58.7 \\
\hline aai. $1-10$ & 0.0 & 0.0 & 0.0 & 0.0 & 0.0 & 0.0 & 0.0 & 0.0 & 1.7 & 4.8 & 50.1 \\
\hline $11-20$ & 0.0 & 0.0 & 0.0 & 0.0 & 0.0 & 0.0 & 0.0 & 0.0 & 0.0 & 29.1 & 93.2 \\
\hline $21-31$ & 0.0 & 0.0 & 0.0 & 0.0 & 0.0 & 0.0 & 0.0 & 0.0 & 0.0 & 41.5 & 206.3 \\
\hline jun $1-10$ & 0.0 & 0.0 & 0.0 & 0.0 & 0.0 & 0.0 & 0.0 & 0.0 & 0.0 & 0.0 & 148.4 \\
\hline $11-20$ & 0.0 & 0.0 & 0.0 & 0.0 & 0.0 & 0.0 & 0.0 & 0.0 & 0.0 & 9.1 & 58.8 \\
\hline $21-30$ & 0.0 & 0.0 & 0.0 & 0.0 & 0.0 & 0.0 & 0.0 & 0.0 & 0.0 & 0.0 & 65.3 \\
\hline jul. $1-10$ & 0.0 & 0.0 & 0.0 & 0.0 & 0.0 & 0.0 & 0.0 & 0.0 & 0.0 & 0.0 & 96.2 \\
\hline $11-20$ & 0.0 & 0.0 & 0.0 & 0.0 & 0.0 & 0.0 & 0.0 & 0.0 & 0.0 & 0.0 & 25.2 \\
\hline $21-31$ & 0.0 & 0.0 & 0.0 & 0.0 & 0.0 & 0.0 & 0.0 & 0.0 & 0.0 & 0.0 & 67.1 \\
\hline ago.1-10 & 0.0 & 0.0 & 0.0 & 0.0 & 0.0 & 0.0 & 0.0 & 0.0 & 0.0 & 0.0 & 27.9 \\
\hline $11-20$ & 0.0 & 0.0 & 0.0 & 0.0 & 0.0 & 0.0 & 0.0 & 0.0 & 0.0 & 0.0 & 21.3 \\
\hline $21-31$ & 0.0 & 0.0 & 0.0 & 0.0 & 0.0 & 0.0 & 0.0 & 0.0 & 0.0 & 0.0 & 58.6 \\
\hline set. $1-10$ & 0.0 & 0.0 & 0.0 & 0.0 & 0.0 & 0.0 & 0.0 & 0.0 & 0.0 & 0.0 & 26.9 \\
\hline $11-20$ & 0.0 & 0.0 & 0.0 & 0.0 & 0.0 & 0.0 & 0.0 & 0.0 & 0.0 & 5.6 & 86.7 \\
\hline $21-30$ & 0.0 & 0.0 & 0.0 & 0.0 & 0.0 & 0.0 & 0.0 & 0.0 & 0.0 & 0.0 & 43.9 \\
\hline out. $1-10$ & 0.0 & 0.0 & 0.0 & 0.0 & 0.0 & 0.0 & 0.0 & 0.0 & 19.8 & 24.5 & 66.5 \\
\hline $11-20$ & 0.0 & 0.0 & 0.0 & 0.0 & 0.0 & 0.0 & 0.0 & 0.0 & 0.0 & 28.5 & 57.5 \\
\hline $21-3 \mid$ & 0.0 & 0.0 & 0.0 & 0.0 & 0.0 & 0.0 & 0.0 & 9.6 & 20.4 & 50.3 & 105.3 \\
\hline nov. $1-10$ & 0.0 & 0.0 & 0.0 & 0.0 & 0.0 & 0.0 & 0.0 & 0.0 & 7.7 & 24.8 & 34.5 \\
\hline $11-20$ & 0.0 & 0.0 & 0.0 & 0.0 & 0.0 & 0.0 & 0.0 & 8.1 & 22.1 & 45.3 & 97.7 \\
\hline $21-30$ & 0.0 & 0.0 & 0.0 & 0.0 & 0.0 & 0.0 & 0.0 & 13.0 & 26.2 & 58.9 & 132.7 \\
\hline dez.1-10 & 0.0 & 0.0 & 0.0 & 0.0 & 13.4 & 20.3 & 35.9 & 41.1 & 64.7 & 95.3 & 110.8 \\
\hline $11-20$ & 0.0 & 0.0 & 0.0 & 0.0 & 8.3 & 14.6 & 29.4 & 47.4 & 68.0 & 100.9 & 186.3 \\
\hline $21-31$ & 0.0 & 0.0 & 0.0 & 5.2 & 28.3 & 32.4 & 46.7 & 58.5 & 88.1 & 129.1 & 162.9 \\
\hline
\end{tabular}


TABELA 12 - CAMPIHAS: AGUA FACILHENTE DISPONIVEL (BALANCO COM AFD $=75$ 잉

DECIL

\begin{tabular}{|c|c|c|c|c|c|c|c|c|c|c|c|}
\hline IECENDIO & KIN. & 1 & 2 & 3 & 4 & 5 & 6 & 7 & 8 & 9 & 10 \\
\hline jan.1-10 & 4.4 & 16.1 & 70.8 & 75.0 & 75.0 & 75.0 & 75.0 & 75.0 & 75.0 & 75.0 & 75.0 \\
\hline $11-20$ & 0.0 & 32.2 & 48.4 & 71.0 & 75.0 & 75.0 & 75.0 & 75.0 & 75.0 & 75.0 & 75.0 \\
\hline $21-31$ & 29.4 & 37.2 & 58.9 & 63.5 & 75.0 & 75.0 & 75.0 & 75.0 & 75.0 & 15.0 & 75.0 \\
\hline fev. $1-10$ & 8.1 & 46.2 & 50.2 & 67.7 & 75.0 & 75.0 & 75.0 & 75.0 & 75.0 & 75.0 & 75.0 \\
\hline $11-20$ & 0.1 & 37.3 & 46.8 & 63.2 & 75.0 & 75.0 & 75.0 & 75.0 & 75.0 & 75.0 & 75.0 \\
\hline $21-28$ & 0.0 & 23.0 & 50.3 & 56.9 & 75.0 & 75.0 & 75.0 & 75.0 & 75.0 & 75.0 & 75.0 \\
\hline$a r .1-10$ & 31.9 & 41.0 & 51.4 & 53.4 & 62.4 & 66.8 & 75.0 & 75.0 & 75.0 & 75.0 & 75.0 \\
\hline $11-20$ & 5.1 & 21.8 & 29.0 & 42.4 & 54.6 & 63.1 & 74.5 & 75.0 & 75.0 & 75.0 & 75.0 \\
\hline $21-31$ & 0.0 & 7.1 & $2 b .7$ & 37.1 & 48.7 & 57.6 & 68.2 & 75.0 & 75.0 & 75.0 & 75.0 \\
\hline$a b r \cdot 1-10$ & 0.0 & 0.0 & 28.3 & 46.6 & 52.8 & 63.2 & 64.6 & 75.0 & 75.0 & 75.0 & 75.0 \\
\hline $11-20$ & 0.0 & 1.3 & 32.4 & 37.5 & 42.7 & 48.2 & 58.6 & 75.0 & 75.0 & 75.0 & 75.0 \\
\hline $21-30$ & 0.0 & 0.0 & 18.9 & 20.1 & 23.0 & 30.2 & 52.0 & 63.5 & 66.1 & 71.4 & 75.0 \\
\hline Eai.1-10 & 0.0 & 0.0 & 10.5 & 15.3 & 29.2 & 37.4 & 46.1 & 58.2 & 67.5 & 75.0 & 75.0 \\
\hline $11-20$ & 0.0 & 0.0 & 0.0 & 0.0 & 29.0 & 42.6 & 54.4 & 57.7 & 73.2 & 75.0 & 75.0 \\
\hline $21-31$ & 0.0 & 0.0 & 0.0 & 12.0 & 22.0 & 26.5 & 34.9 & 53.5 & 63.4 & 75.0 & 75.0 \\
\hline jun. 1-10 & 0.0 & 0.0 & 0.0 & 4.3 & 15.2 & 19.8 & 24.7 & 42.4 & 53.5 & 70.2 & 75.0 \\
\hline $11-20$ & 0.0 & 0.0 & 0.0 & 1.5 & 9.1 & 22.3 & 33.1 & 52.1 & 56.7 & 66.5 & 75.0 \\
\hline $21-30$ & 0.0 & 0.0 & 0.0 & 0.0 & 0.5 & 12.0 & 29.7 & 43.0 & 54.6 & 68.5 & 75.0 \\
\hline jul. $1-10$ & 0.0 & 0.0 & 0.0 & 0.0 & 0.6 & 6.8 & 14.0 & 21.2 & 46.8 & 55.3 & 75.0 \\
\hline $11-20$ & 0.0 & 0.0 & 0.0 & 0.0 & 0.0 & 0.0 & 12.6 & 17.2 & 31.0 & 54.6 & 75.0 \\
\hline $21-31$ & 0.0 & 0.0 & 0.0 & 0.0 & 0.0 & 0.0 & 0.0 & 13.2 & 25.6 & 35.7 & 75.0 \\
\hline ago. $1-10$ & 0.0 & 0.0 & 0.0 & 0.0 & 0.0 & 0.0 & 0.0 & 3.2 & 11.8 & 43.6 & 75.0 \\
\hline $11-20$ & 0.0 & 0.0 & 0.0 & 0.0 & 0.0 & 0.0 & 0.0 & 0.0 & 14.2 & 36.3 & 75.0 \\
\hline $21-31$ & 0.0 & 0.0 & 0.0 & 0.0 & 0.0 & 0.0 & 0.0 & 1.0 & 21.7 & 45.7 & 75.0 \\
\hline set. $1-10$ & 0.0 & 0.0 & 0.0 & 0.0 & 0.0 & 0.0 & 10.8 & 23.6 & 39.9 & 63.5 & 75.0 \\
\hline $11-20$ & 0.0 & 0.0 & 0.0 & 0.0 & 0.0 & 0.0 & 0.0 & 11.1 & 20.2 & 55.6 & 75.0 \\
\hline $21-30$ & 0.0 & 0.0 & 0.0 & 0.0 & 0.0 & 0.6 & 9.3 & 20.1 & 44.2 & 63.6 & 75.0 \\
\hline out. $1-10$ & 0.0 & 0.0 & 0.0 & 0.0 & 5.5 & 27.0 & 38.9 & 42.6 & 73.6 & 75.0 & 75.0 \\
\hline $11-20$ & 0.0 & 0.0 & 0.0 & 0.0 & 12.0 & 30.0 & 52.2 & 57.1 & 69.2 & 75.0 & 75.0 \\
\hline $21-31$ & 0.0 & 0.0 & 0.0 & 4.8 & 28.5 & 45.0 & 64.2 & 70.4 & 75.0 & 75.0 & 75.0 \\
\hline nov. $1-10$ & 0.0 & 0.0 & 0.0 & 28.0 & 34.3 & 50.1 & 63.8 & 67.6 & 72.7 & 75.0 & 75.0 \\
\hline $11-20$ & 0.0 & 0.0 & 11.2 & 27.8 & 45.5 & 52.1 & 66.9 & 74.6 & 75.0 & 75.0 & 75.0 \\
\hline $21-30$ & 0.0 & 2.7 & 25.2 & 36.3 & 44.1 & 57.4 & 64.7 & 75.0 & 75.0 & 75.0 & 75.0 \\
\hline de $2.1-10$ & 0.0 & 8.0 & 35.2 & 63.4 & 75.0 & 75.0 & 75.0 & 75.0 & 75.0 & 75.0 & 75.0 \\
\hline $11-20$ & 0.0 & 24.2 & 56.6 & 72.5 & 75.0 & 75.0 & 75.0 & 75.0 & 75.0 & 75.0 & 75.0 \\
\hline $21-31$ & 0.0 & 33.3 & 67.8 & 75.0 & 75.0 & 75.0 & 75.0 & 75.0 & 75.0 & 75.0 & 75.0 \\
\hline
\end{tabular}


DECIL

\begin{tabular}{|c|c|c|c|c|c|c|c|c|c|c|c|}
\hline DECENDID & MIN. & 1 & 2 & 3 & 4 & 5 & 6 & 7 & 8 & 9 & 10 \\
\hline jan. 1-10 & 0.0 & 0.0 & 0.0 & 0.0 & 0.0 & 0.0 & 0.0 & 0.0 & 0.0 & 0.0 & 0.0 \\
\hline $11-20$ & 0.0 & 0.0 & 0.0 & 0.0 & 0.0 & 0.0 & 0.0 & 0.0 & 0.0 & 0.0 & 22.3 \\
\hline $21-31$ & 0.0 & 0.0 & 0.0 & 0.0 & 0.0 & 0.0 & 0.0 & 0.0 & 0.0 & 0.0 & 0.0 \\
\hline fev. $1-10$ & 0.0 & 0.0 & 0.0 & 0.0 & 0.0 & 0.0 & 0.0 & 0.0 & 0.0 & 0.0 & 0.0 \\
\hline $11-20$ & 0.0 & 0.0 & 0.0 & 0.0 & 0.0 & 0.0 & 0.0 & 0.0 & 0.0 & 0.0 & 0.0 \\
\hline $21-28$ & 0.0 & 0.0 & 0.0 & 0.0 & 0.0 & 0.0 & 0.0 & 0.0 & 0.0 & 0.0 & 10.0 \\
\hline var. $1-10$ & 0.0 & 0.0 & 0.0 & 0.0 & 0.0 & 0.0 & 0.0 & 0.0 & 0.0 & 0.0 & 0.0 \\
\hline $11-20$ & 0.0 & 0.0 & 0.0 & 0.0 & 0.0 & 0.0 & 0.0 & 0.0 & 0.0 & 0.0 & 0.0 \\
\hline $21-31$ & 0.0 & 0.0 & 0.0 & 0.0 & 0.0 & 0.0 & 0.0 & 0.0 & 0.0 & 0.0 & 3.7 \\
\hline$a b r .1-10$ & 0.0 & 0.0 & 0.0 & 0.0 & 0.0 & 0.0 & 0.0 & 0.0 & 0.0 & 0.0 & 25.0 \\
\hline $11-20$ & 0.0 & 0.0 & 0.0 & 0.0 & 0.0 & 0.0 & 0.0 & 0.0 & 0.0 & 0.0 & 20.3 \\
\hline $21-30$ & 0.0 & 0.0 & 0.0 & 0.0 & 0.0 & 0.0 & 0.0 & 0.0 & 0.0 & 0.0 & 26.0 \\
\hline ai. $1-10$ & 0.0 & 0.0 & 0.0 & 0.0 & 0.0 & 0.0 & 0.0 & 0.0 & 0.0 & 0.0 & 24.9 \\
\hline $11-20$ & 0.0 & 0.0 & 0.0 & 0.0 & 0.0 & 0.0 & 0.0 & 0.0 & 7.3 & 10.1 & 24.8 \\
\hline $21-31$ & 0.0 & 0.0 & 0.0 & 0.0 & 0.0 & 0.0 & 0.0 & 0.0 & 12.1 & 20.3 & 25.9 \\
\hline jun. $1-10$ & 0.0 & 0.0 & 0.0 & 0.0 & 0.0 & 0.0 & 0.0 & 0.0 & 0.7 & 9.8 & 24.2 \\
\hline $11-20$ & 0.0 & 0.0 & 0.0 & 0.0 & 0.0 & 0.0 & 0.0 & 0.0 & 5.2 & 21.0 & 23.5 \\
\hline $21-30$ & 0.0 & 0.0 & 0.0 & 0.0 & 0.0 & 0.0 & 0.0 & 0.0 & 13.9 & 22.5 & 24.3 \\
\hline jul $1-10$ & 0.0 & 0.0 & 0.0 & 0.0 & 0.0 & 0.0 & 0.0 & 13.4 & 19.2 & 24.1 & 26.1 \\
\hline $11-20$ & 0.0 & 0.0 & 0.0 & 0.0 & 0.0 & 0.2 & 9.5 & 17.7 & 24.2 & 25.9 & 28.0 \\
\hline $21-31$ & 0.0 & 0.0 & 0.0 & 0.0 & 0.0 & 10.0 & 17.8 & 23.0 & 26.5 & 27.9 & 32.5 \\
\hline $290.1-10$ & 0.0 & 0.0 & 0.0 & 0.0 & 3.2 & 11.8 & 23.6 & 26.9 & 27.6 & 28.3 & 31.2 \\
\hline $11-20$ & 0.0 & 0.0 & 0.0 & 8.7 & 12.7 & 16.7 & 18.7 & 22.8 & 27.0 & 28.7 & 32.8 \\
\hline $21-31$ & 0.0 & 0.0 & 0.0 & 0.0 & 4.2 & 20.8 & 30.8 & 31.9 & 32.8 & 33.7 & 39.0 \\
\hline set. $1-10$ & 0.0 & 0.0 & 0.0 & 0.0 & 0.0 & 7.0 & 17.1 & 27.6 & 30.8 & 33.7 & 38.8 \\
\hline $11-20$ & 0.0 & 0.0 & 0.0 & 0.0 & 0.0 & 6.4 & 27.9 & 31.6 & 33.7 & 35.9 & 38.0 \\
\hline $21-30$ & 0.0 & 0.0 & 0.0 & 0.0 & 0.0 & 0.0 & 1.4 & 15.0 & 25.9 & 31.3 & 38.7 \\
\hline out.1-10 & 0.0 & 0.0 & 0.0 & 0.0 & 0.0 & 0.0 & 0.0 & 15.1 & 31.1 & 45.5 & 46.6 \\
\hline $11-20$ & 0.0 & 0.0 & 0.0 & 0.0 & 0.0 & 0.0 & 0.0 & 0.0 & 10.9 & 31.8 & 49.6 \\
\hline $21-31$ & 0.0 & 0.0 & 0.0 & 0.0 & 0.0 & 0.0 & 0.0 & 0.0 & 5.7 & 33.9 & 43.6 \\
\hline nov. $1-10$ & 0.0 & 0.0 & 0.0 & 0.0 & 0.0 & 0.0 & 0.0 & 0.0 & 0.0 & 16.1 & 35.0 \\
\hline $11-20$ & 0.0 & 0.0 & 0.0 & 0.0 & 0.0 & 0.0 & 0.0 & 0.0 & 0.0 & 2.9 & 42.0 \\
\hline $21-30$ & 0.0 & 0.0 & 0.0 & 0.0 & 0.0 & 0.0 & 0.0 & 0.0 & 0.0 & 0.0 & 27.6 \\
\hline dez.1-10 & 0.0 & 0.0 & 0.0 & 0.0 & 0.0 & 0.0 & 0.0 & 0.0 & 0.0 & 0.0 & 2.7 \\
\hline $11-20$ & 0.0 & 0.0 & 0.0 & 0.0 & 0.0 & 0.0 & 0.0 & 0.0 & 0.0 & 0.0 & 8.2 \\
\hline $21-31$ & 0.0 & 0.0 & 0.0 & 0.0 & 0.0 & 0.0 & 0.0 & 0.0 & 0.0 & 0.0 & 3.0 \\
\hline
\end{tabular}


TABELA 14 - CAMPIHAS: EXCEDENTES HIORICOS (BALANCO COM AFD $=75$ A

DECIL

\begin{tabular}{|c|c|c|c|c|c|c|c|c|c|c|c|}
\hline DECENDIO & MIN. & 1 & 2 & 3 & 4 & 5 & 6 & 7 & 8 & 9 & 10 \\
\hline jan. $1-10$ & 0.0 & 0.0 & 0.0 & 8.1 & 17.3 & 40.0 & 69.9 & 74.9 & 95.4 & 105.6 & 148.5 \\
\hline $11-20$ & 0.0 & 0.0 & 0.0 & 0.0 & 19.4 & 30.0 & 43.0 & 59.3 & 74.2 & 97.9 & 260.6 \\
\hline $21-31$ & 0.0 & 0.0 & 0.0 & 0.0 & 7.1 & 14.1 & 23.0 & 48.8 & 102.3 & 154.3 & 174.2 \\
\hline fer. $1-10$ & 0.0 & 0.0 & 0.0 & 0.0 & 11.3 & 20.0 & 34.5 & 78.8 & 93.6 & 113.3 & 142.6 \\
\hline $11-20$ & 0.0 & 0.0 & 0.0 & 0.0 & 1.8 & 14.2 & 25.3 & 42.2 & 57.6 & 87.9 & 312.6 \\
\hline $21-28$ & 0.0 & 0.0 & 0.0 & 0.0 & 1.6 & 13.9 & 24.5 & 36.5 & 59.4 & 64.5 & 163.0 \\
\hline ar. $1-10$ & 0.0 & 0.0 & 0.0 & 0.0 & 0.0 & 0.0 & 2.3 & 20.6 & 39.6 & 82.5 & 143.1 \\
\hline $11-20$ & 0.0 & 0.0 & 0.0 & 0.0 & 0.0 & 0.0 & 0.0 & 11.3 & 50.7 & 100.6 & 165.0 \\
\hline $21-31$ & 0.0 & 0.0 & 0.0 & 0.0 & 0.0 & 0.0 & 0.0 & 6.2 & 10.4 & 37.4 & 70.9 \\
\hline$a b r \cdot 1-10$ & 0.0 & 0.0 & 0.0 & 0.0 & 0.0 & 0.0 & 0.0 & 3.2 & 7.7 & 21.4 & 55.2 \\
\hline $11-20$ & 0.0 & 0.0 & 0.0 & 0.0 & 0.0 & 0.0 & 0.0 & 3.0 & 19.0 & 22.1 & 63.8 \\
\hline $21-30$ & 0.0 & 0.0 & 0.0 & 0.0 & 0.0 & 0.0 & 0.0 & 0.0 & 0.0 & 0.0 & 58.7 \\
\hline a ai. $1-10$ & 0.0 & 0.0 & 0.0 & 0.0 & 0.0 & 0.0 & 0.0 & 0.0 & 0.0 & 3.1 & 50.1 \\
\hline$=11-20$ & 0.0 & 0.0 & 0.0 & 0.0 & 0.0 & 0.0 & 0.0 & 0.0 & 0.0 & 29.1 & 85.7 \\
\hline $21-31$ & 0.0 & 0.0 & 0.0 & 0.0 & 0.0 & 0.0 & 0.0 & 0.0 & 0.0 & 41.5 & 206.3 \\
\hline jun. $1-10$ & 0.0 & 0.0 & 0.0 & 0.0 & 0.0 & 0.0 & 0.0 & 0.0 & 0.0 & 0.0 & 148.1 \\
\hline $11-20$ & 0.0 & 0.0 & 0.0 & 0.0 & 0.0 & 0.0 & 0.0 & 0.0 & 0.0 & 0.0 & 58.8 \\
\hline $21-30$ & 0.0 & 0.0 & 0.0 & 0.0 & 0.0 & 0.0 & 0.0 & 0.0 & 0.0 & 0.0 & 65.8 \\
\hline jul. 1-10 & 0.0 & 0.0 & 0.0 & 0.0 & 0.0 & 0.0 & 0.0 & 0.0 & 0.0 & 0.0 & 96.2 \\
\hline $11-20$ & 0.0 & 0.0 & 0.0 & 0.0 & 0.0 & 0.0 & 0.0 & 0.0 & 0.0 & 0.0 & 0.2 \\
\hline $21-31$ & 0.0 & 0.0 & 0.0 & 0.0 & 0.0 & 0.0 & 0.0 & 0.0 & 0.0 & 0.0 & 42.1 \\
\hline $290.1-10$ & 0.0 & 0.0 & 0.0 & 0.0 & 0.0 & 0.0 & 0.0 & 0.0 & 0.0 & 0.0 & 27.9 \\
\hline $11-20$ & 0.0 & 0.0 & 0.0 & 0.0 & 0.0 & 0.0 & 0.0 & 0.0 & 0.0 & 0.0 & 21.3 \\
\hline $21-31$ & 0.0 & 0.0 & 0.0 & 0.0 & 0.0 & 0.0 & 0.0 & 0.0 & 0.0 & 0.0 & 33.6 \\
\hline set. $1-10$ & 0.0 & 0.0 & 0.0 & 0.0 & 0.0 & 0.0 & 0.0 & 0.0 & 0.0 & 0.0 & 26.9 \\
\hline $11-20$ & 0.0 & 0.0 & 0.0 & 0.0 & 0.0 & 0.0 & 0.0 & 0.0 & 0.0 & 0.0 & 80.1 \\
\hline $21-30$ & 0.0 & 0.0 & 0.0 & 0.0 & 0.0 & 0.0 & 0.0 & 0.0 & 0.0 & 0.0 & 43.9 \\
\hline out. $1-10$ & 0.0 & 0.0 & 0.0 & 0.0 & 0.0 & 0.0 & 0.0 & 0.0 & 0.0 & 2.1 & 58.6 \\
\hline $11-20$ & 0.0 & 0.0 & 0.0 & 0.0 & 0.0 & 0.0 & 0.0 & 0.0 & 0.0 & 10.6 & 32.5 \\
\hline $21-31$ & 0.0 & 0.0 & 0.0 & 0.0 & 0.0 & 0.0 & 0.0 & 0.0 & 9.6 & 50.3 & 105.3 \\
\hline nov. $1-10$ & 0.0 & 0.0 & 0.0 & 0.0 & 0.0 & 0.0 & 0.0 & 0.0 & 0.0 & 24.8 & 34.5 \\
\hline $11-20$ & 0.0 & 0.0 & 0.0 & 0.0 & 0.0 & 0.0 & 0.0 & 0.0 & 15.7 & 34.0 & 97.7 \\
\hline $21-30$ & 0.0 & 0.0 & 0.0 & 0.0 & 0.0 & 0.0 & 0.0 & 4.9 & 25.8 & 55.6 & 132.7 \\
\hline dez.1-10 & 0.0 & 0.0 & 0.0 & 0.0 & 1.5 & 20.3 & 35.9 & 11.1 & 62.8 & 72.5 & 110.8 \\
\hline $11-20$ & 0.0 & 0.0 & 0.0 & 0.0 & 4.4 & 13.4 & 20.7 & 47.4 & 68.0 & 100.9 & 161.3 \\
\hline $21-31$ & 0.0 & 0.0 & 0.0 & 5.2 & 24.0 & 28.9 & 45.6 & 58.5 & 88.1 & 129.1 & 162.9 \\
\hline
\end{tabular}


TABELA 15 - CORDEIROPULIS: CHUNA

DECIL

\begin{tabular}{|c|c|c|c|c|c|c|c|c|c|c|c|}
\hline & & 1 & 2 & 3 & 4 & 5 & 6 & 7 & 8 & 9 & 10 \\
\hline jan. $1-10$ & 10.7 & 20.2 & 40.9 & 46.5 & 51.6 & 62.7 & 84.6 & 100.6 & 116.7 & 138.2 & 152.5 \\
\hline $11-20$ & 14.8 & 15.6 & 20.5 & 30.3 & 49.4 & 56.8 & 81.8 & 101.3 & 114.8 & 137.1 & 368.7 \\
\hline $21-31$ & 5.7 & 17.4 & 25 & 49.4 & 55.3 & 63.5 & 72.8 & 95.6 & 117.8 & 134.7 & 152.4 \\
\hline fev. $1-10$ & 0.2 & 6.7 & 17.9 & 29.5 & 41.5 & 56.4 & 71.8 & 76.5 & 87.4 & 117.4 & 186.1 \\
\hline $11-20$ & 0 & $\mathbf{5}$ & 17 & 31.7 & 42 & 44.6 & 69.6 & 85.2 & 102.9 & 118.9 & 194.6 \\
\hline $21-28$ & 0 & 6.2 & 11.1 & 13.9 & 30.7 & 38.2 & 43.4 & 60.8 & 86.8 & 124.1 & 251.2 \\
\hline ar. $1-10$ & 1.2 & 3.8 & 15.8 & 21.4 & 27.1 & 34.5 & 50.1 & 62.8 & 101.4 & 131.7 & 253.7 \\
\hline $11-20$ & 0 & 0 & 0.5 & 11.5 & 21.7 & 30.5 & 51.7 & 66.7 & 112.4 & 179.7 & 235.8 \\
\hline $21-31$ & 0 & 1 & 2.1 & 15.2 & 22.5 & 25.9 & 29 & 37.3 & 41.9 & 60.4 & 128.3 \\
\hline abr. $1-10$ & 0 & 0.5 & 6.2 & 13.5 & 16.1 & 18.3 & 26.7 & 43.9 & 55.6 & 69.4 & 81.3 \\
\hline $11-20$ & 0 & 0 & 0.4 & 3.7 & 6.6 & 9.6 & 19.6 & 25.8 & 40 & 54.1 & 78.5 \\
\hline $21-30$ & 0 & 0 & 0.3 & 2.4 & 4 & 6.6 & 7.9 & 12.2 & 21.5 & 28.4 & 66 \\
\hline ai. $1-10$ & 0 & 0 & 0.3 & 3.9 & B.4 & 12.6 & 21.5 & 27.7 & 37.5 & 50.4 & 93.5 \\
\hline $11-20$ & 0 & 0 & 0 & 0 & 2.7 & 7.6 & 11.2 & 19.5 & 46.3 & 57.7 & 106.9 \\
\hline $21-31$ & 0 & 0 & 0 & 0.9 & 2.1 & 10.3 & 15 & 22 & 27.2 & 36.7 & 211.4 \\
\hline jun. 1-10 & 0 & 0 & 0 & 0 & 1.4 & 3 & 5.2 & 12.4 & 27.2 & 54.8 & 100.2 \\
\hline $11-20$ & 0 & 0 & 0 & 0 & 0 & 2.9 & 6.8 & 18.5 & 26.8 & 37.4 & 95.3 \\
\hline $21-30$ & 0 & 0 & 0 & 0 & 0 & 0.2 & 3.6 & 13.3 & 18 & 40.5 & 128.2 \\
\hline jul.1-10 & 0 & 0 & 0 & 0 & 0.8 & 1.4 & 3.5 & 8.3 & 16.9 & 24.6 & 135.5 \\
\hline $11-20$ & 0 & 0 & 0 & 0 & 0 & 0 & 0.4 & 7 & 12.1 & 20 & 84.7 \\
\hline $21-31$ & 0 & 0 & 0 & 0 & 0.6 & 2 & 4.1 & 9.9 & 14.8 & 24.7 & 91.3 \\
\hline $200.1-10$ & 0 & 0 & 0 & 0 & 0 & 0 & 1.5 & 5.2 & 14.1 & 20.3 & 54.5 \\
\hline $11-20$ & 0 & 0 & 0 & 0 & 0 & 0.2 & 2.9 & 7.7 & 15 & 21 & 65.6 \\
\hline $21-31$ & 0 & 0 & 0 & 0 & 0 & 0.8 & 8.5 & 10.4 & 18.4 & 36.7 & 110.6 \\
\hline set. $1-10$ & 0 & 0 & 0 & 0.8 & 2.2 & 10.4 & 15.4 & 29.9 & 36 & 41.1 & 111 \\
\hline $11-20$ & 0 & 0 & 0 & 0 & 0.3 & 2.4 & 5.2 & 12.9 & 35.9 & 59.4 & 82.3 \\
\hline $21-30$ & 0 & 0.5 & 5.4 & 14 & 17.8 & 21.6 & 32.6 & 34.5 & 42.7 & 47.5 & 82.8 \\
\hline out. $1-10$ & 0 & 0 & 1.5 & 11.9 & 24.2 & 32.4 & 57 & 59.7 & 73.8 & 82.6 & 110 \\
\hline $11-20$ & 0 & 1.6 & 13 & 19.2 & 27.2 & 36.1 & 43.1 & 48.4 & 69.6 & 78.6 & 105.5 \\
\hline $21-31$ & 0 & 8.3 & 17.8 & 20 & 23.7 & 29.7 & 46.8 & 62.8 & 74.9 & 106 & 126.8 \\
\hline nov. $1-10$ & 3.7 & 14.1 & 18.5 & 24 & 31.9 & 36 & 39.4 & 46.3 & 57.7 & 75.9 & 124 \\
\hline $11-20$ & 0 & 4.4 & 15.2 & 30.3 & 44.4 & 50.2 & 55 & 65.8 & 78.8 & 80.6 & 130.1 \\
\hline $21-30$ & 2.7 & 8.8 & 27.8 & 31.2 & 35.1 & 40.8 & 52.1 & 70.8 & 82.8 & 92.8 & 156.4 \\
\hline dez. $1-10$ & 0 & 13.4 & 20.6 & 33.2 & 46.3 & 71.9 & 89.4 & 101.2 & 120.6 & 137.9 & 196.2 \\
\hline $11-20$ & 9.5 & 13.5 & 17.1 & 34.6 & 46.5 & 66.2 & 80.2 & 102 & 121.9 & 149.3 & 185.8 \\
\hline $21-31$ & 3.7 & 43.9 & 48.2 & 51.7 & 66.8 & 71.8 & 98.6 & 114.8 & 129.2 & 155.2 & 236 \\
\hline
\end{tabular}


TABELA 16 - CORDEIROFOLIS: EVAPOTRANSPIRACAD DE REFERENCIA

DECIL

\begin{tabular}{|c|c|c|c|c|c|c|c|c|c|c|c|}
\hline DECENDIO & MIM. & 1 & 2 & 3 & 4 & 5 & 6 & 7 & 8 & 9 & 10 \\
\hline an. $1-10$ & 35.5 & 41.8 & 45.3 & 47.5 & 50.0 & 52.7 & 53.5 & 54.7 & 56.9 & 60.0 & 69.2 \\
\hline $11-20$ & 32.3 & 38.0 & 44.2 & 46.3 & 49.2 & 51.7 & 55.1 & 60.1 & 62.1 & 63.0 & 82.4 \\
\hline $21-31$ & 37.5 & 43.0 & 52.6 & 53.3 & 54.6 & 58.4 & 60.6 & 63.8 & 66.6 & 67.9 & 81.1 \\
\hline fev. $1-10$ & 39.7 & 60.7 & 43.4 & 46.7 & 52.0 & $\$ 2.8$ & 56.0 & 60.4 & 62.6 & 63.6 & 71.3 \\
\hline $11-20$ & 36.3 & 40.1 & 44.1 & 46.2 & 49.9 & 51.8 & 54,6 & 60.7 & 62.8 & 67.5 & 73.3 \\
\hline $21-28$ & 25.1 & 32.0 & 34.2 & 36.5 & 38.1 & 39.8 & 41.9 & 43.4 & 47.2 & 50.9 & 57.7 \\
\hline Gar $1-10$ & 34.2 & 38.0 & 40.3 & 45.1 & 48.2 & 50.7 & 53.2 & 53.9 & 56.1 & 58.6 & 65.8 \\
\hline $11-20$ & 31.0 & 34.8 & 40.5 & 47.6 & 48.3 & 49.2 & 50.1 & 51.6 & 55.3 & 58.9 & 68.2 \\
\hline $21-31$ & 32.2 & 43.6 & 45.2 & 49.8 & 50.8 & 52.3 & 52.9 & 55.8 & 56.9 & 60.6 & 65.5 \\
\hline abr. $1-10$ & 24.6 & 31.9 & 34.2 & 35.1 & 36.4 & 37.3 & 39.8 & 41.0 & 41.9 & 43.3 & 48.6 \\
\hline $11-20$ & 28,0 & 30.3 & 32.6 & 35.2 & 35.9 & 36.2 & 36.8 & 37.6 & 39.5 & 42.3 & 45.3 \\
\hline $21-30$ & 24.7 & 30.0 & 32.0 & 32.9 & 34.2 & 34.3 & 35.2 & 36.0 & 37.1 & 38.6 & 40.5 \\
\hline mai. $1-10$ & 24.8 & 26.6 & 27.9 & 30.4 & 31,4 & 32.1 & 32.3 & 33.8 & 34.1 & 35.9 & 36.8 \\
\hline $11-20$ & 22.4 & 26.4 & 27.5 & 28.5 & 29.0 & 30.5 & 30.8 & 31.5 & 32.3 & 34.5 & 36.0 \\
\hline $21-31$ & 26.0 & 27.0 & 29.2 & 30.8 & 31.9 & 32.6 & 33.0 & 34.0 & 34.5 & 36.3 & 42.1 \\
\hline jun. $1-10$ & 20.9 & 22.4 & 25.8 & 27.9 & 28.8 & 30.3 & 31.2 & 31.6 & 32.7 & 34.6 & 36.0 \\
\hline $11-20$ & 15.5 & 23.1 & 23.9 & 25.8 & 26.6 & 27.9 & 28.7 & 29.8 & 30.9 & 33.1 & 36.8 \\
\hline $21-30$ & 22.9 & 23.6 & 25.9 & 26.3 & 27.8 & 28.8 & 30.2 & 30.6 & 31.5 & 32.8 & 39.2 \\
\hline jul. $1-10$ & 18.4 & 24.0 & 27.6 & 29.0 & 30.6 & 31.5 & 31.8 & 32.2 & 33.5 & 35.5 & 40.8 \\
\hline $11-20$ & 24.1 & 27.6 & 26.2 & 29.0 & 30.6 & 32.1 & 33.3 & 33.7 & 35.1 & 36.5 & 42.4 \\
\hline $21-31$ & 28.0 & 31.0 & 32.0 & 34.5 & 35.0 & 37.2 & 38.1 & 38.7 & 40.5 & 41.6 & 44.3 \\
\hline ago. $1-10$ & 28.4 & 30.1 & 31.8 & 33.3 & 33.8 & 34.9 & 36.1 & 36.5 & 40.3 & 43.0 & 50.2 \\
\hline $11-20$ & 24.9 & 31.0 & 33.1 & 34.8 & 35.6 & 36.7 & 37.5 & 39.6 & 42.7 & 43.8 & 49.6 \\
\hline $21-31$ & 30.3 & 33.5 & 39.4 & 40.4 & 41.9 & 42.7 & 44.2 & 45.8 & 50.1 & 53.2 & 59.6 \\
\hline set. $1-10$ & 27.3 & 31.9 & 35.3 & 36.6 & 38.6 & 40.5 & 42.6 & 43.1 & 44.5 & 49.5 & 52.2 \\
\hline $11-20$ & 27.3 & 29.9 & 35.2 & 39.1 & 30.5 & 43.3 & 45.4 & 47.0 & 47.2 & 52.5 & 65.3 \\
\hline $21-30$ & 32.0 & 34.5 & 37.5 & 39.6 & 41.6 & 42.8 & 44.4 & 44.6 & 45.0 & 49.1 & 62.2 \\
\hline out. $1-10$ & 33.8 & 39.7 & 44.5 & 46.1 & 50.2 & 51.8 & 56.4 & 59.9 & 64.4 & 67.2 & 75.5 \\
\hline $11-20$ & 45.8 & 47.4 & 48.5 & 49.9 & 52.8 & 54.4 & 56.2 & 57.6 & 59.6 & 61.7 & 80.0 \\
\hline $21-31$ & 43.5 & 45.1 & 49.5 & 52.2 & 57.0 & 58.7 & 61.1 & 66.9 & 69.2 & 73.2 & 85.2 \\
\hline nov. $1-10$ & 45.5 & 49.3 & 52.0 & 53.4 & 54.6 & 57.5 & 58.8 & 59.0 & 60.9 & 67.5 & 69.9 \\
\hline $11-20$ & 38.7 & 44.9 & 48.2 & 51.4 & 53.2 & 54.3 & 56.2 & 59.4 & 62.4 & 66.7 & 91.9 \\
\hline $21-30$ & 42.9 & 47.9 & 50.2 & 53.8 & 56.3 & 58.1 & 60.4 & 62.0 & 62.8 & 66.0 & 67.5 \\
\hline dez.1-10 & 37.0 & 41.7 & 44.6 & 48.2 & 50.6 & 52.5 & 53.5 & 59.3 & 64.9 & 67.4 & 72.7 \\
\hline $11-20$ & 35.2 & 41.5 & 45.4 & 46.4 & 49.3 & 52.3 & 53.3 & 57.2 & 61.7 & 64.1 & 66.8 \\
\hline $21-31$ & 38.3 & 46.4 & 48.8 & 50.5 & 51.1 & 52.4 & 53.7 & 57.7 & 61.3 & 62.6 & 72.1 \\
\hline
\end{tabular}


TABELA 17 - CORDEIROPOLIS: AGUA FACILKENTE DISPONIUEL (BALAHCO COM AFO $=30$ ma)

DECIL

\begin{tabular}{|c|c|c|c|c|c|c|c|c|c|c|c|}
\hline DECENDIO & MIN. & 1 & 2 & 3 & 4 & 5 & 6 & 7 & 8 & 9 & 10 \\
\hline jan.1-10 & 0.0 & 20.8 & 30.0 & 30.0 & 30.0 & 30.0 & 30.0 & 30.0 & 30.0 & 30.0 & 30.0 \\
\hline $11-20$ & 0.0 & 9.5 & 22.7 & 30.0 & 30.0 & 30.0 & 30.0 & 30.0 & 30.0 & 30.0 & 30.0 \\
\hline $21-31$ & 0.0 & 15.5 & 20.3 & 30.0 & 30.0 & 30.0 & 30.0 & 30.0 & 30.0 & 30.0 & 30.0 \\
\hline fev. $1-10$ & 0.0 & 0.0 & 12.3 & 30.0 & 30.0 & 30.0 & 30.0 & 30.0 & 30.0 & 30.0 & 30.0 \\
\hline $11-20$ & 0.0 & 0.0 & 2.2 & 17.3 & 30.0 & 30.0 & 30.0 & 30.0 & 30.0 & 30.0 & 30.0 \\
\hline $21-2 B$ & 0.0 & 0.0 & 11.6 & 18.0 & 26.8 & 30.0 & 30.0 & 30.0 & 30.0 & 30.0 & 30.0 \\
\hline $\operatorname{ser} .1-10$ & 0.0 & 0.0 & 5.8 & 18.3 & 28.2 & 30.0 & 30.0 & 30.0 & 30.0 & 30.0 & 30.0 \\
\hline $11-20$ & 0.0 & 0.0 & 0.0 & 0.1 & 14.2 & 25.5 & 30.0 & 30.0 & 30.0 & 30.0 & 30.0 \\
\hline $21-31$ & 0.0 & 0.0 & 0.0 & 0.0 & 4.7 & 15.0 & 25.0 & 25.8 & 30.0 & 30.0 & 30.0 \\
\hline abr $: 1-10$ & 0.0 & 0.0 & 0.5 & 7.2 & 8.6 & 15.7 & 30.0 & 30.0 & 30.0 & 30.0 & 30.0 \\
\hline $11-20$ & 0.0 & 0.0 & 0.0 & 5.9 & 10.5 & 12.0 & 16.1 & 29.5 & 30.0 & 30.0 & 30.0 \\
\hline $21-30$ & 0.0 & 0.0 & 0.0 & 0.0 & 0.0 & 9.4 & 12.7 & 20.8 & 23.2 & 26.6 & 30.0 \\
\hline ai. $1-10$ & 0.0 & 0.0 & 0.0 & 0.0 & 2.8 & 11.9 & 15.5 & 21.3 & 30.0 & 30.0 & 30.0 \\
\hline $11-20$ & 0.0 & 0.0 & 0.0 & 0.0 & 1.3 & 9.8 & 15.5 & 22.8 & 30.0 & 30.0 & 30.0 \\
\hline $21-31$ & 0.0 & 0.0 & 0.0 & 0.0 & 0.0 & 7.8 & 13.7 & 23.9 & 29.6 & 30.0 & 30.0 \\
\hline jun. $1-10$ & 0.0 & 0.0 & 0.0 & 0.0 & 0.0 & 3.6 & 9.6 & 15.1 & 21.3 & 30.0 & 30.0 \\
\hline $11-20$ & 0.0 & 0.0 & 0.0 & 0.0 & 0.0 & 3.6 & 7.0 & 13.0 & 25.2 & 30.0 & 30.0 \\
\hline $21-30$ & 0.0 & 0.0 & 0.0 & 0.0 & 0.0 & 0.0 & 2.9 & 11.6 & 18.1 & 30.0 & 30.0 \\
\hline jul.1-10 & 0.0 & 0.0 & 0.0 & 0.0 & 0.0 & 0.0 & 3.7 & 10.7 & 13.1 & 20.2 & 30.0 \\
\hline $11-20$ & 0.0 & 0.0 & 0.0 & 0.0 & 0.0 & 0.0 & 0.0 & 0.0 & 4.9 & 12.6 & 30.0 \\
\hline $21-31$ & 0.0 & 0.0 & 0.0 & 0.0 & 0.0 & 0.0 & 0.0 & 0.0 & 5.6 & 15.9 & 80.0 \\
\hline $\operatorname{sgo} 0.1-10$ & 0.0 & 0.0 & 0.0 & 0.0 & 0.0 & 0.0 & 0.0 & 0.0 & 3.1 & 8.1 & 30.0 \\
\hline $11-20$ & 0.0 & 0.0 & 0.0 & 0.0 & 0.0 & 0.0 & 0.0 & 0.0 & 0.0 & 5.7 & 30.0 \\
\hline $21-31$ & 0.0 & 0.0 & 0.0 & 0.0 & 0.0 & 0.0 & 0.0 & 0.0 & 5.3 & 11.5 & 30.0 \\
\hline set. $1-10$ & 0.0 & 0.0 & 0.0 & 0.0 & 0.0 & 0.0 & 2.9 & 17.1 & 21.0 & 26.3 & 30.0 \\
\hline $11-20$ & 0.0 & 0.0 & 0.0 & 0.0 & 0.0 & 0.0 & 2.7 & 6.9 & 15.2 & 30.0 & 30.0 \\
\hline $21-30$ & 0.0 & 0.0 & 0.0 & 0.0 & 4.2 & 5.5 & 12.0 & 12.6 & 27.8 & 30.0 & 30.0 \\
\hline out. $1-10$ & 0.0 & 0.0 & 0.0 & 0.0 & 9.9 & 15.7 & 29.1 & 30.0 & 30.0 & 30.0 & 30.0 \\
\hline $11-20$ & 0.0 & 0.0 & 0.0 & 6.9 & 13.7 & 18.1 & 28.7 & 30.0 & 30.0 & 30.0 & 30.0 \\
\hline $21-31$ & 0.0 & 0.0 & 0.0 & 2.9 & 5.8 & 17.0 & 30.0 & 30.0 & 30.0 & 30.0 & 30.0 \\
\hline nov. $1-10$ & 0.0 & 0.0 & 0.0 & 2.7 & 14.6 & 20.4 & 28.4 & 30.0 & 30.0 & 30.0 & 30.0 \\
\hline $11-20$ & 0.0 & 0.0 & 0.0 & 10.9 & 30.0 & 30.0 & 30.0 & 30.0 & 30.0 & 30.0 & 30.0 \\
\hline $21-30$ & 0.0 & 2.2 & 4.2 & 16.2 & 24.7 & 30.0 & 30.0 & 30.0 & 30.0 & 30.0 & 30.0 \\
\hline dez. $1-10$ & 0.0 & 0.0 & 12.8 & 28.0 & 30.0 & 30.0 & 30.0 & 30.0 & 30.0 & 30.0 & 30.0 \\
\hline $11-20$ & 0.0 & 0.0 & 12.0 & 28.5 & 30.0 & 30.0 & 30.0 & 30.0 & 30.0 & 30.0 & 30.0 \\
\hline $21-31$ & 0.0 & 23.9 & 30.0 & 30.0 & 30.0 & 30.0 & 30.0 & 30.0 & 30.0 & 30.0 & 30.0 \\
\hline
\end{tabular}


IAEELA 18 - CORDEIROPOLIS: DEFICITES (BALANCO COM AFD = 30 든)

DECIL

\begin{tabular}{|c|c|c|c|c|c|c|c|c|c|c|c|}
\hline DECENDIO & HIN. & 1 & 2 & 3 & 4 & 5 & 6 & 7 & 8 & 9 & 10 \\
\hline jan.1-10 & 0.0 & 0.0 & 0.0 & 0.0 & 0.0 & 0.0 & 0.0 & 0.0 & 0.0 & 0.0 & 1.9 \\
\hline $11-20$ & 0.0 & 0.0 & 0.0 & 0.0 & 0.0 & 0.0 & 0.0 & 0.0 & 0.0 & 0.0 & 16.7 \\
\hline $2 !-31$ & 0.0 & 0.0 & 0.0 & 0.0 & 0.0 & 0.0 & 0.0 & 0.0 & 0.0 & 0.0 & 0.3 \\
\hline fev. $1-10$ & 0.0 & 0.0 & 0.0 & 0.0 & 0.0 & 0.0 & 0.0 & 0.0 & 0.0 & 1.0 & 18.0 \\
\hline $11-20$ & 0.0 & 0.0 & 0.0 & 0.0 & $0.0^{\circ}$ & 0.0 & 0.0 & 0.0 & 0.0 & 0.0 & 17.6 \\
\hline $21-28$ & 0.0 & 0.0 & 0.0 & 0.0 & 0.0 & 0.0 & 0.0 & 0.0 & 0.0 & 0.0 & 21.4 \\
\hline ar. $1-10$ & 0.0 & 0.0 & 0.0 & 0.0 & 0.0 & 0.0 & 0.0 & 0.0 & 0.0 & 1.6 & 28.2 \\
\hline $11-20$ & 0.0 & 0.0 & 0.0 & 0.0 & 0.0 & 0.0 & 0.0 & 0.0 & 2.5 & 3.2 & 37.5 \\
\hline $21-31$ & 0.0 & 0.0 & 0.0 & 0.0 & 0.0 & 0.0 & 0.0 & 2.2 & 4.4 & 11.7 & 29.7 \\
\hline abr. $1-10$ & 0.0 & 0.0 & 0.0 & 0.0 & 0.0 & 0.0 & 0.0 & 0.0 & 0.0 & 5.8 & 21.6 \\
\hline $11-20$ & 0.0 & 0.0 & 0.0 & 0.0 & 0.0 & 0.0 & 0.0 & 0.0 & 1.4 & 11.5 & 23.2 \\
\hline $21-30$ & 0.0 & 0.0 & 0.0 & 0.0 & 0.0 & 0.0 & 0.0 & 3.1 & 10.9 & 13.8 & 21.2 \\
\hline a $1.1-10$ & 0.0 & 0.0 & 0.0 & 0.0 & 0.0 & 0.0 & 0.0 & 2.4 & 12.3 & 18.3 & 19.7 \\
\hline $11-20$ & 0.0 & 0.0 & 0.0 & 0.0 & 0.0 & 0.0 & 0.0 & 1.7 & 6.0 & 17.4 & 19.8 \\
\hline $21-31$ & 0.0 & 0.0 & 0.0 & 0.0 & 0.0 & 0.0 & 4.8 & 6.9 & 17.3 & 18.9 & 20.0 \\
\hline jun. $1-10$ & 0.0 & 0.0 & 0.0 & 0.0 & 0.0 & 0.0 & 0.0 & 11.3 & 15.3 & 18.8 & 21.6 \\
\hline $11-20$ & 0.0 & 0.0 & 0.0 & 0.0 & 0.0 & 0.0 & 0.2 & 12.4 & 15.9 & 17.9 & 22.0 \\
\hline $21-30$ & 0.0 & 0.0 & 0.0 & 0.0 & 0.0 & 1.3 & 12.1 & 15.3 & 18.1 & 19.4 & 23.5 \\
\hline jul. $1-10$ & 0.0 & 0.0 & 0.0 & 0.0 & 0.0 & 6.3 & 12.6 & 16.5 & 17.2 & 19.2 & 21.9 \\
\hline $11-20$ & 0.0 & 0.0 & 0.0 & 2.7 & 3.5 & 7.1 & 0.3 & 18.9 & 20.6 & 21.5 & 25.4 \\
\hline $21-31$ & 0.0 & 0.0 & 0.0 & 5.7 & 8.2 & 14.2 & 17.8 & 22.3 & 23.2 & 24.6 & 26.6 \\
\hline $290.1-10$ & 0.0 & 0.0 & 0.0 & 1.3 & 12.0 & 18.2 & 20.0 & 21.6 & 22.2 & 25.8 & 30.1 \\
\hline $11-20$ & 0.0 & 0.0 & 0.1 & 3.7 & 13.9 & 15.7 & 19.4 & 22.3 & 23.4 & 20.2 & 29.8 \\
\hline $21-31$ & 0.0 & 0.0 & 0.0 & 8.2 & 14.4 & 19.4 & 25.0 & 26.5 & 29.5 & 31.9 & 35.7 \\
\hline set. $1-10$ & 0.0 & 0.0 & 0.0 & 0.0 & 0.0 & 3.4 & 20.8 & 23.6 & 25.6 & 29.7 & 31.3 \\
\hline $11-20$ & 0.0 & 0.0 & 0.0 & 0.0 & 0.0 & 9.3 & 15.3 & 26.1 & 28.2 & 28.5 & 39.2 \\
\hline $21-30$ & 0.0 & 0.0 & 0.0 & 0.0 & 0.0 & 0.0 & 0.0 & 8.0 & 19.5 & 22.8 & 37.3 \\
\hline out. $1-10$ & 0.0 & 0.0 & 0.0 & 0.0 & 0.0 & 0.0 & 0.0 & 11.4 & 19.2 & 36.6 & 40.5 \\
\hline $11-20$ & 0.0 & 0.0 & 0.0 & 0.0 & 0.0 & 0.0 & 0.0 & 0.0 & 9.8 & 22.1 & 48.0 \\
\hline $21-31$ & 0.0 & 0.0 & 0.0 & 0.0 & 0.0 & 0.0 & 0.0 & 0.0 & 6.1 & 25.2 & 51.1 \\
\hline nov.1 10 & 0.0 & 0.0 & 0.0 & 0.0 & 0.0 & 0.0 & 0.0 & 0.0 & 0.0 & 1.6 & 18.8 \\
\hline $11-20$ & 0.0 & 0.0 & 0.0 & 0.0 & 0.0 & 0.0 & 0.0 & 0.0 & 0.0 & 16.6 & 35.9 \\
\hline $21-30$ & 0.0 & 0.0 & 0.0 & 0.0 & 0.0 & 0.0 & 0.0 & 0.0 & 0.0 & 0.0 & 4.4 \\
\hline dez.1-10 & 0.0 & 0.0 & 0.0 & 0.0 & 0.0 & 0.0 & 0.0 & 0.0 & 0.0 & 8.2 & 14.2 \\
\hline $11-20$ & 0.0 & 0.0 & 0.0 & 0.0 & 0.0 & 0.0 & 0.0 & 0.0 & 0.0 & 0.0 & 21.8 \\
\hline $21-31$ & 0.0 & 0.0 & 0.0 & 0.0 & 0.0 & 0.0 & 0.0 & 0.0 & 0.0 & 0.0 & 35.9 \\
\hline
\end{tabular}


TABELA 19 - CORNEIFOPOLIS: EXCEDENTES HIDRICOS (BALAHCO COM AFD = 30 -a)

DECIL

\begin{tabular}{|c|c|c|c|c|c|c|c|c|c|c|c|}
\hline DECEMDIO & MIN. & 1 & 2 & 3 & 4 & 5 & 6 & 7 & 8 & 9 & 10 \\
\hline jon. $1-10$ & 0.0 & 0.0 & 4.4 & 21.5 & 26.6 & 38.9 & 59.3 & 73.9 & 87.9 & 114.9 & 121.1 \\
\hline $11-20$ & 0.0 & 0.0 & 0.0 & 3.4 & 21.9 & 36.4 & 42.7 & 75.5 & 90.8 & 108.9 & 346.6 \\
\hline $21-31$ & 0.0 & 0.0 & 0.0 & 16.5 & 22.5 & 30.7 & 37.2 & 58.1 & 80.4 & 101.0 & 119.3 \\
\hline fev. 1-10 & 0.0 & 0.0 & 0.0 & 1.5 & 9.8 & 26.0 & 34.9 & 49.1 & 67.1 & 89.4 & 166.0 \\
\hline $11-20$ & 0.0 & 0.0 & 0.0 & 0.0 & 7.4 & 18.3 & 44.8 & 57.5 & 78.1 & 95.1 & 176.3 \\
\hline $21-28$ & 0.0 & 0.0 & 0.0 & 0.0 & 0.0 & 9.0 & 14.6 & 28.2 & 70.2 & 110.0 & 237.6 \\
\hline ar $.1-10$ & 0.0 & 0.0 & 0.0 & 0.0 & 0.0 & 2.1 & 13.4 & 36.5 & 76.8 & 97.5 & 228.7 \\
\hline $11-20$ & 0.0 & 0.0 & 0.0 & 0.0 & 0.0 & 0.0 & 12.4 & 31.8 & 90.6 & 152.6 & 217.3 \\
\hline $21-31$ & 0.0 & 0.0 & 0.0 & 0.0 & 0.0 & 0.0 & 0.0 & 0.0 & 1.7 & 17.9 & 103.4 \\
\hline abr. $1-10$ & 0.0 & 0.0 & 0.0 & 0.0 & 0.0 & 0.0 & 0.8 & 8.2 & 17.1 & 32.4 & 61.5 \\
\hline $11-20$ & 0.0 & 0.0 & 0.0 & 0.0 & 0.0 & 0.0 & 0.0 & 0.0 & 1.8 & 13.3 & 57.8 \\
\hline $21-30$ & 0.0 & 0.0 & 0.0 & 0.0 & 0.0 & 0.0 & 0.0 & 0.0 & 0.0 & 0.0 & 40.5 \\
\hline ad. $1-10$ & 0.0 & 0.0 & 0.0 & 0.0 & 0.0 & 0.0 & 0.0 & 0.0 & 2.6 & 15.3 & 76.9 \\
\hline $11-20$ & 0.0 & 0.0 & 0.0 & 0.0 & 0.0 & 0.0 & 0.0 & 0.0 & 4.4 & 38.0 & 91.9 \\
\hline $21-31$ & 0.0 & 0.0 & 0.0 & 0.0 & 0.0 & 0.0 & 0.0 & 0.0 & 0.0 & 12.0 & 195.9 \\
\hline jun. $1-10$ & 0.0 & 0,0 & 0.0 & 0.0 & 0.0 & 0.0 & 0.0 & 0.0 & 0.0 & 11.7 & 78.7 \\
\hline $11-20$ & 0.0 & 0.0 & 0.0 & 0.0 & 0.0 & 0.0 & 0.0 & 0.0 & 0.0 & 15.2 & 65.6 \\
\hline $21-30$ & 0.0 & 0.0 & 0.0 & 0.0 & 0.0 & 0.0 & 0.0 & 0.0 & 0.0 & 7.7 & 83.5 \\
\hline jul. $1-10$ & 0.0 & 0.0 & 0.0 & 0.0 & 0.0 & 0.0 & 0.0 & 0.0 & 0.0 & 0.0 & 94.6 \\
\hline $11-20$ & 0.0 & 0.0 & 0.0 & 0.0 & 0.0 & 0.0 & 0.0 & 0.0 & 0.0 & 0.0 & 59.4 \\
\hline $21-31$ & 0.0 & 0.0 & 0.0 & 0.0 & 0.0 & 0.0 & 0.0 & 0.0 & 0.0 & 0.0 & 38.5 \\
\hline $290.1-10$ & 0.0 & 0.0 & 0.0 & 0.0 & 0.0 & 0.0 & 0.0 & 0.0 & 0.0 & 0.0 & 23.4 \\
\hline $11-20$ & 0.0 & 0.0 & 0.0 & 0.0 & 0.0 & 0.0 & 0.0 & 0.0 & 0.0 & 0.0 & 20.7 \\
\hline $21-31$ & 0.0 & 0.0 & 0.0 & 0.0 & 0.0 & 0.0 & 0.0 & 0.0 & 0.0 & 0.0 & 60.0 \\
\hline set. $1-10$ & 0.0 & 0.0 & 0.0 & 0.0 & 0.0 & 0.0 & 0.0 & 0.0 & 0.0 & 0.0 & 64.6 \\
\hline $11-20$ & 0.0 & 0.0 & 0.0 & 0.0 & 0.0 & 0.0 & 0.0 & 0.0 & 0.0 & 23.1 & 65.9 \\
\hline $21-30$ & 0.0 & 0.0 & 0.0 & 0.0 & 0.0 & 0.0 & 0.0 & 0.0 & 0.0 & 20.5 & 29.0 \\
\hline out. $1-10$ & 0.0 & 0.0 & 0.0 & 0.0 & 0.0 & 0.0 & 0.0 & 14.9 & 33.5 & 46.7 & 57.9 \\
\hline $11-20$ & 0.0 & 0.0 & 0.0 & 0.0 & 0.0 & 0.0 & 0.0 & 2.9 & 40.6 & 46.4 & 73.1 \\
\hline $21-31$ & 0.0 & 0.0 & 0.0 & 0.0 & 0.0 & 0.0 & 5.0 & 17.8 & 37.6 & 61.2 & 85.1 \\
\hline nov. $1-10$ & 0.0 & 0.0 & 0.0 & 0.0 & 0.0 & 0.0 & 0.0 & 6.3 & 11.1 & 32.7 & 96.7 \\
\hline $11-20$ & 0.0 & 0.0 & 0.0 & 0.0 & 0.8 & 7.4 & 14.0 & 23.6 & 29.1 & 48.3 & 103.0 \\
\hline $21-30$ & 0.0 & 0.0 & 0.0 & 0.0 & 0.0 & 3.0 & 9.1 & 15.7 & 52.8 & 66.6 & 132.8 \\
\hline dez. $1-10$ & 0.0 & 0.0 & 0.0 & 0.0 & 11.6 & 25.8 & 48.0 & 70.4 & 89.7 & 111.9 & 172.4 \\
\hline $11-20$ & 0.0 & 0.0 & 0.0 & 0.0 & 18.8 & 36.9 & 46.9 & 64.9 & 82.9 & 106.2 & 135.1 \\
\hline $21-31$ & 0.0 & 0.0 & 12.2 & 21.2 & 24.1 & 39.2 & 67.7 & 80.0 & 95.3 & 128.9 & 207.5 \\
\hline
\end{tabular}


TABELA 20 - CORDEIROPOLIS: AGUA FACILMENTE DISPDUIVEL (BRLANCO COM AFO = 40 \#A)

DECIL

\begin{tabular}{|c|c|c|c|c|c|c|c|c|c|c|c|}
\hline DECENDIO & MIN. & 1 & 2 & 3 & 4 & 5 & 6 & 7 & 8 & 9 & 10 \\
\hline jan. $1-10$ & 0.0 & 30.8 & 40.0 & 40.0 & 40.0 & 40.0 & 40.0 & 40.0 & 40.0 & 40.0 & 40.0 \\
\hline $11-20$ & 0.0 & 19.5 & 32.7 & 40.0 & 40.0 & 40.0 & 40.0 & 40.0 & 40.0 & 40.0 & 40.0 \\
\hline $21-31$ & 9.7 & 25.5 & 30.3 & 40.0 & 40.0 & 40.0 & 80.0 & 40.0 & 40.0 & 10.0 & 40.0 \\
\hline fev.1-10 & 0.0 & 8.6 & 22.3 & 40.0 & 40.0 & 40.0 & 40.0 & 40.0 & 40.0 & 40.0 & 40.0 \\
\hline $11-20$ & 0.0 & 6.1 & 12.2 & 25.9 & 40.0 & 40.0 & 40.0 & 40.0 & 40.0 & 40.0 & 40.0 \\
\hline $21-28$ & 0.0 & 0.0 & 21.6 & 28.0 & 31.9 & 40.0 & 40.0 & 40.0 & 40.0 & 40.0 & 40.0 \\
\hline $\operatorname{ar} .1-10$ & 0.0 & 2.5 & 14.3 & 28.3 & 38.2 & 40.0 & 40.0 & 40.0 & 40.0 & 40.0 & 40.0 \\
\hline $11-20$ & 0.0 & 0.0 & 6.8 & 10.1 & 24.2 & 35.5 & 40.0 & 40.0 & 80.0 & 40.0 & 40.0 \\
\hline $21-31$ & 0.0 & 0.0 & 4.0 & 7.8 & 11.9 & 21.5 & 35.0 & 35.8 & 40.0 & 40.0 & 40.0 \\
\hline$a b r .1-10$ & 0.0 & 0.0 & 10.5 & 16.0 & 18.6 & 23.9 & 32.3 & 40.0 & 40.0 & 40.0 & 40.0 \\
\hline $11-20$ & 0.0 & 0.0 & 2.7 & 8.8 & 19.5 & 21.2 & 26.1 & 39.3 & 40.0 & 40.0 & 40.0 \\
\hline $21-30$ & 0.0 & 0.0 & 0.0 & 0.0 & 7.7 & 17.7 & 22.7 & 26.8 & 32.2 & 36.0 & 40.0 \\
\hline Ha: $1-10$ & 0.0 & 0.0 & 0.0 & 0.0 & 12.6 & 18.5 & 23.8 & 31.3 & 33.1 & 40.0 & 40.0 \\
\hline $11-20$ & 0.0 & 0.0 & 0.0 & 1.3 & 7.3 & 19.8 & 23.1 & 26.4 & 37.0 & 40.0 & 40.0 \\
\hline $21-31$ & 0.0 & 0.0 & 0.0 & 0.0 & 3.4 & 7.8 & 21.4 & 31.6 & 39.3 & 10.0 & 40.0 \\
\hline jun. $1-10$ & 0.0 & 0.0 & 0.0 & 0.0 & 0.9 & 12.9 & 19.5 & 22.3 & 28.9 & 40.0 & 40.0 \\
\hline $11-20$ & 0.0 & 0.0 & 0.0 & 0.0 & 1.0 & 7.0 & 14.4 & 22.6 & 29.2 & 40.0 & 80.0 \\
\hline $21-30$ & 0.0 & 0.0 & 0.0 & 0.0 & 0.0 & 0.0 & 11.6 & 19.6 & 25.9 & 40.0 & 40.0 \\
\hline jul.1-10 & 0.0 & 0.0 & 0.0 & 0.0 & 0.0 & 0.0 & 3.7 & 19.2 & 22.8 & 25.5 & 40.0 \\
\hline $11-20$ & 0.0 & 0.0 & 0.0 & 0.0 & 0.0 & 0.0 & 1.7 & 4.9 & 7.1 & 21.5 & 40.0 \\
\hline $21-31$ & 0.0 & 0.0 & 0.0 & 0.0 & 0.0 & 0,0 & 0.0 & 1.4 & 5.6 & 21.6 & 40.0 \\
\hline $200.1-10$ & 0.0 & 0.0 & 0.0 & 0.0 & 0.0 & 0.0 & 0.0 & 0.0 & 5.9 & 11.5 & 40.0 \\
\hline $11-20$ & 0.0 & 0.0 & 0.0 & 0.0 & 0.0 & 0.0 & 0.0 & 0.0 & 0.0 & 8.1 & 40.0 \\
\hline $21-31$ & 0.0 & 0.0 & 0.0 & 0.0 & 0.0 & 0.0 & 0.0 & 0.0 & 6.1 & 21.4 & 40.0 \\
\hline set. $1-10$ & 0.0 & 0.0 & 0.0 & 0.0 & 0.0 & 0.0 & 2.9 & 17.1 & 26.3 & 32.1 & 40.0 \\
\hline $11-20$ & 0.0 & 0.0 & 0.0 & 0.0 & 0.0 & 0.0 & 3.0 & 12.9 & 16.9 & 40.0 & 40.0 \\
\hline $21-30$ & 0.0 & 0.0 & 0.0 & 0.0 & 4.2 & 5.5 & 12.0 & 17.1 & 34.2 & 40.0 & 40.0 \\
\hline out. $1-10$ & 0.0 & 0.0 & 0.0 & 0.0 & 11.8 & 15.7 & 34.5 & 40.0 & 40.0 & 40.0 & 40.0 \\
\hline $11-20$ & 0.0 & 0.0 & 0.0 & 6.9 & 20.4 & 23.7 & 35.9 & 40.0 & 40.0 & 40.0 & 40.0 \\
\hline $2|-3|$ & 0.0 & 0.0 & 0.0 & 3.9 & 15.8 & 25.9 & 40.0 & 40.0 & 40.0 & 40.0 & 40.0 \\
\hline nov. $1-10$ & 0.0 & 0.0 & 4.4 & 11.2 & 23.5 & 28.4 & 34.0 & 40.0 & 40.0 & 40.0 & 10.0 \\
\hline $11-20$ & 0.0 & 0.0 & 9.7 & 20.9 & 40.0 & 40.0 & 40.0 & 40.0 & 40.0 & 10.0 & 40.0 \\
\hline $21-30$ & 2.2 & 7.2 & 14.2 & 26.2 & 32.9 & 40.0 & 40.0 & 40.0 & 40.0 & 40.0 & 40.0 \\
\hline $\operatorname{dez}, 1-10$ & 0.0 & 0.0 & 22.8 & 36.3 & 40.0 & 40.0 & 40.0 & 10.0 & 40.0 & 40.0 & 40.0 \\
\hline $11-20$ & 0.0 & 1.1 & 22.0 & 38.5 & 40.0 & 40.0 & 40.0 & 40.0 & 40.0 & 10.0 & 40.0 \\
\hline $21-31$ & 0.0 & 33.9 & 40.0 & 40.0 & 40.0 & 40.0 & 40.0 & 40.0 & 40.0 & 40.0 & 40.0 \\
\hline
\end{tabular}


IABELA 21 - CORDEIROROLIS: DEFICITES (BALANCO COM AFD = 40 )

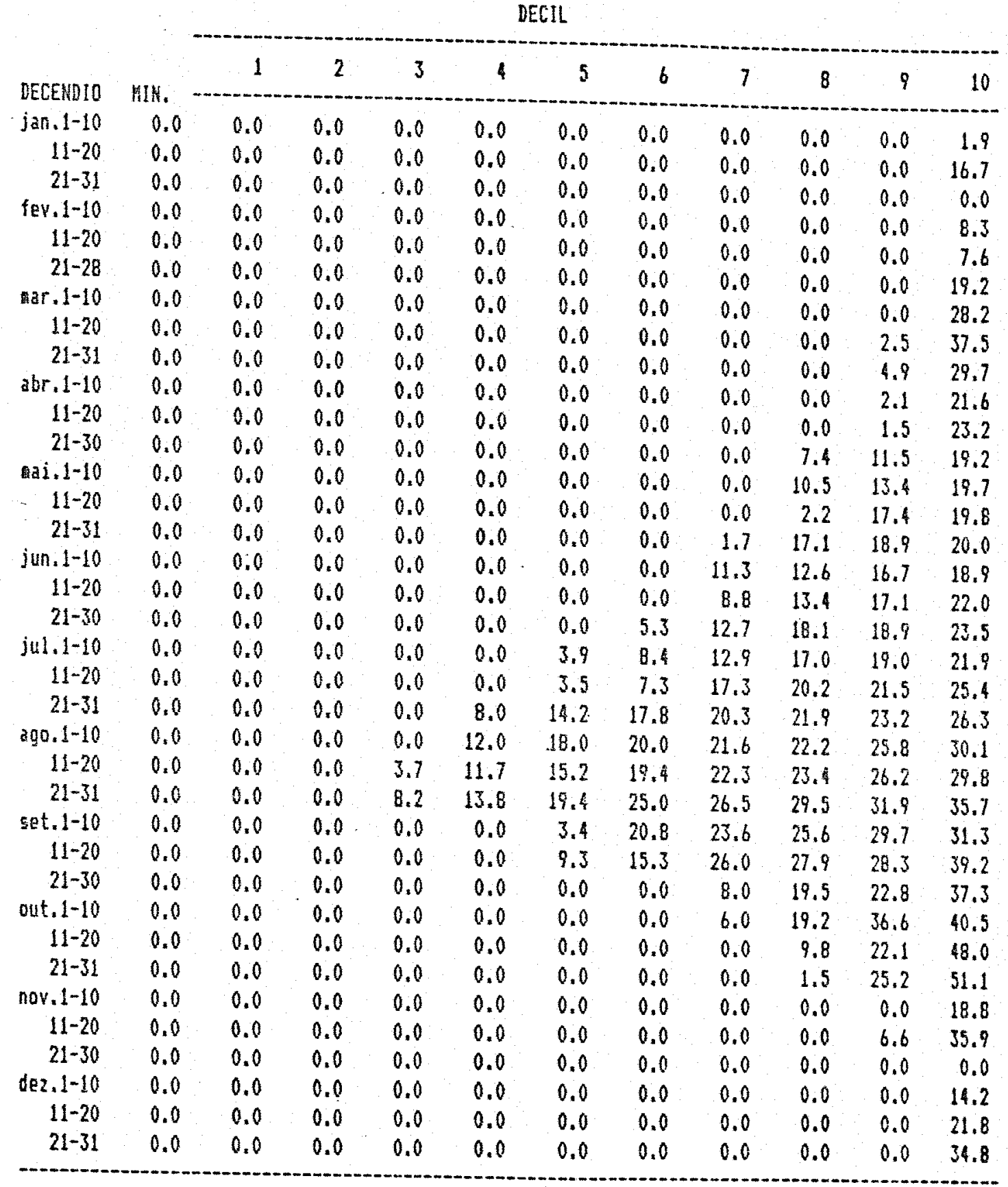


TABELA 22 - CORDEIROPOLIS: EXCEDENTES HIDRICOS (BALAHCO COM AFD = 40 )

DECIL

\begin{tabular}{|c|c|c|c|c|c|c|c|c|c|c|c|}
\hline DECENDIO & HIN. & 1 & 2 & 3 & 4 & 5 & 6 & 7 & 8 & 9 & 10 \\
\hline jan. 1-10 & 0.0 & 0.0 & 1.8 & 21.5 & 26.6 & 38.9 & 59.3 & 73.8 & 87.9 & 114.9 & 121.1 \\
\hline $11-20$ & 0.0 & 0.0 & 0.0 & 3.4 & 21.9 & 36.4 & 42.7 & 75.5 & 90.8 & 108.9 & 346.6 \\
\hline $21-31$ & 0.0 & 0.0 & 0.0 & 16.5 & 22.5 & 30.7 & 37.2 & 58.1 & 80.4 & 101.0 & 119.3 \\
\hline fev. $1-10$ & 0.0 & 0.0 & 0.0 & 1.5 & 9.8 & 26.0 & 34.9 & 49.1 & 67.1 & 89.4 & 166.0 \\
\hline $11-20$ & 0.0 & 0.0 & 0.0 & 0.0 & 7.4 & 18.3 & 44.8 & 54.8 & 78.1 & 95.1 & 176.3 \\
\hline $21-2 B$ & 0.0 & 0.0 & 0.0 & 0.0 & 0.0 & 9.0 & 14.6 & 28.2 & 70.2 & 110.0 & 237.6 \\
\hline $\operatorname{mar} .1-10$ & 0.0 & 0.0 & 0.0 & 0.0 & 0.0 & 2.1 & 11.6 & 36.5 & 76.8 & 97.5 & 228.7 \\
\hline $11-20$ & 0.0 & 0.0 & 0.0 & 0.0 & 0.0 & 0.0 & 10.5 & 31.8 & 90.6 & 152.6 & 217.3 \\
\hline $21-31$ & 0.0 & 0.0 & 0.0 & 0.0 & 0.0 & 0.0 & 0.0 & 0.0 & 1.1 & 17.9 & 103.4 \\
\hline$a b r .1-10$ & 0.0 & 0.0 & 0.0 & 0.0 & 0.0 & 0.0 & 0.0 & 6.6 & 15.4 & 28.3 & 61.5 \\
\hline $11-20$ & 0.0 & 0.0 & 0.0 & 0.0 & 0.0 & 0.0 & 0.0 & 0.0 & 0.9 & 13.3 & 57.8 \\
\hline $21-30$ & 0.0 & 0.0 & 0.0 & 0.0 & 0.0 & 0.0 & 0.0 & 0.0 & 0.0 & 0.0 & 60.5 \\
\hline ai. $1-10$ & 0.0 & 0.0 & 0.0 & 0.0 & 0.0 & 0.0 & 0.0 & 0.0 & 0.0 & 15.3 & 70.7 \\
\hline$\therefore 11-20$ & 0.0 & 0.0 & 0.0 & 0.0 & 0.0 & 0.0 & 0.0 & 0.0 & 0.0 & 35.2 & 91.9 \\
\hline $21-31$ & 0.0 & 0.0 & 0.0 & 0.0 & 0.0 & 0.0 & 0.0 & 0.0 & 0.0 & 2.0 & 195.9 \\
\hline jun. $1-10$ & 0.0 & $0: 0$ & 0.0 & 0.0 & 0.0 & 0.0 & 0.0 & 0.0 & 0.0 & 1.7 & 76.7 \\
\hline $11-20$ & 0.0 & 0.0 & 0.0 & 0.0 & 0.0 & 0.0 & 0.0 & 0.0 & 0.0 & 5.2 & 65.6 \\
\hline $21-30$ & 0.0 & 0.0 & 0.0 & 0.0 & 0.0 & 0.0 & 0.0 & 0.0 & 0.0 & 7.7 & 73.3 \\
\hline jul.1-10 & 0.0 & 0.0 & 0.0 & 0.0 & 0.0 & 0.0 & 0.0 & 0.0 & 0.0 & 0.0 & 91.6 \\
\hline $11-20$ & 0.0 & 0.0 & 0.0 & 0.0 & 0.0 & 0.0 & 0.0 & 0.0 & 0.0 & 0.0 & 49.4 \\
\hline $2|-3|$ & 0.0 & 0.0 & 0.0 & 0.0 & 0.0 & 0.0 & 0.0 & 0.0 & 0.0 & 0.0 & 28.5 \\
\hline ago. $1-10$ & 0.0 & 0.0 & 0.0 & 0.0 & 0.0 & 0.0 & 0.0 & 0.0 & 0.0 & 0.0 & 23.4 \\
\hline $11-20$ & 0.0 & 0.0 & 0.0 & 0.0 & 0.0 & 0.0 & 0.0 & 0.0 & 0.0 & 0.0 & 10.7 \\
\hline $21-31$ & 0.0 & 0.0 & 0.0 & 0.0 & 0.0 & 0.0 & 0.0 & 0.0 & 0.0 & 0.0 & 50.0 \\
\hline set. $1-10$ & 0.0 & 0.0 & 0.0 & 0.0 & 0.0 & 0.0 & 0.0 & 0.0 & 0.0 & 0.0 & 54.6 \\
\hline $11-20$ & 0.0 & 0.0 & 0.0 & 0.0 & 0.0 & 0.0 & 0.0 & 0.0 & 0.0 & 13.1 & 65.9 \\
\hline $21-30$ & 0.0 & 0.0 & 0.0 & 0.0 & 0.0 & 0.0 & 0,0 & 0.0 & 0.0 & 11.9 & 22.1 \\
\hline out. $1-10$ & 0.0 & 0.0 & 0.0 & 0.0 & 0.0 & 0.0 & 0.0 & 4.9 & 24.2 & 43.3 & 57.9 \\
\hline $11-20$ & 0.0 & 0.0 & 0.0 & 0.0 & 0.0 & 0.0 & 0.0 & 2.9 & 40.6 & 46.2 & 66.1 \\
\hline $21-31$ & 0.0 & 0.0 & 0.0 & 0.0 & 0.0 & 0.0 & 3.7 & 17.8 & 37.6 & 51.2 & 77.4 \\
\hline nov. $1-10$ & 0.0 & 0.0 & 0.0 & 0.0 & 0.0 & 0.0 & 0.0 & 4.8 & 7.6 & 32.7 & 96.7 \\
\hline $11-20$ & 0.0 & 0.0 & 0.0 & 0.0 & 0.8 & 6.4 & 13.3 & 15.4 & 29.1 & 48.3 & 103.0 \\
\hline $21-30$ & 0.0 & 0.0 & 0.0 & 0.0 & 0.0 & 0.7 & 6.7 & 10.2 & 52.8 & 66.6 & 132.8 \\
\hline de2.1-10 & 0.0 & 0.0 & 0.0 & 0.0 & 11.6 & 22.1 & 48.0 & 70.4 & 80.5 & 111.9 & 172.4 \\
\hline $11-20$ & 0.0 & 0.0 & 0.0 & 0.0 & 18.6 & 36.9 & 46.9 & 56.8 & 82.9 & 104.9 & 135.1 \\
\hline $21-31$ & 0.0 & 0.0 & 12.2 & 21.2 & 24.1 & 39.2 & 67.7 & 80.0 & 95.3 & 128.9 & 207.5 \\
\hline
\end{tabular}


TABELA 23 - CORDEIROPOLIS: AGUA FACILHENTE DISFONIUEL (BALAMCO COM AFO $=50$.

DECIL

\begin{tabular}{|c|c|c|c|c|c|c|c|c|c|c|c|}
\hline DECENDIO & MIN. & 1 & 2 & 3 & 4 & 5 & 6 & 7 & 8 & 9 & 10 \\
\hline jan. $1-10$ & 0.0 & 34.4 & 50.0 & 50.0 & 50.0 & 50.0 & 50.0 & 50.0 & 50.0 & 50.0 & 50.0 \\
\hline $11-20$ & 0.0 & 29.5 & 42.7 & 50.0 & 50.0 & 50.0 & 50.0 & 50.0 & 50.0 & 50.0 & 50.0 \\
\hline $21-31$ & 19.7 & 35.5 & 40.3 & 50.0 & 50.0 & 50.0 & 50.0 & 50.0 & 50.0 & 50.0 & 50.0 \\
\hline fev. $1-10$ & 1.7 & 18.6 & 32.3 & 50.0 & 50.0 & 50.0 & 50.0 & 50.0 & 50.0 & 50.0 & 50.0 \\
\hline $11-20$ & 2.4 & 16.1 & 22.2 & 35.9 & 50.0 & 50.0 & 50.0 & 50.0 & 50.0 & 50.0 & 50.0 \\
\hline $21-28$ & 0.0 & 1.0 & 31.6 & 35.6 & 41.9 & 50.0 & 50.0 & 50.0 & 50.0 & 50.0 & 50.0 \\
\hline ar. $1-10$ & 0.0 & 2.5 & 24.3 & 38.3 & 48.2 & 50.0 & 50.0 & 50.0 & 50.0 & 50.0 & 50.0 \\
\hline $11-20$ & 0.0 & 0.0 & 16.8 & 20.1 & 25.1 & 45.5 & 50.0 & 50.0 & 50.0 & 50.0 & 50.0 \\
\hline $21-31$ & 0.0 & 0.0 & 14.0 & 17.0 & 21.9 & 31.5 & 45.0 & 45.8 & 50.0 & 50.0 & 50.0 \\
\hline$a b r .1-10$ & 0.0 & 0.0 & 20.5 & 26.0 & 28.6 & 32.3 & 41.7 & 50.0 & 50.0 & 50.0 & 50.0 \\
\hline $11-20$ & 0.0 & 0.0 & 8.5 & 16.4 & 29.5 & 31.2 & 36.1 & 41.4 & 50.0 & 50.0 & 50.0 \\
\hline $21-30$ & 0.0 & 0.0 & 0.0 & 10.0 & 17.2 & 27.7 & 30.1 & 36.5 & $\$ 2.2$ & 46.0 & 50.0 \\
\hline ai. $1-10$ & 0.0 & 0.0 & 0.0 & 9.6 & $1 B .5$ & 23.1 & 32.2 & 38.1 & 43.0 & 50.0 & 50.0 \\
\hline $11-20$ & 0.0 & 0.0 & 0.0 & 2.4 & 17.3 & 27.5 & 30.8 & 34.7 & 44.3 & 50.0 & 50.0 \\
\hline $21-31$ & 0.0 & 0.0 & 0.0 & 0.0 & 8.3 & 15.2 & 29.6 & 41.6 & 49.3 & 50.0 & 50.0 \\
\hline jun. 1-10 & 0.0 & 0.0 & 0.0 & 0.0 & 3.1 & 14.6 & 25.1 & 32.3 & 38.9 & 45.3 & 50.0 \\
\hline $11-20$ & 0.0 & 0.0 & 0.0 & 0.0 & 5.0 & 12.5 & 23.6 & 27.3 & 39.2 & 45.5 & 50.0 \\
\hline $21-30$ & 0.0 & 0.0 & 0.0 & 0.0 & 0.0 & 9.0 & 13.0 & 25.9 & 32.4 & 50.0 & 50.0 \\
\hline jul.1-10 & 0.0 & 0.0 & 0.0 & 0.0 & 0.0 & 0.0 & 9.4 & 19.2 & 32.8 & 35.5 & 50.0 \\
\hline $11-20$ & 0.0 & 0.0 & 0.0 & 0.0 & 0.0 & 0.0 & 6.2 & 12.6 & 16.3 & 31.5 & 50.0 \\
\hline $21-31$ & 0.0 & 0.0 & 0.0 & 0.0 & 0.0 & 0.0 & 0.0 & 5.6 & 12.5 & 30. & 50.0 \\
\hline ago. $1-10$ & 0.0 & 0.0 & 0.0 & 0.0 & 0.0 & 0.0 & 0.0 & 2.8 & 8.8 & 18.2 & 50.0 \\
\hline $11-20$ & 0.0 & 0.0 & 0.0 & 0.0 & 0.0 & 0.0 & 0.0 & 0.0 & 0.8 & 18.1 & 50.0 \\
\hline $21-31$ & 0.0 & 0.0 & 0.0 & 0.0 & 0.0 & 0.0 & 0.0 & 0.0 & 6.1 & 31.6 & 50.0 \\
\hline set. $1-10$ & 0.0 & 0.0 & 0.0 & 0.0 & 0.0 & 0.0 & 2.9 & 17.5 & 26.3 & 42.1 & 50.0 \\
\hline $11-20$ & 0.0 & 0.0 & 0.0 & 0.0 & 0.0 & 0.0 & 3.0 & 12.9 & 19.8 & 50.0 & 50.0 \\
\hline $21-30$ & 0.0 & 0.0 & 0.0 & 0.0 & 4.2 & 5.5 & 12.0 & 17.1 & 44.2 & 50.0 & 50.0 \\
\hline out. $1-10$ & 0.0 & 0.0 & 0.0 & 0.0 & 11.8 & 23.6 & 36.5 & 49.1 & 50.0 & 50.0 & 50.0 \\
\hline $11-20$ & 0.0 & 0.0 & 0.0 & 6.9 & 21.7 & 32.7 & 43.4 & 47.8 & 50.0 & 50.0 & 50.0 \\
\hline $21-31$ & 0.0 & 0.0 & 0.0 & 13.9 & 24.1 & 35.9 & 43.7 & 50.0 & 50.0 & 50.0 & 50.0 \\
\hline nov. $1-10$ & 0.0 & 0.0 & 12.0 & 14.6 & 28.4 & 35.9 & 43.4 & 50.0 & 50.0 & 50.0 & 50.0 \\
\hline $11-20$ & 0.0 & 0.0 & 17.7 & 24.0 & 44.2 & 50.0 & 50.0 & 50.0 & 50.0 & 50.0 & 50.0 \\
\hline $21-30$ & 2.2 & 17.2 & 24.2 & 30.1 & 42.9 & 44.7 & 50.0 & 50.0 & 50.0 & 50.0 & 50.0 \\
\hline dez.1-10 & 0.0 & 9.0 & 32.8 & 46.3 & 50.0 & 50.0 & 50.0 & 50.0 & 50.0 & 50.0 & 50.0 \\
\hline $11-20$ & 0.0 & 11.1 & 32.0 & 48.5 & 50.0 & 50.0 & 50.0 & 50.0 & 50.0 & 50.0 & 50.0 \\
\hline $21-31$ & 0.0 & 39.5 & 50.0 & 50.0 & 50.0 & 50.0 & 50.0 & 50.0 & 50.0 & 50.0 & 50.0 \\
\hline
\end{tabular}


TABELA 24 - CORDEIROPOLIS: DEFICITES (BALARCO COM AFD = 50

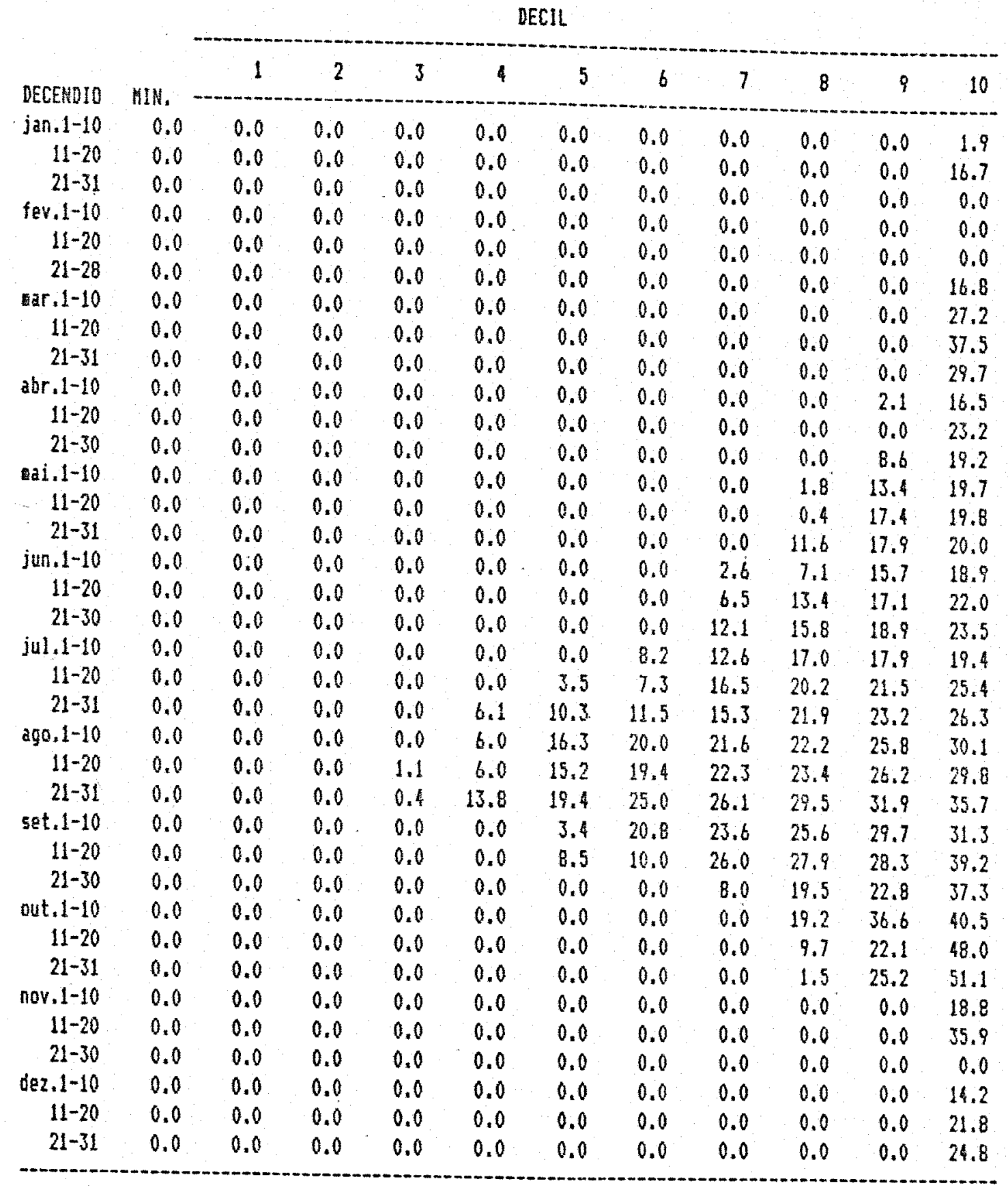


TABELA 25 - CORDEIROPOLIS: EXCENEMTES HIDRICOS (BALANCO COM AFD $=50$ a

DECIL

\begin{tabular}{|c|c|c|c|c|c|c|c|c|c|c|c|}
\hline DECENDIO & MIN. & 1 & 2 & 3 & 4 & 5 & 6 & 7 & 8 & 9 & 10 \\
\hline$j a n .1-10$ & 0.0 & 0.0 & 1.8 & 21.5 & 26.6 & 38.9 & 59.3 & 73.9 & 87.9 & 114.9 & 121.1 \\
\hline $11-20$ & 0.0 & 0.0 & 0.0 & 3.4 & 21.9 & 36.4 & 42.7 & 75.5 & 90.8 & 108.9 & 346.6 \\
\hline $21-31$ & 0.0 & 0.0 & 0.0 & 16.5 & 22.5 & 30.7 & 35.9 & 58.1 & 80.4 & 101.0 & 119.3 \\
\hline fev. $1-10$ & 0.0 & 0.0 & 0.0 & 1.5 & 9.8 & 26.0 & 34.9 & 49.1 & 67.1 & 89.4 & 166.0 \\
\hline $11-20$ & 0.0 & 0.0 & 0.0 & 0.0 & $7.4^{\circ}$ & 18.3 & 44.8 & 54.8 & 78.1 & 95.1 & 176.3 \\
\hline $21-28$ & 0.0 & 0.0 & 0.0 & 0.0 & 0.0 & 9.0 & 14.6 & 28.2 & 70.2 & 110.0 & 237.6 \\
\hline Mar $1-10$ & 0.0 & 0.0 & 0.0 & 0.0 & 0.0 & 2.1 & 11.6 & 36.5 & 70.7 & 97.5 & 228.7 \\
\hline $11-20$ & 0.0 & 0.0 & 0.0 & 0.0 & 0.0 & 0.0 & 10.5 & 31.8 & 90.6 & 152.6 & 217.3 \\
\hline $21-31$ & 0.0 & 0.0 & 0.0 & 0.0 & 0.0 & 0.0 & 0.0 & 0.0 & 1.1 & 17.9 & 103.4 \\
\hline$a b r .1-10$ & 0.0 & 0.0 & 0.0 & 0.0 & 0.0 & 0.0 & 0.0 & 6.6 & 15.4 & 28.3 & 61.5 \\
\hline $11-20$ & 0.0 & 0.0 & 0.0 & 0.0 & 0.0 & 0.0 & 0.0 & 0.0 & 0.3 & 13.3 & 57.8 \\
\hline $21-30$ & 0.0 & 0.0 & 0.0 & 0.0 & 0.0 & 0.0 & 0.0 & 0.0 & 0.0 & 0.0 & 40.5 \\
\hline 1. $1.1-10$ & 0.0 & 0.0 & 0.0 & 0.0 & 0.0 & 0.0 & 0.0 & 0.0 & 0.0 & 15.3 & 69.1 \\
\hline $11-20$ & 0.0 & 0.0 & 0.0 & 0.0 & 0.0 & 0.0 & 0.0 & 0.0 & 0.0 & 35.2 & 91.9 \\
\hline $21-31$ & 0.0 & 0.0 & 0.0 & 0.0 & 0.0 & 0.0 & 0.0 & 0.0 & 0.0 & 2.0 & 195.9 \\
\hline jun. $1-10$ & 0.0 & 0.0 & 0.0 & 0.0 & 0.0 & 0.0 & 0.0 & 0.0 & 0.0 & 0.0 & 78.7 \\
\hline $11-20$ & 0.0 & 0.0 & 0.0 & 0.0 & 0.0 & 0.0 & 0.0 & 0.0 & 0.0 & 0.0 & 65.6 \\
\hline $21-30$ & 0.0 & 0.0 & 0.0 & 0.0 & 0.0 & 0.0 & 0.0 & 0.0 & 0.0 & 7.7 & 63.3 \\
\hline jul.1-10 & 0.0 & 0.0 & 0.0 & 0.0 & 0.0 & 0.0 & 0.0 & 0.0 & 0.0 & 0.0 & 94.6 \\
\hline $11-20$ & 0.0 & 0.0 & 0.0 & 0.0 & 0.0 & 0.0 & 0.0 & 0.0 & 0.0 & 0.0 & 39.4 \\
\hline $21-31$ & 0.0 & 0.0 & 0.0 & 0.0 & 0.0 & 0.0 & 0.0 & 0.0 & 0.0 & 0.0 & 18.5 \\
\hline ago.1-10 & 0.0 & 0.0 & 0.0 & 0.0 & 0.0 & 0.0 & 0.0 & 0.0 & 0.0 & 0.0 & 23.4 \\
\hline $11-20$ & 0.0 & 0.0 & 0.0 & 0.0 & 0.0 & 0.0 & 0.0 & 0.0 & 0.0 & 0.0 & 7.4 \\
\hline $21-31$ & 0.0 & 0.0 & 0.0 & 0.0 & 0.0 & 0.0 & 0.0 & 0.0 & 0.0 & 0.0 & 40.0 \\
\hline set. $1-10$ & 0.0 & 0.0 & 0.0 & 0.0 & 0.0 & 0.0 & 0.0 & 0.0 & 0.0 & 0.0 & 54.6 \\
\hline $11-20$ & 0.0 & 0.0 & 0.0 & 0.0 & 0.0 & 0.0 & 0.0 & 0.0 & 0.0 & 3.1 & 65.9 \\
\hline $21-30$ & 0.0 & 0.0 & 0.0 & 0.0 & 0.0 & 0.0 & 0.0 & 0.0 & 0.0 & 6.7 & 22.1 \\
\hline out. $1-10$ & 0.0 & 0.0 & 0.0 & 0.0 & 0.0 & 0.0 & 0.0 & 0.0 & 14.2 & 34.2 & 57.9 \\
\hline $11-20$ & 0.0 & 0.0 & 0.0 & 0.0 & 0.0 & 0.0 & 0.0 & 0.0 & 35.9 & 46.2 & 62.1 \\
\hline $21-31$ & 0.0 & 0.0 & 0.0 & 0.0 & 0.0 & 0.0 & 0.0 & 17.8 & 32.1 & 43.4 & 73.8 \\
\hline nov. $1-10$ & 0.0 & 0.0 & 0.0 & 0.0 & 0.0 & 0.0 & 0.0 & 4.8 & 7.6 & 32.7 & 96.7 \\
\hline $11-20$ & 0.0 & 0.0 & 0.0 & 0.0 & 0.0 & 4.6 & 7.4 & 14.0 & 29.1 & 48.3 & 103.0 \\
\hline $21-30$ & 0.0 & 0.0 & 0.0 & 0.0 & 0.0 & 0.0 & 3.3 & 10.2 & 52.8 & 65.8 & 132.8 \\
\hline dez.1-10 & 0.0 & 0.0 & 0.0 & 0.0 & 11.6 & 22.1 & 48.0 & 69.7 & 80.5 & 108.8 & 172.4 \\
\hline $11-20$ & 0.0 & 0.0 & 0.0 & 0.0 & 18.6 & 36.9 & 46.9 & 56.8 & 82.9 & 104.9 & 135.1 \\
\hline $21-31$ & 0.0 & 0.0 & 12.2 & 21.2 & 24.1 & 39.2 & 67.7 & 80.0 & 95.3 & 128.9 & 207.5 \\
\hline
\end{tabular}




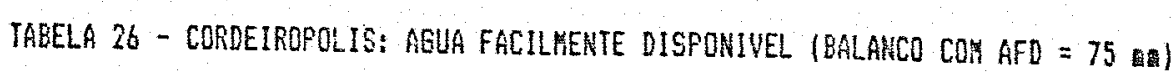

DECIL

\begin{tabular}{|c|c|c|c|c|c|c|c|c|c|c|c|}
\hline DECENDIO & MIN. & 1 & 2 & 3 & $\begin{array}{r}4 \\
-\end{array}$ & 5 & 6 & 7 & 8 & 9 & 10 \\
\hline jan. 1-10 & 0.0 & 55.8 & 75.0 & 75.0 & 75.0 & 75.0 & 75.0 & 75.0 & 75.0 & 75.0 & 75.0 \\
\hline $11-20$ & 0.0 & 54.5 & 67.7 & 75.0 & 75.0 & 75.0 & 75.0 & 75.0 & 75.0 & 75.0 & 75.0 \\
\hline $21-31$ & 44.7 & 60.5 & 65.3. & .75 .0 & 75.0 & 75.0 & 75.0 & 75.0 & 75.0 & 75.0 & 75.0 \\
\hline fev. $1-10$ & 26.7 & 43.6 & 57.3 & 75.0 & 75.0 & 75.0 & 75.0 & 75.0 & 75.0 & 75.0 & 75.0 \\
\hline $11-20$ & 27.4 & 41.1 & 47.2 & 60.9 & 75.0 & 75.0 & 75.0 & 75.0 & 75.0 & 75.0 & 75.0 \\
\hline $21-28$ & 8.2 & 26.0 & 56.6 & 60.6 & 66.9 & 75.0 & 75.0 & 75.0 & 75.0 & 75.0 & 75.0 \\
\hline ar $=1-10$ & 0.0 & 26.0 & 49.3 & 63.3 & 73.2 & 75.0 & 75.0 & 75.0 & 75.0 & 75.0 & 75.0 \\
\hline $11-20$ & 0.0 & 20.9 & 41.5 & 43.5 & 47.6 & 70.5 & 75.0 & 75.0 & 75.0 & 75.0 & 75.0 \\
\hline $21-31$ & 0.0 & 6.8 & 39.0 & 42.0 & 46.9 & 56.5 & 70.0 & 70.8 & 75.0 & 75.0 & 75.0 \\
\hline abr.1-10 & 0.0 & 8.5 & 33.2 & 47.0 & 52.3 & 56.5 & 66.7 & 75.0 & 75.0 & 75.0 & 75.0 \\
\hline $11-20$ & 0.0 & 13.6 & 33.4 & 39.3 & 48.3 & 55.5 & 61.0 & 66.4 & 75.0 & 75.0 & 75.0 \\
\hline $21-30$ & 0.0 & 4.5 & 16.4 & 30.1 & 41.9 & 45.5 & 55.0 & 61.5 & 67.2 & 71.0 & 75.0 \\
\hline (ci.1-10 & 0.0 & 0.0 & 21.5 & 24.5 & 37.2 & 47.6 & 56.9 & 63.1 & 68.0 & 75.0 & 75.0 \\
\hline $11-20$ & 0.0 & 0.0 & 4.3 & 24.6 & 32.8 & 42.3 & 54.8 & 58.1 & 69.3 & 75.0 & 75.0 \\
\hline $21-31$ & 0.0 & 0.0 & 0.0 & 12.5 & 24.3 & 33.3 & 41.5 & 66.6 & 74.3 & 75.0 & 75.0 \\
\hline jun. $1-10$ & 0.0 & 0.0 & 0.0 & 14.6 & 18.3 & 28.8 & 46.1 & 54.5 & 60.1 & 66.0 & 75.0 \\
\hline $11-20$ & 0.0 & 0.0 & 0.0 & 5.9 & 25.8 & 29.1 & 39.4 & 48.6 & 58.6 & 70.5 & 75.0 \\
\hline $21-30$ & 0.0 & 0.0 & 0.0 & 2.4 & 11.0 & 26.7 & 31.7 & 45.2 & 57.4 & 75.0 & 75.0 \\
\hline jul. $1-10$ & 0.0 & 0.0 & 0.0 & 0.0 & 3.7 & 9.6 & 18.8 & 38.7 & 57.8 & 60.5 & 75.0 \\
\hline $11-20$ & 0.0 & 0.0 & 0.0 & 0.0 & 0.0 & 0.0 & 18.4 & 36.7 & 38.8 & 44.6 & 75.0 \\
\hline $21-31$ & 0.0 & 0.0 & 0.0 & 0.0 & 0.0 & 0.0 & 13.6 & 18.9 & 36.8 & 48.7 & 68.5 \\
\hline $290.1-10$ & 0.0 & 0.0 & 0.0 & 0.0 & 0.0 & 0.0 & 2.8 & 5.9 & 19.0 & 40.8 & 75.0 \\
\hline $11-20$ & 0.0 & 0.0 & 0.0 & 0.0 & 0.0 & 0.0 & 0.0 & 0.0 & 5.7 & 21.9 & 75.0 \\
\hline $21-31$ & 0.0 & 0.0 & 0.0 & 0.0 & 0.0 & 0.0 & 0.0 & 0.4 & 13.4 & 50.3 & 75.0 \\
\hline set. $1-10$ & 0.0 & 0.0 & 0.0 & 0.0 & 0.0 & 0.0 & 4.9 & 17.5 & 30.3 & 66.0 & 79.0 \\
\hline $11-20$ & 0.0 & 0.0 & 0.0 & 0.0 & 0.0 & 0.0 & 6.4 & 16.5 & 24.7 & 53.1 & 75.0 \\
\hline $21-30$ & 0.0 & 0.0 & 0.0 & 0.0 & 4.8 & 10.2 & 12.1 & 20.7 & 45.2 & 75.0 & 75.0 \\
\hline out. $1-10$ & 0.0 & 0.0 & 0.0 & 0.0 & 11.8 & 23.6 & 44.9 & 52.6 & 74.1 & 75.0 & 75.0 \\
\hline $11-20$ & 0.0 & 0.0 & 0.0 & 6.9 & 21.7 & 43.4 & 55.4 & 64.4 & 75.0 & 75.0 & 75.0 \\
\hline $21-31$ & 0.0 & 0.0 & 0.0 & 21.4 & 43.7 & 51.3 & 60.9 & 75.0 & 75.0 & 75.0 & 75.0 \\
\hline nov. $1-10$ & 0.0 & 0.0 & 12.3 & 32.3 & 43.4 & 58.5 & 66.8 & 69.2 & 75.0 & 75.0 & 75.0 \\
\hline $11-20$ & 0.0 & 0.0 & 28.4 & 44.7 & 54.2 & 55.9 & 75.0 & 75.0 & 75.0 & 75.0 & 75.0 \\
\hline $21-30$ & 2.2 & 40.6 & 47.9 & 53.3 & 61.2 & 68.6 & 72.7 & 75.0 & 75.0 & 75.0 & 75.0 \\
\hline dez.1-10 & 0.0 & 34.0 & 57.8 & 71.3 & 75.0 & 75.0 & 75.0 & 75.0 & 75.0 & 75.0 & 75.0 \\
\hline $11-20$ & 0.0 & 36.1 & 57.0 & 73.5 & 75.0 & 75.0 & 75.0 & 75.0 & 75.0 & 75.0 & 75.0 \\
\hline $21-31$ & 0.2 & 49.5 & 75.0 & 75.0 & 75.0 & 75.0 & 75.0 & 75.0 & 75.0 & 75.0 & 75.0 \\
\hline
\end{tabular}


TABELA 27 - CORDEIROPOLIS: DEFICITES (EALANCO COM AFD $=75$ ต

DECIL

\begin{tabular}{|c|c|c|c|c|c|c|c|c|c|c|c|}
\hline DECEHDIO & BIN. & 1 & 2 & 3 & 4 & 5 & 6 & 7 & 8 & 9 & 10 \\
\hline jan. $1-10$ & 0.0 & 0.0 & 0.0 & 0.0 & 0.0 & 0.0 & 0.0 & 0.0 & 0.0 & 0.0 & 1.7 \\
\hline $11-20$ & 0.0 & 0.0 & 0.0 & 0.0 & 0.0 & 0.0 & 0.0 & 0.0 & 0.0 & 0.0 & 16.7 \\
\hline $21-31$ & 0.0 & 0.0 & 0.0 & 0.0 & 0.0 & 0.0 & 0.0 & 0.0 & 0.0 & 0.0 & 0.0 \\
\hline fev. $1-10$ & 0.0 & 0.0 & 0.0 & 0.0 & 0.0 & 0.0 & 0.0 & 0.0 & 0.0 & 0.0 & 0.0 \\
\hline $11-20$ & 0.0 & 0.0 & 0.0 & 0.0 & 0.0 & 0.0 & 0.0 & 0.0 & 0.0 & 0.0 & 0.0 \\
\hline $21-28$ & 0.0 & 0.0 & 0.0 & 0.0 & 0.0 & 0.0 & 0.0 & 0.0 & 0.0 & 0.0 & 0.0 \\
\hline mar. $1-10$ & 0.0 & 0.0 & 0.0 & 0.0 & 0.0 & 0.0 & 0.0 & 0.0 & 0.0 & 0.0 & 2.2 \\
\hline $11-20$ & 0.0 & 0.0 & 0.0 & 0.0 & 0.0 & 0.0 & 0.0 & 0.0 & 0.0 & 0.0 & 37.5 \\
\hline $2|-3|$ & 0.0 & 0.0 & 0.0 & 0.0 & 0.0 & 0.0 & 0.0 & 0.0 & 0.0 & 0.0 & 29.7 \\
\hline$a b r, 1-10$ & 0.0 & 0.0 & 0.0 & 0.0 & 0.0 & 0.0 & 0.0 & 0.0 & 0.0 & 0.0 & 4.2 \\
\hline$\quad 11-20$ & 0.0 & 0.0 & 0.0 & 0.0 & 0.0 & 0.0 & 0.0 & 0.0 & 0.0 & 0.0 & 14.7 \\
\hline $21-30$ & 0.0 & 0.0 & 0.0 & 0.0 & 0.0 & 0.0 & 0.0 & 0.0 & 0.0 & 0.0 & 10.9 \\
\hline -2i.1-10 & 0.0 & 0.0 & 0.0 & 0.0 & 0.0 & 0.0 & 0.0 & 0.0 & 0.0 & 2.4 & 19.6 \\
\hline$\quad 11-20$ & 0.0 & 0.0 & 0.0 & 0.0 & 0.0 & 0.0 & 0.0 & 0.0 & 0.0 & 0.0 & 19.4 \\
\hline $21-31$ & 0.0 & 0.0 & 0.0 & 0.0 & 0.0 & 0.0 & 0.0 & 0.0 & 0.0 & 17.3 & 20.0 \\
\hline jun. 1-10 & 0.0 & 0.0 & 0.0 & 0.0 & 0.0 & 0.0 & 0.0 & 0.0 & 1.9 & 11.5 & 18.9 \\
\hline $11-20$ & 0.0 & 0.0 & 0.0 & 0.0 & 0.0 & 0.0 & 0.0 & 0.0 & 9.6 & 17.1 & 22.0 \\
\hline $21-30$ & 0.0 & 0.0 & 0.0 & 0.0 & 0.0 & 0.0 & 0.0 & 0.0 & 5.2 & 18.6 & 23.5 \\
\hline jul. $1-10$ & 0.0 & 0.0 & 0.0 & 0.0 & 0.0 & 0.0 & 0.0 & 4.9 & 10.8 & 13.6 & 19.0 \\
\hline $11-20$ & 0.0 & 0.0 & 0.0 & 0.0 & 0.0 & 0.0 & 3.5 & 11.0 & 14.3 & 20.6 & 25.4 \\
\hline $21-31$ & 0.0 & 0.0 & 0.0 & 0.0 & 0.0 & 0.0 & 4.1 & 14.9 & 20.3 & 23.2 & 26.3 \\
\hline ago.1-10 & 0.0 & 0.0 & 0.0 & 0.0 & 0.0 & 1.3 & 8.4 & 20.9 & 21.9 & 25.8 & 30.1 \\
\hline $11-20$ & 0.0 & 0.0 & 0.0 & 0.0 & 3.7 & 11.7 & 15.7 & 19.9 & 23.1 & 26.1 & 28.4 \\
\hline $2 \mid-31$ & 0.0 & 0.0 & 0.0 & 0.0 & 8.2 & 18.5 & 25.0 & 26.1 & 29.5 & 31.9 & 35.7 \\
\hline set. $1-10$ & 0.0 & 0.0 & 0.0 & 0.0 & 0.0 & 0.0 & 12.7 & 22.5 & 25.6 & 29.7 & 31.3 \\
\hline $11-20$ & 0.0 & 0.0 & 0.0 & 0.0 & 0.0 & 2.3 & 10.0 & 26.0 & 27.3 & 28.2 & 39.2 \\
\hline $21-30$ & 0.0 & 0.0 & 0.0 & 0.0 & 0.0 & 0.0 & 0.0 & 8.0 & 19.5 & 22.8 & 37.3 \\
\hline out. $1-10$ & 0.0 & 0.0 & 0.0 & 0.0 & 0.0 & 0.0 & 0.0 & 0.0 & 14.3 & 36.6 & 40.5 \\
\hline $11-20$ & 0.0 & 0.0 & 0.0 & 0.0 & 0.0 & 0.0 & 0.0 & 0.0 & 9.7 & 22.1 & 48.0 \\
\hline $21-31$ & 0.0 & 0.0 & 0.0 & 0.0 & 0.0 & 0.0 & 0.0 & 0.0 & 1.5 & 25.2 & 51.1 \\
\hline nov.1-10 & 0.0 & 0.0 & 0.0 & 0.0 & 0.0 & 0.0 & 0.0 & 0.0 & 0.0 & 0.0 & 18.8 \\
\hline $11-20$ & 0.0 & 0.0 & 0.0 & 0.0 & 0.0 & 0.0 & 0.0 & 0.0 & 0.0 & 0.0 & 35.9 \\
\hline $21-30$ & 0.0 & 0.0 & 0.0 & 0.0 & 0.0 & 0.0 & 0.0 & 0.0 & 0.0 & 0.0 & 0.0 \\
\hline dez.1-10 & 0.0 & 0.0 & 0.0 & 0.0 & 0.0 & 0.0 & 0.0 & 0.0 & 0.0 & 0.0 & 14.2 \\
\hline $11-20$ & 0.0 & 0.0 & 0.0 & 0.0 & 0.0 & 0.0 & 0.0 & 0.0 & 0.0 & 0.0 & 21.8 \\
\hline $21-31$ & 0.0 & 0.0 & 0.0 & 0.0 & 0.0 & 0.0 & 0.0 & 0.0 & 0.0 & 0.0 & 0.0 \\
\hline
\end{tabular}


TABELA 28 - CORDEIROPOLIS: EXCEDENTES HIDRICOS (BALANCO COM AFO $=75$ )

DECIL

\begin{tabular}{|c|c|c|c|c|c|c|c|c|c|c|c|}
\hline & & 1 & 2 & 3 & 4 & 5 & 6 & 7 & 8 & 9 & 10 \\
\hline $\operatorname{jan} .1-10$ & 0.0 & 0.0 & 1.8 & 21.5 & 26.6 & 38.9 & 59.3 & 73.9 & 84.9 & 114.9 & 121.1 \\
\hline $11-20$ & 0.0 & 0.0 & 0.0 & 3.4 & 21.9 & 35.6 & 40.8 & 75.5 & 90.8 & 108.9 & 346.6 \\
\hline $21-31$ & 0.0 & 0.0 & 0.0 & 10.9 & 19.7 & 28.7 & 35.9 & 58.1 & 80.4 & 101.0 & 119.3 \\
\hline fev. $1-10$ & 0.0 & 0.0 & 0.0 & 1.5 & 9.8 & 26.0 & 34.9 & 49.1 & 67.1 & 89.4 & 166.0 \\
\hline $11-20$ & 0.0 & 0.0 & 0.0 & 0.0 & 7.4 & 18.3 & 44.8 & 54.8 & 78.1 & 95.1 & 176.3 \\
\hline $21-28$ & 0.0 & 0.0 & 0.0 & 0.0 & 0.0 & 9.0 & 14.6 & 28.2 & 70.2 & 110.0 & 237.6 \\
\hline $\operatorname{mar} .1-10$ & 0.0 & 0.0 & 0.0 & 0.0 & 0.0 & 2.1 & 11.6 & 36.5 & 70.7 & 97.5 & 228.7 \\
\hline $11-20$ & 0.0 & 0.0 & 0.0 & 0.0 & 0.0 & 0.0 & 10.5 & 31.8 & 90.6 & 152.6 & 217.3 \\
\hline $21-31$ & 0.0 & 0.0 & 0.0 & 0.0 & 0.0 & 0.0 & 0.0 & 0.0 & 1.1 & 17.9 & 103.4 \\
\hline $8 b r \cdot 1-10$ & 0.0 & 0.0 & 0.0 & 0.0 & 0.0 & 0.0 & 0.0 & 6.6 & 15.4 & 28.3 & 61.5 \\
\hline $11-20$ & 0.0 & 0.0 & 0.0 & 0.0 & 0.0 & 0.0 & 0.0 & 0.0 & 0.3 & 13.3 & 57.8 \\
\hline $21-30$ & 0.0 & 0.0 & 0.0 & 0.0 & 0.0 & 0.0 & 0.0 & 0.0 & 0.0 & 0.0 & 40.5 \\
\hline adi. $1-10$ & 0.0 & 0.0 & 0.0 & 0.0 & 0.0 & 0.0 & 0.0 & 0.0 & 0.0 & 15.3 & 69.1 \\
\hline $11-20$ & 0.0 & 0.0 & 0.0 & 0.0 & 0.0 & 0.0 & 0.0 & 0.0 & 0.0 & 35.2 & 91.9 \\
\hline $21-31$ & 0.0 & 0.0 & 0.0 & 0.0 & 0.0 & 0.0 & 0.0 & 0.0 & 0.0 & 2.0 & 195.9 \\
\hline jun. $1-10$ & 0.0 & 0.0 & 0.0 & 0.0 & 0.0 & 0.0 & 0.0 & 0.0 & 0.0 & 0.0 & 78.7 \\
\hline $11-20$ & 0.0 & 0.0 & 0.0 & 0.0 & 0.0 & 0.0 & 0.0 & 0.0 & 0.0 & 0.0 & 65.6 \\
\hline $21-30$ & 0.0 & 0.0 & 0.0 & 0.0 & 0.0 & 0.0 & 0.0 & 0.0 & 0.0 & 7.7 & 53.5 \\
\hline jul. $1-10$ & 0.0 & 0.0 & 0.0 & 0.0 & 0.0 & 0.0 & 0.0 & 0.0 & 0.0 & 0.0 & 94.6 \\
\hline $11-20$ & 0.0 & 0.0 & 0.0 & 0.0 & 0.0 & 0.0 & 0.0 & 0.0 & 0.0 & 0.0 & 14.4 \\
\hline $21-31$ & 0.0 & 0.0 & 0.0 & 0.0 & 0.0 & 0.0 & 0.0 & 0.0 & 0.0 & 0.0 & 0.0 \\
\hline $290.1-10$ & 0.0 & 0.0 & 0.0 & 0.0 & 0.0 & 0.0 & 0.0 & 0.0 & 0.0 & 0.0 & 23.4 \\
\hline $11-20$ & 0.0 & 0.0 & 0.0 & 0.0 & 0.0 & 0.0 & 0.0 & 0.0 & 0.0 & 0.0 & 7.1 \\
\hline $21-31$ & 0.0 & 0.0 & 0.0 & 0.0 & 0.0 & 0.0 & 0.0 & 0.0 & 0.0 & 0.0 & 15.0 \\
\hline set. $1-10$ & 0.0 & 0.0 & 0.0 & 0.0 & 0.0 & 0.0 & 0.0 & 0.0 & 0.0 & 0.0 & 19.6 \\
\hline $11-20$ & 0.0 & 0.0 & 0.0 & 0.0 & 0.0 & 0.0 & 0.0 & 0.0 & 0.0 & 0.0 & 65.9 \\
\hline $21-30$ & 0.0 & 0.0 & 0.0 & 0.0 & 0.0 & 0.0 & 0.0 & 0.0 & 0.0 & 5.6 & 22.1 \\
\hline out. $1-10$ & 0.0 & 0.0 & 0.0 & 0.0 & 0.0 & 0.0 & 0.0 & 0.0 & 0.0 & 17.5 & 57.9 \\
\hline $11-20$ & 0.0 & 0.0 & 0.0 & 0.0 & 0.0 & 0.0 & 0.0 & 0.0 & 10.9 & 35.4 & 62.1 \\
\hline $21-31$ & 0.0 & 0.0 & 0.0 & 0.0 & 0.0 & 0.0 & 0.0 & 3.4 & 27.8 & 40.1 & 73.8 \\
\hline nov. $1-10$ & 0.0 & 0.0 & 0.0 & 0.0 & 0.0 & 0.0 & 0.0 & 0.0 & 7.4 & 31.4 & 96.7 \\
\hline $11-20$ & 0.0 & 0.0 & 0.0 & 0.0 & 0.0 & 0.0 & 7.4 & 14.0 & 29.1 & 40.3 & 97.2 \\
\hline $21-30$ & 0.0 & 0.0 & 0.0 & 0.0 & 0.0 & 0.0 & 0.0 & 6.7 & 32.1 & 52.8 & 112.0 \\
\hline dez.1-10 & 0.0 & 0.0 & 0.0 & 0.0 & 11.6 & 22.1 & 44.7 & 59.4 & 80.5 & 98.6 & $\$ 70.1$ \\
\hline $11-20$ & 0.0 & 0.0 & 0.0 & 0.0 & 18.6 & 36.9 & 46.9 & 56.8 & 82.9 & 104.9 & 135.1 \\
\hline $21-31$ & 0.0 & 0.0 & 12.2 & 21.2 & 24.1 & 39.2 & 67.7 & 80.0 & 95.3 & 128.9 & 207.5 \\
\hline
\end{tabular}


DECIL

\begin{tabular}{|c|c|c|c|c|c|c|c|c|c|c|c|}
\hline DECENDIO & HIN. & 1 & 2 & 3 & 4 & 5 & 6 & 7 & 8 & 9 & 10 \\
\hline jan. 1-10 & 14.8 & 20.8 & 36.9 & 41.8 & 61.4 & 83.9 & 103.2 & 110.3 & 114.2 & 121.7 & 193.2 \\
\hline $11-20$ & 2.1 & 4.3 & 13.2 & 23.3 & 39.4 & 57.5 & 78.9 & 113.5 & 129.9 & 156.3 & 223.5 \\
\hline $21-31$ & 2.4 & 18.7 & 26.8 & 34.9 & 55.3 & 64.5 & 68.9 & 80.4 & 103.2 & 130 & 207 \\
\hline fev. $1-10$ & 1.1 & 17.6 & 29 & 43.7 & 49.6 & 60.1 & 70 & 93.1 & 106.7 & 166.8 & 192.9 \\
\hline $11-20$ & 3.4 & 14.1 & 21.7 & 36.6 & 41.1 & 63.3 & 70.4 & 75.6 & 106.2 & 127.8 & 305 \\
\hline $21-28$ & 1.4 & 8.8 & 17.6 & 29.2 & 39.3 & 42.9 & 52.5 & 70.1 & 99.4 & 132.8 & 191.3 \\
\hline 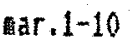 & 4.8 & 6.8 & 11.8 & 19.4 & 23 & 31.2 & 47.3 & 68.8 & 72.5 & 88.9 & 154.1 \\
\hline $11-20$ & 0 & 0 & 4.4 & 14.7 & 24.1 & 32.6 & 58.8 & 62.2 & 77.1 & 136.6 & 298.7 \\
\hline $21-31$ & 0 & 0.5 & 5.9 & 9.5 & 19.3 & 29.6 & 33.8 & 45.3 & 56.7 & 75.8 & 185.9 \\
\hline$a b r .1-10$ & 0 & 0 & 2.4 & 5.9 & 12.7 & 26.2 & 36.5 & 42.5 & 52.2 & 81.4 & 136.2 \\
\hline $11-20$ & 0 & 0 & 1 & 2.0 & 6.3 & 16 & 18.8 & 25.5 & 45 & 59.8 & 98.9 \\
\hline $21-30$ & 0 & 0 & 0 & 0.5 & 6.2 & 6.6 & 10.3 & 21.3 & 29.3 & 39.8 & 110.1 \\
\hline ai. $1-10$ & 0 & 0 & 0.5 & 2.8 & 4.4 & 9.1 & 14.5 & 28.1 & 32.0 & 40.9 & 114.8 \\
\hline $11-20$ & 0 & 0 & 0 & 0 & 1 & 1.7 & 8.7 & 30 & 41.2 & 59.5 & 111.4 \\
\hline $21-31$ & 0 & 0 & 0 & 0.2 & 1.5 & 8.6 & 14.6 & 16.8 & 32.6 & 51.3 & 261.8 \\
\hline jun. 1-10 & 0 & 0 & 0 & 0 & 0 & 2.7 & 8.4 & 13.9 & 20.6 & 37.2 & 120.3 \\
\hline $11-20$ & 0 & 0 & 0 & 0 & 0 & 2.9 & 5.6 & 24.5 & 29.1 & 61.3 & 108.6 \\
\hline $21-30$ & 0 & 0 & 0 & 0 & 0 & 0.5 & 4 & 15.7 & 27.5 & 47.7 & 109 \\
\hline juL. $1-10$ & 0 & 0 & 0 & 0 & 0 & 4.7 & 10 & 14.7 & 16.8 & 33 & 69.2 \\
\hline $11-20$ & 0 & 0 & 0 & 0 & 0 & 0 & 4 & 5.7 & 11.3 & 19.2 & 88.1 \\
\hline $21-31$ & 0 & 0 & 0 & 0 & 0 & 2.5 & 3.7 & 8.5 & 10.8 & 34.2 & 106.7 \\
\hline $290.1-10$ & 0 & 0 & 0 & 0 & 0 & 0 & 1 & 5.8 & 13 & 20.5 & 35.2 \\
\hline $11-20$ & 0 & 0 & 0 & 0 & 0 & 0.2 & 0.7 & 4.8 & 12.3 & 19.7 & 78.5 \\
\hline $21-31$ & 0 & 0 & 0 & 0 & 0.5 & 2.1 & 4.8 & 8 & 19.5 & 31.6 & 98.1 \\
\hline set. $1-10$ & 0 & 0 & 0 & 0 & 1.8 & 6.4 & 17.3 & 30.4 & 34.1 & 50.5 & 74.5 \\
\hline $11-20$ & 0 & 0 & 0 & 0 & 1.2 & 3.2 & 7.4 & 16.7 & 32.2 & 46.9 & 74.4 \\
\hline $21-30$ & 0 & 0.5 & 6 & 8.3 & 11.5 & 20 & 27.6 & 38.7 & 52.6 & 74.3 & 86.8 \\
\hline out. $1-10$ & 0 & 0 & 5.3 & 8.4 & 18.3 & 24.6 & 32.5 & 56.8 & 60.7 & 90.3 & 116.8 \\
\hline $11-20$ & 0 & 2.2 & 8.1 & 10 & 24.5 & 26.2 & 34.4 & 47.2 & 74.5 & 112.3 & 143 \\
\hline $21-31$ & 0 & 0 & 22 & 27.2 & 32.7 & 37.8 & 42.5 & 48.7 & 58.7 & 76.7 & 138.3 \\
\hline nov. $1-10$ & 5.6 & 8.7 & 13.2 & 19.4 & 20.3 & 24.8 & 45.2 & 59.9 & 75 & 89.8 & 202.5 \\
\hline $11-20$ & 0.6 & 2.3 & 18.2 & 26 & 32.2 & 39 & 43.2 & 56.8 & 78.2 & 99.2 & 212 \\
\hline $21-30$ & 0 & 4.7 & 11.7 & 24.2 & 29.8 & 37.4 & 50.5 & 57.5 & 66.3 & 89.8 & 279.7 \\
\hline dez. $1-10$ & 0.4 & 17.8 & 26.1 & 40.3 & 48.2 & 51.7 & 60.4 & 86.8 & 114.7 & 147.2 & 298.1 \\
\hline $11-20$ & 2.8 & 24 & 36.4 & 45.8 & 57 & 61.3 & 69.3 & 89.6 & 109.3 & 129.7 & 238.6 \\
\hline $21-31$ & 20 & 33.3 & 44.7 & 56.5 & 72.4 & 87 & 105.2 & 114.2 & 131.5 & 186.5 & 259.2 \\
\hline
\end{tabular}


TABELA 30 - JAU: EVAPOTRANSPIRACAO DE REFERENCIA

DECIL

\begin{tabular}{|c|c|c|c|c|c|c|c|c|c|c|c|}
\hline DECENDIO & MIN. & 1 & 2 & 3 & 4 & 5 & 6 & 7 & $B$ & 9 & 10 \\
\hline $33 n .1-10$ & 28.8 & 43.8 & 48.6 & 50.6 & 55.5 & 56.6 & 57.6 & 61.4 & 63.4 & 68.3 & 70.4 \\
\hline $11-20$ & 28.8 & 42.5 & 48.3 & 53.7 & 54.5 & 60.9 & 61.5 & 64.7 & 65.5 & 67.1 & 73.4 \\
\hline $21-31$ & 31.3 & 42.5 & 52.8 & 56.1 & 59.7 & 60.7 & 67.4 & 67.9 & 69.3 & 74.8 & 88.1 \\
\hline fev. $1-10$ & 41.6 & 42.6 & 49.2 & 51.4 & 54.7 & 58.0 & 61.0 & 64.7 & 66.3 & 68.7 & 72.2 \\
\hline $11-20$ & 34.5 & 43.4 & 46.4 & 50.4 & 53.2 & 54.7 & 61.0 & 64.7 & 65.8 & 67.6 & 70.1 \\
\hline $21-28$ & 29.6 & 33.4 & 36.3 & 40.4 & 42.7 & 43.6 & 45.2 & 46.5 & 49.2 & 52.1 & 57.6 \\
\hline ar. 1-10 & 37.5 & 43.3 & 46.9 & 51.3 & 51.8 & 53.6 & 56.1 & 57.2 & 58.5 & 63.2 & 65.8 \\
\hline $11-20$ & 34.6 & 37.9 & 49.9 & 50.9 & 51.8 & 53.5 & 56.3 & 57.3 & 60.4 & 63.6 & 67.4 \\
\hline $21-31$ & 47.9 & 50.7 & 53.2 & 54.1 & 54.9 & 57.2 & 58.3 & 61.8 & 62.9 & 64.8 & 70.7 \\
\hline abr. $1-10$ & 36.1 & 37.8 & 38.5 & $\$ 1.1$ & 42.1 & 43.5 & 45.4 & 46.0 & 47.5 & 48.6 & 54.8 \\
\hline $11-20$ & 36.5 & 37.6 & 38.8 & 39.9 & 42.4 & 43.0 & 43.8 & 44.8 & 46.5 & 46.9 & 48.5 \\
\hline $21-30$ & 32.0 & 34.9 & 35.8 & 37.0 & 39.2 & 40.7 & 41.3 & $\$ 1.8$ & 43.1 & 46.2 & 54.3 \\
\hline 12i. $1-10$ & 27.7 & 30.0 & 34.0 & 34.5 & 34.8 & 35.4 & 36.0 & 37.8 & 39.1 & 60.3 & 47.4 \\
\hline $11-20$ & 25.4 & 27.8 & 30.7 & 33.3 & 34.7 & 36.1 & 36.3 & 36.9 & 37.5 & 40.8 & 45.5 \\
\hline $21-31$ & 28.8 & 29.6 & 34.6 & 35.5 & 37.1 & 37.4 & 38.9 & 39.8 & 40.5 & 42.4 & 48.5 \\
\hline jun. $1-10$ & 19.0 & 27.2 & 28.9 & 30.7 & 32.1 & 34.5 & 35.5 & 37.4 & 38.1 & 38.9 & 43.1 \\
\hline $11-20$ & 15.9 & 27.6 & 28.0 & 28.9 & 30.9 & 32.3 & 32.9 & 34.9 & 36.3 & 37.6 & 41.9 \\
\hline $21-30$ & 25.7 & 27.8 & 30.2 & 31.8 & 34.2 & 34.5 & 35.9 & 37.4 & 38.2 & 38.4 & 41.8 \\
\hline jul. $1-10$ & 21.4 & 30.2 & 33.0 & 34.9 & 35.9 & 36.1 & 36.6 & 37.3 & 39.6 & 41.3 & 47.7 \\
\hline $11-20$ & 29.2 & 32.6 & 33.7 & 34.8 & 35.4 & 36.8 & 37.7 & 38.3 & 41.1 & 43.9 & 47.2 \\
\hline $21-31$ & 32.5 & 37.0 & 39.0 & 41.0 & 42.5 & 44.3 & 44.7 & 45.0 & 46.8 & 49.6 & 53.7 \\
\hline $200.1-10$ & 27.6 & 32.8 & 35.4 & 37.3 & 41.5 & 42.4 & 44.0 & 45.0 & 45.9 & 49.5 & 50.3 \\
\hline $11-20$ & 27.3 & 32.5 & 37.8 & 40.3 & 41.7 & 43.6 & 45.1 & 46.6 & 87.4 & 49.5 & 55.2 \\
\hline $21-31$ & 32.0 & 37.0 & 40.9 & 46.0 & 48.2 & 50.8 & 53.3 & 55.6 & 57.3 & 60.0 & 65.2 \\
\hline set. $1-10$ & 27.4 & 34.8 & 38.5 & $\$ 1.9$ & 43.3 & 45.1 & 48.7 & 52.5 & 53.2 & 58.6 & 72.4 \\
\hline $11-20$ & 30.1 & 31.6 & 37.9 & 46.4 & 48.1 & 49.8 & 53.8 & 56.7 & 57.7 & 99.4 & 66.4 \\
\hline $21-30$ & 33.6 & 40.0 & 43.0 & 44.0 & 46.4 & 48.8 & 50.3 & 52.2 & 52.7 & 53.2 & 64.8 \\
\hline out $.1-10$ & 37.8 & 41.2 & 45.5 & 48.9 & 54.8 & 57.3 & 61.6 & 65.7 & 69.7 & 73.9 & 76.2 \\
\hline $11-20$ & 40.0 & 48.2 & 53.9 & 56.6 & 59.1 & 60.6 & 62.4 & 63.9 & 65.5 & 68.5 & 85.8 \\
\hline $21-31$ & 44.8 & 50.7 & 55.1 & 58.6 & 62.8 & 66.2 & 70.0 & 73.1 & 75.2 & 77.4 & 88.8 \\
\hline ov $1-10$ & 43.4 & 52.7 & 54.5 & 58.8 & 60.9 & 64.0 & 66.2 & 68.1 & 70.4 & 71.0 & 78.4 \\
\hline $11-20$ & 41.1 & 46.2 & 50.3 & 55.6 & 57.8 & 60.4 & 64.9 & 66.7 & 69.1 & 73.9 & 91.1 \\
\hline $21-30$ & 41.8 & 43.1 & 56.4 & 58.5 & 62.7 & 64.0 & 65.1 & 69.3 & 69.8 & 73.6 & 79.2 \\
\hline dez.1-10 & 37.0 & 40.6 & 48.2 & 51.7 & 53.9 & 60.0 & 61.3 & 63.9 & 70.4 & 75.3 & 82.0 \\
\hline $11-20$ & 34.9 & 45.4 & 47.5 & 51.0 & 55.5 & 57.2 & 58.1 & 64.2 & 68.1 & 74.8 & 77.9 \\
\hline $21-31$ & 37.1 & 43.7 & 50.3 & 52.8 & 57.1 & 59.7 & 60.8 & 64.8 & 66.1 & 72.8 & 93.1 \\
\hline
\end{tabular}




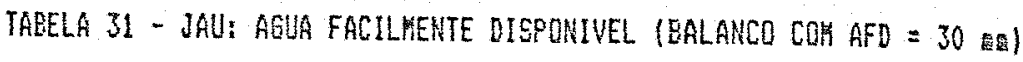

DECIL

\begin{tabular}{|c|c|c|c|c|c|c|c|c|c|c|c|}
\hline & & 1 & 2 & 3 & 4 & $\mathfrak{5}$ & 6 & 7 & 8 & 9 & 10 \\
\hline jan.t-10 & 10.0 & 13.9 & 30.0 & 30.0 & 30.0 & 30.0 & 30.0 & 30.0 & 30.0 & 30.0 & 30.0 \\
\hline $11-20$ & 0.0 & 1.7 & 12.5 & 20.8 & 30.0 & 30.0 & 30.0 & 30.0 & 30.0 & 30.0 & 30.0 \\
\hline $21-31$ & 0.0 & 6.8 & 19.5 & 30.0 & 30.0 & 30.0 & 30.0 & 30.0 & 30.0 & 30.0 & 30.0 \\
\hline fEv. $1-10$ & 0.0 & 13.6 & 29.4 & 30.0 & 30.0 & 30.0 & 30.0 & 30.0 & 30.0 & 30.0 & 30.0 \\
\hline $11-20$ & 0.0 & 2.3 & 12.6 & 28.8 & 30.0 & 30.0 & 30.0 & 30.0 & 30.0 & 30.0 & 30.0 \\
\hline $21-28$ & 0.0 & 3.4 & 21.0 & 27.3 & 30.0 & 30.0 & 30.0 & 30.0 & 30.0 & 30.0 & 30.0 \\
\hline ar: $1-10$ & 0.0 & 0.0 & 5.3 & 14.7 & 20.5 & 25.5 & 30.0 & 30.0 & 30.0 & 30.0 & 30.0 \\
\hline $11-20$ & 0.0 & 0.0 & 0.0 & 0.8 & 20.6 & 30.0 & 30.0 & 30.0 & 30.0 & 30.0 & 30.0 \\
\hline $21-31$ & 0.0 & 0.0 & 0.0 & 2.6 & 4.0 & 11.8 & 21.5 & 29.9 & 30.0 & 30.0 & 30.0 \\
\hline abr. $1-10$ & 0.0 & 0.0 & 0.0 & 3.3 & 8.5 & 17.2 & 18.8 & 29.9 & 30.0 & 30.0 & 30.0 \\
\hline $11-20$ & 0.0 & 0.0 & 0.0 & 0.0 & 4.9 & 9.0 & 14.7 & 26.3 & 30.0 & 30.0 & 50.0 \\
\hline $21-30$ & 0.0 & 0.0 & 0.0 & 0.0 & 1.6 & 3.6 & 6.7 & 10.2 & 17.5 & 30.0 & 30.0 \\
\hline ai.1-10 & 0.0 & 0.0 & 0.0 & 0.0 & 0.0 & 7.2 & 11.5 & 15.2 & 19.7 & 30.0 & 30.0 \\
\hline$-11-20$ & 0.0 & 0.0 & 0.0 & 0.0 & 0.0 & 0.0 & 10.4 & 11.1 & 30.0 & 30.0 & 30.0 \\
\hline $21-31$ & 0.0 & 0.0 & 0.0 & 0.0 & 0.0 & 0.0 & 4.5 & 9.6 & 30.0 & 30.0 & 30.0 \\
\hline jun $21-10$ & 0.0 & 0.0 & 0.0 & 0.0 & 0.0 & 0.0 & 7.0 & 14.0 & 21.1 & 29.0 & 30.0 \\
\hline $11-20$ & 0.0 & 0.0 & 0.0 & 0.0 & 0.0 & 0.0 & 8.1 & 10.9 & 29.7 & 30.0 & 30.0 \\
\hline $21-30$ & 0.0 & 0.0 & 0.0 & 0.0 & 0.0 & 0.0 & 7.9 & 12.9 & 25.3 & 30.0 & 30.0 \\
\hline jul $: 1-10$ & 0.0 & 0.0 & 0.0 & 0.0 & 0.0 & 0.0 & 0.2 & 6.8 & 11.3 & 25.9 & 30.0 \\
\hline $11-20$ & 0.0 & 0.0 & 0.0 & 0.0 & 0.0 & 0.0 & 0.0 & 0.0 & 0.0 & 17.6 & 30.0 \\
\hline $21-31$ & 0.0 & 0.0 & 0.0 & 0.0 & 0.0 & 0.0 & 0.0 & 0.0 & 0.0 & 14.2 & 30.0 \\
\hline $200.1-10$ & 0.0 & 0.0 & 0.0 & 0.0 & 0.0 & 0.0 & 0.0 & 0.0 & 0.0 & 6.2 & 29.5 \\
\hline $11-20$ & 0.0 & 0.0 & 0.0 & 0.0 & 0.0 & 0.0 & 0.0 & 0.0 & 0.0 & 6.3 & 30.0 \\
\hline $21-31$ & 0.0 & 0.0 & 0.0 & 0.0 & 0.0 & 0.0 & 0.0 & 0.0 & 1.6 & 12.4 & 30.0 \\
\hline set.1-10 & 0.0 & 0.0 & 0.0 & 0.0 & 0.0 & 0.0 & 2.5 & 6.3 & 14.9 & 30.0 & 30.0 \\
\hline $11-20$ & 0.0 & 0.0 & 0.0 & 0.0 & 0.0 & 0.0 & 0.0 & 11.5 & 18.8 & 30.0 & 30.0 \\
\hline $21-30$ & 0.0 & 0.0 & 0.0 & 0.0 & 0.0 & 0.0 & 19.1 & 21.2 & 28.4 & 30.0 & 30.0 \\
\hline out.1-10 & 0.0 & 0.0 & 0.0 & 0.0 & 0.0 & 0.0 & 25.8 & 30.0 & 30.0 & 30.0 & 30.0 \\
\hline $11-20$ & 0.0 & 0.0 & 0.0 & 0.0 & 4.0 & 11.8 & 15.3 & 29.8 & 30.0 & 30.0 & 50.0 \\
\hline $21-31$ & 0.0 & 0.0 & 0.0 & 0.0 & 6.0 & 14.7 & 25.4 & 30.0 & 30.0 & 30.0 & 30.0 \\
\hline nov. $1-10$ & 0.0 & 0.0 & 0.0 & 0.0 & 0.4 & 18.5 & 29.0 & 30.0 & 30.0 & 30.0 & 30.0 \\
\hline $11-20$ & 0.0 & 0.0 & 0.0 & 1.4 & 6.6 & 22.1 & 30.0 & 30.0 & 30.0 & 30.0 & 30.0 \\
\hline $21-30$ & 0.0 & 0.0 & 0.0 & 4.6 & 14.5 & 20.5 & 27.1 & 30.0 & 30.0 & 30.0 & 30.0 \\
\hline dez.1-10 & 0.0 & 3.2 & 16.3 & 17.7 & 23.5 & 30.0 & 30.0 & 30.0 & 30.0 & 30.0 & 30.0 \\
\hline $11-20$ & 0.0 & 0.0 & 26.5 & 30.0 & 30.0 & 30.0 & 30.0 & 30.0 & 30.0 & 30.0 & 30.0 \\
\hline $21-31$ & 0.0 & 12.2 & 30.0 & 30.0 & 30.0 & 30.0 & 30.0 & 30.0 & 30.0 & 30.0 & 30.0 \\
\hline
\end{tabular}


DECIL

\begin{tabular}{|c|c|c|c|c|c|c|c|c|c|c|c|}
\hline DECENDIO & MIN. & 1 & 2 & 3 & 4 & 5 & 6 & 7 & 8 & 9 & 10 \\
\hline jan. $1-10$ & 0.0 & 0.0 & 0.0 & 0.0 & 0.0 & 0.0 & 0.0 & 0.0 & 0.0 & 0.0 & 0.0 \\
\hline $11-20$ & 0.0 & 0.0 & 0.0 & 0.0 & 0.0 & 0.0 & 0.0 & 0.0 & 0.0 & 0.0 & 4.3 \\
\hline $21-31$ & 0.0 & 0.0 & 0.0 & 0.0 & 0.0 & 0.0 & 0.0 & 0.0 & 0.0 & 0.0 & 18.9 \\
\hline fev. $1-10$ & 0.0 & 0.0 & 0.0 & 0.0 & 0.0 & 0.0 & 0.0 & 0.0 & 0.0 & 0.0 & 18.4 \\
\hline $11-20$ & 0.0 & 0.0 & 0.0 & 0.0 & 0.0 & 0.0 & 0.0 & 0.0 & 0.0 & 0.0 & 0.4 \\
\hline $21-28$ & 0.0 & 0.0 & 0.0 & 0.0 & 0.0 & 0.0 & 0.0 & 0.0 & 0.0 & 0.0 & 21.7 \\
\hline ar. $1-10$ & 0.0 & 0.0 & 0.0 & 0.0 & 0.0 & 0.0 & 0.0 & 0.0 & 0.0 & 0.0 & 20.6 \\
\hline $11-20$ & 0.0 & 0.0 & 0.0 & 0.0 & 0.0 & 0.0 & 0.0 & 0.0 & 1.1 & 7.1 & 28.4 \\
\hline $21-31$ & 0.0 & 0.0 & 0.0 & 0.0 & 0.0 & 0.0 & 0.0 & 0.0 & 0.0 & 3.7 & 28.2 \\
\hline $26 r .1-10$ & 0.0 & 0.0 & 0.0 & 0.0 & 0.0 & 0.0 & 0.0 & 0.0 & 6.2 & 16.9 & 29.5 \\
\hline $11-20$ & 0.0 & 0.0 & 0.0 & 0.0 & 0.0 & 0.0 & 0.0 & 2.8 & 6.0 & 17.8 & 23.6 \\
\hline $21-30$ & 0.0 & 0.0 & 0.0 & 0.0 & 0.0 & 0.0 & 0.0 & 3.0 & 11.8 & 16.4 & 29.9 \\
\hline ถ⿻一, $1-10$ & 0.0 & 0.0 & 0.0 & 0.0 & 0.0 & 0.0 & 0.0 & 10.4 & 15.1 & 19.2 & 26.1 \\
\hline $11-20$ & 0.0 & 0.0 & 0.0 & 0.0 & 0.0 & 0.0 & 4.8 & 8.5 & 17.7 & 22.4 & 25.0 \\
\hline $21-31$ & 0.0 & 0.0 & 0.0 & 0.0 & 0.0 & 0.0 & 10.7 & 13.1 & 20.3 & 21.9 & 26.7 \\
\hline jun. $1-10$ & 0.0 & 0.0 & 0.0 & 0.0 & 0.0 & 3.6 & 11.0 & 18.0 & 20.7 & 22.5 & 25.9 \\
\hline $11-20$ & 0.0 & 0.0 & 0.0 & 0.0 & 0.0 & 0.0 & 9.3 & 13.0 & 15.2 & 22.6 & 25.1 \\
\hline $21-30$ & 0.0 & 0.0 & 0.0 & 0.0 & 0.0 & 4.3 & 10.7 & 20.6 & 22.4 & 22.9 & 25.1 \\
\hline jul.1-10 & 0.0 & 0.0 & 0.0 & 0.0 & 0.0 & 2.3 & 7.7 & 11.6 & 21.2 & 24.1 & 28.6 \\
\hline $11-20$ & 0.0 & 0.0 & 0.0 & 4.1 & 10.6 & 14.8 & 16.2 & 20.7 & 22.6 & 26.3 & 28.3 \\
\hline $21-31$ & 0.0 & 0.0 & 0.0 & 8.5 & 17.1 & 22.0 & 24.0 & 25.6 & 26.2 & 29.8 & 32.2 \\
\hline ago. $1-10$ & 0.0 & 0.0 & 2.1 & 8.7 & 10.7 & 20.2 & 25.9 & 26.5 & 27.6 & 29.7 & 30.2 \\
\hline $11-20$ & 0.0 & 0.0 & 6.1 & 13.9 & 16.7 & 25.0 & 26.8 & 28.0 & 28.3 & 29.6 & 33.1 \\
\hline $21-31$ & 0.0 & 0.0 & 0.0 & 4.4 & 22.0 & 24.5 & 28.6 & 32.5 & 34.2 & 36.0 & 38.1 \\
\hline set. $1-10$ & 0.0 & 0.0 & 0.0 & 0.0 & 0.0 & 8.2 & 23.4 & 29.2 & 31.5 & 35.1 & 43.4 \\
\hline $11-20$ & 0.0 & 0.0 & 0.0 & 0.0 & 5.2 & 18.1 & 24.5 & 30.9 & 34.3 & 35.2 & 39.8 \\
\hline $21-30$ & 0.0 & 0.0 & 0.0 & 0.0 & 0.0 & 0.0 & 3.9 & 15.7 & 22.7 & 26.3 & 31.7 \\
\hline out. $1-10$ & 0.0 & 0.0 & 0.0 & 0.0 & 0.0 & 0.0 & 6.8 & 20.1 & 25.4 & 40.4 & 44.3 \\
\hline $11-20$ & 0.0 & 0.0 & 0.0 & 0.0 & 0.0 & 0.0 & 0.0 & 0.2 & 14.8 & 32.4 & 51.5 \\
\hline $21-31$ & 0.0 & 0.0 & 0.0 & 0.0 & 0.0 & 0.0 & 0.0 & 0.0 & 6.8 & 20.1 & 53.3 \\
\hline nov. $1-10$ & 0.0 & 0.0 & 0.0 & 0.0 & 0.0 & 0.0 & 0.0 & 2.2 & 11.8 & 18.8 & $25 . ?$ \\
\hline $11-20$ & 0.0 & 0.0 & 0.0 & 0.0 & 0.0 & 0.0 & 0.0 & 0.0 & 7.5 & 10.6 & 38.4 \\
\hline $21-30$ & 0.0 & 0.0 & 0.0 & 0.0 & 0.0 & 0.0 & 0.0 & 0.0 & 6.1 & 10.9 & 21.9 \\
\hline dez.1-10 & 0.0 & 0.0 & 0.0 & 0.0 & 0.0 & 0.0 & 0.0 & 0.0 & 0.0 & 0.0 & 26.3 \\
\hline $11-20$ & 0.0 & 0.0 & 0.0 & 0.0 & 0.0 & 0.0 & 0.0 & 0.0 & 0.0 & 0.0 & 38.7 \\
\hline $21-31$ & 0.0 & 0.0 & 0.0 & 0.0 & 0.0 & 0.0 & 0.0 & 0.0 & 0.0 & 0.0 & 31.2 \\
\hline
\end{tabular}


TABELA 33 - JAL: EXCEDENTES HIDRICOS (BALANCO COM AFD = 30

DECIL

\begin{tabular}{|c|c|c|c|c|c|c|c|c|c|c|c|}
\hline DECEHDIO & EIII. & 1 & 2 & 3 & 4 & 5 & 6 & 7 & $B$ & 9 & 10 \\
\hline jan. $1-10$ & 0.0 & 0.0 & 7.7 & 12.0 & 30.4 & 56.1 & 70.2 & 81.4 & 87.9 & 92.4 & 142.3 \\
\hline $11-20$ & 0.0 & 0.0 & 0.0 & 0.0 & 6.5 & 17.5 & 29.2 & 86.4 & 101.5 & 141.9 & 204.3 \\
\hline $21-31$ & 0.0 & 0.0 & 0.0 & 8.5 & 13.8 & 25.8 & 33.5 & 39.5 & 59.9 & 92.6 & 175.0 \\
\hline fev. $1-10$ & 0.0 & 0.0 & 0.0 & 9.8 & 12.9 & 24.0 & 35.5 & 52.4 & 75.1 & 142.2 & 17.5 \\
\hline $11-20$ & 0.0 & 0.0 & 0.0 & 0.0 & 15.7 & 37.3 & 43.5 & 53.8 & 79.0 & 103.9 & 287.8 \\
\hline $21-28$ & 0.0 & 0.0 & 0.0 & 0.0 & 4.2 & 15.9 & 26.9 & 49.7 & 75.0 & 106.6 & 175.8 \\
\hline ar. $1-10$ & 0.0 & 0.0 & 0.0 & 0.0 & 0.0 & 0.0 & 11.0 & 21.5 & 42.7 & 68.3 & 125.8 \\
\hline $11-20$ & 0.0 & 0.0 & 0.0 & 0.0 & 0.0 & 0.8 & 4.8 & 16.4 & 36.2 & 107.2 & 275,2 \\
\hline $21-31$ & 0.0 & 0.0 & 0.0 & 0.0 & 0.0 & 0.0 & 0.0 & 0.0 & 9.6 & 16.7 & 118.0 \\
\hline$a b r .1-10$ & 0.0 & 0.0 & 0.0 & 0.0 & 0.0 & 0.0 & 0.0 & 0.0 & 19.5 & 40.5 & 114.7 \\
\hline $11-20$ & 0.0 & 0.0 & 0.0 & 0.0 & 0.0 & 0.0 & 0.0 & 0.0 & 4.2 & 17.4 & 55.5 \\
\hline $21-30$ & 0.0 & 0.0 & 0.0 & 0.0 & 0.0 & 0.0 & 0.0 & 0.0 & 0.0 & 1.3 & 77.2 \\
\hline 1.1.1-10 & 0.0 & 0.0 & 0.0 & 0.0 & 0.0 & 0.0 & 0.0 & 0.0 & 0.0 & 4.2 & 69.6 \\
\hline $11-20$ & 0.0 & 0.0 & 0.0 & 0.0 & 0.0 & 0.0 & 0.0 & 0.0 & 15.0 & 23.7 & 84.8 \\
\hline $21-31$ & 0.0 & 0.0 & 0.0 & 0.0 & 0.0 & 0.0 & 0.0 & 0.0 & 1.0 & 14.9 & 284.8 \\
\hline jun. $1-10$ & 0.0 & 0.0 & 0.0 & 0.0 & 0.0 & 0.0 & 0.0 & 0.0 & 0.0 & 0.0 & 118.9 \\
\hline $11-20$ & 0.0 & 0.0 & 0.0 & 0.0 & 0.0 & 0,0 & 0.0 & 0.0 & 0.0 & 13.9 & 69.0 \\
\hline $21-30$ & 0.0 & 0.0 & 0.0 & 0.0 & 0.0 & 0.0 & 0.0 & 0.0 & 0.0 & 1.9 & 85.5 \\
\hline jul. $1-10$ & 0.0 & 0.0 & 0.0 & 0.0 & 0.0 & 0.0 & 0.0 & 0.0 & 0.0 & 0.0 & 26.3 \\
\hline $11-20$ & 0.0 & 0.0 & 0.0 & 0.0 & 0.0 & 0.0 & 0.0 & 0.0 & 0.0 & 0.0 & 51.7 \\
\hline $21-31$ & 0.0 & 0.0 & 0.0 & 0.0 & 0.0 & 0.0 & 0.0 & 0.0 & 0.0 & 0.0 & 54.1 \\
\hline $290.1-10$ & 0.0 & 0.0 & 0.0 & 0.0 & 0.0 & 0.0 & 0.0 & 0.0 & 0.0 & 0.0 & 0.0 \\
\hline $11-20$ & 0.0 & 0.0 & 0.0 & 0.0 & 0.0 & 0.0 & 0,0 & 0.0 & 0.0 & 0.0 & 32.1 \\
\hline $21-31$ & 0.0 & 0.0 & 0.0 & 0.0 & 0.0 & 0.0 & 0.0 & 0.0 & 0.0 & 0.0 & 51.8 \\
\hline set.1-10 & 0.0 & 0.0 & 0.0 & 0.0 & 0.0 & 0.0 & 0.0 & 0.0 & 0.0 & 11.9 & 38.2 \\
\hline $11-20$ & 0.0 & 0.0 & 0.0 & 0.0 & 0.0 & 0.0 & 0.0 & 0.0 & 0.0 & 2.9 & 40.9 \\
\hline $21-30$ & 0.0 & 0.0 & 0.0 & 0.0 & 0.0 & 0.0 & 0.0 & 0.0 & 0.0 & 21.4 & so.1 \\
\hline out. $1-10$ & 0.0 & 0.0 & 0.0 & 0.0 & 0.0 & 0.0 & 0.0 & 15.7 & 21.1 & 59.1 & 86.1 \\
\hline $11-20$ & 0.0 & 0.0 & 0.0 & 0.0 & 0.0 & 0.0 & 0.0 & 0.0 & 10.5 & 66.0 & 89.8 \\
\hline $21-31$ & 0.0 & 0.0 & 0.0 & 0.0 & 0.0 & 0.0 & 0.0 & 1.5 & 7.4 & 31.0 & 83.5 \\
\hline nov. $1-10$ & 0.0 & 0.0 & 0.0 & 0.0 & 0.0 & 0.0 & 0.0 & 4.2 & 26.4 & 60.8 & 135.0 \\
\hline $11-20$ & 0.0 & 0.0 & 0.0 & 0.0 & 0.0 & 0.0 & 5.2 & 14.0 & 24.2 & 68.4 & 182.3 \\
\hline $21-30$ & 0.0 & 0.0 & 0.0 & 0.0 & 0.0 & 0.0 & 0.0 & 2.5 & 27.4 & 36.9 & 232.4 \\
\hline dez. $1-10$ & 0.0 & 0.0 & 0.0 & 0.0 & 0.0 & 1.6 & 14.2 & 49.6 & 73.6 & 114.1 & 250.6 \\
\hline $11-20$ & 0.0 & 0.0 & 0.0 & 9.0 & 16.3 & 23.8 & 32.4 & 45.3 & 78.8 & 110.5 & 178.2 \\
\hline $21-31$ & 0.0 & 0.0 & 9.6 & 23.2 & 33.3 & 46.4 & 71.6 & 84.3 & 111.1 & 157.5 & 202.6 \\
\hline
\end{tabular}




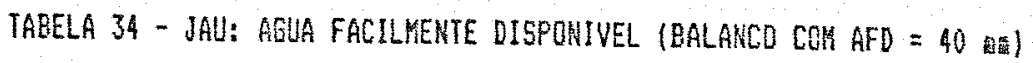

DECIL

\begin{tabular}{|c|c|c|c|c|c|c|c|c|c|c|c|}
\hline DECENDIO & MIK. & 1 & 2 & 3 & 4 & 5 & 6 & 7 & 8 & 9 & 10 \\
\hline $\operatorname{jan}_{x} \mathrm{i}-10$ & 11.0 & 23.9 & 40.0 & 40.0 & 40.0 & 40.0 & 40.0 & 40.0 & 40.0 & 40.0 & 40.0 \\
\hline $11-20$ & 5.7 & 11.7 & 22.5 & 30.8 & 40.0 & 40.0 & 40.0 & 40.0 & 40.0 & 40.0 & 40.0 \\
\hline $21-31$ & 0.0 & 16.8 & 29.5 & .40 .0 & 40.0 & 40.0 & 40.0 & 40.0 & 40.0 & 40.0 & 40.0 \\
\hline fer. $1-10$ & 0.0 & 23.6 & 39.4 & 40.0 & 40.0 & 80.0 & 40.0 & 40.0 & 40.0 & 40.0 & 40.0 \\
\hline $11-20$ & 4.8 & 11.9 & 22.6 & 37.8 & 40.0 & 40.0 & $\$ 0.0$ & 40.0 & 40.0 & $\$ 0.0$ & 60.0 \\
\hline $21-28$ & 0.0 & 13.4 & 25.0 & 37.3 & 40.0 & 40.0 & 40.0 & 40.0 & 40.0 & 40.0 & 40.0 \\
\hline tar. $1-10$ & 0.0 & 9.2 & 15.3 & 24.7 & 30.5 & 35.5 & 40.0 & 40.0 & 40.0 & 40.0 & 40.0 \\
\hline $11-20$ & 0.0 & 0.0 & 6.8 & 10.8 & 30.6 & 39.3 & 40.0 & 40.0 & 40.0 & 40.0 & 40.0 \\
\hline $21-31$ & 0.0 & 1.1 & 3.2 & 9.6 & 14.0 & 21.8 & 29.9 & 36.1 & 40.0 & 40.0 & 40.0 \\
\hline$a b r .1-10$ & 0.0 & 0.0 & 1.1 & 10.9 & 13.8 & 22.0 & 27.4 & 37.8 & 40.0 & 40.0 & 40.0 \\
\hline $11-20$ & 0.0 & 0.0 & 0.0 & 0.9 & 14.9 & 19.0 & 21.0 & 30.2 & 38.9 & 40.0 & 40.0 \\
\hline $21-30$ & 0.0 & 0.0 & 0.0 & 0.0 & 2.9 & 8.2 & 11.7 & 15.9 & 27.5 & 40.0 & 40.0 \\
\hline adi.1-10 & 0.0 & 0.0 & 0.0 & 0.0 & 4.0 & 11.5 & 17.2 & 21.5 & 29.2 & 36.8 & 40.0 \\
\hline $11-20$ & 0.0 & 0.0 & 0.0 & 0.0 & 1.1 & 5.7 & 14.6 & 20.2 & 40.0 & 40.0 & 40.0 \\
\hline $21-31$ & 0.0 & 0.0 & 0.0 & 0.0 & 0.0 & 0.0 & 10.2 & 18.6 & 40.0 & 40.0 & 40.0 \\
\hline jun.1-10 & 0.0 & 0.0 & 0.0 & 0.0 & 0.0 & 0.0 & 13.1 & 17.0 & 24.0 & 35.7 & 40.0 \\
\hline $11-20$ & 0.0 & 0.0 & 0.0 & 0.0 & 0.0 & 5.1 & 10.0 & 19.3 & 29.7 & 40.0 & 40.0 \\
\hline $21-30$ & 0.0 & 0.0 & 0.0 & 0.0 & 0.0 & 0.0 & 7.8 & 12.9 & 29.7 & 35.3 & 40.0 \\
\hline jul : $1-10$ & 0.0 & 0.0 & 0.0 & 0.0 & 0.0 & 0.0 & 0.2 & 9.3 & 18.2 & 32.7 & 60.0 \\
\hline $11-20$ & 0.0 & 0.0 & 0.0 & 0.0 & 0.0 & 0.0 & 0.0 & 0.0 & 5.9 & 20.3 & 40.0 \\
\hline $21-31$ & 0.0 & 0.0 & 0.0 & 0.0 & 0.0 & 0.0 & 0.0 & 0.0 & 2.2 & 23.9 & 80.0 \\
\hline ago.1-10 & 0.0 & 0.0 & 0.0 & 0.0 & 0.0 & 0.0 & 0.0 & 0.0 & 0.0 & 8.7 & 39.5 \\
\hline $11-20$ & 0.0 & 0.0 & 0.0 & 0.0 & 0.0 & 0.0 & 0.0 & 0.0 & 0.0 & 16.3 & 60.0 \\
\hline $21-31$ & 0.0 & 0.0 & 0.0 & 0.0 & 0.0 & 0.0 & 0.0 & 0.0 & 11.6 & 20.4 & 40.0 \\
\hline $\operatorname{set} .1-10$ & 0.0 & 0.0 & 0.0 & 0.0 & 0.0 & 0.0 & 2.5 & 8.6 & 24.9 & 40.0 & 10.0 \\
\hline $11-20$ & 0.0 & 0.0 & 0.0 & 0.0 & 0.0 & 0.0 & 0.0 & 13.6 & 27.0 & 35.0 & 40.0 \\
\hline $21-30$ & 0.0 & 0.0 & 0.0 & 0.0 & 0.0 & 3.4 & 19.1 & 28.4 & 36.3 & 40.0 & 40.0 \\
\hline out. 1-10 & 0.0 & 0.0 & 0.0 & 0.0 & 0.0 & 5.8 & 25.8 & 40.0 & 40.0 & 40.0 & 40.0 \\
\hline $11-20$ & 0.0 & 0.0 & 0.0 & 0.0 & 11.4 & 15.3 & 24.2 & 34.9 & 40.0 & 40.0 & 40.0 \\
\hline $21-31$ & 0.0 & 0.0 & 0.0 & 0.0 & 12.1 & 22.5 & 31.1 & 40.0 & 40.0 & 40.0 & 80.0 \\
\hline nev. $1-10$ & 0.0 & 0.0 & 0.0 & 1.2 & 7.8 & 28.5 & 34.1 & 39.0 & 40.0 & 40.0 & 10.0 \\
\hline $11-20$ & 0.0 & 0.0 & 0.0 & 4.2 & 7.7 & 32.1 & 40.0 & 40.0 & 40.0 & 40.0 & 00.0 \\
\hline $21-30$ & 0.0 & 0.0 & 0.0 & 7.3 & 22.3 & 25.8 & 32.5 & 39.1 & 40.0 & 40.0 & 10.0 \\
\hline $\operatorname{dez} .1-10$ & 0.0 & 9.5 & 16.4 & 23.5 & 28.9 & 40.0 & 40.0 & 40.0 & 40.0 & 10.0 & 10.0 \\
\hline $11-20$ & 0.0 & 4.3 & 36.5 & 40.0 & 40.0 & 40.0 & 40.0 & 40.0 & 40.0 & 40.0 & 40.0 \\
\hline $21-31$ & 0.0 & 18.1 & 40.0 & 40.0 & 40.0 & 40.0 & 40.0 & 40.0 & 40.0 & 10.0 & 40.0 \\
\hline
\end{tabular}


DECIL.

\begin{tabular}{|c|c|c|c|c|c|c|c|c|c|c|c|}
\hline DECENDIO & HIII & 1 & 2 & 3 & 4 & 5 & 6 & 7 & 8 & 9 & 10 \\
\hline jan. $1-10$ & 0.0 & 0.0 & 0.0 & 0.0 & 0.0 & 0.0 & 0.0 & 0.0 & 0.0 & 0.0 & 0.0 \\
\hline $11-20$ & 0.0 & 0.0 & 0.0 & 0.0 & 0.0 & 0.0 & 0.0 & 0.0 & 0.0 & 0.0 & 0.0 \\
\hline $21-31$ & 0.0 & 0.0 & 0.0 & 0.0 & 0.0 & 0.0 & 0.0 & 0.0 & 0.0 & 0.0 & 8.9 \\
\hline fev. $1-10$ & 0.0 & 0.0 & 0.0 & 0.0 & 0.0 & 0.0 & 0.0 & 0.0 & 0.0 & 0.0 & 8.4 \\
\hline $11-20$ & 0.0 & 0.0 & 0.0 & 0.0 & 0.0 & 0.0 & 0.0 & 0.0 & 0.0 & 0.0 & 0.0 \\
\hline $21-28$ & 0.0 & 0.0 & 0.0 & 0.0 & 0.0 & 0.0 & 0.0 & 0.0 & 0.0 & 0.0 & 11.7 \\
\hline arar. $1-10$ & 0.0 & 0.0 & 0.0 & 0.0 & 0.0 & 0.0 & 0.0 & 0.0 & 0.0 & 0.0 & 11.3 \\
\hline $11-20$ & 0.0 & 0.0 & 0.0 & 0.0 & 0.0 & 0.0 & 0.0 & 0.0 & 0.0 & 0.0 & 18.4 \\
\hline $21-3 \mid$ & 0.0 & 0.0 & 0.0 & 0.0 & 0.0 & 0.0 & 0.0 & 0.0 & 0.0 & 0.0 & 23.2 \\
\hline abr. $1-10$ & 0.0 & 0.0 & 0.0 & 0.0 & 0.0 & 0.0 & 0.0 & 0.0 & 0.0 & 6.9 & 29.5 \\
\hline $11-20$ & 0.0 & 0.0 & 0.0 & 0.0 & 0.0 & 0.0 & 0.0 & 0.0 & 4.4 & 8.7 & 21.8 \\
\hline $21-30$ & 0.0 & 0.0 & 0.0 & 0.0 & 0.0 & 0.0 & 0.0 & 0.0 & 4.3 & 16.4 & 29.9 \\
\hline ad. $1-10$ & 0.0 & 0.0 & 0.0 & 0.0 & 0.0 & 0.0 & 0.0 & 7.1 & 14.7 & 18.1 & 26.1 \\
\hline $11-20$ & 0.0 & 0.0 & 0.0 & 0.0 & 0.0 & 0.0 & 0.0 & 4.8 & 13.7 & 22.4 & 25.0 \\
\hline $21-31$ & 0.0 & 0.0 & 0.0 & 0.0 & 0.0 & 0.0 & 3.4 & 12.6 & 19.5 & 21.4 & 26.7 \\
\hline jun. $1-10$ & 0.0 & 0.0 & 0.0 & 0.0 & 0.0 & 0.0 & 8.0 & 11.2 & 20.7 & 22.5 & 25.9 \\
\hline $11-20$ & 0.0 & 0.0 & 0.0 & 0.0 & 0.0 & 0.0 & 2.2 & 9.4 & 15.0 & 22.6 & 25.1 \\
\hline $21-30$ & 0.0 & 0.0 & 0.0 & 0.0 & 0.0 & 0.0 & 6.1 & 12.1 & 21.7 & 22.9 & 25.1 \\
\hline jul. $1-10$ & 0.0 & 0.0 & 0.0 & 0.0 & 0.0 & 2.3 & 7.3 & 11.6 & 19.5 & 23.9 & 28.6 \\
\hline $11-20$ & 0.0 & 0.0 & 0.0 & 1.3 & 5.4 & 13.9 & 16.2 & 20.7 & 22.6 & 26.3 & 28.3 \\
\hline $2 \mid-31$ & 0.0 & 0.0 & 0.0 & 8.3 & 14.3 & 19.5 & 23.7 & 25.6 & 26.9 & 29.8 & 32.2 \\
\hline $800.1-10$ & 0.0 & 0.0 & 0.0 & 3.0 & 10.3 & 18.0 & 25.9 & 26.5 & 27.6 & 29.7 & 30.2 \\
\hline $11-20$ & 0.0 & 0.0 & 4.6 & 8.2 & 16.1 & 25.0 & 26.8 & 28.0 & 28.3 & 29.6 & 33.1 \\
\hline $2|-3|$ & 0.0 & 0.0 & 0.0 & 4.4 & 22.0 & 24.5 & 28.6 & 32.5 & 34.2 & 36.0 & 39.1 \\
\hline set. $1-10$ & 0.0 & 0.0 & 0.0 & 0.0 & 0.0 & 0.0 & 23.4 & 29.2 & 31.5 & 35.1 & 43.4 \\
\hline $11-20$ & 0.0 & 0.0 & 0.0 & 0.0 & 5.2 & 16.0 & 24.5 & 30.9 & 34.3 & 35.2 & 39.8 \\
\hline $21-30$ & 0.0 & 0.0 & 0.0 & 0.0 & 0.0 & 0.0 & 3.9 & 15.4 & 20.9 & 26.3 & 31.7 \\
\hline out.1-10 & 0.0 & 0.0 & 0.0 & 0.0 & 0.0 & 0.0 & 0.6 & 20.1 & 25.4 & 40.4 & 41.8 \\
\hline $11-20$ & 0.0 & 0.0 & 0.0 & 0.0 & 0.0 & 0.0 & 0.0 & 0.0 & 14.8 & 32.4 & 51.5 \\
\hline $21-31$ & 0.0 & 0.0 & 0.0 & 0.0 & 0.0 & 0.0 & 0.0 & 0.0 & 6.7 & 14.6 & 53.3 \\
\hline nov. $1-10$ & 0.0 & 0.0 & 0.0 & 0.0 & 0.0 & 0.0 & 0.0 & 0.0 & 1.8 & 18.8 & 25.2 \\
\hline $11-20$ & 0.0 & 0.0 & 0.0 & 0.0 & 0.0 & 0.0 & 0.0 & 0.0 & 0.0 & 9.5 & 37.2 \\
\hline $21-30$ & 0.0 & 0.0 & 0.0 & 0.0 & 0.0 & 0.0 & 0.0 & 0.0 & 0.0 & 8.1 & 21.9 \\
\hline dez. $1-10$ & 0.0 & 0.0 & 0.0 & 0.0 & 0.0 & 0.0 & 0.0 & 0.0 & 0.0 & 0.0 & 16.3 \\
\hline $11-20$ & 0.0 & 0.0 & 0.0 & 0.0 & 0.0 & 0.0 & 0.0 & 0.0 & 0.0 & 0.0 & 38.7 \\
\hline $21-31$ & 0.0 & 0.0 & 0.0 & 0.0 & 0.0 & 0.0 & 0.0 & 0.0 & 0.0 & 0.0 & 26.9 \\
\hline
\end{tabular}


TABELA 36 - JAU: EXCEDENTES HDRICOS (BALAMCO COM AFD $=40$ -

DECIL

\begin{tabular}{|c|c|c|c|c|c|c|c|c|c|c|c|}
\hline DECEHDIO & MIN. & 1 & 2 & 3 & 4 & 5 & 6 & 7 & 8 & 9 & 10 \\
\hline jan.1-10 & 0.0 & 0.0 & 4.3 & 12.0 & 30.4 & 56.1 & 70.2 & 81.4 & 87.9 & 92.4 & 142.3 \\
\hline $11-20$ & 0.0 & 0.0 & 0.0 & 0.0 & 6.5 & 17.5 & 27.6 & 86.4 & 101.5 & 141.9 & 204.3 \\
\hline $21-31$ & 0.0 & 0.0 & 0.0 & 8.5 & 11.9 & 25.8 & 33.5 & 39.5 & 59.9 & 92.6 & 175.0 \\
\hline fer. $1-10$ & 0.0 & 0.0 & 0.0 & 9.8 & 12.9 & 24.8 & 33.6 & 52.4 & 75.1 & 142.2 & 171.5 \\
\hline $11-20$ & 0.0 & 0.0 & 0.0 & 0.0 & 15.7 & 37.3 & 43.5 & 53.8 & 79.0 & 103.9 & 287.8 \\
\hline $21-28$ & 0.0 & 0.0 & 0.0 & 0.0 & 4.2 & 15.9 & 26.9 & 49.7 & 75.0 & 106.6 & 175.8 \\
\hline tar. $1-10$ & 0.0 & 0.0 & 0.0 & 0.0 & 0.0 & 0.0 & 7.4 & 21.5 & 42.7 & 68.3 & 125.8 \\
\hline $11-20$ & 0.0 & 0.0 & 0.0 & 0.0 & 0.0 & 0.0 & 4.8 & 16.4 & 36.2 & 107.2 & 275.2 \\
\hline $21-31$ & 0.0 & 0.0 & 0.0 & 0.0 & 0.0 & 0.0 & 0.0 & 0.0 & 9.6 & 16.7 & 109.0 \\
\hline$a b r .1-10$ & 0.0 & 0.0 & 0.0 & 0.0 & 0.0 & 0.0 & 0.0 & 0.0 & 14.3 & 40.5 & 114.7 \\
\hline $11-20$ & 0.0 & 0.0 & 0.0 & 0.0 & 0.0 & 0.0 & 0.0 & 0.0 & 0.0 & 17.4 & 46.6 \\
\hline $21-30$ & 0.0 & 0.0 & 0.0 & 0.0 & 0.0 & 0.0 & 0.0 & 0.0 & 0.0 & 1.3 & 75.8 \\
\hline ai. $1-10$ & 0.0 & 0.0 & 0.0 & 0.0 & 0.0 & 0.0 & 0.0 & 0.0 & 0.0 & 0.0 & 59.6 \\
\hline $11-20$ & 0.0 & 0.0 & 0.0 & 0.0 & 0.0 & 0.0 & 0.0 & 0.0 & 5.0 & 23.7 & 74.8 \\
\hline $21-31$ & 0.0 & 0.0 & 0.0 & 0.0 & 0.0 & 0.0 & 0.0 & 0.0 & 1.0 & 12.2 & 244.8 \\
\hline jun. $1-10$ & 0.0 & 0.0 & 0.0 & 0.0 & 0.0 & 0.0 & 0.0 & 0.0 & 0.0 & 0.0 & 118.9 \\
\hline $11-20$ & 0.0 & 0.0 & 0.0 & 0.0 & 0.0 & 0.0 & 0.0 & 0.0 & 0.0 & 3.9 & 59.0 \\
\hline $21-30$ & 0.0 & 0.0 & 0.0 & 0.0 & 0.0 & 0.0 & 0.0 & 0.0 & 0.0 & 0.0 & 85.5 \\
\hline jul.1-10 & 0.0 & 0.0 & 0.0 & 0.0 & 0.0 & 0.0 & 0.0 & 0.0 & 0.0 & 0.0 & 16.3 \\
\hline $11-20$ & 0.0 & 0.0 & 0.0 & 0.0 & 0.0 & 0.0 & 0.0 & 0.0 & 0.0 & 0.0 & 41.7 \\
\hline $21-31$ & 0.0 & 0.0 & 0.0 & 0.0 & 0.0 & 0.0 & 0.0 & 0.0 & 0.0 & 0.0 & 44.1 \\
\hline $290.1-10$ & 0.0 & 0.0 & 0.0 & 0.0 & 0.0 & 0.0 & 0.0 & 0.0 & 0.0 & 0.0 & 0.0 \\
\hline $11-20$ & 0.0 & 0.0 & 0.0 & 0.0 & 0.0 & 0.0 & 0.0 & 0.0 & 0.0 & 0.0 & 22.1 \\
\hline $21-31$ & 0.0 & 0.0 & 0.0 & 0.0 & 0.0 & 0.0 & 0.0 & 0.0 & 0.0 & 0.0 & 41.8 \\
\hline set. $1-10$ & 0.0 & 0.0 & 0.0 & 0.0 & 0.0 & 0.0 & 0.0 & 0.0 & 0.0 & 1.9 & 32.1 \\
\hline $11-20$ & 0.0 & 0.0 & 0.0 & 0.0 & 0.0 & 0.0 & 0.0 & 0.0 & 0.0 & 0.0 & 40.9 \\
\hline $21-30$ & 0.0 & 0.0 & 0.0 & 0.0 & 0.0 & 0.0 & 0.0 & 0.0 & 0.0 & 11.4 & 50.1 \\
\hline out.1-10 & 0.0 & 0.0 & 0.0 & 0.0 & 0.0 & 0.0 & 0.0 & 6.9 & 21.1 & 49.1 & 86.1 \\
\hline $11-20$ & 0.0 & 0.0 & 0.0 & 0.0 & 0.0 & 0.0 & 0.0 & 0.0 & 4.0 & 64.9 & 89.8 \\
\hline $21-31$ & 0.0 & 0.0 & 0.0 & 0.0 & 0.0 & 0.0 & 0.0 & 0.3 & 2.7 & 31.0 & 73.5 \\
\hline nov. $1-10$ & 0.0 & 0.0 & 0.0 & 0.0 & 0.0 & 0.0 & 0.0 & 0.0 & 26.4 & 60.8 & 125.0 \\
\hline $11-20$ & 0.0 & 0.0 & 0.0 & 0.0 & 0.0 & 0.0 & 1.1 & 9.5 & 15.3 & 68.4 & 182.3 \\
\hline $21-30$ & 0.0 & 0.0 & 0.0 & 0.0 & 0.0 & 0.0 & 0.0 & 0.0 & 27.2 & 36.9 & 225.7 \\
\hline dez.1-10 & 0.0 & 0.0 & 0.0 & 0.0 & 0.0 & 1.6 & 7.3 & 39.6 & 73.6 & 112.1 & 250.6 \\
\hline $11-20$ & 0.0 & 0.0 & 0.0 & 2.2 & 13.3 & 19.9 & 32.4 & 45.3 & 68.8 & 110.5 & 168.2 \\
\hline $21-31$ & 0.0 & 0.0 & 9.6 & 23.2 & 32.7 & 46.4 & 71.6 & 84.3 & 111.1 & 157.5 & 197.5 \\
\hline
\end{tabular}


TABELA 37 - JAN: AGUA FACILUENTE DISFOHIVEL (BALANCO COH AFN = 50 9E)

DECIL

\begin{tabular}{|c|c|c|c|c|c|c|c|c|c|c|c|}
\hline DECEVDIO & MIN. & 1 & 2 & 3 & 4 & 5 & 6 & 7 & 8 & 9 & 10 \\
\hline jan.1-10 & 11.4 & 33.9 & 50.0 & 50.0 & 50.0 & 50.0 & 50.0 & 50.0 & 50.0 & 50.0 & 50.0 \\
\hline $11-20$ & 15.7 & 21.7 & 30.8 & 40.8 & 90.0 & 50.0 & 50.0 & 50.0 & 50.0 & 50.0 & 50.0 \\
\hline $21-31$ & 1.1 & 26.8 & 39.5 & 50.0 & 50.0 & 50.0 & 50.0 & 50.0 & 50.0 & 50.0 & 50.0 \\
\hline fev. $1-10$ & 1.6 & 33.6 & 49.4 & 50.0 & 50.0 & 50.0 & 50.0 & 50.0 & 50.0 & 50.0 & 50.0 \\
\hline $11-20$ & 6.4 & 21.9 & 32.6 & 47.8 & 50.0 & 50.0 & 50.0 & 50,0 & 50.0 & 50.0 & 50.0 \\
\hline $21-28$ & 0.0 & 23.4 & 30.9 & 47.3 & 50.0 & 50.0 & 50.0 & 50.0 & 50.0 & 50.0 & 50.0 \\
\hline ar. $1-10$ & 0.0 & 19.2 & 25.3 & 34.7 & 40.5 & $\$ 4.0$ & 50.0 & 50.0 & 50.0 & 50.0 & 50.0 \\
\hline $11-20$ & 0.0 & 7.5 & 15.0 & 20.8 & 31.0 & 49.3 & 50.0 & 50.0 & 50.0 & 50.0 & 50.0 \\
\hline $21-31$ & 0.0 & 6.8 & 13.2 & 19.6 & 24.0 & 31.8 & 39.9 & 45.5 & 50.0 & 50.0 & 50.0 \\
\hline$a b r=1-10$ & 0.0 & 0.0 & 11.1 & 19.6 & 23.3 & 32.0 & 36.6 & 47.8 & 50.0 & 50.0 & 50.0 \\
\hline $11-20$ & 0.0 & 0.0 & 0.9 & 5.0 & 19.2 & 26.4 & 31.0 & 35.2 & 47.6 & 50.0 & 50.0 \\
\hline $21-30$ & 0.0 & 0.0 & 0.0 & 2.9 & 6.7 & 14.9 & 21.7 & 24.6 & 37.5 & 50.0 & 50.0 \\
\hline - $1.1-10$ & 0.0 & 0.0 & 0.0 & 0.0 & 11.5 & 15.2 & 25.3 & 30.8 & 36.5 & 42.4 & 50.0 \\
\hline $11-20$ & 0.0 & 0.0 & 0.0 & 0.0 & 5.7 & 11.4 & 16.8 & 30.2 & 48.6 & 50.0 & 50.0 \\
\hline $21-31$ & 0.0 & 0.0 & 0.0 & 0.0 & 0.0 & 6.9 & 18.9 & 26.1 & 44.9 & 50.0 & 50.0 \\
\hline jun. $1-10$ & 0.0 & 0.0 & 0.0 & 0.0 & 0.0 & 3.5 & 14.9 & 22.0 & 34.0 & 45.3 & 50.0 \\
\hline $11-20$ & 0.0 & 0.0 & 0.0 & 0.0 & 4.5 & 6.7 & 18.5 & 24.8 & 31.6 & 43.9 & 50.0 \\
\hline $21-30$ & 0.0 & 0.0 & 0.0 & 0.0 & 0.0 & 6.4 & 9.3 & 15.6 & 31.9 & 45.3 & 50.0 \\
\hline$j u l: L-10$ & 0.0 & 0.0 & 0.0 & 0.0 & 0.0 & 0.0 & 0.2 & 9.3 & 28.2 & 39.9 & 50.6 \\
\hline $11-20$ & 0.0 & 0.0 & 0.0 & 0.0 & 0.0 & 0.0 & 0.0 & 0.0 & 15.9 & 29.8 & 50.0 \\
\hline $21-31$ & 0.0 & 0.0 & 0.0 & 0.0 & 0.0 & 0.0 & 0.0 & 0.0 & 2.2 & 33,9 & 50.0 \\
\hline $200.1-10$ & 0.0 & 0.0 & 0.0 & 0.0 & 0.0 & 0.0 & 0.0 & 0.0 & 6.2 & 10.6 & 49.5 \\
\hline $11-20$ & 0.0 & 0.0 & 0.0 & 0.0 & 0.0 & 0.0 & 0.0 & 0.0 & 0.0 & 26.2 & 50.0 \\
\hline $21-31$ & 0.0 & 0.0 & 0.0 & 0.0 & 0.0 & 0.0 & 0.0 & 0.0 & 20.4 & 26.3 & 50.0 \\
\hline set. $1-10$ & 0.0 & 0.0 & 0.0 & 0.0 & 0.0 & 0.0 & 4.2 & 11.8 & 30.5 & 41.9 & 50.0 \\
\hline $11-20$ & 0.0 & 0.0 & 0.0 & 0.0 & 0.0 & 0.0 & 0.0 & 15.5 & 35.0 & 44.1 & 50.0 \\
\hline $21-30$ & 0.0 & 0.0 & 0.0 & 0.0 & 0.0 & 3.4 & 19.1 & 28.4 & 46.3 & 50.0 & 50.0 \\
\hline out. $1-10$ & 0.0 & 0.0 & 0.0 & 0.0 & 0.0 & 9.4 & 25.8 & 46.9 & 50.0 & 50.0 & 50.0 \\
\hline $11-20$ & 0.0 & 0.0 & 0.0 & 0.0 & 15.3 & 24.0 & 34.2 & 40.5 & 50.0 & 50.0 & 50.0 \\
\hline $2|-3|$ & 0.0 & 0.0 & 0.0 & 3.5 & 20.3 & 31.1 & 37.4 & 45.4 & 50.0 & 50.0 & 50.0 \\
\hline nov. $1-10$ & 0.0 & 0.0 & 0.4 & 7.1 & 17.8 & 34.9 & 38.5 & 49.0 & 50.0 & 50,0 & 50.0 \\
\hline $11-20$ & 0.0 & 0.0 & 0.5 & 8.7 & 14.9 & 35.3 & 43.9 & 50.0 & 50.0 & 50.0 & 50.0 \\
\hline $21-30$ & 0.0 & 0.0 & 7.0 & 17.3 & 23.6 & 33.4 & 40.7 & 49.1 & 50.0 & 50.0 & 50.0 \\
\hline dez. $1-10$ & 0.0 & 11.6 & 18.7 & 24.0 & 37.4 & 48.1 & 50.0 & 50.0 & 50.0 & 50.0 & $\$ 0.0$ \\
\hline $11-20$ & 0.0 & 11.4 & 39.0 & 46.3 & 50.0 & 50.0 & 50.0 & 50.0 & 50.0 & 50.0 & 50.0 \\
\hline $21-31$ & 0.0 & 28.1 & 50.0 & 50.0 & 50.0 & 50.0 & 50.0 & 50.0 & 50.0 & 50.0 & 50.0 \\
\hline
\end{tabular}


DECIL

\begin{tabular}{|c|c|c|c|c|c|c|c|c|c|c|c|}
\hline DECENDIO & MIM. & 1 & 2 & 3 & 4 & 5 & 6 & 7 & 8 & 9 & 10 \\
\hline jan. $1-10$ & 0.0 & 0.0 & 0.0 & 0.0 & 0.0 & 0.0 & 0.0 & 0.0 & 0.0 & 0.0 & 0.0 \\
\hline $11-20$ & 0.0 & 0.0 & 0.0 & 0.0 & 0.0 & 0.0 & 0.0 & 0.0 & 0.0 & 0.0 & 0.0 \\
\hline $21-31$ & 0.0 & 0.0 & 0.0 & 0.0 & 0.0 & 0.0 & 0.0 & 0.0 & 0.0 & 0.0 & 0.0 \\
\hline fer. $1-10$ & 0.0 & 0.0 & 0.0 & 0.0 & 0.0 & 0.0 & 0.0 & 0.0 & 0.0 & 0.0 & 0.0 \\
\hline $11-20$ & 0.0 & 0.0 & 0.0 & 0.0 & 0.0 & 0.0 & 0.0 & 0.0 & 0.0 & 0.0 & 0.0 \\
\hline $21-28$ & 0.0 & 0.0 & 0.0 & 0.0 & 0.0 & 0.0 & 0.0 & 0.0 & 0.0 & 0.0 & 1.7 \\
\hline Ear. $1-10$ & 0.0 & 0.0 & 0.0 & 0.0 & 0.0 & 0.0 & 0.0 & 0.0 & 0.0 & 0.0 & 1.3 \\
\hline $11-20$ & 0.0 & 0.0 & 0.0 & 0.0 & 0.0 & 0.0 & 0.0 & 0.0 & 0.0 & 0.0 & 8.4 \\
\hline $21-31$ & 0.0 & 0.0 & 0.0 & 0.0 & 0.0 & 0.0 & 0.0 & 0.0 & 0.0 & 0.0 & 13.2 \\
\hline abr, $1-10$ & 0.0 & 0.0 & 0.0 & 0.0 & 0.0 & 0.0 & 0.0 & 0.0 & 0.0 & 0.0 & 29.5 \\
\hline $11-20$ & 0.0 & 0.0 & 0.0 & 0.0 & 0.0 & 0.0 & 0.0 & 0.0 & 0.0 & 3.6 & 18.7 \\
\hline $21-30$ & 0.0 & 0.0 & 0.0 & 0.0 & 0.0 & 0.0 & 0.0 & 0.0 & 0.0 & 12.5 & 29.9 \\
\hline $2 a 1.1-10$ & 0.0 & 0.0 & 0.0 & 0.0 & 0.0 & 0.0 & 0.0 & 0.0 & 5.4 & 15.1 & 26.1 \\
\hline $11-20$ & 0.0 & 0.0 & 0.0 & 0.0 & 0.0 & 0.0 & 0.0 & 4.1 & 11.2 & 20.7 & 25.0 \\
\hline $21-31$ & 0.0 & 0.0 & 0.0 & 0.0 & 0.0 & 0.0 & 2.6 & 10.7 & 14.7 & 21.4 & 26.7 \\
\hline jun $1-10$ & 0.0 & 0.0 & 0.0 & 0.0 & 0.0 & 0.0 & 3.6 & 11.0 & 19.1 & 22.3 & 25.9 \\
\hline $11-20$ & 0.0 & 0.0 & 0.0 & 0.0 & 0.0 & 0.0 & 0.0 & 5.0 & 13.6 & 21.8 & 23.7 \\
\hline $21-30$ & 0.0 & 0.0 & 0.0 & 0.0 & 0.0 & 0.0 & 0.0 & 7.0 & 18.0 & 22.4 & 25.1 \\
\hline jul. $1-10$ & 0.0 & 0.0 & 0.0 & 0.0 & 0.0 & 2.3 & 7.3 & 10.2 & 14.2 & 23.9 & 28.6 \\
\hline $11-20$ & 0.0 & 0.0 & 0.0 & 0.0 & 5.4 & 13.9 & 16.2 & 20.7 & 22.6 & 26.3 & 28.3 \\
\hline $21-31$ & 0.0 & 0.0 & 0.0 & 1.1 & 11.8 & 17.1 & 20.8 & 23.7 & 25.8 & 29.8 & 32.2 \\
\hline $290.1-10$ & 0.0 & 0.0 & 0.0 & 3.0 & 10.3 & 18.0 & 25.9 & 26.5 & 27.6 & 29.7 & 30.2 \\
\hline $11-20$ & 0.0 & 0.0 & 0.0 & 7.0 & 16.1 & 18.1 & 26.6 & 28.0 & 29.3 & 29.6 & 32.1 \\
\hline $21-31$ & 0.0 & 0.0 & 0.0 & 4.8 & 21.3 & 23.9 & 28.6 & 32.5 & 34.2 & 36.0 & 89.1 \\
\hline set. $1-10$ & 0.0 & 0.0 & 0.0 & 0.0 & 0.0 & 0.0 & 23.4 & 29.2 & 31.5 & 35.1 & 43.4 \\
\hline $11-20$ & 0.0 & 0.0 & 0.0 & 0.0 & 0.0 & 16.0 & 24.5 & 30.9 & 34.3 & 35.2 & 39.8 \\
\hline $21-30$ & 0.0 & 0.0 & 0.0 & 0.0 & 0.0 & 0.0 & 3.9 & 13.5 & 20.9 & 26.3 & 31.7 \\
\hline out. $1-10$ & 0.0 & 0.0 & 0.0 & 0.0 & 0.0 & 0.0 & 0.4 & 20.1 & 25.4 & 40.1 & 41.8 \\
\hline $11-20$ & 0.0 & 0.0 & 0.0 & 0.0 & 0.0 & 0.0 & 0.0 & 0.0 & 14.8 & 32.4 & 51.5 \\
\hline $21-31$ & 0.0 & 0.0 & 0.0 & 0.0 & 0.0 & 0.0 & 0.0 & 0.0 & 2.3 & 8.8 & 53.3 \\
\hline nov. $1-10$ & 0.0 & 0.0 & 0.0 & 0.0 & 0.0 & 0.0 & 0.0 & 0.0 & 0.0 & 18.8 & 25.2 \\
\hline $11-20$ & 0.0 & 0.0 & 0.0 & 0.0 & 0.0 & 0.0 & 0.0 & 0.0 & 0.0 & 0.4 & 37.2 \\
\hline $21-30$ & 0.0 & 0.0 & 0.0 & 0.0 & 0.0 & 0.0 & 0.0 & 0.0 & 0.0 & 6.1 & 21.9 \\
\hline dez.1-10 & 0.0 & 0.0 & 0.0 & 0.0 & 0.0 & 0.0 & 0.0 & 0.0 & 0.0 & 0.0 & 6.3 \\
\hline $11-20$ & 0.0 & 0.0 & 0.0 & 0.0 & 0.0 & 0.0 & 0.0 & 0.0 & 0.0 & 0.0 & 38.7 \\
\hline $21-31$ & 0.0 & 0.0 & 0.0 & 0.0 & 0.0 & 0.0 & 0.0 & 0.0 & 0.0 & 0.0 & 16.9 \\
\hline
\end{tabular}


TABELA 39 - JAU: EXCEDENTES HIDRICOS (BALANCO COM AFD = 50 GAI

DECIL

\begin{tabular}{|c|c|c|c|c|c|c|c|c|c|c|c|}
\hline & & 1 & 2 & 3 & 4 & 5 & 6 & 7 & $B$ & 9 & 10 \\
\hline jan.1-10 & 0.0 & 0.0 & 4.3 & 12.0 & 30.4 & 56.1 & 70.2 & 81.4 & 87.9 & 92.4 & 142.3 \\
\hline $11-20$ & 0.0 & 0.0 & 0.0 & 0.0 & 6.5 & 12.2 & 27.6 & 86.4 & 101.5 & 141.9 & 204.3 \\
\hline $21-31$ & 0.0 & 0.0 & 0.0 & 8.5 & 11.9 & 25.8 & 31.5 & 39.5 & 59.9 & 92.6 & 175.0 \\
\hline fev. $1-10$ & 0.0 & 0.0 & 0.0 & 9.8 & 12.9 & 24.6 & 33.3 & 52.4 & 75.1 & 142.2 & 171.5 \\
\hline $11-20$ & 0.0 & 0.0 & 0.0 & 0.0 & 15.7 & 37.3 & 43.5 & 53.8 & 79.0 & 103.9 & 287.8 \\
\hline $21-28$ & 0.0 & 0.0 & 0.0 & 0.0 & 4.2 & 15.9 & 26.4 & 49.7 & 75.0 & 106.6 & 175.8 \\
\hline ex.1-10 & 0.0 & 0.0 & 0.0 & 0.0 & 0.0 & 0.0 & 7.4 & 21.3 & 42.7 & 68.3 & 125.8 \\
\hline $11-20$ & 0.0 & 0.0 & 0.0 & 0.0 & 0.0 & 0.0 & 4.8 & 16.4 & 36.2 & 107.2 & 275.2 \\
\hline $21-31$ & 0.0 & 0.0 & 0.0 & 0.0 & 0.0 & 0.0 & 0.0 & 0.0 & 9.6 & 16.7 & 99.0 \\
\hline$a b r \cdot 1-10$ & 0.0 & 0.0 & 0.0 & 0.0 & 0.0 & 0.0 & 0.0 & 0.0 & 14.3 & 40.5 & 114.7 \\
\hline $11-20$ & 0.0 & 0.0 & 0.0 & 0.0 & 0.0 & 0.0 & 0.0 & 0.0 & 0.0 & 17.4 & 46.6 \\
\hline $21-30$ & 0.0 & 0.0 & 0.0 & 0.0 & 0.0 & 0.0 & 0.0 & 0.0 & 0.0 & 1.3 & 75.8 \\
\hline ai.1-10 & 0.0 & 0.0 & 0.0 & 0.0 & 0.0 & 0.0 & 0.0 & 0.0 & 0.0 & 0.0 & 49.6 \\
\hline $11-20$ & 0.0 & 0.0 & 0.0 & 0.0 & 0.0 & 0.0 & 0.0 & 0.0 & 0.0 & 23.7 & 64.8 \\
\hline $21-31$ & 0.0 & 0.0 & 0.0 & 0.0 & 0.0 & 0.0 & 0.0 & 0.0 & 0.0 & 12.2 & 244.8 \\
\hline jun $: 1-10$ & 0.0 & 0.0 & 0.0 & 0.0 & 0.0 & 0.0 & 0.0 & 0.0 & 0.0 & 0.0 & 118.9 \\
\hline $11-20$ & 0.0 & 0.0 & 0.0 & 0.0 & 0.0 & 0.0 & 0.0 & 0.0 & 0.0 & 0.0 & 49.0 \\
\hline $21-30$ & 0.0 & 0.0 & 0.0 & 0.0 & 0.0 & 0.0 & 0.0 & 0.0 & 0.0 & 0.0 & 79.4 \\
\hline jul.1-10 & 0.0 & 0.0 & 0.0 & 0.0 & 0.0 & 0.0 & 0.0 & 0.0 & 0.0 & 0.0 & 15.6 \\
\hline $11-20$ & 0.0 & 0.0 & 0.0 & 0.0 & 0.0 & 0.0 & 0.0 & 0.0 & 0.0 & 0.0 & 31.7 \\
\hline $21-31$ & 0.0 & 0.0 & 0.0 & 0.0 & 0.0 & 0.0 & 0.0 & 0.0 & 0.0 & 0.0 & 34.1 \\
\hline $\operatorname{ag} 0.1-10$ & 0.0 & 0.0 & 0.0 & 0.0 & 0.0 & 0.0 & 0.0 & 0.0 & 0.0 & 0.0 & 0.0 \\
\hline $11-20$ & 0.0 & 0.0 & 0.0 & 0.0 & 0.0 & 0.0 & 0.0 & 0.0 & 0.0 & 0.0 & 12.1 \\
\hline $21-31$ & 0.0 & 0.0 & 0.0 & 0.0 & 0.0 & 0.0 & 0.0 & 0.0 & 0.0 & 0.0 & 31.8 \\
\hline set.1-10 & 0.0 & 0.0 & 0.0 & 0.0 & 0.0 & 0.0 & 0.0 & 0.0 & 0.0 & 0.0 & 32.1 \\
\hline $11-20$ & 0.0 & 0.0 & 0.0 & 0.0 & 0.0 & 0.0 & 0.0 & 0.0 & 0.0 & 0.0 & 40.9 \\
\hline $21-30$ & 0.0 & 0.0 & 0.0 & 0.0 & 0.0 & 0.0 & 0.0 & 0.0 & 0.0 & 1.4 & 50.1 \\
\hline out.1-10 & 0.0 & 0.0 & 0.0 & 0.0 & 0.0 & 0.0 & 0.0 & 0.0 & 18.1 & 39.1 & 86.1 \\
\hline $11-20$ & 0.0 & 0.0 & 0.0 & 0.0 & 0.0 & 0.0 & 0.0 & 0.0 & 0.9 & 61.8 & 89.8 \\
\hline $21-31$ & 0.0 & 0.0 & 0.0 & 0.0 & 0.0 & 0.0 & 0.0 & 0.0 & 2.7 & 31.0 & 63.5 \\
\hline nov. $1-10$ & 0.0 & 0.0 & 0.0 & 0.0 & 0.0 & 0.0 & 0.0 & 0.0 & 26.4 & 60.8 & 115.0 \\
\hline $11-20$ & 0.0 & 0.0 & 0.0 & 0.0 & 0.0 & 0.0 & 0.0 & 5.3 & 14.7 & 68.4 & 182.3 \\
\hline $21-30$ & 0.0 & 0.0 & 0.0 & 0.0 & 0.0 & 0.0 & 0.0 & 0.0 & 27.2 & 36.9 & 219.2 \\
\hline$d e 2.1-10$ & 0.0 & 0.0 & 0.0 & 0.0 & 0.0 & 0.0 & 7.3 & 37.2 & 73.6 & 107.7 & 244.1 \\
\hline $11-20$ & 0.0 & 0.0 & 0.0 & 0.0 & 7.0 & 19.9 & 32.4 & 45.2 & 66.9 & 110.5 & 163.5 \\
\hline $21-31$ & 0.0 & 0.0 & 6.0 & 23.2 & 31.1 & 45.2 & 71.6 & 84.3 & 111.1 & 157.5 & 187.5 \\
\hline
\end{tabular}


TABELA 40 - JAU: AGUA FACLLMENE DISPONIVEL (BALARCO COM AFD = 75 Ad

DECIL

\begin{tabular}{|c|c|c|c|c|c|c|c|c|c|c|c|}
\hline & & 1 & 2 & 3 & 4 & 5 & 6 & 7 & 8 & 9 & 10 \\
\hline a ถูก.1-10 & 36.8 & 55.0 & 75.0 & 75.0 & 75.0 & 75.0 & 75.0 & 75.0 & 75.0 & 75.0 & 75.0 \\
\hline $11-20$ & 25.1 & 45.5 & 55.8 & 65.8 & 75.0 & 75.0 & 75.0 & 75.0 & 75.0 & 75.0 & 75.0 \\
\hline $21-31$ & 26.1 & 51.8 & 64.5 & 75.0 & 75.0 & 75.0 & 75.0 & 75.0 & 75.0 & 75.0 & 75.0 \\
\hline fey. $1-10$ & 26.6 & 58.6 & 74.4 & 75.0 & 75.0 & 75.0 & 75.0 & 75.0 & 75.0 & 75.0 & 75.0 \\
\hline $11-20$ & 31.4 & 46.9 & 57.6 & 72.8 & 75.0 & 75.0 & 75.0 & 75.0 & 75.0 & 75.0 & 75.0 \\
\hline $21-28$ & 23.3 & 48.4 & 55.9 & 72.3 & 75.0 & 75.0 & 75.0 & 75.0 & 75.0 & 75.0 & 75.0 \\
\hline $\operatorname{cor} .1-10$ & 23.7 & 44.2 & 50.3 & 59.7 & 65.5 & 69.0 & 75.0 & 75.0 & 75.0 & 75.0 & 75.0 \\
\hline $11-20$ & 16.6 & 32.5 & 40.0 & 45.8 & 55.1 & 78.3 & 75.0 & 75.0 & 75.0 & 75.0 & 75.0 \\
\hline $21-31$ & 11.8 & 30.1 & 39.2 & 44.6 & 49.0 & 56.8 & 64.9 & 70.5 & 75.0 & 75.0 & 75.0 \\
\hline abr $: 1-10$ & 0.0 & 24.5 & 33.7 & 40.7 & 48.3 & 57.0 & 61.6 & 72.8 & 75.0 & 75.0 & 75.0 \\
\hline $11-20$ & 0.0 & 7.5 & 24.0 & 30.0 & 43.8 & 51.4 & 58.0 & 64.2 & 72.6 & 75.0 & 75.0 \\
\hline $21-30$ & 0.0 & 0.0 & 14.2 & 27.0 & 31.3 & 39.9 & 86.7 & 49.6 & 62.5 & 75.0 & 75.0 \\
\hline Mai. $1-10$ & 0.0 & 0.0 & 16.6 & 21.9 & 27.1 & 39.0 & 43.6 & 55.2 & 61.4 & 67.4 & 75.0 \\
\hline $11-20$ & 0.0 & 0.0 & 4.3 & 13.2 & 20.2 & 34.9 & 41.3 & 59.6 & 62.3 & 75.0 & 75.0 \\
\hline $21-31$ & 0.0 & 0.0 & 0.0 & 0.0 & 14.4 & 29.2 & 34.6 & 45.2 & 67.5 & 75.0 & 75.0 \\
\hline jun. $1-10$ & 0.0 & 0.0 & 0.0 & 5.1 & 11.2 & 16.5 & 22.0 & 35.2 & 54.2 & 68.9 & 75.0 \\
\hline $11-20$ & 0.0 & 0.0 & 0.0 & 5.1 & 6.0 & 20.0 & 29.7 & 36.2 & 45.0 & 57.1 & 75.0 \\
\hline $21-30$ & 0.0 & 0.0 & 0.0 & 0.0 & 8.8 & 15.6 & 22.9 & 29.7 & 34.8 & 70.3 & 75.0 \\
\hline jul, $1-10$ & 0.0 & 0.0 & 0.0 & 0.0 & 0.0 & 3.8 & 11.0 & 15.5 & 52.7 & 64.9 & 75.0 \\
\hline $11-20$ & 0.0 & 0.0 & 0.0 & 0.0 & 0.0 & 0.0 & 0.0 & 1.1 & 40.3 & 54.6 & 75.0 \\
\hline $21-31$ & 0.0 & 0.0 & 0.0 & 0.0 & 0.0 & 0.0 & 0.0 & 8.1 & 22.2 & 58.9 & 75.0 \\
\hline $200 \times 1-10$ & 0.0 & 0.0 & 0.0 & 0.0 & 0.0 & 0.0 & 0.0 & 2.0 & 8.7 & 35.6 & 74.5 \\
\hline $11-20$ & 0.0 & 0.0 & 0.0 & 0.0 & 0.0 & 0.0 & 0.0 & 0.0 & 21.0 & 38.9 & 75.0 \\
\hline $21-31$ & 0.0 & 0.0 & 0.0 & 0.0 & 0.0 & 0.0 & 0.0 & 0.0 & 20.4 & 46.9 & 75.0 \\
\hline set. $1-10$ & 0.0 & 0.0 & 0.0 & 0.0 & 0.0 & 0.0 & 4.2 & 26.1 & 41.9 & 53.1 & 75.0 \\
\hline $11-20$ & 0.0 & 0.0 & 0.0 & 0.0 & 0.0 & 0.0 & 11.5 & 21.5 & 38.7 & 62.0 & 75.0 \\
\hline $21-30$ & 0.0 & 0.0 & 0.0 & 0.0 & 0.0 & 7.1 & 21.2 & 32.2 & 52.4 & 75.0 & 75.0 \\
\hline out.1-10 & 0.0 & 0.0 & 0.0 & 0.0 & 0.0 & 19.1 & 40.8 & 67.7 & 75.0 & 75.0 & 75.0 \\
\hline $11-20$ & 0.0 & 0.0 & 0.0 & 5.4 & 15.3 & 40.5 & 50.9 & 59.2 & 74.8 & 75.0 & 75.0 \\
\hline $21-31$ & 0.0 & 0.0 & 0.0 & 16.5 & 31.1 & 40.6 & 57.5 & 70.4 & 75.0 & 75.0 & 75.0 \\
\hline nov. $1-10$ & 0.0 & 0.0 & 0.4 & 27.1 & 39.8 & 58.6 & 63.5 & 74.0 & 75.0 & 75.0 & 75.0 \\
\hline $11-20$ & 0.0 & 0.0 & 14.2 & 25.5 & 39.9 & 48.4 & 30.3 & 75.0 & 75.0 & 75.0 & 75.0 \\
\hline $21-30$ & 0.0 & 0.7 & 16.5 & 26.0 & 46.0 & 57.6 & 6.5 .5 & 72.1 & 75.0 & 75.0 & 75.0 \\
\hline dez.1-10 & 16.4 & 22.7 & 30.3 & 43.7 & 59.0 & 73.1 & 75.0 & 73.0 & 75.0 & 75.0 & 75.0 \\
\hline $11-20$ & 0.0 & 31.8 & 40.7 & 62.8 & 75.0 & 75.0 & 75.0 & 75.0 & 75.0 & 75.0 & 75.0 \\
\hline $21-31$ & 0.0 & 53.1 & 73.1 & 75.0 & 75.0 & 75.0 & 75.0 & 75.0 & 75.0 & 75.0 & 75.0 \\
\hline
\end{tabular}


DECIL

\begin{tabular}{|c|c|c|c|c|c|c|c|c|c|c|c|}
\hline DECEMDIO & MIN. & 1 & 2 & 3 & 4 & 5 & $b$ & 7 & 8 & 9 & 10 \\
\hline jan. $1-10$ & 0.0 & 0.0 & 0.0 & 0.0 & 0.0 & 0.0 & 0.0 & 0.0 & 0.0 & 0.0 & 0.0 \\
\hline $11-20$ & 0.0 & 0.0 & 0.0 & 0.0 & 0.0 & 0.0 & 0.0 & 0.0 & 0.0 & 0.0 & 0.0 \\
\hline $21-31$ & 0.0 & 0.0 & 0.0 & 0.0 & 0.0 & 0.0 & 0.0 & 0.0 & 0.0 & 0.0 & 0.0 \\
\hline fev. $1-10$ & 0.0 & 0.0 & 0.0 & 0.0 & 0.0 & 0.0 & 0.0 & 0.0 & 0.0 & 0.0 & 0.0 \\
\hline $11-20$ & 0.0 & 0.0 & 0.0 & 0.0 & 0.0 & 0.0 & 0.0 & 0.0 & 0.0 & 0.0 & 0.0 \\
\hline $21-28$ & 0.0 & 0.0 & 0.0 & 0.0 & 0.0 & 0.0 & 0.0 & 0.0 & 0.0 & 0.0 & 0.0 \\
\hline ar $.1-10$ & 0.0 & 0.0 & 0.0 & 0.0 & 0.0 & 0.0 & 0.0 & 0.0 & 0.0 & 0.0 & 0.0 \\
\hline $11-20$ & 0.0 & 0.0 & 0.0 & 0.0 & 0.0 & 0.0 & 0.0 & 0.0 & 0.0 & 0.0 & 0.0 \\
\hline $21-31$ & 0.0 & 0.0 & 0.0 & 0.0 & 0.0 & 0.0 & 0,0 & 0.0 & 0.0 & 0.0 & 0.0 \\
\hline$a b r .1-10$ & 0.0 & 0.0 & 0.0 & 0.0 & 0.0 & 0.0 & 0.0 & 0.0 & 0.0 & 0.0 & 12.8 \\
\hline $11-20$ & 0.0 & 0.0 & 0.0 & 0.0 & 0.0 & 0.0 & 0.0 & 0.0 & 0.0 & 0.0 & 8.7 \\
\hline $21-30$ & 0.0 & 0.0 & 0.0 & 0.0 & 0.0 & 0.0 & 0.0 & 0.0 & 0.0 & 0.0 & 29.9 \\
\hline ad, $1-10$ & 0.0 & 0.0 & 0.0 & 0.0 & 0.0 & 0.0 & 0.0 & 0.0 & 0.0 & 0.0 & 26.1 \\
\hline $11-20$ & 0.0 & 0.0 & 0.0 & 0.0 & 0.0 & 0.0 & 0.0 & 0.0 & 0.0 & 4.7 & 25.0 \\
\hline $21-31$ & 0,0 & 0.0 & 0.0 & 0.0 & 0.0 & 0.0 & 0.0 & 0.0 & 4.3 & 19.2 & 26.7 \\
\hline jun. $1-10$ & 0.0 & 0.0 & 0.0 & 0.0 & 0.0 & 0.0 & 0.0 & 0.0 & 6.2 & 21.1 & 25.9 \\
\hline $11-20$ & 0.0 & 0.0 & 0.0 & 0.0 & 0.0 & 0.0 & 0.0 & 0.0 & 5.2 & 21.8 & 23.7 \\
\hline $21-30$ & 0.0 & 0.0 & 0.0 & 0.0 & 0.0 & 0.0 & 0.0 & 0.0 & 16.2 & 22.4 & 25.1 \\
\hline jul $.1-10$ & 0.0 & 0.0 & 0.0 & 0.0 & 0.0 & 0.0 & 1.0 & 7.3 & 12.4 & 21.8 & 28.6 \\
\hline $11-20$ & 0.0 & 0.0 & 0.0 & 0.0 & 1.3 & 7.3 & 14.9 & 17.6 & 22.6 & 26.3 & 28.3 \\
\hline $21-31$ & 0.0 & 0.0 & 0.0 & 0.0 & 1.1 & 13.2 & 22.0 & 24.5 & 26.9 & 29.6 & 32.2 \\
\hline $290.1-10$ & 0.0 & 0.0 & 0.0 & 0.0 & 3.0 & 12.2 & 25.3 & 26.5 & 27.6 & 29.7 & 30.2 \\
\hline $11-20$ & 0.0 & 0.0 & 0.0 & 4.6 & 13.9 & 18.1 & 25.0 & 27.9 & 28.3 & 29.6 & 33.1 \\
\hline $21-31$ & 0.0 & 0.0 & 0.0 & 3.0 & 13.3 & 23.2 & 26.0 & 31.5 & 33.9 & 36.0 & 39.1 \\
\hline set. $1-10$ & 0.0 & 0.0 & 0.0 & 0.0 & 0.0 & 0.0 & 23.4 & 29.2 & 31,5 & 35.1 & 43.4 \\
\hline $11-20$ & 0.0 & 0.0 & 0.0 & 0.0 & 0.0 & 16.0 & 26.5 & 30.9 & $34 . ?$ & 35.2 & 99.8 \\
\hline $21-30$ & 0.0 & 0.0 & 0.0 & 0.0 & 0.0 & 0.0 & 3.9 & 13.5 & 20.9 & 26.3 & 31.7 \\
\hline out. $1-10$ & 0.0 & 0.0 & 0.0 & 0.0 & 0.0 & 0.0 & 0.4 & 12.4 & 25.4 & 37.5 & 41.8 \\
\hline $11-20$ & 0.0 & 0.0 & 0.0 & 0.0 & 0.0 & 0.0 & 0.0 & 0.0 & 7.4 & 32.4 & 51.5 \\
\hline $21-31$ & 0.0 & 0.0 & 0.0 & 0.0 & 0.0 & 0.0 & 0.0 & 0.0 & 0.0 & 8.8 & 47.9 \\
\hline nov. $1-10$ & 0.0 & 0.0 & 0.0 & 0.0 & 0.0 & 0.0 & 0.0 & 0.0 & 0.0 & 18.8 & 25.2 \\
\hline $11-20$ & 0.0 & 0.0 & 0.0 & 0.0 & 0.0 & 0.0 & 0.0 & 0.0 & 0.0 & 0.0 & 37.2 \\
\hline $21-30$ & 0.0 & 0.0 & 0.0 & 0.0 & 0.0 & 0.0 & 0.0 & 0.0 & 0.0 & 0.0 & 21.9 \\
\hline dez.1-10 & 0.0 & 0.0 & 0.0 & 0.0 & 0.0 & 0.0 & 0.0 & 0.0 & 0.0 & 0.0 & 0.0 \\
\hline $11-20$ & 0.0 & 0.0 & 0.0 & 0.0 & 0.0 & 0.0 & 0.0 & 0.0 & 0.0 & 0.0 & 20.0 \\
\hline $21-31$ & 0.0 & 0.0 & 0.0 & 0.0 & 0.0 & 0.0 & 0.0 & 0.0 & 0.0 & 0.0 & 11.6 \\
\hline
\end{tabular}




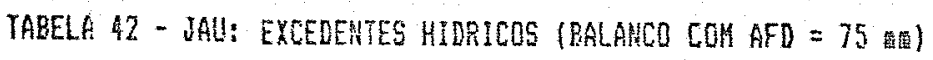

DECIL

\begin{tabular}{|c|c|c|c|c|c|c|c|c|c|c|c|}
\hline & & 1 & 2 & 3 & 4 & 5 & 6 & 7 & 8 & 9 & 10 \\
\hline jañ.1-10 & 0.0 & 0.0 & 4.3 & 12.0 & 22.6 & 56.1 & 70.2 & 81.4 & 87.9 & 92.4 & 142.3 \\
\hline $11-20$ & 0.0 & 0.0 & 0.0 & 0.0 & 6.5 & 12.2 & 27.6 & 86.4 & 101.5 & 141.9 & 204.3 \\
\hline $21-31$ & 0.0 & 0.0 & 0.0 & 3.4 & 11.1 & 22.9 & 31.5 & 39.5 & 59.9 & 92.6 & 175.0 \\
\hline fev.1-10 & 0.0 & 0.0 & 0.0 & 9.8 & 12.9 & 24.6 & 33.3 & 52.4 & 75.1 & 142.2 & 171.5 \\
\hline $11-20$ & 0.0 & 0.0 & 0.0 & 0.0 & 15.7 & 37.3 & 43.5 & 53.8 & 79.0 & 103.9 & 287.8 \\
\hline $21-28$ & 0.0 & 0.0 & 0.0 & 0.0 & 4.2 & 15.9 & 26.9 & 49.7 & 73.0 & 106.6 & 175.8 \\
\hline tar. $1-10$ & 0.0 & 0.0 & 0.0 & 0.0 & 0.0 & 0.0 & 7.4 & 21.3 & 42.7 & 68.3 & 125.8 \\
\hline $11-20$ & 0.0 & 0.0 & 0.0 & 0.0 & 0.0 & 0.0 & 4.8 & 16.4 & 36.2 & 107.2 & 275.2 \\
\hline $21-31$ & 0.0 & 0.0 & 0.0 & 0.0 & 0.0 & 0.0 & 0.0 & 0.0 & 9.6 & 16.7 & 97.7 \\
\hline abr. $1-10$ & 0.0 & 0.0 & 0.0 & 0.0 & 0.0 & 0.0 & 0.0 & 0.0 & 14.3 & 40.5 & 114.7 \\
\hline $11-20$ & 0.0 & 0.0 & 0.0 & 0.0 & 0.0 & 0.0 & 0.0 & 0.0 & 0.0 & 17.4 & 16.6 \\
\hline $21-30$ & 0.0 & 0.0 & 0.0 & 0.0 & 0.0 & 0.0 & 0.0 & 0.0 & 0.0 & 1.3 & 75.8 \\
\hline$=\mathrm{a}, 1-10$ & 0.0 & 0.0 & 0.0 & 0.0 & 0.0 & 0.0 & 0.0 & 0.0 & 0.0 & 0.0 & 12.2 \\
\hline $11-20$ & 0.0 & 0.0 & 0.0 & 0.0 & 0.0 & 0.0 & 0.0 & 0.0 & 0.0 & 23.7 & 63.0 \\
\hline $21-31$ & 0.0 & 0.0 & 0.0 & 0.0 & 0.0 & 0.0 & 0.0 & 0.0 & 0.0 & 8.6 & 24.8 \\
\hline jun. $1-10$ & 0.0 & 0.0 & 0.0 & 0.0 & 0.0 & 0.0 & 0.0 & 0.0 & 0.0 & 0.0 & 118.9 \\
\hline $11-20$ & 0.0 & 0.0 & 0.0 & 0.0 & 0.0 & 0.0 & 0.0 & 0.0 & 0.0 & 0.0 & 49.9 \\
\hline $21-30$ & 0.0 & 0.0 & 0.0 & 0.0 & 0.0 & 0.0 & 0.0 & 0.0 & 0.0 & 0.0 & 54.4 \\
\hline jul.1-10 & 0.0 & 0.0 & 0.0 & 0.0 & 0.0 & 0.0 & 0.0 & 0.0 & 0.0 & 0.0 & 15.6 \\
\hline $11-20$ & 0.0 & 0.0 & 0.0 & 0.0 & 0.0 & 0.0 & 0.0 & 0.0 & 0.0 & 0.0 & 6.7 \\
\hline $21-31$ & 0.0 & 0.0 & 0.0 & 0.0 & 0.0 & 0.0 & 0.0 & 0.0 & 0.0 & 0.0 & 21.0 \\
\hline $290.1-10$ & 0.0 & 0.0 & 0.0 & 0.0 & 0.0 & 0.0 & 0.0 & 0.0 & 0.0 & 0.0 & 0.0 \\
\hline $11-20$ & 0.0 & 0.0 & 0.0 & 0.0 & 0.0 & 0.0 & 0.0 & 0.0 & 0.0 & 0.0 & 6.7 \\
\hline $21-31$ & 0.0 & 0.0 & 0.0 & 0.0 & 0.0 & 0.0 & 0.0 & 0.0 & 0.0 & 0.0 & 6.6 \\
\hline set. $1-10$ & 0.0 & 0.0 & 0.0 & 0.0 & 0.0 & 0.0 & 0.0 & 0.0 & 0.0 & 0.0 & 32.1 \\
\hline $11-20$ & 0.0 & 0.0 & 0.0 & 0.0 & 0.0 & 0.0 & 0.0 & 0.0 & 0.0 & 0.0 & 40.9 \\
\hline $21-30$ & 0.0 & 0.0 & 0.0 & 0.0 & 0.0 & 0.0 & 0.0 & 0.0 & 0.0 & 0.8 & 50.1 \\
\hline out. $1-10$ & 0.0 & 0.0 & 0.0 & 0.0 & 0.0 & 0.0 & 0.0 & 0.0 & 6.9 & 18.4 & 86.1 \\
\hline $11-20$ & 0.0 & 0.0 & 0.0 & 0.0 & 0.0 & 0.0 & 0.0 & 0.0 & 0.0 & 36.8 & 09.8 \\
\hline $21-31$ & 0.0 & 0.0 & 0.0 & 0.0 & 0.0 & 0.0 & 0.0 & 0.0 & 2.7 & 24.9 & 38.5 \\
\hline nov. $1-10$ & 0.0 & 0.0 & 0.0 & 0.0 & 0.0 & 0.0 & 0.0 & 0.0 & 25.6 & 45.3 & 113.6 \\
\hline $11-20$ & 0.0 & 0.0 & 0.0 & 0.0 & 0.0 & 0.0 & 0.0 & 1.1 & 14.7 & 53.2 & 182.3 \\
\hline $21-30$ & 0.0 & 0.0 & 0.0 & 0.0 & 0.0 & 0.0 & 0.0 & 0.0 & 27.2 & 36.9 & 195.2 \\
\hline dez.1-10 & 0.0 & 0.0 & 0.0 & 0.0 & 0.0 & 0.0 & 7.3 & 21.8 & 73.6 & 107.7 & 219.1 \\
\hline $11-20$ & 0.0 & 0.0 & 0.0 & 0.0 & 7.0 & 19.9 & 32.4 & 41.2 & 66.9 & 110.5 & 163.5 \\
\hline $21-31$ & 0.0 & 0.0 & 0.0 & 16.3 & 31.1 & 34.2 & 71.6 & 84.3 & 111.1 & 157.5 & 197.5 \\
\hline
\end{tabular}


DECIL

\begin{tabular}{|c|c|c|c|c|c|c|c|c|c|c|c|}
\hline DECENDIO & MIN. & 1 & 2 & 3 & 4 & 5 & 6 & 7 & 8 & 9 & 10 \\
\hline jan. $1-10$ & 2.2 & 9.5 & 32 & 36.2 & 38.5 & 50.9 & 59 & 108.7 & 149 & 179.5 & 241.7 \\
\hline $11-20$ & 0 & 13.1 & 32.7 & 40.2 & 58.7 & 71.1 & 89.1 & 99.5 & 121.1 & 144.96 & 378.9 \\
\hline $21-31$ & 19.9 & 22.8 & 36 & 54.4 & 60.9 & 69.3 & 91 & 96.4 & 102.6 & 151.9 & 219.1 \\
\hline fev. $1-10$ & 2.7 & 10.5 & 13.3 & 29 & 45.3 & 63.9 & 84.5 & 115.8 & 139.7 & 174.2 & 236.8 \\
\hline $11-20$ & 0 & 2.4 & 26.7 & 33.2 & 35.7 & 45.7 & 54.7 & 93.5 & $1 \notin 2,6$ & 152.3 & 223.5 \\
\hline $21-28$ & 1.4 & 12.9 & 28.8 & 33.5 & 42.7 & 45.2 & 59.2 & 67.2 & 81.9 & 131.7 & 166.5 \\
\hline ner. $1-10$ & 3.5 & 14.5 & 30.9 & 39 & 42.3 & 55.1 & 68.5 & 73.1 & 93 & 126.7 & 162 \\
\hline $11-20$ & 0.5 & 3.2 & 7.1 & 19.3 & 22.8 & 34.8 & 53.8 & 66.1 & 74.2 & 113.1 & 240 \\
\hline $21-31$ & 0 & 4.6 & 9.5 & 13.5 & 28.8 & 30.6 & 37.5 & 50.5 & 66.7 & 103.4 & 185.6 \\
\hline$a b r \cdot 1-10$ & 0 & 0 & 0.1 & 5.8 & 11.4 & 15.3 & 28 & 31.5 & 43.9 & 67.8 & 112.6 \\
\hline $11-20$ & 0 & 0 & 2 & 3.5 & 6.9 & 12.8 & 16.1 & 21.5 & 32.4 & 59.3 & 96 \\
\hline $21-30$ & 0 & 0 & 0.6 & 2.2 & 3.5 & 4.6 & 7.5 & 10.9 & 19.8 & 37 & 136.3 \\
\hline Q⿱一⿻上丨). $2-10$ & 0 & 0 & 0 & 1.3 & 4.3 & 6.3 & 9.8 & 22.2 & 46.4 & 51.5 & 146.3 \\
\hline $11-20$ & 0 & 0 & 0 & 0 & 0.2 & 1 & 6.8 & $14: B$ & 25.9 & 39 & 88 \\
\hline $21-31$ & 0 & 0 & 0 & 0.5 & 4.5 & 8.1 & 20.5 & 27 & 29.9 & 47.8 & 131 \\
\hline jun. $1-10$ & 0 & 0 & 0 & 0 & 0.2 & 3.1 & 5.8 & 11.5 & 24.9 & 38.4 & 71.9 \\
\hline $11-20$ & 0 & 0 & 0 & 0 & 0 & 0 & 2 & 7.2 & 15 & 21.2 & 131 \\
\hline $21-30$ & 0 & 0 & 0 & 0 & 0 & 0 & 1.4 & 3.9 & 14.3 & 31.3 & $64+1$ \\
\hline jul.1-10 & 0 & 0 & 0 & 0 & 0 & 0 & 0.4 & 3.5 & 16.7 & 23 & 49.3 \\
\hline $11-20$ & 0 & 0 & 0 & 0 & 0 & 0 & 0 & 3 & 9.5 & 19.4 & 71 \\
\hline $2|-3|$ & 0 & 0 & 0 & 0 & 0 & 0 & 1.9 & 3.1 & 7.1 & 31.5 & 79.1 \\
\hline $290.1-10$ & 0 & 0 & 0 & 0 & 0 & 0 & 1.1 & 3.9 & 7.5 & 34.8 & 60 \\
\hline $11-20$ & 0 & 0 & 0 & 0 & 0 & 0 & 0.4 & 2.5 & 7.1 & 14.6 & 99.6 \\
\hline $21-31$ & 0 & 0 & 0 & 0 & 0 & 0.3 & 5 & 11.2 & 17.1 & 36.7 & 65.5 \\
\hline set. $1-10$ & 0 & 0 & 0 & 0.1 & 1.6 & 6.9 & 7.6 & 12.3 & 22.1 & 23.8 & 82.8 \\
\hline $11-20$ & 0 & 0 & 0 & 0 & 0 & 0.5 & 3.8 & 19.8 & 52.2 & 62 & 131.6 \\
\hline $21-30$ & 0 & 0 & 3.5 & 6.8 & 12.8 & 16.4 & 20.1 & 28.6 & 36.3 & 50.9 & 116.9 \\
\hline out. $1-10$ & 0 & 0.2 & 1.6 & 12.7 & 18.5 & 32.6 & 37 & 50.8 & 64.1 & 90 & 100.7 \\
\hline $11-20$ & 0.3 & 7.6 & 14.1 & 20.1 & 28.7 & 30.5 & 33.5 & 45.6 & 64.8 & 100.6 & 135.9 \\
\hline $2 !-3 !$ & 0 & 1.7 & 16.3 & 26.7 & 31.6 & 36 & 40.5 & 43.1 & 55.5 & 87.1 & 109.: \\
\hline nov. $1-10$ & 0 & 3.3 & 10 & 14.1 & 32.1 & 35.4 & 47.4 & 56.2 & 67 & 78.0 & 191.7 \\
\hline $11-20$ & 0.6 & 8.6 & 17 & 26.7 & 35 & 43.2 & 59.1 & 69.9 & 86.7 & 88.4 & 151.3 \\
\hline $21-30$ & 0.4 & 1.7 & 14 & 17.8 & 25.6 & 32.9 & 47.8 & 67.9 & 72.8 & 120.7 & 163.6 \\
\hline dez.1-10 & 4.9 & 18.2 & 20.8 & 26 & 36.5 & 49.5 & 57.5 & 76.6 & 77.9 & 140.8 & 190.1 \\
\hline $11-20$ & 0 & 14.2 & 31.1 & 44.3 & 49.2 & 53.8 & 60.7 & 76.9 & 102.1 & 137.3 & 177.1 \\
\hline $21-31$ & 3.3 & 6.1 & 36.7 & 68.4 & 79.6 & 93.9 & 121.7 & 143.9 & 154.4 & 186.6 & 242.1 \\
\hline
\end{tabular}




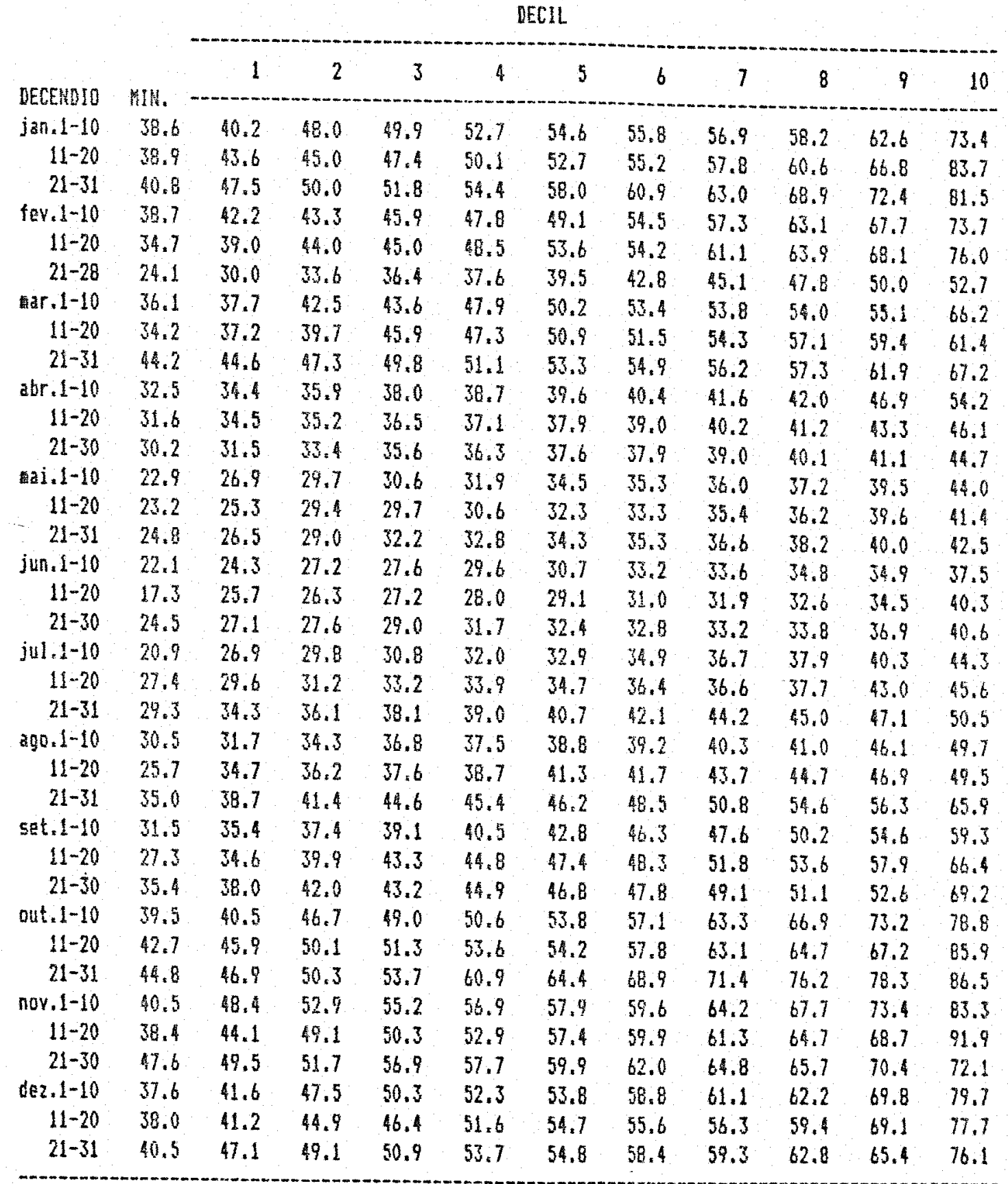


TABELA 45 - PINDORAMA: ANUA FACILMENTE DISFONYUEL (BALANCO COA AFD $=30 \mathrm{gm}$ )

DECIL

\begin{tabular}{|c|c|c|c|c|c|c|c|c|c|c|c|}
\hline DECENDIO & MIN. & 1 & 2 & 3 & 4 & 5 & $b$ & 7 & $B$ & 9 & 10 \\
\hline jan.1-10 & 4.3 & 10.7 & 30.0 & 30.0 & 30.0 & 30.0 & 30.0 & 30.0 & 30.0 & 30.0 & 30.0 \\
\hline $11-20$ & 0.0 & 9.6 & 25.2 & 30.0 & 30.0 & 30.0 & 30.0 & 30.0 & 30.0 & 30.0 & 30.0 \\
\hline $21-31$ & 0.0 & 23.1 & 30.0 & 30.0 & 30.0 & 30.0 & 30.0 & 30.0 & 30.0 & 30.0 & 30.0 \\
\hline fev. $1-10$ & 0.0 & 4.5 & 12.3 & 30.0 & 30.0 & 30.0 & 30.0 & 30.0 & 30.0 & 30.0 & 30.0 \\
\hline $11-20$ & 0.0 & 0.0 & 16.9 & 23.6 & 30.0 & 30.0 & 30.0 & 30.0 & 30.0 & 30.0 & 30.0 \\
\hline $21-2 B$ & 0.0 & 19.0 & 30.0 & 30.0 & 30.0 & 30.0 & 30.0 & 30.0 & 30.0 & 30.0 & 30.0 \\
\hline ar. 1-10 & 1.4 & 6.9 & 30.0 & 30.0 & 30.0 & 30.0 & 30.0 & 30.0 & 30.0 & 30.0 & 30.0 \\
\hline $11-20$ & 0.0 & 0.0 & 5.2 & 13.9 & 19.0 & 30.0 & 30.0 & 30.0 & 30.0 & 30.0 & 30.0 \\
\hline $21-31$ & 0.0 & 0.0 & 4.8 & 11.0 & 15.2 & 20.2 & 26.7 & 30.0 & 30.0 & 30.0 & 30.0 \\
\hline abr. $1-10$ & 0,0 & 0.0 & 1.1 & 4.2 & 5.8 & 16.6 & 25.0 & 30.0 & 30.0 & 30.0 & 30.0 \\
\hline $11-20$ & 0.0 & 0.0 & 0.0 & 1.9 & 8.4 & 11.4 & 13.6 & 17.1 & 30.0 & 30.0 & 30.0 \\
\hline $21-30$ & 0.0 & 0.0 & 0.0 & 0.0 & 0.0 & 5.3 & 8.4 & 13.8 & 16.0 & 20.0 & 30.0 \\
\hline (1) $a \cdot 1-10$ & 0.0 & 0.0 & 0.0 & 0.0 & 0.0 & 0.3 & 15.7 & 18.4 & 28.5 & 30.0 & 30.0 \\
\hline $11-20$ & 0.0 & 0.0 & 0.0 & 0.0 & 0.0 & 7.4 & 13.0 & 16.0 & 23.8 & 28.3 & 30.0 \\
\hline $21-31$ & 0.0 & 0.0 & 0.0 & 0.0 & 0.0 & 0.0 & 16.9 & 20.2 & 30.0 & 30.0 & 30.0 \\
\hline jun. $1-10$ & 0.0 & 0.0 & 0.0 & 0.0 & 0.0 & 2.7 & 9.1 & 13.5 & 19.9 & 30.0 & 30.0 \\
\hline $11-20$ & 0.0 & 0.0 & 0.0 & 0.0 & 0.0 & 0.0 & 0.0 & 11.2 & 13.4 & 27.0 & 30.0 \\
\hline $21-30$ & 0.0 & 0.0 & 0.0 & 0.0 & 0.0 & 0.0 & 0.0 & 0.0 & 10.1 & 17.3 & 30.0 \\
\hline jul.1-10 & 0.0 & 0.0 & 0.0 & 0.0 & 0.0 & 0.0 & 0.0 & 0.0 & 4.9 & 12.1 & 30.0 \\
\hline $11-20$ & 0.0 & 0.0 & 0.0 & 0.0 & 0.0 & 0.0 & 0.0 & 0.0 & 0.0 & 10.7 & 30.0 \\
\hline $21-31$ & 0.0 & 0.0 & 0.0 & 0.0 & 0.0 & 0.0 & 0.0 & 0.0 & 1.0 & 12.3 & 30.0 \\
\hline $890.1-10$ & 0.0 & 0.0 & 0.0 & 0.0 & 0.0 & 0.0 & 0.0 & 0.0 & 0.0 & 15.3 & 30.0 \\
\hline $11-20$ & 0.0 & 0.0 & 0.0 & 0.0 & 0.0 & 0.0 & 0.0 & 0.0 & 0.0 & 7.2 & 30.0 \\
\hline $21-31$ & 0.0 & 0.0 & 0.0 & 0.0 & 0.0 & 0.0 & 0.0 & 0.0 & 0.0 & 9.1 & 30.0 \\
\hline Set.1-10 & 0.0 & 0.0 & 0.0 & 0.0 & 0.0 & 0.0 & 0.0 & 0.0 & 1.5 & 14.6 & 30.0 \\
\hline $11-20$ & 0.0 & 0.0 & 0.0 & 0.0 & 0.0 & 0.0 & 0.0 & 0.0 & 28.3 & 30.0 & 30.0 \\
\hline $21-30$ & 0.0 & 0.0 & 0.0 & 0.0 & 0.0 & 0.0 & 7.8 & 16.0 & 22.2 & 25.0 & 30.0 \\
\hline out. $1-10$ & 0.0 & 0.0 & 0.0 & 0.0 & 0.0 & 12.3 & 24.1 & 29.3 & 30.0 & 30.0 & 30.0 \\
\hline $11-20$ & 0.0 & 0.0 & 0.0 & 0.2 & 7.1 & 14.9 & 16.6 & 23.4 & 30.0 & 30.0 & 30.0 \\
\hline $21-31$ & 0.0 & 0.0 & 0.0 & 0.0 & 3.8 & 13.7 & 19.8 & 30.0 & 30.0 & 30.0 & 30.0 \\
\hline nov. $1-10$ & 0.0 & 0.0 & 0.0 & 1.3 & 13.6 & 26.1 & 30.0 & 30.0 & 30.0 & 30.0 & 30.0 \\
\hline $11-20$ & 0.0 & 0.0 & 1.1 & 5.9 & 26.2 & 30.0 & 30.0 & 30.0 & 30.0 & 30.0 & 30.0 \\
\hline $21-30$ & 0.0 & 0.0 & 0.0 & 1.9 & 14.7 & 23.0 & 30.0 & 30.0 & 30.0 & 30.0 & 30.0 \\
\hline dez.1-10 & 0.0 & 0.0 & 0.0 & 4.6 & 23.0 & 30.0 & 30.0 & 30.0 & 30.0 & 30.0 & 30.0 \\
\hline $11-20$ & 0.0 & 0.0 & 20.4 & 28.7 & 30.0 & 30.0 & 30.0 & 30.0 & 30.0 & 30.0 & 30.0 \\
\hline $21-31$ & 0.0 & 0.0 & 28.0 & 30.0 & 30.0 & 30.0 & 30.0 & 30.0 & 30.0 & 30.0 & 30.0 \\
\hline
\end{tabular}


TABELA 46-PIMDCRAMA: DEFICITES (EALANCO CON AFD $=30$ 的)

DEEIL

\begin{tabular}{|c|c|c|c|c|c|c|c|c|c|c|c|}
\hline DECENDIO & MIN. & 1 & 2 & 3 & 4 & 5 & 6 & 7 & 8 & 9 & 10 \\
\hline jan $1-10$ & 0.0 & 0.0 & 0.0 & 0.0 & 0.0 & 0.0 & 0.0 & 0.0 & 0.0 & 0.0 & 0.0 \\
\hline $11-20$ & 0.0 & 0.0 & 0.0 & 0.0 & 0.0 & 0.0 & 0.0 & 0.0 & 0.0 & 0.0 & 31.2 \\
\hline $21-31$ & 0.0 & 0.0 & 0.0 & 0.0 & 0.0 & 0.0 & 0.0 & 0.0 & 0.0 & 0.0 & 6.1 \\
\hline fev. $1-10$ & 0.0 & 0.0 & 0.0 & 0.0 & 0.0 & 0.0 & 0.0 & 0.0 & 0.0 & 0.0 & 24.2 \\
\hline $11-20$ & 0.0 & 0.0 & 0.0 & 0.0 & 0.0 & 0.0 & 0.0 & 0.0 & 0.0 & 2.6 & 19.3 \\
\hline $21-2 a$ & 0.0 & 0.0 & 0.0 & 0.0 & 0.0 & 0.0 & 0.0 & 0.0 & 0.0 & 0.0 & 7.6 \\
\hline Ear.1-10 & 0.0 & 0.0 & 0.0 & 0.0 & 0.0 & 0.0 & 0.0 & 0.0 & 0.0 & 0.0 & 0.0 \\
\hline $11-20$ & 0.0 & 0.0 & 0.0 & 0.0 & 0.0 & 0.0 & 0.0 & 0.0 & 0.0 & 0.0 & 29.2 \\
\hline $21-31$ & 0.0 & 0.0 & 0.0 & 0.0 & 0.0 & 0.0 & 0.0 & 0.0 & 0.0 & 0.0 & 22.4 \\
\hline$a b r .1-10$ & 0.0 & 0.0 & 0.0 & 0.0 & 0.0 & 0.0 & 0.0 & 0.0 & 0.0 & 8.4 & 20.7 \\
\hline $11-20$ & 0.0 & 0.0 & 0.0 & 0.0 & 0.0 & 0.0 & 0.0 & 0.0 & 4.2 & 15.1 & 21.1 \\
\hline $21-30$ & 0.0 & 0.0 & 0.0 & 0.0 & 0.0 & 0.0 & 2.7 & 8.3 & 11.5 & 15.8 & 20.2 \\
\hline ai. $1-10$ & 0.0 & 0.0 & 0.0 & 0.0 & 0.0 & 0.0 & 5.2 & 9.5 & 14.5 & 19.4 & 23.7 \\
\hline $11-20$ & 0.0 & 0.0 & 0.0 & 0.0 & 0.0 & 0.0 & 0.0 & 16.4 & 18.6 & 20.6 & 22.3 \\
\hline $21-31$ & 0.0 & 0.0 & 0.0 & 0.0 & 0.0 & 0.0 & 4.3 & 6.2 & 16.9 & 20.9 & 22.1 \\
\hline jun. $1-10$ & 0.0 & 0.0 & 0.0 & 0.0 & 0.0 & 0.0 & 1.8 & 6.2 & 14.1 & 18.3 & 22.5 \\
\hline $11-20$ & 0.0 & 0.0 & 0.0 & 0.0 & 0.0 & 5.5 & 11.1 & 15.8 & 18.8 & 20.7 & 24.2 \\
\hline $21-30$ & 0.0 & 0.0 & 0.0 & 0.0 & 3.7 & 5.4 & 8.3 & 16.2 & 19.7 & 22.1 & 24.3 \\
\hline ju1.1-10 & 0.0 & 0.0 & 0.0 & 0.5 & 7.2 & 14.0 & 17.4 & 19.1 & 20.8 & 22.3 & 26.6 \\
\hline $11-20$ & 0.0 & 0.0 & 0.0 & 4.4 & 12.7 & 20.2 & 20.8 & 21.8 & 22.6 & 25.8 & 27.4 \\
\hline $21-31$ & 0.0 & 0.0 & 0.0 & 6.1 & 17.3 & 21.6 & 25.1 & 25.4 & 26.9 & 27.2 & 30.3 \\
\hline $390.1-10$ & 0.0 & 0.0 & 0.0 & 7.1 & 15.7 & 17.6 & 22.1 & $23 . \overline{4}$ & 24.2 & 24.7 & 29.8 \\
\hline $11-20$ & 0.0 & 0.0 & 3.2 & 14.9 & 20.1 & 21.4 & 24.6 & 23.4 & 26.5 & 27.6 & 29.7 \\
\hline $21-31$ & 0.0 & 0.0 & 0.0 & 11.5 & 16.6 & 23.6 & 27.5 & 30.3 & 32.7 & 33.4 & 39.5 \\
\hline set. $1-10$ & 0.0 & 0.0 & 0.0 & 0.0 & 11.1 & 16.5 & 22.2 & 28.2 & 30.1 & 32.8 & 35.6 \\
\hline $11-20$ & 0.0 & 0.0 & 0.0 & 0.4 & 8.9 & 25.3 & 28.1 & 29.0 & 31.8 & 33.4 & 39.9 \\
\hline $21-30$ & 0.0 & 0.0 & 0.0 & 0.0 & 0.0 & 0.0 & 2.9 & 10.4 & 21.3 & 28.9 & 41.5 \\
\hline out. $1-10$ & 0.0 & 0.0 & 0.0 & 0.0 & 0.0 & 0.0 & 0.0 & 9.6 & 31.8 & 38.2 & 45.9 \\
\hline $11-20$ & 0.0 & 0.0 & 0.0 & 0.0 & 0.0 & 0.0 & 0.0 & 0.0 & 14.5 & 18.0 & 46.5 \\
\hline $21-31$ & 0.0 & 0.0 & 0.0 & 0.0 & 0.0 & 0.0 & 0.0 & 1.2 & 14.7 & 34.5 & 31.9 \\
\hline nov. $1-10$ & 0.0 & 0.0 & 0.0 & 0.0 & 0.0 & 0.0 & 0.0 & 0.0 & 2.1 & 21.5 & 48.0 \\
\hline $11-20$ & 0.0 & 0.0 & 0.0 & 0.0 & 0.0 & 0.0 & 0.0 & 0.0 & 0.0 & 3.6 & 30.4 \\
\hline $21-30$ & 0.0 & 0.0 & 0.0 & 0.0 & 0.0 & 0.0 & 0.0 & 0.0 & 0.7 & 13.5 & 28.0 \\
\hline dez.1-10 & 0.0 & 0.0 & 0.0 & 0.0 & 0.0 & 0.0 & 0.0 & 0.0 & 0.9 & 6.5 & 38.9 \\
\hline $11-20$ & 0.0 & 0.0 & 0.0 & 0.0 & 0.0 & 0.0 & 0.0 & 0.0 & 0.0 & 0.0 & 42.2 \\
\hline $21-31$ & 0.0 & 0.0 & 0.0 & 0.0 & 0.0 & 0.0 & 0.0 & 0.0 & 0.0 & 0.0 & 11.5 \\
\hline
\end{tabular}


TABELA 47 - PINDOFAKA: EXCEDEUTES HIDRICOS (BALANCD COK AFD = 30 a

DECIL

\begin{tabular}{|c|c|c|c|c|c|c|c|c|c|c|c|}
\hline DECEMDIO & HIN: & 1 & 2 & 3 & 4 & 5 & 6 & 7 & 8 & 9 & 10 \\
\hline jan.1-10 & 0.0 & 0.0 & 4.6 & 9.5 & 13.3 & 20.1 & 30.6 & 73.6 & 119.0 & 138.2 & 222.2 \\
\hline $11-20$ & 0.0 & 0.0 & 0.0 & 8.0 & 21.2 & 42.7 & 52.9 & 75.5 & 97.4 & 119.9 & 359.4 \\
\hline $21-31$ & 0.0 & 0.0 & 1.2 & 20.9 & 33.9 & $\$ 4.1$ & 55.8 & 66.0 & 73.7 & 115.7 & 198.7 \\
\hline fer. $1-10$ & 0.0 & 0.0 & 0.0 & 0.5 & 13.7 & 42.4 & 60.9 & 91.4 & 111.0 & 150.0 & 200.2 \\
\hline $11-20$ & 0.0 & 0.0 & 0.0 & 0.0 & 3.8 & 9.9 & 20.6 & 73.2 & 119.7 & 129.0 & 206.1 \\
\hline $21-28$ & 0.0 & 0.0 & 0.2 & 6.5 & 11.5 & 17.6 & 26.4 & 41.6 & 63.6 & 105.1 & 151.5 \\
\hline at $1-10$ & 0.0 & 0.0 & 0.8 & 9.4 & 14.8 & 17.4 & 37.1 & 50.3 & 65.4 & 101.4 & 135.7 \\
\hline $11-20$ & 0.0 & 0.0 & 0.0 & 0.0 & 0.0 & 7.6 & 23.7 & 29.0 & 53.1 & 87.4 & 221.2 \\
\hline $21-31$ & 0.0 & 0.0 & 0.0 & 0.0 & 0.0 & 0.0 & 0.0 & 19.8 & 39.3 & 54.9 & 87.7 \\
\hline$a b r \cdot 1-10$ & 0.0 & 0.0 & 0.0 & 0.0 & 0.0 & 0.0 & 0.0 & 5.2 & 10.1 & 31.2 & 109.6 \\
\hline $11-20$ & 0.0 & 0.0 & 0.0 & 0.0 & 0.0 & 0.0 & 0.0 & 0.0 & 1.3 & 14.6 & 76.7 \\
\hline $21-30$ & 0.0 & 0.0 & 0.0 & 0.0 & 0.0 & 0.0 & 0.0 & 0.0 & 0.0 & 0.0 & 99.2 \\
\hline mai. $1-10$ & 0.0 & 0.0 & 0.0 & 0.0 & 0.0 & 0.0 & 0.0 & 0.0 & 0.0 & 6.7 & 94.2 \\
\hline $11-20$ & 0.0 & 0.0 & 0.0 & 0.0 & 0.0 & 0.0 & 0.0 & 0.0 & 0.0 & 0.0 & 58.0 \\
\hline $21-31$ & 0.0 & 0.0 & 0.0 & 0.0 & 0.0 & 0.0 & 0.0 & 0.0 & 1.9 & 18.1 & 110.4 \\
\hline jun. 1-10 & 0.0 & 0.0 & 0.0 & 0.0 & 0.0 & 0.0 & 0.0 & 0.0 & 0.0 & 8.4 & 28.6 \\
\hline $11-20$ & 0.0 & 0.0 & 0.0 & 0.0 & 0.0 & 0.0 & 0.0 & 0.0 & 0.0 & 0.0 & 90.6 \\
\hline $21-30$ & 0.0 & 0.0 & 0.0 & 0.0 & 0.0 & 0.0 & 0.0 & 0.0 & 0.0 & 0.0 & 18.6 \\
\hline jul. $1-10$ & 0.0 & 0.0 & 0.0 & 0.0 & 0.0 & 0.0 & 0.0 & 0.0 & 0.0 & 0.0 & 6.8 \\
\hline $11-20$ & 0.0 & 0.0 & 0.0 & 0.0 & 0.0 & 0.0 & 0.0 & 0.0 & 0.0 & 0.0 & 38.5 \\
\hline $21-31$ & 0.0 & 0.0 & 0.0 & 0.0 & 0.0 & 0.0 & 0.0 & 0.0 & 0.0 & 0.0 & 24.8 \\
\hline $290.1-10$ & 0.0 & 0.0 & 0.0 & 0.0 & 0.0 & 0.0 & 0.0 & 0.0 & 0.0 & 0.0 & 3.9 \\
\hline $11-20$ & 0.0 & 0.0 & 0.0 & 0.0 & 0.0 & 0.0 & 0.0 & 0.0 & 0.0 & 0.0 & 49.5 \\
\hline $21-31$ & 0.0 & 0,0 & 0.0 & 0.0 & 0.0 & 0.0 & 0.0 & 0.0 & 0.0 & 0.0 & 20.0 \\
\hline set. $1-10$ & 0.0 & 0.0 & 0.0 & 0.0 & 0.0 & 0.0 & 0.0 & 0.0 & 0.0 & 0.0 & 33.9 \\
\hline $11-20$ & 0.0 & 0.0 & 0.0 & 0.0 & 0.0 & 0.0 & 0.0 & 0.0 & 0.0 & 37.8 & 85.2 \\
\hline $21-30$ & 0.0 & 0.0 & 0.0 & 0.0 & 0.0 & 0.0 & 0.0 & 0.0 & 0.0 & 0.0 & 62.7 \\
\hline out. $1-10$ & 0.0 & 0.0 & 0.0 & 0.0 & 0.0 & 0.0 & 0.0 & 0.0 & 23.9 & 33.1 & 71.2 \\
\hline $11-20$ & 0.0 & 0.0 & 0.0 & 0.0 & 0.0 & 0.0 & 0.0 & 0.0 & 24.7 & 65.3 & 73.4 \\
\hline $21-31$ & 0.0 & 0.0 & 0.0 & 0.0 & 0.0 & 0.0 & 0.0 & 2.1 & 17.6 & 44.2 & 59.1 \\
\hline nov. $1-10$ & 0.0 & 0.0 & 0.0 & 0.0 & 0.0 & 0.0 & 4.9 & 9.8 & 20.5 & 29.6 & 153.1 \\
\hline $11-20$ & 0.0 & 0.0 & 0.0 & 0.0 & 0.0 & 2.8 & 17.2 & 21.5 & 35.6 & 54.2 & 128.8 \\
\hline $21-30$ & 0.0 & 0.0 & 0.0 & 0.0 & 0.0 & 0.0 & 5.0 & 20.3 & 39.5 & 87.6 & 137.4 \\
\hline $\operatorname{dez} .1-10$ & 0.0 & 0.0 & 0.0 & 0.0 & 0.0 & 13.7 & 20.7 & 42.4 & 43.6 & 100.4 & 158.1 \\
\hline $11-20$ & 0.0 & 0.0 & 0.0 & 0.0 & 12.1 & 14.3 & 20.5 & 46.0 & 63.9 & 94.3 & 127.2 \\
\hline $21-31$ & 0.0 & 0.0 & 0.0 & 19.2 & 49.0 & 67.5 & 91.6 & 104.8 & 123.7 & 128.0 & 210.0 \\
\hline
\end{tabular}


TABELA 48 - PINDORAMA: AGUA FACLLHENTE DISPONIVEL (BALANCO COH AFD $=40$ ma)

DECIL

\begin{tabular}{|c|c|c|c|c|c|c|c|c|c|c|c|}
\hline DECENDIO & MIN. & 1 & 2 & 3 & 4 & 5 & 6 & 7 & 8 & 9 & 10 \\
\hline jan.1-10 & 14.3 & 20.7 & 40.0 & 40.0 & 40.0 & 40.0 & 40.0 & 80.0 & 40.0 & 40.0 & 40.0 \\
\hline $11-20$ & 0.0 & 19.0 & 35.2 & 40.0 & 40.0 & $\$ 0.0$ & 40.0 & 40.0 & 40.0 & 50.0 & 40.0 \\
\hline $21-31$ & 2.1 & 33.1 & 40.0 & 40.0 & 40.0 & 40.0 & 60.0 & 40.0 & 40.0 & 40.0 & 40.0 \\
\hline fev. $1-10$ & 0.0 & 14.5 & 22.3 & 40.0 & 40.0 & 40.0 & 40.0 & 40.0 & $\$ 0.0$ & 40.0 & 40.0 \\
\hline $11-20$ & 0.0 & 5.4 & 23.6 & 32.4 & 40.0 & 40.0 & 40.0 & 40.0 & 40.0 & 60.0 & 40.0 \\
\hline $21-28$ & 2.4 & 29.0 & 40.0 & 40.0 & 40.0 & 40.0 & 40.0 & 40.0 & 40.0 & 40.0 & 40.0 \\
\hline ar. $1-10$ & 3.8 & 16.9 & 31.0 & 40,0 & 40.0 & 40.0 & 40.0 & 80.0 & 40.0 & 40.0 & 40.0 \\
\hline $11-20$ & 0.0 & 4.7 & 15.0 & 22.3 & 29.0 & 40.0 & 40.0 & 40.0 & 40.0 & 40.0 & 40.0 \\
\hline $21-31$ & 0.0 & 2.9 & 11.2 & 21.0 & 25.2 & 30.2 & 36.7 & 40.0 & 40.0 & 40.0 & 40.0 \\
\hline abr. $1-10$ & 0.0 & 0.0 & 7.6 & 14.2 & 15.8 & 26.6 & 35.0 & 40.0 & 40.0 & 40.0 & 40.0 \\
\hline $11-20$ & 0.0 & 0.0 & 1.9 & 5.8 & 18.4 & 21.4 & 23.6 & 27.1 & 39.7 & $\$ 0.0$ & 40.0 \\
\hline $21-30$ & 0.0 & 0.0 & 0.0 & 0.0 & 3.1 & 15.3 & 17.1 & 23.3 & 24.5 & 30.0 & 40,0 \\
\hline aล:1-10 & 0.0 & 0.0 & 0.0 & 0.0 & 0.5 & 10.3 & 16.9 & 28.4 & 31.9 & 40.0 & 40.0 \\
\hline $11-20$ & 0.0 & 0.0 & 0.0 & 0.0 & 0.0 & 17.3 & 21.0 & 26.0 & 28.5 & 38.3 & 40.0 \\
\hline $21-31$ & 0.0 & 0.0 & 0.0 & 0.0 & 0.6 & 5,1 & 18.6 & 30.2 & 35.9 & 40.0 & $\$ 0.0$ \\
\hline jun. $1-10$ & 0.0 & 0.0 & 0.0 & 0.0 & 0.0 & 5.6 & 15.0 & 20.2 & 23.5 & 40.0 & 40.0 \\
\hline $11-20$ & 0.0 & 0.0 & 0.0 & 0.0 & 0.0 & 0.0 & 4.5 & 19.7 & 22.8 & 27.0 & $40.0^{\circ}$ \\
\hline $21-30$ & 0.0 & 0.0 & 0.0 & 0.0 & 0.0 & 0.3 & 3.3 & 8.0 & 14.2 & 20.1 & 40.0 \\
\hline jul.1-10 & 0.0 & 0.0 & 0.0 & 0.0 & 0.0 & 0.0 & 0.0 & 0.0 & 5.3 & 10.3 & 40.0 \\
\hline $11-20$ & 0.0 & 0.0 & 0.0 & 0.0 & 0.0 & 0.0 & 0.0 & 0.0 & 0.0 & 15.7 & 40.0 \\
\hline $21-31$ & 0,0 & 0.0 & 0.0 & 0.0 & 0.0 & 0.0 & 0.0 & 0.0 & 1.0 & 13.8 & 40.0 \\
\hline ago $1-10$ & 0.0 & 0.0 & 0.0 & 0.0 & 0.0 & 0.0 & 0.0 & 0.0 & 0.0 & 16.8 & 40.0 \\
\hline $11-20$ & 0.0 & 0.0 & 0.0 & 0.0 & 0.0 & 0.0 & 0.0 & 0.0 & 0.0 & 7.2 & 40.0 \\
\hline $21-31$ & 0.0 & 0.0 & 0.0 & 0.0 & 0.0 & 0.0 & 0.0 & 0.0 & 0.0 & 14.1 & 40.0 \\
\hline set.1-10 & 0.0 & 0.0 & 0.0 & 0.0 & 0.0 & 0.0 & 0.0 & 0.0 & 1.5 & 20.3 & 80.0 \\
\hline $11-20$ & 0.0 & 0.0 & 0.0 & 0.0 & 0.0 & 0.0 & 0.0 & 0.0 & 28.3 & 40.0 & 40.0 \\
\hline $21-30$ & 0.0 & 0.0 & 0.0 & 0.0 & 0.0 & 0.5 & 7.8 & 21.3 & 26.1 & 34.8 & 40.0 \\
\hline out.1-10 & 0.0 & 0.0 & 0.0 & 0.0 & 0.0 & 12.3 & 24.1 & 32.4 & 40.0 & 40.0 & 40.0 \\
\hline $11-20$ & 0.0 & 0.0 & 0.0 & 0.2 & 11.6 & 16.9 & 20.1 & 30.5 & 40.0 & 10.0 & $\begin{array}{l}60.0 \\
40.0\end{array}$ \\
\hline $21-31$ & 0.0 & 0.0 & 0.0 & 0.0 & 8.8 & 23.7 & 28.4 & 36.9 & 40.0 & 40.0 & 40.0 \\
\hline nov. $1-10$ & 0.0 & 0.0 & 1.3 & 7.9 & 18.2 & 36.0 & 39.8 & 40.0 & 80.0 & 40.0 & 40.0 \\
\hline $11-20$ & 0.0 & 1.1 & 11.1 & 15.5 & 33.0 & 40.0 & 40.0 & 40.0 & 40.0 & 40.0 & 40.0 \\
\hline $21-30$ & 0.0 & 0.0 & 5.4 & 11.9 & 24.7 & 33.0 & 40.0 & 40.0 & 40.0 & 40.0 & 40.0 \\
\hline dez.1-10 & 0.0 & 0.0 & 6.3 & 13.1 & 33.0 & 40.0 & 40.0 & 40.0 & 40.0 & 40.0 & 40.0 \\
\hline $11-20$ & 0.0 & 9.9 & 30.4 & 34.5 & 40.0 & 10.0 & 40.0 & 40.0 & 40.0 & 10.0 & 10.0 \\
\hline $21-31$ & 0.0 & 8.5 & 35.0 & 40.0 & 40.0 & 40.0 & 40.0 & 40.0 & 40.0 & 40.0 & 60.0 \\
\hline
\end{tabular}


TABELA 49 - PINDORAMA: DEFICITES (BALANCO COM AFD = 40 D)

DECIL

\begin{tabular}{|c|c|c|c|c|c|c|c|c|c|c|c|}
\hline & & 1 & 2 & 3 & 4 & 5 & 6 & 7 & 8 & 9 & 10 \\
\hline jan.1-10 & 0.0 & 0.0 & 0.0 & 0.0 & 0.0 & 0.0 & 0.0 & 0.0 & 0.0 & 0.0 & 0.0 \\
\hline $11-20$ & 0.0 & 0.0 & 0.0 & 0.0 & 0.0 & 0.0 & 0.0 & 0.0 & 0.0 & 0.0 & 21.2 \\
\hline $21-31$ & 0.0 & 0.0 & 0.0 & 0.0 & 0.0 & 0.0 & 0.0 & 0.0 & 0.0 & 0.0 & 0.0 \\
\hline fev. $1-10$ & 0.0 & 0.0 & 0.0 & 0.0 & 0.0 & 0.0 & 0.0 & 0.0 & 0.0 & 0.0 & 22.1 \\
\hline $11-20$ & 0.0 & 0.0 & 0.0 & 0.0 & 0.0 & 0.0 & 0.0 & 0.0 & 0.0 & 0.0 & 9.3 \\
\hline $21-28$ & 0.0 & 0.0 & 0.0 & 0.0 & 0.0 & 0.0 & 0.0 & 0.0 & 0.0 & 0.0 & 0.0 \\
\hline ar, $1-10$ & 0.0 & 0.0 & 0.0 & 0.0 & 0.0 & 0.0 & 0.0 & 0.0 & 0.0 & 0.0 & 0.0 \\
\hline $11-20$ & 0.0 & 0.0 & 0.0 & 0.0 & 0.0 & 0.0 & 0.0 & 0.0 & 0.0 & 0.0 & 26.7 \\
\hline $21-31$ & 0.0 & 0.0 & 0.0 & 0.0 & 0.0 & 0.0 & 0.0 & 0.0 & 0.0 & 0.0 & 12,4 \\
\hline$a b r \cdot 1-10$ & 0.0 & 0.0 & 0.0 & 0.0 & 0.0 & 0.0 & 0.0 & 0.0 & 0.0 & 1.4 & 19.0 \\
\hline $11-20$ & 0.0 & 0.0 & 0.0 & 0.0 & 0.0 & 0.0 & 0.0 & 0.0 & 0.0 & 11.1 & 20.4 \\
\hline $21-30$ & 0.0 & 0.0 & 0.0 & 0.0 & 0.0 & 0.0 & 0.0 & 1.5 & 6.0 & 14.9 & 20.2 \\
\hline (6:1.1-10 & 0.0 & 0.0 & 0.0 & 0.0 & 0.0 & 0.0 & 0.0 & 4.5 & 11.6 & 19.0 & 20.8 \\
\hline $11-20$ & 0.0 & 0.0 & 0.0 & 0.0 & 0.0 & 0.0 & 0.0 & 14.7 & 16.4 & 18.6 & 22.3 \\
\hline $21-31$ & 0.0 & 0.0 & 0.0 & 0.0 & 0.0 & 0.0 & 0.0 & 2.1 & 14.9 & 20.9 & 22.1 \\
\hline jun. $1-10$ & 0.0 & 0.0 & 0.0 & 0.0 & 0.0 & 0.0 & 0.0 & 4.9 & 14.0 & 17.6 & 20.2 \\
\hline $11-20$ & 0.0 & 0.0 & 0.0 & 0.0 & 0.0 & 2.1 & 4.6 & 15.8 & 18.6 & 19.5 & 23.6 \\
\hline $21-30$ & 0.0 & 0.0 & 0.0 & 0.0 & 0.0 & 0.0 & 5.4 & 14.6 & 19.7 & 22.1 & 24.3 \\
\hline jul. $1-10$ & 0.0 & 0.0 & 0.0 & 0.0 & 4.1 & 10.9 & 15.5 & 17.8 & 20.8 & 22.3 & 26.6 \\
\hline $11-20$ & 0.0 & 0.0 & 0.0 & 3.3 & 11.3 & 15.7 & 20.7 & 21.8 & 22.6 & 25.8 & 27.4 \\
\hline $21-31$ & 0.0 & 0.0 & 0.0 & 3.8 & 17.3 & 21.6 & 25.1 & 25.4 & 26.9 & 27.2 & 30.3 \\
\hline $290.1-10$ & 0.0 & 0.0 & 0.0 & 7.1 & 15.7 & 17.6 & 22.1 & 23.4 & 24.2 & 24.7 & 29.8 \\
\hline $11-20$ & 0.0 & 0.0 & 3.2 & 11.4 & 17.9 & 20.7 & 24.6 & 25.4 & 26.5 & 27.6 & 29.7 \\
\hline $21-31$ & 0.0 & 0.0 & 0.0 & 11.5 & 16.6 & 23.6 & 27.5 & 30.3 & 32.7 & 33.4 & 39.5 \\
\hline $\operatorname{set} 1-10$ & 0.0 & 0.0 & 0.0 & 0.0 & 11.1 & 16.5 & 22.2 & 28.2 & 30.1 & 32.8 & 35.6 \\
\hline $11-20$ & 0.0 & 0.0 & 0.0 & $0 . \frac{6}{4}$ & 8.9 & 24.2 & 28.1 & 29.0 & 31.8 & ME.4 & 39.9 \\
\hline $21-30$ & 0.0 & 0.0 & 0.0 & 0.0 & 0.0 & 0.0 & 2.9 & 10.4 & 21.3 & 28.9 & 41.5 \\
\hline out $.1-10$ & 0.0 & 0.0 & 0.0 & 0.0 & 0.0 & 0.0 & 0.0 & 9.6 & 29.0 & 37.7 & 45.9 \\
\hline $11-20$ & 0.0 & 0.0 & 0.0 & 0.0 & 0.0 & 0.0 & 0.0 & 0.0 & 12.1 & 17.3 & 46.5 \\
\hline $21-31$ & 0.0 & 0.0 & 0.0 & 0.0 & 0.0 & 0.0 & 0.0 & 0.0 & 14.7 & 34.5 & 51.9 \\
\hline nov. $1-10$ & 0.0 & 0.0 & 0.0 & 0.0 & 0.0 & 0.0 & 0.0 & 0.0 & 0.0 & 21.5 & 44.0 \\
\hline $11-20$ & 0.0 & 0.0 & 0.0 & 0.0 & 0.0 & 0.0 & 0.0 & 0.0 & 0.0 & 0.0 & 30.4 \\
\hline $21-30$ & 0.0 & 0.0 & 0.0 & 0.0 & 0.0 & 0.0 & 0.0 & 0.0 & 0.0 & 3.5 & 24.9 \\
\hline dez.1-10 & 0.0 & 0.0 & 0.0 & 0.0 & 0.0 & 0.0 & 0.0 & 0.0 & 0.0 & 0.0 & 33.5 \\
\hline $11-20$ & 0.0 & 0.0 & 0.0 & 0.0 & 0.0 & 0.0 & 0.0 & 0.0 & 0.0 & 0.0 & 42.2 \\
\hline $21-31$ & 0.0 & 0.0 & 0.0 & 0.0 & 0.0 & 0.0 & 0.0 & 0.0 & 0.0 & 0.0 & 1.5 \\
\hline
\end{tabular}


TABELA 50 - PINDORAMA: EXCEDENTES HIDRICOS (BALANCO COH AFD = 40 a)

DECIL

\begin{tabular}{|c|c|c|c|c|c|c|c|c|c|c|c|}
\hline DECENDID & HIK. & 1 & 2 & 3 & 4 & 5 & 6 & 7 & 8 & 9 & 10 \\
\hline jan. $1-10$ & 0.0 & 0.0 & 4.6 & 9.5 & 13.3 & 20.1 & 30.6 & 73.6 & 109.0 & 134.2 & 222.2 \\
\hline $11-20$ & 0.0 & 0.0 & 0.0 & 8.0 & 16.2 & 42.7 & 52.9 & 75.5 & 97.4 & 119.9 & 359.4 \\
\hline $21-31$ & 0.0 & 0.0 & 1.2 & 20.9 & 33.9 & 44.1 & 55.8 & 66.0 & 73.7 & 115.7 & 198.7 \\
\hline fev. $1-10$ & 0.0 & 0.0 & 0.0 & 0.5 & 13.7 & 42.4 & 60.9 & 91.4 & 111.0 & 150.0 & 200.2 \\
\hline $11-20$ & 0.0 & 0.0 & 0.0 & 0.0 & 3.8 & 9.9 & 20.6 & 73.2 & 119.7 & 129.0 & 206.1 \\
\hline $21-28$ & 0.0 & 0.0 & 0.2 & 4.5 & 11.5 & 17.6 & 25.9 & 41.6 & 63.6 & 103.1 & 151.5 \\
\hline a & 0.0 & 0.0 & 0.0 & 9.4 & 14.8 & 17.4 & 37.1 & 30.3 & 65.4 & 101.4 & 135.7 \\
\hline $11-20$ & 0.0 & 0.0 & 0.0 & 0.0 & 0.0 & 7.6 & 23.7 & 29.0 & 53.1 & 87.4 & 221.2 \\
\hline $21-31$ & 0.0 & 0.0 & 0.0 & 0.0 & 0.0 & 0.0 & 0.0 & 19.8 & 39.3 & 54.9 & 86.8 \\
\hline $26 r \cdot 1-10$ & 0.0 & 0.0 & 0.0 & 0.0 & 0.0 & 0.0 & 0.0 & 5.2 & 10.1 & 31.2 & 109.6 \\
\hline $11-20$ & 0.0 & 0.0 & 0.0 & 0.0 & 0.0 & 0.0 & 0.0 & 0.0 & 0.0 & 14.6 & 76.7 \\
\hline $21-30$ & 0.0 & 0.0 & 0.0 & 0.0 & 0.0 & 0.0 & 0.0 & 0.0 & 0.0 & 0.0 & 99.2 \\
\hline $23.1-10$ & 0.0 & 0.0 & 0.0 & 0.0 & 0.0 & 0.0 & 0.0 & 0.0 & 0.0 & 3.2 & 84.2 \\
\hline $11-20$ & 0.0 & 0.0 & 0.0 & 0.0 & 0.0 & 0.0 & 0.0 & 0,0 & 0.0 & 0.0 & 48.0 \\
\hline $21-31$ & 0.0 & 0.0 & 0.0 & 0.0 & 0.0 & 0.0 & 0.0 & 0.0 & 0.0 & 18.1 & 110.4 \\
\hline jun.1-10 & 0.0 & 0.0 & 0.0 & 0.0 & 0.0 & 0.0 & 0.0 & 0.0 & 0.0 & 3.6 & 18.6 \\
\hline $11-20$ & 0.0 & 0.0 & 0.0 & 0.0 & 0.0 & 0.0 & 0.0 & 0.0 & 0.0 & 0.0 & 80.6 \\
\hline $21-30$ & 0.0 & 0.0 & 0.0 & 0.0 & 0.0 & 0.0 & 0.0 & 0.0 & 0.0 & 0.0 & 6.6 \\
\hline jul. $1-10$ & 0.0 & 0.0 & 0.0 & 0.0 & 0.0 & 0.0 & 0.0 & 0.0 & 0.0 & 0.0 & 0.1 \\
\hline $11-20$ & 0.0 & 0.0 & 0.0 & 0.0 & 0.0 & 0.0 & 0.0 & 0.0 & 0.0 & 0.0 & 28.5 \\
\hline $21-31$ & 0.0 & 0.0 & 0.0 & 0.0 & 0.0 & 0.0 & 0.0 & 0.0 & 0.0 & 0.0 & $1+.8$ \\
\hline $200.1-10$ & 0.0 & 0.0 & 0.0 & 0.0 & 0.0 & 0.0 & 0.0 & 0.0 & 0.0 & 0.0 & 1.8 \\
\hline $11-20$ & 0.0 & 0.0 & 0.0 & 0.0 & 0.0 & 0.0 & 0.0 & 0.0 & 0.0 & 0.0 & 39.5 \\
\hline $21-31$ & 0.0 & 0.0 & 0.0 & 0.0 & 0.0 & 0.0 & 0.0 & 0.0 & 0.0 & 0.0 & 13.9 \\
\hline set. $1-10$ & 0.0 & 0.0 & 0.0 & 0.0 & 0.0 & 0.0 & 0.0 & 0.0 & 0.0 & 0.0 & 23.9 \\
\hline $11-20$ & 0.0 & 0.0 & 0.0 & 0.0 & 0.0 & 0.0 & 0.0 & 0.0 & 0.0 & 37.8 & 75.2 \\
\hline $21-30$ & 0.0 & 0.0 & 0.0 & 0.0 & 0.0 & 0.0 & 0.0 & 0.0 & 0.0 & 0.0 & 52.7 \\
\hline out.1-10 & 0.0 & 0.0 & 0.0 & 0.0 & 0.0 & 0.0 & 0.0 & 0.0 & 13.9 & 29.2 & 71.2 \\
\hline $11-20$ & 0.0 & 0.0 & 0.0 & 0.0 & 0.0 & 0.0 & 0.0 & 0.0 & 14.7 & 63.4 & 67.9 \\
\hline $21-31$ & 0.0 & 0.0 & 0.0 & 0.0 & 0.0 & 0.0 & 0.0 & 2.1 & 17.6 & 34.2 & 57.2 \\
\hline nov. $1-10$ & 0.0 & 0.0 & 0.0 & 0.0 & 0.0 & 0.0 & 0.0 & 5.0 & 11.8 & 27.4 & 153.1 \\
\hline $11-20$ & 0.0 & 0.0 & 0.0 & 0.0 & 0.0 & 2.1 & 9.2 & 15.4 & 25.6 & 54.2 & 128.8 \\
\hline $21-30$ & 0.0 & 0.0 & 0.0 & 0.0 & 0.0 & 0.0 & 3.1 & 20.3 & 39.5 & 82.8 & 137.0 \\
\hline$d e 2.1-10$ & 0.0 & 0.0 & 0.0 & 0.0 & 0.0 & 10.2 & 20.7 & 42.4 & 43.6 & 100.4 & 158.1 \\
\hline $11-20$ & 0.0 & 0.0 & 0.0 & 0.0 & 9.2 & 14.3 & 20.5 & 46.0 & 55.8 & 84.3 & 127.2 \\
\hline $21-31$ & 0.0 & 0.0 & 0.0 & 19.1 & 49.0 & 67.5 & 91.0 & 104.8 & 119.4 & 129.0 & 210.0 \\
\hline
\end{tabular}




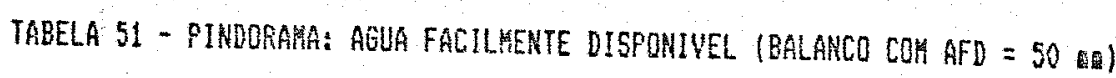

DECIL

\begin{tabular}{|c|c|c|c|c|c|c|c|c|c|c|c|}
\hline DECEHDIO & MIN, & 1 & 2 & 3 & 4 & 5 & 6 & 7 & 8 & 9 & 10 \\
\hline jan.1-10 & 24.3 & 28.9 & 50.0 & 50.0 & 50.0 & 50.0 & 50.0 & 50.0 & 50.0 & 50.0 & 50.0 \\
\hline $11-20$ & 0.0 & 29.0 & 45.2 & 50.0 & 50.0 & 50.0 & 50.0 & 50.0 & 50.0 & 50.0 & 50.0 \\
\hline $21-31$ & 12.1 & 43.1 & 50.0 & 50.0 & 50.0 & 50.0 & 50.0 & 50.0 & 50.0 & 50.0 & 50.0 \\
\hline fev. $1-10$ & 0.0 & 24.5 & 32.3 & 50.0 & 50.0 & 50.0 & 50.0 & 50.0 & 50.0 & 50.0 & 50.0 \\
\hline $11-20$ & 0.7 & 15.4 & 32.8 & 42,4 & 50.0 & 50.0 & 50.0 & 50.0 & 50.0 & 50.0 & 50.0 \\
\hline $21-2 B$ & 3.3 & 39.0 & 50.0 & 50.0 & 50.0 & 50.0 & 50.0 & 50.0 & 50.0 & 50.0 & 50.0 \\
\hline ar. $1-10$ & 13.8 & 26.9 & 35.2 & 50.0 & 50.0 & 50.0 & 50.0 & 50.0 & 50.0 & 50.0 & 50.0 \\
\hline $11-20$ & 0.0 & 14.7 & 25.0 & 32.3 & 39.0 & 50.0 & 50,0 & 50.0 & 50.0 & 50.0 & 50.0 \\
\hline $21-31$ & 0.0 & 12.3 & 21.2 & 31,0 & 35.2 & 40.2 & 46.7 & 50.0 & 50.0 & 50.0 & 50.0 \\
\hline abr. $1-10$ & 0.0 & 4.5 & 17.6 & $2 \xi .2$ & 25.8 & 36.6 & 45.0 & 50.0 & 50.0 & 50.0 & 50.0 \\
\hline $11-20$ & 0.0 & 0.0 & 10.5 & 15.8 & 28.4 & 31.4 & 33.6 & 37.1 & 47.9 & 50.0 & 50.0 \\
\hline $21-30$ & 0.0 & 0.0 & 3.0 & 4.3 & 13.1 & 18.7 & 25.4 & 37.3 & 34.5 & 40.0 & 50.0 \\
\hline $12 \div 1-10$ & 0.0 & 0.0 & 0.0 & 0.7 & 9.8 & 16.9 & 26.8 & 37.1 & 40.2 & 50.0 & 50.0 \\
\hline $11-20$ & 0.0 & 0.0 & 0.0 & 0.0 & 0.0 & 24.0 & 28.3 & 35.8 & 38.5 & 48.3 & 50.0 \\
\hline $21-31$ & 0.0 & 0.0 & 0.0 & 0.0 & 9.2 & 13.8 & $2 b .9$ & 35.9 & 43.3 & 50.0 & 50.0 \\
\hline jun. $1-10$ & 0.0 & 0.0 & 0.0 & 0.0 & 2.8 & 15.0 & 20.2 & 28.1 & 33.5 & 50.0 & 50.0 \\
\hline $11-20$ & 0.0 & 0.0 & 0.0 & 0.0 & 0.0 & 3.5 & 14.5 & 27.0 & 31.2 & 34.6 & 50.0 \\
\hline $21-30$ & 0.0 & 0.0 & 0.0 & 0.0 & 0.0 & 0.3 & 12.4 & 14.2 & 18.7 & 30.1 & 46.6 \\
\hline jul. $1-10$ & 0.0 & 0.0 & 0.0 & 0.0 & 0.0 & 0.0 & 0.0 & 4.9 & 13.9 & 23.4 & 50.0 \\
\hline $11-20$ & 0.0 & 0.0 & 0.0 & 0.0 & 0.0 & 0.0 & 0.0 & 0.0 & 6.3 & 15.7 & 50.0 \\
\hline $21-31$ & 0.0 & 0.0 & 0.0 & 0.0 & 0.0 & 0,0 & 0.0 & 0.0 & 6.2 & 16.7 & 50.0 \\
\hline $200.1-10$ & 0.0 & 0.0 & 0.0 & 0.0 & 0.0 & 0.0 & 0.0 & 0.0 & 0.0 & 26.8 & 50.0 \\
\hline $11-20$ & 0.0 & 0.0 & 0.0 & 0.0 & 0.0 & 0.0 & 0.0 & 0.0 & 0.0 & 7.2 & 50.0 \\
\hline $21-31$ & 0.0 & 0.0 & 0.0 & 0.0 & 0.0 & 0.0 & 0.0 & 0.0 & 0.0 & 24.1 & 50.0 \\
\hline set.1-10 & 0.0 & 0.0 & 0.0 & 0.0 & 0.0 & 0.0 & 0.0 & 0.0 & 1.5 & 80.3 & 50.0 \\
\hline $11-20$ & 0.0 & 0.0 & 0.0 & 0.0 & 0.0 & 0.0 & 0.0 & 0.0 & 28.3 & 50.0 & 50.0 \\
\hline $21-30$ & 0.0 & 0.0 & 0.0 & 0.0 & 0.0 & 0.5 & 7.8 & 21.3 & 32.3 & 44.8 & 50.0 \\
\hline out.1-10 & 0,0 & 0.0 & 0.0 & 0.0 & 0.0 & 12.3 & 24.1 & 32.4 & 50.0 & 50.0 & 50.0 \\
\hline $11-20$ & 0.0 & 0.0 & 0.0 & 0.2 & 11.8 & 16.0 & 23.4 & 36.6 & 50.0 & 50.0 & 50.0 \\
\hline $21-31$ & 0.0 & 0.0 & 0.0 & 0.5 & 12.0 & 28.4 & 34.2 & 39.8 & 50.0 & 50.0 & 50.0 \\
\hline nov. $1-10$ & 0.0 & 0.0 & 6.8 & 16.3 & 26.1 & 39.8 & 48.1 & 50.0 & 50.0 & 50.0 & 50.0 \\
\hline $11-20$ & 0.0 & 11.1 & 16.4 & 25.5 & 41.1 & 50.0 & 50.0 & 50.0 & 50.0 & 50.0 & 50.0 \\
\hline $21-30$ & 0.0 & 0.0 & 15.4 & 21.9 & 34.7 & 43.0 & 50.0 & 50.0 & 50.0 & 50.0 & 50.0 \\
\hline dez.1-10 & 0.0 & 0.0 & 13.6 & 23.1 & 43.0 & 50.0 & 50.0 & 50.0 & 50.0 & 50.0 & 50.0 \\
\hline $11-20$ & 0.0 & 19.9 & 40.4 & 44.5 & 50.0 & 50.0 & 50.0 & 50.0 & 50.0 & 50.0 & 50.0 \\
\hline $21-31$ & 8.5 & 18.5 & 43.0 & 50.0 & 50.0 & 50.0 & 50.0 & 50.0 & 50.0 & 50.0 & 50.0 \\
\hline
\end{tabular}


TAEELA 52 - PINDORAMA: DEFICITES (BALGNCO COM AFD = 50 a ANI)

DECIL

\begin{tabular}{|c|c|c|c|c|c|c|c|c|c|c|c|}
\hline DECEUDIO & MiN. & 1 & 2 & 3 & 4 & 5 & 6 & 7 & 8 & 9 & 10 \\
\hline$j a n .1-10$ & 0.0 & 0.0 & 0.0 & 0.0 & 0.0 & 0.0 & 0.0 & 0.0 & 0.0 & 0.0 & 0.0 \\
\hline $11-20$ & 0.0 & 0.0 & 0.0 & 0.0 & 0.0 & 0.0 & 0.0 & 0.0 & 0.0 & 0.0 & 11.2 \\
\hline $21-31$ & 0.0 & 0.0 & 0.0 & 0.0 & 0.0 & 0.0 & 0.0 & 0.0 & 0.0 & 0.0 & 0.0 \\
\hline fev. $1-10$ & 0.0 & 0.0 & 0.0 & 0.0 & 0.0 & 0.0 & 0.0 & 0.0 & 0.0 & 0.0 & 12.1 \\
\hline $11-20$ & 0.0 & 0.0 & 0.0 & 0.0 & 0.0 & 0.0 & 0.0 & 0.0 & 0.0 & 0.0 & 0.0 \\
\hline $21-28$ & 0.0 & 0.0 & 0.0 & 0.0 & 0.0 & 0.0 & 0.0 & 0.0 & 0.0 & 0.0 & 0.0 \\
\hline ar. $1-10$ & 0.0 & 0.0 & 0.0 & 0.0 & 0.0 & 0.0 & 0.0 & 0.0 & 0.0 & 0.0 & 0.0 \\
\hline $11-20$ & 0.0 & 0.0 & 0.0 & 0.0 & 0.0 & 0.0 & 0.0 & 0.0 & 0.0 & 0.0 & 16.7 \\
\hline $21-31$ & 0.0 & 0.0 & 0.0 & 0.0 & 0.0 & 0.0 & 0.0 & 0.0 & 0.0 & 0.0 & 2.1 \\
\hline br. $1-10$ & 0.0 & 0.0 & 0.0 & 0.0 & 0.0 & 0.0 & 0.0 & 0.0 & 0.0 & 0.0 & 10.7 \\
\hline $11-20$ & 0.0 & 0.0 & 0.0 & 0.0 & 0.0 & 0.0 & 0.0 & 0.0 & 0.0 & 1.1 & 20.4 \\
\hline $21-30$ & 0.0 & 0.0 & 0.0 & 0.0 & 0.0 & 0.0 & 0.0 & 0.0 & 0.0 & 8.0 & 20.2 \\
\hline ai. $1-10$ & 0.0 & 0.0 & 0.0 & 0.0 & 0.0 & 0.0 & 0.0 & 0.0 & 8.0 & 15.0 & 20.8 \\
\hline $11-20$ & 0.0 & 0.0 & 0.0 & 0.0 & 0.0 & 0.0 & 0.0 & 4.7 & 16.4 & 17.9 & 22.1 \\
\hline $21-31$ & 0.0 & 0.0 & 0.0 & 0.0 & 0.0 & 0.0 & 0.0 & 2.1 & 14.9 & 20.9 & 22.1 \\
\hline jun. $1-10$ & 0.0 & 0.0 & 0.0 & 0.0 & 0.0 & 0.0 & 0.0 & 4.0 & 9.6 & 14.1 & 20.2. \\
\hline $11-20$ & 0.0 & 0.0 & 0.0 & 0.0 & 0.0 & 0.0 & 4.2 & 9.6 & 17.0 & 19.5 & 23.6 \\
\hline $21-30$ & 0.0 & 0.0 & 0.0 & 0.0 & 0.0 & 0.0 & 4.6 & 9.4 & 19.0 & 22.1 & 24.3 \\
\hline jul. $1-10$ & 0.0 & 0.0 & 0.0 & 0.0 & 0.0 & 3.5 & 10.9 & 17.4 & 19.7 & 21.4 & 26.6 \\
\hline $11-20$ & 0.0 & 0.0 & 0.0 & 0.7 & 5.7 & 15.3 & 18.7 & 20.8 & 22.3 & 25.7 & 27.4 \\
\hline $21-3 \mid$ & 0.0 & 0.0 & 0.0 & 0.6 & 17.3 & 20.6 & 24.7 & 25.3 & 26.8 & 27.2 & 30.3 \\
\hline $290.1-10$ & 0.0 & 0.0 & 0.0 & 4.0 & 15.7 & 17.6 & 22.1 & 23.4 & 24.2 & 24.7 & 29.8 \\
\hline $11-20$ & 0.0 & 0.0 & 1.4 & 9.3 & 17.9 & 20.7 & 24,6 & 25.4 & 26.5 & 27.6 & 29.7 \\
\hline $21-31$ & 0.0 & 0.0 & 0.0 & 11.5 & 16.6 & 23.6 & 27.5 & 30.3 & 32.7 & 33.4 & 39.5 \\
\hline set. $1-10$ & 0.0 & 0.0 & 0.0 & 0.0 & 10.9 & 16.5 & 22.2 & 28.2 & 30.1 & 32.8 & 35.6 \\
\hline $11-20$ & 0.0 & 0.0 & 0.0 & 0.4 & 8.9 & 24.2 & 28.1 & 29.0 & 31.8 & 33.4 & 39.9 \\
\hline $21-30$ & 0.0 & 0.0 & 0.0 & 0.0 & 0.0 & 0.0 & 2.9 & 10.4 & 21.3 & 28.9 & 41.5 \\
\hline out. $1-10$ & 0.0 & 0.0 & 0.0 & 0.0 & 0.0 & 0.0 & 0.0 & 9.6 & 29.0 & 37.7 & 45.9 \\
\hline $11-20$ & 0.0 & 0.0 & 0.0 & 0.0 & 0.0 & 0.0 & 0.0 & 0.0 & 12.1 & 17.3 & 46.5 \\
\hline $21-31$ & 0.0 & 0.0 & 0.0 & 0.0 & 0.0 & 0.0 & 0.0 & 0.0 & 14.7 & 34.5 & 51.9 \\
\hline nov. $1-10$ & 0.0 & 0.0 & 0.0 & 0.0 & 0.0 & 0.0 & 0.0 & 0.0 & 0.0 & 21.5 & 44.0 \\
\hline $11-20$ & 0.0 & 0.0 & 0.0 & 0.0 & 0.0 & 0.0 & 0.0 & 0.0 & 0.0 & 0.0 & 30.4 \\
\hline $21-30$ & 0.0 & 0.0 & 0.0 & 0.0 & 0.0 & 0.0 & 0.0 & 0.0 & 0.0 & 0.7 & 16.2 \\
\hline dez. $1-10$ & 0.0 & 0.0 & 0.0 & 0.0 & 0.0 & 0.0 & 0.0 & 0.0 & 0.0 & 0.0 & 23.5 \\
\hline $11-20$ & 0.0 & 0.0 & 0.0 & 0.0 & 0.0 & 0.0 & 0.0 & 0.0 & 0.0 & 0.0 & 12.2 \\
\hline $21-31$ & 0.0 & 0.0 & 0.0 & 0.0 & 0.0 & 0.0 & 0.0 & 0.0 & 0.0 & 0.0 & 0.0 \\
\hline
\end{tabular}


IABELA 53 - PIMDORAEÁ: EXCEDENTES HIDRICOS (BALAHCO COH AFD $=50$ AR)

DECIL

\begin{tabular}{|c|c|c|c|c|c|c|c|c|c|c|c|}
\hline DECEMDIO & HIIl. & 1 & 2 & 3 & 4 & 5 & $b$ & 7 & 8 & 9 & 10 \\
\hline jan.1-10 & 0.0 & 0.0 & 4.6 & 9.5 & 13.3 & 20.1 & 30.6 & 73.6 & 107.6 & 134.2 & 222.2 \\
\hline $11-20$ & 0.0 & 0.0 & 0.0 & 8.0 & 15.4 & 42.7 & 52.9 & 75.5 & 97.4 & 119.9 & 359.4 \\
\hline $21-31$ & 0.0 & 0.0 & 1.2 & 20.9 & 33.9 & 44.1 & 55.8 & 66.0 & 73.7 & 209.7 & 198.7 \\
\hline fev.1-10 & 0.0 & 0.0 & 0.0 & 0.5 & 13.7 & 42.4 & 60.9 & 91.4 & 111.0 & 150.0 & 200.2 \\
\hline $11-20$ & 0.0 & 0.0 & 0.0 & 0.0 & 3.8 & 9.9 & 20.6 & 73.2 & 119.7 & 129.0 & 206.1 \\
\hline $21-28$ & 0.0 & 0.0 & 0.2 & 4.5 & 11.5 & 15.9 & 25.7 & 41.6 & 63.6 & 103.1 & 151.5 \\
\hline ar. $1-10$ & 0.0 & 0.0 & 0.0 & 9.4 & 14.8 & 17.4 & 37.1 & 50.3 & 65.4 & 101.4 & 135.7 \\
\hline $11-20$ & 0.0 & 0.0 & 0.0 & 0.0 & 0.0 & 7.6 & 23.7 & 29.0 & 53.1 & 87.4 & 221.2 \\
\hline $21-31$ & 0.0 & 0.0 & 0.0 & 0.0 & 0.0 & 0.0 & 0.0 & 19.8 & 34.0 & 54.9 & 86.8 \\
\hline abr. $1-10$ & 0.0 & 0.0 & 0.0 & 0.0 & 0.0 & 0.0 & 0.0 & 5.2 & 10.1 & 31.2 & 109.6 \\
\hline $11-20$ & 0.0 & 0.0 & 0.0 & 0.0 & 0.0 & 0.0 & 0.0 & 0.0 & 0.0 & 14.6 & 76.7 \\
\hline $21-30$ & 0.0 & 0.0 & 0.0 & 0.0 & 0.0 & 0.0 & 0.0 & 0.0 & 0.0 & 0.0 & 99.2 \\
\hline ตล. $1-10$ & 0.0 & 0.0 & 0.0 & 0.0 & 0.0 & 0.0 & 0.0 & 0.0 & 0.0 & 3.2 & 78.4 \\
\hline $11-20$ & 0.0 & 0.0 & 0.0 & 0.0 & 0.0 & 0.0 & 0.0 & 0.0 & 0.0 & 0.0 & 44.8 \\
\hline $21-31$ & 0.0 & 0.0 & 0.0 & 0.0 & 0.0 & 0.0 & 0.0 & 0.0 & 0.0 & 18.1 & 110.4 \\
\hline jun.1-10 & 0.0 & 0.0 & 0.0 & 0.0 & 0.0 & 0.0 & 0.0 & 0.0 & 0.0 & 3.6 & 16.0 \\
\hline $11-20$ & 0.0 & 0.0 & 0.0 & 0.0 & 0.0 & 0.0 & 0.0 & 0.0 & 0.0 & 0.0 & 70.6 \\
\hline $21-30$ & 0.0 & 0.0 & 0.0 & 0.0 & 0.0 & 0.0 & 0.0 & 0.0 & 0.0 & 0.0 & 0.0 \\
\hline jul.1-10 & 0.0 & 0.0 & 0.0 & 0.0 & 0.0 & 0.0 & 0.0 & 0.0 & 0.0 & 0.0 & 0.1 \\
\hline $11-20$ & 0.0 & 0.0 & 0.0 & 0.0 & 0.0 & 0.0 & 0.0 & 0.0 & 0.0 & 0.0 & 18.5 \\
\hline $21-31$ & 0.0 & 0.0 & 0.0 & 0.0 & 0.0 & 0.0 & 0.0 & 0.0 & 0.0 & 0.0 & 4.8 \\
\hline $2 g 0.1-10$ & 0.0 & 0.0 & 0.0 & 0.0 & 0.0 & 0.0 & 0.0 & 0.0 & 0.0 & 0.0 & 1.8 \\
\hline $11-20$ & 0.0 & 0.0 & 0.0 & 0.0 & 0.0 & 0.0 & 0.0 & 0.0 & 0.0 & 0.0 & 35.7 \\
\hline $21-31$ & 0.0 & 0,0 & 0.0 & 0.0 & 0.0 & 0.0 & 0.0 & 0.0 & 0.0 & 0.0 & 3.9 \\
\hline set. $1-10$ & 0.0 & 0.0 & 0.0 & 0.0 & 0.0 & 0.0 & 0.0 & 0.0 & 0.0 & 0.0 & 13.9 \\
\hline $11-20$ & 0.0 & 0.0 & 0.0 & 0.0 & 0.0 & 0.0 & 0.0 & 0.0 & 0.0 & 30.1 & 65.2 \\
\hline $21-30$ & 0.0 & 0.0 & 0.0 & 0.0 & 0.0 & 0.0 & 0.0 & 0.0 & 0.0 & 0.0 & 42.7 \\
\hline out.1-10 & 0.0 & 0.0 & 0.0 & 0.0 & 0.0 & 0.0 & 0.0 & 0.0 & 7.8 & 29.2 & 71.2 \\
\hline $11-20$ & 0.0 & 0.0 & 0.0 & 0.0 & 0.0 & 0.0 & 0.0 & 0.0 & 4.7 & 33.4 & 67.9 \\
\hline $21-31$ & 0.0 & 0.0 & 0.0 & 0.0 & 0.0 & 0.0 & 0.0 & 0.0 & 4.7 & 26.2 & 57.2 \\
\hline nov. $1-10$ & 0.0 & 0.0 & 0.0 & 0.0 & 0.0 & 0.0 & 0.0 & 4.8 & 5.7 & 27.4 & 153.1 \\
\hline $11-20$ & 0.0 & 0.0 & 0.0 & 0.0 & 0.0 & 0.0 & 2.8 & 9.2 & 21.2 & 54.1 & 128.8 \\
\hline $21-30$ & 0.0 & 0.0 & 0.0 & 0.0 & 0.0 & 0.0 & 3.1 & 20.3 & 39.5 & 82.8 & 132.5 \\
\hline$d e 2.1-10$ & 0.0 & 0.0 & 0.0 & 0.0 & 0.0 & 0.2 & 20.7 & 42.4 & 43.6 & 100.6 & 158.1 \\
\hline $11-20$ & 0.0 & 0.0 & 0.0 & 0.0 & 6.5 & 14.3 & 20.5 & 43.9 & 55.8 & 76.1 & 127.2 \\
\hline $21-31$ & 0.0 & 0.0 & 0.0 & 19.1 & 49.0 & 67.5 & 91.0 & 104.8 & 119.4 & 129.0 & 210.0 \\
\hline
\end{tabular}


TABELA 54 - PINDORAME: RGUA FACILHENTE DISPONIVEL (BALANCO COM AFD $=75$ OM)

DECIL

\begin{tabular}{|c|c|c|c|c|c|c|c|c|c|c|c|}
\hline DECEADIO & MIN, & 1 & 2 & 3 & 4 & 5 & 6 & 7 & 8 & 9 & 10 \\
\hline jan.1-10 & 49.3 & 53.9 & 75.0 & 75.0 & 75.0 & 75.0 & 75.0 & 75.0 & 75.0 & 75.0 & 75.0 \\
\hline $11-20$ & 13.8 & 54.0 & 70.2 & 75.0 & 75.0 & 75.0 & 75.0 & 75.0 & 75.0 & 75.0 & 75.0 \\
\hline $21-31$ & 37.1 & 68.1 & 75.0 & 75.0 & 75.0 & 75.0 & 75.0 & 75.0 & 75.0 & 75.0 & 75.0 \\
\hline fev.1-10 & 12.9 & 49.5 & 57.3 & 75.0 & 75.0 & 75.0 & 75.0 & 75.0 & 75.0 & 75.0 & 75.0 \\
\hline $11-20$ & 25.7 & 38.2 & 57.8 & 67.4 & 75.0 & 75.0 & 75.0 & 75.0 & 75.0 & 75.0 & 75.0 \\
\hline $21-26$ & 28.3 & $6 \% .0$ & 75.0 & 75.0 & 75.0 & 75.0 & 75.0 & 75.0 & 75.0 & 75.0 & 75.0 \\
\hline $\operatorname{mar} .1-10$ & 38.8 & 51.9 & 59.2 & 75.0 & 75.0 & 75.0 & 75.0 & 75.0 & 75.0 & 75.0 & 75.0 \\
\hline $11-20$ & 8.3 & 39.7 & 50.0 & 57.3 & 64.0 & 75.0 & 75.0 & 75.0 & 75.0 & 75.0 & 75.0 \\
\hline $21-31$ & 22.6 & 37.3 & 46.2 & 56,0 & 60.2 & 65.2 & 71.7 & 75.0 & 75.0 & 75.0 & 75.0 \\
\hline$a b r .1-10$ & 11.9 & 29.5 & 42.6 & 49.2 & 50.8 & 61.6 & 70.0 & 75.0 & 75.0 & 75,0 & 75.0 \\
\hline $11-20$ & 0.0 & 17.8 & 35.5 & 40.8 & 53.4 & 56.4 & 58.6 & 62.1 & 72.9 & 75.0 & 75.0 \\
\hline $21-30$ & 0.0 & 2.9 & 28.0 & 29.3 & 38.1 & 43.7 & 50.4 & 58.3 & 59.5 & 65.0 & 75.0 \\
\hline 面立. $1-10$ & 0.0 & 8.7 & 14.7 & 17.8 & 33.1 & 35.5 & 47.1 & 62.1 & 65.2 & 75.0 & 75.0 \\
\hline $11-20$ & 0.0 & 0.0 & 7.1 & 14.3 & 20.3 & 42.2 & 52.7 & 58.8 & 62.1 & 69.0 & 75.0 \\
\hline $21-31$ & 0.0 & 0.0 & 0.0 & 9.4 & 29.0 & 35.6 & 44.1 & 54.6 & 68.3 & 75.0 & 75.0 \\
\hline jun. 1-10 & 0.0 & 0.0 & 0.0 & 12.4 & 21.0 & 33.1 & 40.6 & 48.7 & 58.1 & 72.8 & 75.0 \\
\hline $11-20$ & 0.0 & 0.0 & 0.0 & 3.6 & 8.1 & 27.0 & 32.2 & 41.1 & 56.1 & 58.4 & 75.0 \\
\hline $21-30$ & 0.0 & 0.0 & 0.0 & 0.0 & 12.5 & 14.9 & 20.4 & 36.7 & 38.4 & 45.3 & 62.3 \\
\hline jul.1-10 & 0.0 & 0.0 & 0.0 & 0.0 & 0.0 & 3.0 & 10.5 & 16.7 & 27.3 & 37.0 & 75.0 \\
\hline $11-20$ & 0.0 & 0.0 & 0.0 & 0.0 & 0.0 & 0.0 & 0.0 & 7.0 & 19.3 & 32.0 & 68.5 \\
\hline $21-31$ & 0.0 & 0.0 & 0.0 & 0.0 & 0.0 & 0.0 & 0.0 & 1.0 & 13.4 & 39.7 & 58.1 \\
\hline $200.1-10$ & 0.0 & 0.0 & 0.0 & 0.0 & 0.0 & 0.0 & 0.0 & 0.0 & 23.9 & 33.9 & 70.2 \\
\hline $11-20$ & 0.0 & 0.0 & 0.0 & 0.0 & 0.0 & 0.0 & 0.0 & 0.0 & 2.2 & 13.3 & 75.0 \\
\hline $21-31$ & 0.0 & 0.0 & 0.0 & 0.0 & 0.0 & 0.0 & 0.0 & 0.0 & 1.2 & 41.5 & 53.9 \\
\hline set. $1-10$ & 0.0 & 0.0 & 0.0 & 0.0 & 0.0 & 0.0 & 0.0 & 1.1 & 14.4 & 34.2 & 63.9 \\
\hline $11-20$ & 0.0 & 0.0 & 0.0 & 0.0 & 0.0 & 0.0 & 0.0 & 0.0 & 28.3 & 75.0 & 75.0 \\
\hline $21-30$ & 0.0 & 0.0 & 0.0 & 0.0 & 0.0 & 0.5 & 7.9 & 22.2 & 35.8 & 68.1 & 75.0 \\
\hline out. $1-10$ & 0.0 & 0.0 & 0.0 & 0.0 & 0.0 & 12.3 & 24.1 & 32.4 & 65.4 & 75.0 & 75.0 \\
\hline $11-20$ & 0.0 & 0.0 & 0.0 & 0.2 & 11.8 & 16.0 & 35.3 & 54.5 & 72.9 & 75.0 & 75.0 \\
\hline $21-31$ & 0.0 & 0.0 & 0.0 & 0.5 & 28.4 & 36.9 & 48.8 & 56.5 & 74.2 & 75.0 & 75.0 \\
\hline nov. $1-10$ & 0.0 & 0.0 & 7.8 & 26.1 & 39.8 & 48.1 & 55.7 & $6 t .5$ & 74.2 & 75.0 & 75.0 \\
\hline $11-20$ & 0.0 & 11,6 & 26.2 & 41.1 & 50.5 & 55.4 & 70.1 & 75.0 & 75.0 & 75.0 & 75.0 \\
\hline $21-30$ & 0.0 & 0.0 & 28.9 & 44.5 & 57.0 & 60.9 & 68.0 & 75.0 & 75.0 & 75.0 & 75.0 \\
\hline dez.1-10 & 1.5 & 5.8 & 37.2 & 46.6 & 50.2 & 68.9 & 75.0 & 75.0 & 75.0 & 75.0 & 75.0 \\
\hline $11-20$ & 0.0 & 44.9 & 58.4 & 67.5 & 72.8 & 75.0 & 75.0 & 75.0 & 75.0 & 75.0 & 75.0 \\
\hline $21-31$ & 21.4 & 43.5 & 68.0 & 75.0 & 75.0 & 75.0 & 75.0 & 75.0 & 75.0 & 75.0 & 75.0 \\
\hline
\end{tabular}


IABCLA 55 - PIWDORAMA: DEFICITES (BALANCO COK AFD = 75 a

DECIL

\begin{tabular}{|c|c|c|c|c|c|c|c|c|c|c|c|}
\hline & & 1 & 2 & 3 & 4 & 5 & 6 & 7 & 8 & 9 & 10 \\
\hline jan. $1-10$ & 0.0 & 0.0 & 0.0 & 0.0 & 0.0 & 0.0 & 0.0 & 0.0 & 0.0 & 0.0 & 0.0 \\
\hline $11-20$ & 0.0 & 0.0 & 0.0 & 0.0 & 0.0 & 0.0 & 0.0 & 0.0 & 0.0 & 0.0 & 0.0 \\
\hline $21-31$ & 0.0 & 0.0 & 0.0 & 0.0 & 0.0 & 0.0 & 0.0 & 0.0 & 0.0 & 0.0 & 0.0 \\
\hline fev. $1-10$ & 0.0 & 0.0 & 0.0 & 0.0 & 0.0 & 0.0 & 0.0 & 0.0 & 0.0 & 0.0 & 0.0 \\
\hline $11-20$ & 0.0 & 0.0 & 0.0 & 0.0 & 0.0 & 0.0 & 0.0 & 0.0 & 0.0 & 0.0 & 0.0 \\
\hline $21-28$ & 0.0 & 0.0 & 0.0 & 0.0 & 0.0 & 0.0 & 0.0 & 0.0 & 0.0 & 0.0 & 0.0 \\
\hline tar. $1-10$ & 0.0 & 0.0 & 0.0 & 0.0 & 0.0 & 0.0 & 0.0 & 0.0 & 0.0 & 0.0 & 0.0 \\
\hline $11-20$ & 0.0 & 0.0 & 0.0 & 0.0 & 0.0 & 0.0 & 0.0 & 0.0 & 0.0 & 0.0 & 0.0 \\
\hline $21-31$ & 0.0 & 0.0 & 0.0 & 0.0 & 0.0 & 0.0 & 0.0 & 0.0 & 0.0 & 0.0 & 0.0 \\
\hline $\mathrm{dbr} .1-10$ & 0.0 & 0.0 & 0.0 & 0.0 & 0.0 & 0.0 & 0.0 & 0.0 & 0.0 & 0.0 & 0.0 \\
\hline $11-20$ & 0.0 & 0.0 & 0.0 & 0.0 & 0.0 & 0.0 & 0.0 & 0.0 & 0.0 & 0.0 & 6.5 \\
\hline $21-30$ & 0.0 & 0.0 & 0.0 & 0.0 & 0.0 & 0.0 & 0.0 & 0.0 & 0.0 & 0.0 & 20.2 \\
\hline nai. $1-10$ & 0.0 & 0.0 & 0.0 & 0.0 & 0.0 & 0.0 & 0.0 & 0.0 & 0.0 & 0.0 & 20.8 \\
\hline $11-20$ & 0.0 & 0.0 & 0.0 & 0.0 & 0.0 & 0.0 & 0.0 & 0.0 & 0.0 & 6.2 & 16.4 \\
\hline $21-31$ & 0.0 & 0.0 & 0.0 & 0.0 & 0.0 & 0.0 & 0.0 & 0.0 & 4.9 & 15.6 & 21.4 \\
\hline jun. $1-10$ & 0.0 & 0.0 & 0.0 & 0.0 & 0.0 & 0.0 & 0.0 & 0.0 & 0.0 & 14.1 & 19.6 \\
\hline $11-20$ & 0.0 & 0.0 & 0.0 & 0.0 & 0.0 & 0.0 & 0.0 & 0.0 & 9.6 & 18.6 & 20.7 \\
\hline $21-30$ & 0.0 & 0.0 & 0.0 & 0.0 & 0.0 & 0.0 & 0.0 & 1.3 & 7.8 & 19.0 & 23.1 \\
\hline jul. $1-10$ & 0.0 & 0.0 & 0.0 & 0.0 & 0.0 & 0.0 & 0.0 & 7.2 & 17.4 & 20.8 & 26.6 \\
\hline $11-20$ & 0.0 & 0.0 & 0.0 & 0.0 & 0.7 & 4.4 & 12.7 & 19.5 & 21.8 & 24.2 & 27.4 \\
\hline $21-31$ & 0.0 & 0.0 & 0.0 & 0.0 & 7.8 & $19.0^{\circ}$ & 21.6 & 25.1 & 25.4 & 27.0 & 30.3 \\
\hline $290.1-10$ & 0.0 & 0.0 & 0.0 & 4.0 & 10.8 & 17.6 & 22.1 & 23.4 & 24.2 & 24.7 & 29.8 \\
\hline $11-20$ & 0.0 & 0.0 & 0.0 & 3.2 & 16.1 & 20.2 & 24.6 & 25.4 & 26.5 & 27.6 & 29.7 \\
\hline $21-31$ & 0.0 & 0.0 & 0.0 & 11.5 & 16.1 & 22.3 & 26.8 & 30.3 & 32.7 & 3.4 & 39.5 \\
\hline set. $1-10$ & 0.0 & 0.0 & 0.0 & 0.0 & 10.9 & 16.5 & 22.2 & 28.2 & 30.1 & 32.8 & 35.6 \\
\hline $11-20$ & 0.0 & 0.0 & 0.0 & 0.0 & 8.9 & 24.2 & 28.1 & 29.0 & 31.8 & 33.4 & 39.9 \\
\hline $21-30$ & 0.0 & 0.0 & 0.0 & 0.0 & 0.0 & 0.0 & 2.9 & 10.4 & 21.3 & 28.9 & 41.5 \\
\hline out. $1-10$ & 0.0 & 0.0 & 0.0 & 0.0 & 0.0 & 0.0 & 0.0 & 7.9 & 29.0 & 37.7 & 45.9 \\
\hline $11-20$ & 0.0 & 0.0 & 0.0 & 0.0 & 0.0 & 0.0 & 0.0 & 0.0 & 12.1 & 17.3 & 46.5 \\
\hline $2|-3|$ & 0.0 & 0.0 & 0.0 & 0.0 & 0.0 & 0.0 & 0.0 & 0.0 & 14.7 & 34.5 & 51.9 \\
\hline nov. $1-10$ & 0.0 & 0.0 & 0.0 & 0.0 & 0.0 & 0.0 & 0.0 & 0.0 & 0.0 & 21.5 & 44.0 \\
\hline $11-20$ & 0.0 & 0.0 & 0.0 & 0.0 & 0.0 & 0.0 & 0.0 & 0.0 & 0.0 & 0.0 & 30.1 \\
\hline $21-30$ & 0.0 & 0.0 & 0.0 & 0.0 & 0.0 & 0.0 & 0.0 & 0.0 & 0.0 & 0.0 & 16.2 \\
\hline dez.1-10 & 0.0 & 0.0 & 0.0 & 0.0 & 0.0 & 0.0 & 0.0 & 0.0 & 0.0 & 0.0 & 0.0 \\
\hline $11-20$ & 0.0 & 0.0 & 0.0 & 0.0 & 0.0 & 0.0 & 0.0 & 0.0 & 0.0 & 0.0 & 40.8 \\
\hline $21-31$ & 0.0 & 0.0 & 0.0 & 0.0 & 0.0 & 0.0 & 0.0 & 0.0 & 0.0 & 0.0 & 0.0 \\
\hline
\end{tabular}


TABELA 56 - FIMDORARA: EXCEDENTES HIDRICOS (BALAMCO COH AFD $=75$ AE)

DECIL

\begin{tabular}{|c|c|c|c|c|c|c|c|c|c|c|c|}
\hline DECEMDIO & MIN, & 1 & 2 & 3 & 4 & 5 & 6 & 7 & 8 & 9 & 10 \\
\hline jan.1-10 & 0.0 & 0.0 & 4.6 & 9.5 & 13.3 & 20.1 & 30.6 & 73.6 & 107.6 & 134.2 & 222.2 \\
\hline $11-20$ & 0.0 & 0.0 & 0.0 & 8.0 & 15.4 & 42.7 & 52.9 & 75.5 & 97.4 & 119.9 & 359.4 \\
\hline $21-31$ & 0.0 & 0.0 & 1.2 & 20.9 & 33.9 & 44.1 & 55.8 & 66.0 & 73.7 & 98.6 & 198.7 \\
\hline fev. $1-10$ & 0.0 & 0.0 & 0.0 & 0.5 & 13.7 & 42.4 & 60.9 & 91.4 & 111.0 & 150.0 & 200.2 \\
\hline $11-20$ & 0.0 & 0.0 & 0.0 & 0.0 & 3.8 & 9.9 & 20.6 & 73.2 & 119.7 & 129.0 & 206.1 \\
\hline $21-28$ & 0.0 & 0.0 & 0.2 & 3.8 & 10.9 & 14.6 & 25.7 & 41.6 & 63.6 & 103.1 & 151.5 \\
\hline ar. 1-10 & 0.0 & 0.0 & 0.0 & 9.4 & 14.8 & 17.4 & 37.1 & 50.3 & 65.4 & 101.4 & 135.7 \\
\hline $11-20$ & 0.0 & 0.0 & 0.0 & 0.0 & 0.0 & 7.6 & 23.7 & 29.0 & 53.1 & 87.4 & 221.2 \\
\hline $21-31$ & 0.0 & 0.0 & 0.0 & 0.0 & 0.0 & 0.0 & 0.0 & 19.8 & 34.0 & 51.0 & 86.8 \\
\hline$a b r \cdot 1-10$ & 0.0 & 0.0 & 0.0 & 0.0 & 0.0 & 0.0 & 0.0 & 5.2 & 10.1 & 31.2 & 109.6 \\
\hline $11-20$ & 0.0 & 0.0 & 0.0 & 0.0 & 0.0 & 0.0 & 0.0 & 0.0 & 0.0 & 14.6 & 76.7 \\
\hline $21-30$ & 0.0 & 0.0 & 0.0 & 0.0 & 0.0 & 0.0 & 0.0 & 0.0 & 0.0 & 0.0 & 99.2 \\
\hline ai. $1-10$ & 0.0 & 0.0 & 0.0 & 0.0 & 0.0 & 0.0 & 0.0 & 0.0 & 0.0 & 3.2 & 78.4 \\
\hline $11-20$ & 0.0 & 0.0 & 0.0 & 0.0 & 0.0 & 0.0 & 0.0 & 0.0 & 0.0 & 0.0 & 44.8 \\
\hline $21-31$ & 0.0 & 0.0 & 0.0 & 0.0 & 0.0 & 0.0 & 0.0 & 0.0 & 0.0 & 10.2 & 110.4 \\
\hline jun. $1-10$ & 0.0 & 0.0 & 0.0 & 0.0 & 0.0 & 0.0 & 0.0 & 0.0 & 0.0 & 0.0 & 16.0 \\
\hline $11-20$ & 0.0 & 0.0 & 0.0 & 0.0 & 0.0 & 0.0 & 0.0 & 0.0 & 0.0 & 0.0 & 66.6 \\
\hline $21-30$ & 0.0 & 0.0 & 0.0 & 0.0 & 0.0 & 0.0 & 0.0 & 0.0 & 0.0 & 0.0 & 0.0 \\
\hline jul. 1-10 & 0.0 & 0.0 & 0.0 & 0.0 & 0.0 & 0.0 & 0.0 & 0.0 & 0.0 & 0.0 & 0.1 \\
\hline $11-20$ & 0.0 & 0.0 & 0.0 & 0.0 & 0.0 & 0.0 & 0.0 & 0.0 & 0.0 & 0.0 & 0.0 \\
\hline $21-31$ & 0.0 & 0.0 & 0.0 & 0.0 & 0.0 & 0.0 & 0.0 & 0.0 & 0.0 & 0.0 & 0.0 \\
\hline $\operatorname{ag} 0.1-10$ & 0.0 & 0.0 & 0.0 & 0.0 & 0.0 & 0.0 & 0.0 & 0.0 & 0.0 & 0.0 & 0.0 \\
\hline $11-20$ & 0.0 & 0.0 & 0.0 & 0.0 & 0.0 & 0.0 & 0.0 & 0.0 & 0.0 & 0.0 & 35.7 \\
\hline $21-31$ & 0.0 & 0.0 & 0.0 & 0.0 & 0.0 & 0.0 & 0.0 & 0.0 & 0.0 & 0.0 & 0.0 \\
\hline set. $1-10$ & 0.0 & 0.0 & 0.0 & 0.0 & 0.0 & 0.0 & 0.0 & 0.0 & 0.0 & 0.0 & 0.0 \\
\hline $11-20$ & 0.0 & 0.0 & 0.0 & 0.0 & 0.0 & 0.0 & 0.0 & 0.0 & 0.0 & 5.1 & 63.1 \\
\hline $21-30$ & 0.0 & 0.0 & 0.0 & 0.0 & 0.0 & 0.0 & 0.0 & 0.0 & 0.0 & 0.0 & 17.7 \\
\hline out. $1-10$ & 0.0 & 0.0 & 0.0 & 0.0 & 0.0 & 0.0 & 0.0 & 0.0 & 0.0 & 29.2 & 71.2 \\
\hline $11-20$ & 0.0 & 0.0 & 0.0 & 0.0 & 0.0 & 0.0 & 0.0 & 0.0 & 0.0 & 34.8 & 65.3 \\
\hline $21-31$ & 0.0 & 0.0 & 0.0 & 0.0 & 0.0 & 0.0 & 0.0 & 0.0 & 0.0 & 14.1 & 55.1 \\
\hline nov. $1-10$ & 0.0 & 0.0 & 0.0 & 0.0 & 0.0 & 0.0 & 0.0 & 0.0 & 0.0 & 11.8 & 153.1 \\
\hline $11-20$ & 0.0 & 0.0 & 0.0 & 0.0 & 0.0 & 0.0 & 0.0 & 2.1 & 21.2 & 41.4 & 123.9 \\
\hline $21-30$ & 0.0 & 0.0 & 0.0 & 0.0 & 0.0 & 0.0 & 0.0 & 3.8 & 39.5 & 63.2 & 132.5 \\
\hline dez.1-10 & 0.0 & 0.0 & 0.0 & 0.0 & 0.0 & 0.0 & 20.7 & 28.4 & 42.4 & 100.4 & 158.1 \\
\hline $11-20$ & 0.0 & 0.0 & 0.0 & 0.0 & 0.0 & 13.0 & 20.5 & 41.3 & 46.3 & 76.1 & 127.2 \\
\hline $21-31$ & 0.0 & 0.0 & 0.0 & 19.1 & 49.0 & 67.5 & 82.6 & 95.8 & 119.4 & 129.0 & 210.0 \\
\hline
\end{tabular}


TABELA 57 - PINDORAKAS: AGUA FACILHENTE DISPONIVEL (BÁLANCO COM AFD = 100 ME)

DECIL

\begin{tabular}{|c|c|c|c|c|c|c|c|c|c|c|c|}
\hline & & 1 & 2 & 3 & 4 & 5 & 6 & 7 & 8 & 9 & 10 \\
\hline $\begin{array}{l}\text { DECEADID } \\
\text { jan: } 1-10\end{array}$ & $\begin{array}{l}\text { MIN. } \\
74.3\end{array}$ & 78.9 & 81.6 & 100.0 & 100.0 & 100.0 & 100.0 & 100.0 & 100.0 & 100.0 & 100.0 \\
\hline $11-20$ & 38.8 & 79.0 & 95.2 & 100.0 & 100.0 & 100.0 & 100.0 & 100.0 & 100.0 & 100.0 & 100.0 \\
\hline $21-31$ & 62.1 & 93.1 & 100.0 & 100.0 & 100,0 & 100.0 & 100.0 & 100.0 & 100.0 & 100.0 & 100.0 \\
\hline fEV. $1-10$ & 37.9 & 74.5 & 82.3 & 100.0 & 100.0 & 100.0 & 100.0 & 100,0 & 100.0 & 100.0 & 100.0 \\
\hline $11-20$ & 50.7 & 63.2 & 82.8 & 92.4 & 100.0 & 100.0 & 100.0 & 100,0 & 100.0 & 100.0 & 100.0 \\
\hline $21-28$ & 53.3 & 89.0 & 100.0 & 100.0 & 100.0 & 100.0 & 100.0 & 100.0 & 100.0 & 100.0 & 100.0 \\
\hline ara. 1-10 & 63.8 & 76.9 & 84.2 & 100.0 & 100.0 & 100.0 & 100.0 & 100.0 & 100.0 & 100.0 & 100.0 \\
\hline $11-20$ & 33.3 & 64.7 & 75.0 & 82.3 & 89.0 & 100.0 & 100.0 & 100.0 & 100.0 & 100.0 & 100.0 \\
\hline $21-31$ & 47.6 & 62.3 & 71.2 & 81.0 & 85.2 & 90.2 & 96.7 & 100.0 & 100.0 & 100.0 & 100.0 \\
\hline$a b r .1-10$ & 36.9 & 54.5 & 67.6 & 74.2 & 75.8 & 86.6 & 95.0 & 100.0 & 100.0 & 100.0 & 100.0 \\
\hline $11-20$ & 18.5 & 42.8 & 60.5 & 65.8 & 78.4 & 81.4 & 83.6 & 87.1 & 97.9 & 100.0 & 100.0 \\
\hline $21-30$ & 0.3 & 27.9 & 53.0 & 54.3 & 63.1 & 68.7 & 75.4 & 83.3 & 84.5 & 90.0 & 100.0 \\
\hline na.1-10 & 0.0 & 25.0 & 35.0 & 42.8 & 58.1 & 60.5 & $72 \times 1$ & 67.1 & 90.2 & 100.0 & 100.0 \\
\hline $11-20$ & 8.6 & 16.5 & 32.1 & 39.3 & 45.3 & 60.7 & 77.3 & 83.0 & 87.1 & 93.8 & 100.0 \\
\hline $21-31$ & 0.0 & 0.6 & 14.8 & 34,4 & 54.0 & 60,6 & 69.1 & 79.6 & 90.2 & 97.1 & 100.0 \\
\hline jun. $1-10$ & 0.0 & 0.0 & 19.9 & 31.4 & 46.0 & 55.9 & 59.9 & 72.7 & 78.6 & 88.8 & 100.0 \\
\hline $11-20$ & 0,0 & 0.0 & 6.1 & 27.0 & 29.8 & 41.5 & 54.7 & 63.2 & 73.4 & 81.2 & 100.0 \\
\hline $21-30$ & 0.0 & 0.0 & 0.8 & 14.5 & 22.8 & 37.5 & 41.6 & 52.3 & 61.7 & 70.3 & 87.3 \\
\hline jul $1-10$ & 0.0 & 0.0 & 0.0 & 0.0 & 16.6 & 21.2 & 27.2 & 35.5 & 52.3 & 62.0 & 100.0 \\
\hline $11-20$ & 0.0 & 0.0 & 0.0 & 0.0 & 0.0 & 6.7 & 19.3 & 28.4 & 44.3 & 56.0 & 80.7 \\
\hline $21-31$ & 0.0 & 0.0 & 0.0 & 0.0 & 0.0 & 0.0 & 3.7 & 17.2 & 32.5 & 58.1 & 76.6 \\
\hline $290.1-10$ & 0.0 & 0.0 & 0.0 & 0.0 & 0.0 & 0.0 & 0.0 & 14.2 & 27.2 & 48.9 & 77.6 \\
\hline $11-20$ & 0.0 & 0.0 & 0.0 & 0.0 & 0.0 & 0.0 & 0.0 & 0.0 & 7.2 & 25.3 & 100.0 \\
\hline $21-31$ & 0.0 & 0.0 & 0.0 & 0.0 & 0.0 & 0.0 & 0.0 & 0.0 & 9.1 & 45.5 & 73.2 \\
\hline set. $1-10$ & 0.0 & 0.0 & 0.0 & 0.0 & 0.0 & 0.0 & 0.0 & 1.4 & 19.0 & 34.2 & 86.0 \\
\hline $11-20$ & 0.0 & 0.0 & 0.0 & 0.0 & 0.0 & 0.0 & 0.0 & 0.0 & 28.3 & 80.1 & 100.0 \\
\hline $21-30$ & 0.0 & 0.0 & 0.0 & 0.0 & 0.0 & 0.5 & 7.9 & 32.3 & 40.3 & 92.7 & 95.0 \\
\hline out.1-10 & 0.0 & 0.0 & 0.0 & 0.0 & 1.4 & 13.5 & 24.1 & 32.4 & 65.4 & 100.0 & 100.0 \\
\hline $11-20$ & 0.0 & 0.0 & 0.0 & 0.2 & 11.8 & 16.0 & 35.3 & 55.8 & 79.5 & 100.0 & 100.0 \\
\hline $21-31$ & 0.0 & 0.0 & 0.0 & 0.5 & 28.4 & 45.8 & 55.5 & 73.8 & 83.7 & 100.0 & 100.0 \\
\hline nov. $1-10$ & 0.0 & 0.0 & 7.8 & 26.1 & 48.1 & 56.8 & 66.7 & 70.1 & 85.1 & 100.0 & 100.0 \\
\hline $11-20$ & 0.0 & 11.6 & 26.2 & 47.2 & 55.4 & 65.6 & 75.8 & 95.1 & 100.0 & 100.0 & 100.0 \\
\hline $21-30$ & 0.0 & 0.0 & 35.1 & 56.5 & 69.5 & 78.8 & 84.7 & 93.2 & 100.0 & 100.0 & 100.0 \\
\hline dez, $1-10$ & 1.6 & 13.6 & 49.6 & 68.2 & 74.6 & 93.0 & 98.4 & 100.0 & 100.0 & 100.0 & 100.0 \\
\hline $11-20$ & 0.0 & 56.5 & 69.9 & 90.4 & 97.8 & 100.0 & 100.0 & 100.0 & 100.0 & 100.0 & 100.0 \\
\hline $21-31$ & 21.4 & 60.4 & 93.0 & 100.0 & 100.0 & 100.0 & 100.0 & 100.0 & 100.0 & 100.0 & 100.0 \\
\hline
\end{tabular}


TABELA 58-PINDORAMA: DEFICITES (BALANCO COM AFD = 100 on)

DECIL

\begin{tabular}{|c|c|c|c|c|c|c|c|c|c|c|c|}
\hline DECENDIO & MIN. & 1 & 2 & 3 & 4 & 5 & 6 & 7 & 8 & 9 & 10 \\
\hline jan. $1-10$ & 0.0 & 0.0 & 0.0 & 0.0 & 0.0 & 0.0 & 0.0 & 0.0 & 0.0 & 0.0 & 0.0 \\
\hline $11-20$ & 0.0 & 0.0 & 0.0 & 0.0 & 0.0 & 0.0 & 0.0 & 0.0 & 0.0 & 0.0 & 0.0 \\
\hline $21-31$ & 0.0 & 0.0 & 0.0 & 0.0 & 0.0 & 0.0 & 0.0 & 0.0 & 0.0 & 0.0 & 0.0 \\
\hline fev. $1-10$ & 0.0 & 0.0 & 0.0 & 0.0 & 0.0 & 0.0 & 0.0 & 0.0 & 0.0 & 0.0 & 0.0 \\
\hline $11-20$ & 0.0 & 0.0 & 0.0 & 0.0 & 0.0 & 0.0 & 0.0 & 0.0 & 0.0 & 0.0 & 0.0 \\
\hline $21-28$ & 0.0 & 0.0 & 0.0 & 0.0 & 0.0 & 0.0 & 0.0 & 0.0 & 0.0 & 0.0 & 0.0 \\
\hline $\operatorname{car} .1-10$ & 0.0 & 0.0 & 0.0 & 0.0 & 0.0 & 0.0 & 0.0 & 0.0 & 0.0 & 0.0 & 0.0 \\
\hline $11-20$ & 0.0 & 0.0 & 0.0 & 0.0 & 0.0 & 0.0 & 0.0 & 0.0 & 0.0 & 0.0 & 0.0 \\
\hline $21-31$ & 0.0 & 0.0 & 0.0 & 0.0 & 0.0 & 0.0 & 0.0 & 0.0 & 0.0 & 0.0 & 0.0 \\
\hline abr. $1-10$ & 0.0 & 0.0 & 0.0 & 0.0 & 0.0 & 0.0 & 0.0 & 0.0 & 0.0 & 0.0 & 0.0 \\
\hline $11-20$ & 0.0 & 0.0 & 0.0 & 0.0 & 0.0 & 0.0 & 0.0 & 0.0 & 0.0 & 0.0 & 0.0 \\
\hline $21-30$ & 0.0 & 0.0 & 0.0 & 0.0 & 0.0 & 0.0 & 0.0 & 0.0 & 0.0 & 0.0 & 0.0 \\
\hline a $21.1-10$ & 0.0 & 0.0 & 0.0 & 0.0 & 0.0 & 0.0 & 0.0 & 0.0 & 0.0 & 0.0 & 20.5 \\
\hline $11-20$ & 0.0 & 0.0 & 0.0 & 0.0 & 0.0 & 0.0 & 0.0 & 0.0 & 0.0 & 0.0 & 0.0 \\
\hline $21-3 \mid$ & 0.0 & 0.0 & 0.0 & 0.0 & 0.0 & 0.0 & 0.0 & 0.0 & 0.0 & 0.0 & 12.8 \\
\hline jun. $1-10$ & 0.0 & 0.0 & 0.0 & 0.0 & 0.0 & 0.0 & 0.0 & 0.0 & 0.0 & 0.0 & 15.9 \\
\hline $11-20$ & 0.0 & 0.0 & 0.0 & 0.0 & 0.0 & 0.0 & 0.0 & 0.0 & 0.0 & 7.9 & 20.7 \\
\hline $21-30$ & 0.0 & 0.0 & 0.0 & 0.0 & 0.0 & 0.0 & 0.0 & 0.0 & 0.0 & 4.0 & 20.1 \\
\hline jul. $1-10$ & 0.0 & 0.0 & 0.0 & 0.0 & 0.0 & 0.0 & 0.0 & 0.0 & 9.1 & 18.9 & 26.6 \\
\hline $11-20$ & 0.0 & 0.0 & 0.0 & 0.0 & 0.0 & 0.0 & 0.0 & 12.7 & 21.3 & 24.2 & 27.4 \\
\hline $21-3 \mid$ & 0.0 & 0.0 & 0.0 & 0.0 & 0.0 & 7.6 & 19.7 & 21.6 & 25.3 & 26.8 & 30.3 \\
\hline $390,1-10$ & 0.0 & 0.0 & 0.0 & 0.0 & 2.1 & 10.0 & 17.6 & 22.1 & 23.5 & 24.4 & 29.8 \\
\hline $11-20$ & 0.0 & 0.0 & 0.0 & 1.4 & 7.1 & 16.1 & 20.7 & 25.0 & 26.5 & 27.6 & 29.7 \\
\hline $21-31$ & 0.0 & 0.0 & 0.0 & 4.2 & 11.7 & 19.1 & 26.7 & 29.9 & 32.7 & 33.4 & 33.5 \\
\hline set. $1-10$ & 0.0 & 0.0 & 0.0 & 0.0 & 10.9 & 16.5 & 22.2 & 28.2 & 30.1 & 32.8 & 35.6 \\
\hline $11-20$ & 0.0 & 0.0 & 0.0 & 0.0 & 8.9 & 24.2 & 28.1 & 29.0 & 31.8 & 33.4 & 39.9 \\
\hline $21-30$ & 0.0 & 0.0 & 0.0 & 0.0 & 0.0 & 0.0 & 2.9 & 10.4 & 21.3 & 28.9 & 41.5 \\
\hline out. $1-10$ & 0.0 & 0.0 & 0.0 & 0.0 & 0.0 & 0.0 & 0.0 & 7.9 & 29.0 & 37.7 & 45.9 \\
\hline $11-20$ & 0.0 & 0.0 & 0.0 & 0.0 & 0.0 & 0.0 & 0.0 & 0.0 & 10.3 & 15.8 & 46.5 \\
\hline $21-31$ & 0.0 & 0.0 & 0.0 & 0.0 & 0.0 & 0.0 & 0.0 & 0.0 & 14.7 & 34.5 & 51.9 \\
\hline noy. $1-10$ & 0.0 & 0.0 & 0.0 & 0.0 & 0.0 & 0.0 & 0.0 & 0.0 & 0.0 & 21.5 & 44.0 \\
\hline $11-20$ & 0.0 & 0.0 & 0.0 & 0.0 & 0.0 & 0.0 & 0.0 & 0.0 & 0.0 & 0.0 & 30.4 \\
\hline $21-30$ & 0.0 & 0.0 & 0.0 & 0.0 & 0.0 & 0.0 & 0.0 & 0.0 & 0.0 & 0.0 & 16.2 \\
\hline dez.1-10 & 0.0 & 0.0 & 0.0 & 0.0 & 0.0 & 0.0 & 0.0 & 0.0 & 0.0 & 0.0 & 0.0 \\
\hline $11-20$ & 0.0 & 0.0 & 0.0 & 0.0 & 0.0 & 0.0 & 0.0 & 0.0 & 0.0 & 0.0 & 40.6 \\
\hline $21-31$ & 0.0 & 0.0 & 0.0 & 0.0 & 0.0 & 0.0 & 0.0 & 0.0 & 0.0 & 0.0 & 0.0 \\
\hline
\end{tabular}


TABELA 59 - PINQORAHA: EXCEDENTES HIDRICOS (BALANCO COM AFD $=100$ )

DECIL

\begin{tabular}{|c|c|c|c|c|c|c|c|c|c|c|c|}
\hline & & 1 & 2 & 3 & 4 & 5 & 6 & 7 & 8 & 9 & 10 \\
\hline jan. $1-10$ & 0.0 & 0.0 & 0.0 & 8.7 & 10.1 & 16.5 & 29.7 & 73.6 & 107.6 & 134.2 & 222.2 \\
\hline $11-20$ & 0.0 & 0.0 & 0.0 & 8.0 & 15.4 & 62.7 & 52.5 & 75.5 & 97.4 & 119.9 & 359.4 \\
\hline $21-31$ & 0.0 & 0.0 & 1.2 & 20.9 & 33.9 & 44.1 & 55.8 & 66.0 & 73.7 & 98.6 & 196.7 \\
\hline fev. $1-10$ & 0.0 & 0.0 & 0.0 & 0.5 & 13.7 & 42.4 & 60.9 & 91.4 & 111.0 & 150.0 & 200.2 \\
\hline $11-20$ & 0.0 & 0.0 & 0.0 & 0.0 & 3,8 & 9.9 & 20.6 & 73.2 & 119.7 & 129.0 & 206.1 \\
\hline $21-28$ & 0.0 & 0.0 & 0.2 & 3.8 & 10.9 & 14.6 & 25.7 & 41.6 & 63.6 & 103.1 & 151.5 \\
\hline ar. $1-10$ & 0.0 & 0.0 & 0.0 & 9.4 & 14.8 & 17.4 & 37.1 & 50.3 & 65.4 & 101.4 & 135.7 \\
\hline $11-20$ & 0.0 & 0.0 & 0.0 & 0.0 & 0.0 & 7.6 & 23.7 & 29.0 & 53.1 & 87.4 & 221.2 \\
\hline $21-31$ & 0.0 & 0.0 & 0.0 & 0.0 & 0.0 & 0.0 & 0.0 & 19.8 & 34.0 & 51.0 & 86.8 \\
\hline abr. $1-10$ & 0.0 & 0.0 & 0.0 & 0.0 & 0.0 & 0.0 & 0.0 & 5.2 & 10.1 & 31.2 & 109.6 \\
\hline $11-20$ & 0.0 & 0.0 & 0.0 & 0.0 & 0.0 & 0.0 & 0.0 & 0.0 & 0.0 & 14.6 & 76.7 \\
\hline $21-30$ & 0.0 & 0.0 & 0.0 & 0.0 & 0.0 & 0.0 & 0.0 & 0.0 & 0.0 & 0.0 & 99.2 \\
\hline aลi. $1-10$ & 0.0 & 0.0 & 0.0 & 0.0 & 0.0 & 0.0 & 0.0 & 0.0 & 0.0 & 3.2 & 78.4 \\
\hline $11-20$ & 0.0 & 0.0 & 0.0 & 0.0 & 0.0 & 0.0 & 0.0 & 0.0 & 0.0 & 0.0 & 44.8 \\
\hline $21-31$ & 0.0 & 0.0 & 0.0 & 0.0 & 0.0 & 0.0 & 0.0 & 0.0 & 0.0 & 0.0 & 110.4 \\
\hline jun. $1-10$ & 0.0 & 0.0 & 0.0 & 0.0 & 0.0 & 0.0 & 0.0 & 0.0 & 0.0 & 0.0 & 16.0 \\
\hline $11-20$ & 0.0 & 0.0 & 0.0 & 0.0 & 0.0 & 0.0 & 0.0 & 0.0 & 0.0 & 0.0 & 66.6 \\
\hline $21-30$ & 0.0 & 0.0 & 0.0 & 0.0 & 0.0 & 0.0 & 0.0 & 0.0 & 0.0 & 0.0 & 0.0 \\
\hline jul. $1-10$ & 0.0 & 0.0 & 0.0 & 0.0 & 0.0 & 0.0 & 0.0 & 0.0 & 0.0 & 0.0 & 0.1 \\
\hline $11-20$ & 0.0 & 0.0 & 0.0 & 0.0 & 0.0 & 0.0 & 0.0 & 0.0 & 0.0 & 0.0 & 0.0 \\
\hline $21-31$ & 0.0 & 0.0 & 0.0 & 0.0 & 0.0 & 0.0 & 0.0 & 0.0 & 0.0 & 0.0 & 0.0 \\
\hline ago.: $1-10$ & 0.0 & 0.0 & 0.0 & 0.0 & 0.0 & 0.0 & 0.0 & 0.0 & 0.0 & 0.0 & 0.0 \\
\hline $11-20$ & 0.0 & 0.0 & 0.0 & 0.0 & 0.0 & 0.0 & 0.0 & 0.0 & 0.0 & 0.0 & 35.7 \\
\hline $21-31$ & 0.0 & 0.0 & 0.0 & 0.0 & 0.0 & 0.0 & 0.0 & 0.0 & 0.0 & 0.0 & 0.0 \\
\hline set. $1-10$ & 0.0 & 0.0 & 0.0 & 0.0 & 0.0 & 0.0 & 0.0 & 0.0 & 0.0 & 0.0 & 0.0 \\
\hline $11-20$ & 0.0 & 0.0 & 0.0 & 0.0 & 0.0 & 0.0 & 0.0 & 0.0 & 0.0 & 0.0 & 43.1 \\
\hline $21-30$ & 0.0 & 0.0 & 0.0 & 0.0 & 0.0 & 0.0 & 0.0 & 0.0 & 0.0 & 0.0 & 0.0 \\
\hline out. $1-10$ & 0.0 & 0.0 & 0.0 & 0.0 & 0.0 & 0.0 & 0.0 & 0.0 & 0.0 & 26.2 & 63.9 \\
\hline $11-20$ & 0.0 & 0.0 & 0.0 & 0.0 & 0.0 & 0.0 & 0.0 & 0.0 & 0.0 & 29.9 & 65.3 \\
\hline $21-31$ & 0.0 & 0.0 & 0.0 & 0.0 & 0.0 & 0.0 & 0.0 & 0.0 & 0.0 & 2.1 & 30.1 \\
\hline nov. $1-10$ & 0.0 & 0.0 & 0.0 & 0.0 & 0.0 & 0.0 & 0.0 & 0.0 & 0.0 & 11.8 & 153.1 \\
\hline $11-20$ & 0.0 & 0.0 & 0.0 & 0.0 & 0.0 & 0.0 & 0.0 & 0.0 & 15.7 & 30.7 & 98.9 \\
\hline $21-30$ & 0.0 & 0.0 & 0.0 & 0.0 & 0.0 & 0.0 & 0.0 & 0.0 & 15.3 & 39.5 & 132.5 \\
\hline dez.1-10 & 0.0 & 0.0 & 0.0 & 0.0 & 0.0 & 0.0 & 0.0 & 20.7 & 31.9 & 75.9 & 158.1 \\
\hline $11-20$ & 0.0 & 0.0 & 0.0 & 0.0 & 0.0 & 12.1 & 19.9 & 41.3 & 46.3 & 55.8 & 127.2 \\
\hline $21-31$ & 0.0 & 0.0 & 0.0 & 19.1 & 46.5 & 57.1 & 82.6 & 95.8 & 119.4 & 129.0 & 210.0 \\
\hline
\end{tabular}


TABELA 60 - RIBEIRAO PRETO: CHUVA

DECIL

\begin{tabular}{|c|c|c|c|c|c|c|c|c|c|c|c|}
\hline & & 1 & 2 & 3 & 4 & 5 & 6 & 7 & 8 & 9 & 10 \\
\hline jan. $1-10$ & 4.5 & 24.6 & 38.2 & 45.5 & 72.5 & 77.5 & 89 & 98.4 & 125.1 & 144 & 169.1 \\
\hline $11-20$ & 2 & 5.6 & 34.3 & 54.3 & 56.7 & 77.4 & 111.6 & 128.1 & 153.8 & 161 & 178.5 \\
\hline $21-31$ & 1.2 & 18.3 & 37.8 & 54.1 & 70.2 & 104.2 & 107.7 & 118.2 & 127.6 & 175.3 & 230.5 \\
\hline fer. $1-10$ & 2.3 & 10.6 & 26.5 & 37.5 & 46 & 52.8 & 83.9 & 93.6 & 134.5 & 154.6 & 289.9 \\
\hline $11-20$ & 0.1 & 5.4 & 18 & 27.8 & 35.5 & 45.9 & 67.6 & 107.8 & 120.8 & 175 & 219.9 \\
\hline $21-28$ & 0 & 10.2 & 17.6 & 33.7 & 41.9 & 51.2 & 66.3 & 80 & 93.3 & 156.9 & 181.4 \\
\hline ar. $1-10$ & 2.8 & 10.2 & 19.5 & 35.3 & 50.1 & 59.2 & 66.7 & $B 4.3$ & 96.1 & 112.6 & 153.65 \\
\hline $11-20$ & 0 & 0.2 & 2.3 & 18.2 & 28.2 & $3 B$ & 49.4 & 52.7 & 85 & 110.6 & 263.2 \\
\hline $21-31$ & 0 & 4.3 & 6.9 & 11.4 & 17 & 25,3 & 40.1 & 48.8 & 60 & 94.5 & 114.1 \\
\hline abr. $1-10$ & 0 & 2.4 & 3.5 & 7.4 & 16.2 & 25.7 & 35.6 & 41.6 & 49.5 & 93.9 & 109.6 \\
\hline $11-20$ & 0 & 0 & 0.4 & 2.3 & 4.5 & 7.5 & 15.1 & 28.1 & 39.6 & 62.1 & 127 \\
\hline $21-30$ & 0 & 0 & 0.3 & 2.3 & 8.7 & 13 & 15.5 & 23.6 & 35.4 & 53.6 & 120.6 \\
\hline 1ai. $1-10$ & 0 & 0 & 0.2 & 2.2 & 5.6 & 9.9 & 12.6 & 27.5 & 34.7 & 45.2 & 85.4 \\
\hline $11-20$ & 0 & 0 & 0 & 0 & 1.4 & 5.5 & 10.3 & 14.7 & 25.7 & 45 & 54.2 \\
\hline $21-31$ & 0 & 0 & 0 & 0 & 1.8 & B.6 & 12.3 & 24.3 & 34.5 & 51.2 & 150.5 \\
\hline jun. 1-10 & 0 & 0 & 0 & 0 & 0 & 0.8 & 5 & 15.3 & 22.7 & 45.7 & 67.5 \\
\hline $11-20$ & 0 & 0 & 0 & 0 & 0 & 0.2 & 3.2 & 6.7 & 11.5 & 29.4 & 116.6 \\
\hline $22-30$ & 0 & 0 & 0 & 0 & 0 & 0 & 1.8 & 2.5 & 7.4 & 29.8 & 69 \\
\hline jul. $1-10$ & 0 & 0 & 0 & 0 & 0 & 0 & 0.2 & 0.6 & 8.4 & 33.4 & 104.1 \\
\hline $11-20$ & 0 & 0 & 0 & 0 & 0 & 0 & 0 & 1.7 & 7.4 & 24.6 & 88.5 \\
\hline $21-31$ & 0 & 0 & 0 & 0 & 0 & 1 & 3.2 & 5.5 & 12.7 & 19.6 & 62.3 \\
\hline $300.1-10$ & 0 & 0 & 0 & 0 & 0 & 0 & 0.3 & 1.1 & 4.6 & 16.1 & 66.6 \\
\hline $11-20$ & 0 & 0 & 0 & 0 & 0 & 0.2 & 0.5 & 1.3 & 3.6 & 13.4 & 80.9 \\
\hline $21-31$ & 0 & 0 & 0 & 0 & 0 & 0 & 4.6 & 12.4 & 19 & 27.5 & 107.7 \\
\hline set. $1-10$ & 0 & 0 & 0 & 0.9 & 1.3 & 2.3 & 8.8 & 18 & 23.7 & 43 & 69.5 \\
\hline $11-20$ & 0 & 0 & 0 & 0 & 0 & 1.8 & 3 & 13.3 & 24.9 & 58.8 & 118.2 \\
\hline $21-30$ & 0 & 0 & 2.8 & 5.3 & 13 & 18.3 & 24.8 & 31.5 & 44.6 & 53 & 76.2 \\
\hline out. $1-10$ & 0 & 2.4 & 6.9 & 14.2 & 21 & 38.5 & 50.5 & 61.1 & 66.5 & 83.4 & 97.9 \\
\hline $11-20$ & 0.2 & 3.3 & 8.8 & 17.5 & 29.7 & 38.9 & 42.5 & 56.6 & 66.6 & 92.8 & 113.5 \\
\hline $21-31$ & 0 & 2.5 & 21.5 & 32.5 & 44.2 & 56.4 & 62.8 & 77.6 & 84.4 & 107.9 & 117.1 \\
\hline nov. $1-10$ & 2.5 & 3.6 & 16.8 & 26.8 & 42.8 & 52 & 59.2 & 62.9 & 78.3 & 117.5 & 127 \\
\hline $11-20$ & 8.5 & 8.9 & 19 & 26.7 & 31.6 & 39 & 48.7 & 83 & 100 & 137.6 & 188 \\
\hline $21-30$ & 0.7 & 6.5 & 14 & 21.6 & 30.6 & 51.2 & 70.8 & 80.7 & 101.1 & 120.6 & 274.2 \\
\hline dez:1-10 & 3.7 & 21 & 29.5 & 44 & 53 & 68 & 85.5 & 117.5 & 138.3 & 183.6 & 259.9 \\
\hline $11-20$ & 7.5 & 18.7 & 28.1 & 41.7 & 53.2 & 63.2 & 82.6 & 108.1 & 165.4 & 209.5 & 293.5 \\
\hline $21-31$ & 10.2 & 46.2 & 79.4 & 95.4 & 116.4 & 124.7 & 127.7 & 133.5 & 157.2 & 174.1 & 381.4 \\
\hline
\end{tabular}


TABELA 61 - RIBEIRAD PRETO: EVAPOTRANSPIRACAO DE REFERENCIA

DECIL

\begin{tabular}{|c|c|c|c|c|c|c|c|c|c|c|c|}
\hline DECENDIO & KIN. & 1 & 2 & 3 & 4 & 5 & 6 & 7 & 8 & 9 & 10 \\
\hline jan. 1-10 & 41.2 & 42.4 & 48.8 & 52.6 & 56.2 & 57.3 & 58.5 & 58.9 & 59.4 & 68.5 & 70.0 \\
\hline $11-20$ & 36.9 & 45.3 & 50.3 & 51.9 & 52.9 & 55.3 & 56.8 & 62.1 & 64.0 & 66.8 & 80.5 \\
\hline $21-31$ & 38.4 & 44.6 & 55.7 & 56.2 & 57.9 & 62.1 & 64.3 & 65.5 & 69.5 & 71.9 & 80.3 \\
\hline fev. $1-10$ & 39.3 & 14.2 & 47.3 & 49.0 & 53.3 & 55.1 & 60.4 & 61.9 & 63.4 & 66.4 & 74.0 \\
\hline $11-20$ & 37.2 & 43.1 & 44.7 & 49.5 & 53.6 & 55.8 & 59.3 & 62.4 & 64.0 & 66.1 & 68.5 \\
\hline $21-28$ & 23.9 & 32.0 & 34.6 & 37.4 & 39.0 & 41.1 & 45.0 & 46.8 & 48.7 & 49.8 & 52,8 \\
\hline ar. $1-10$ & 37.4 & 42.5 & 43.3 & 47.8 & 49.1 & $\cdot 51,4$ & 53.4 & 55.1 & 57.9 & 61.0 & 65.5 \\
\hline $11-20$ & 33.7 & 39.0 & 47.6 & 49.2 & 50.4 & 52.0 & 53.5 & 55.9 & 57.8 & 61.6 & 63.9 \\
\hline $21-31$ & 48.7 & 49.3 & 52.9 & 54.3 & 55.8 & 56.3 & 57.6 & 61.3 & 61.9 & 63.6 & 65.1 \\
\hline abr. $1-10$ & 33.6 & 37.6 & 38.8 & 39.5 & 40.1 & 41.8 & 42.5 & 43.9 & 45.2 & 46.9 & 55.5 \\
\hline $11-20$ & 30.6 & 36.2 & 38.1 & 38.6 & 40.5 & 41.8 & 42.8 & 44.2 & 44.7 & 45.2 & 46.4 \\
\hline $21-30$ & 31.4 & 34.3 & 36.3 & 37.1 & 38.0 & 39.0 & 39.9 & 60.5 & 40.6 & 42.5 & 49.6 \\
\hline ai. $1-10$ & 25.4 & 30.9 & 32.2 & 33.3 & 34.2 & 34.6 & 36.6 & 37.2 & 38.4 & 39.8 & 17.0 \\
\hline $11-20$ & 25.3 & 27.9 & 30.6 & 33.5 & 33.7 & 34.8 & 35.7 & 36.5 & 36.9 & 38.7 & 10.7 \\
\hline $21-31$ & 26.8 & 30.2 & 32.4 & 35.2 & 36.1 & 36.9 & 37.4 & 38.8 & 40.5 & 10.9 & 43.3 \\
\hline jun.1-10 & 23.1 & 25.7 & 28.8 & 30.7 & 31.2 & 32.8 & 34.6 & 34.8 & 36.3 & 37.2 & 41.4 \\
\hline $11-20$ & 18.5 & 26.4 & 29.6 & 30.6 & 31.2 & 31.9 & 32.8 & 33.8 & 35,6 & 37.7 & 80.2 \\
\hline $21-30$ & 25.6 & 27.5 & 29.2 & 31.6 & 33.2 & 33.9 & 34.4 & 35.2 & 36.9 & 37.9 & 41.2 \\
\hline jul.1-10 & 23.9 & 27.5 & 32.8 & 33.6 & 35.1 & 35.5 & 36.2 & 37.2 & 38.8 & 40.9 & 43.4 \\
\hline $11-20$ & 27.8 & 32.4 & 33.1 & 34.4 & 36.5 & 37.1 & 37.4 & 38.4 & 40.2 & 42.3 & 45.0 \\
\hline $21-31$ & 33.2 & 35.8 & 37.5 & 39.4 & 41.8 & $\$ 2.8$ & 43.7 & 44.4 & 46.2 & 47.5 & 51.4 \\
\hline ago.1-10 & 31.3 & 35.2 & 36.3 & 39.4 & 40.1 & 41.1 & 41.7 & 43.8 & 45.8 & 47.6 & 49.8 \\
\hline $11-20$ & 27.8 & 38.8 & 40.0 & 42.4 & 42.6 & 44.0 & 44.9 & 46.1 & 47.6 & 49.6 & 56.0 \\
\hline $21-31$ & 35.8 & 42.0 & 47.1 & 49.4 & 49.7 & 52.5 & 53.3 & 55.5 & 58.4 & 59.0 & 64.7 \\
\hline set.1-10 & 30.6 & 38.6 & 40.5 & 41.5 & 42.7 & 47.0 & 48.1 & 50.3 & 55.3 & 57.4 & 69.6 \\
\hline $11-20$ & 31.5 & 34.5 & 43.2 & 46.3 & 49.7 & 50.4 & 55.7 & 57.6 & 60.3 & 64.1 & 69.6 \\
\hline $21-30$ & 38.5 & 42.7 & 44.2 & 45.5 & 48.4 & 49.1 & 50.6 & 51.9 & 54.1 & 60.6 & 67.7 \\
\hline out. $1-10$ & 42.4 & 43.1 & 48.9 & 50.7 & 52.4 & 56.2 & 62.1 & 68.2 & 70.3 & 72.7 & 78.7 \\
\hline $11-20$ & 48.7 & 50.7 & 53.2 & 56.5 & 57.5 & 59.4 & 61.1 & 63.9 & 64.5 & 70.3 & 87.9 \\
\hline $21-31$ & 49.2 & 53.4 & 57.9 & 61.0 & 63.6 & 65.2 & 67.4 & 70.4 & 77.2 & 79.7 & 84.8 \\
\hline nov. $1-10$ & 46.9 & 51.8 & 56.3 & $\$ 8.1$ & 58.8 & 62.0 & 62.6 & 63.9 & 67.5 & 69.3 & 85.8 \\
\hline $11-20$ & 39.5 & 45.5 & 53.2 & 53.7 & 57.6 & $\$ 8.1$ & 60.8 & 63.4 & 65.0 & 69.6 & 90.2 \\
\hline $21-30$ & 44.2 & $\$ 1.2$ & 55.1 & 57.0 & 58.7 & 61.1 & 61.4 & 63.1 & 67.1 & 70.6 & 78.0 \\
\hline dez.1-10 & 43.3 & 44.5 & 50.4 & 53.5 & 54.6 & 55.4 & 56.3 & 63.3 & 67.8 & 72.8 & 77.7 \\
\hline $11-20$ & 42.9 & 45.2 & 49.4 & 50.4 & 51.1 & 54.4 & 56.0 & 58.3 & 65.4 & 67.1 & 17.9 \\
\hline $2 d-31$ & 39.7 & 47.6 & 49.4 & 50.5 & 54.3 & 58.6 & 59.5 & 62.2 & 66.1 & 69.1 & 95.9 \\
\hline
\end{tabular}


TABELA 62 - RIBEIRAO PRETO: AGUA FACILAENTE DISPONIVEL (BALANCO COM AFD = 30 (1)

DECIL

\begin{tabular}{|c|c|c|c|c|c|c|c|c|c|c|c|}
\hline DECENDIO & KIN. & 1 & 2 & 3 & 4 & 5 & 6 & 7 & 8 & 9 & 10 \\
\hline jan. 1-10 & 0.2 & 18.7 & 30.0 & 30.0 & 30.0 & 30.0 & 30.0 & 30.0 & 30.0 & 30.0 & 30.0 \\
\hline $11-20$ & 0.0 & 2.9 & 26.3 & 30.0 & 30.0 & 30.0 & 30.0 & 30.0 & 30.0 & 30.0 & 30.0 \\
\hline $21-31$ & 0.0 & B.1 & 30.0 & 30.0 & 30.0 & 30.0 & 30.0 & 30.0 & 30.0 & 30.0 & 30.0 \\
\hline fEv. $1-10$ & 0.0 & 6.5 & 24.3 & 30.0 & 30.0 & 30.0 & 30.0 & 30.0 & 30.0 & 30.0 & 30.0 \\
\hline $11-20$ & 0.0 & 0.0 & 11.3 & 22.4 & 30.0 & 30.0 & 30.0 & 30.0 & 30.0 & 30.0 & 30.0 \\
\hline $21-2 B$ & 0.0 & 5.4 & 18.7 & 26.5 & 30.0 & 30.0 & 30.0 & 30.0 & 30.0 & 30.0 & 30.0 \\
\hline ar. $1-10$ & 2.2 & 8.6 & 15.9 & 30.0 & 30.0 & 30.0 & 30.0 & 30.0 & 30.0 & 30.0 & 30.0 \\
\hline $11-20$ & 0.0 & 0.0 & 0.0 & 18.7 & 24.5 & 30.0 & 30.0 & 30.0 & 30.0 & 30.0 & 30.0 \\
\hline $21-31$ & 0.0 & 0.0 & 0.0 & 1.8 & 10.2 & 17.2 & 21.2 & 30.0 & 30.0 & 30.0 & 30.0 \\
\hline$a b r .1-10$ & 0.0 & 0.0 & 0.0 & 7.4 & 11.7 & 18.4 & 25.3 & 30.0 & 30.0 & 30.0 & 50.0 \\
\hline $11-20$ & 0.0 & 0.0 & 0.0 & 0.6 & 6.5 & 7.4 & 10.2 & 14.5 & 23.9 & 30.0 & 30.0 \\
\hline $21-30$ & 0.0 & 0.0 & 0.0 & 0.0 & 0.4 & 3.8 & 7.7 & 9.6 & 26.7 & 30.0 & 30.0 \\
\hline ai. $1-10$ & 0.0 & 0.0 & 0.0 & 0.0 & 0.0 & 6.1 & 13.9 & 16.8 & 22.0 & 30.0 & 30.0 \\
\hline $11-20$ & 0.0 & 0.0 & 0.0 & 0.0 & 0.0 & 0.0 & 10.8 & 19.7 & 26.2 & 29.9 & 30.0 \\
\hline $21-31$ & 0.0 & 0.0 & 0.0 & 0.0 & 0.0 & 2.3 & 10.6 & 17.4 & 28.2 & 30.0 & 30.0 \\
\hline jun. $1-10$ & 0.0 & 0.0 & 0.0 & 0.0 & 0.0 & 0.0 & 2.0 & 6.7 & 28.2 & 30.0 & 30.0 \\
\hline $11-20$ & 0.0 & 0.0 & 0.0 & 0.0 & 0.0 & 0.0 & 0.0 & 9.0 & 10.5 & 28.0 & 30.0 \\
\hline $21-30$ & 0.0 & 0.0 & 0.0 & 0.0 & 0.0 & 0.0 & 0.0 & 0.0 & 9.2 & 30.0 & 30.0 \\
\hline jul.1-10 & 0.0 & 0.0 & 0.0 & 0.0 & 0.0 & 0.0 & 0.0 & 7.4 & 8.9 & 12.8 & 30.0 \\
\hline $11-20$ & 0.0 & 0.0 & 0.0 & 0.0 & 0.0 & 0.0 & 0.0 & 0.0 & 9.3 & 18.0 & 30.0 \\
\hline $21-31$ & 0.0 & 0.0 & 0.0 & 0.0 & 0.0 & $0.0^{\circ}$ & 0.0 & 0,0 & 3.2 & 16.4 & 30.0 \\
\hline ago. $1-10$ & 0.0 & 0.0 & 0.0 & 0.0 & 0.0 & 0.0 & 0.0 & 0.0 & 0.0 & 7.4 & 30.0 \\
\hline $11-20$ & 0.0 & 0.0 & 0.0 & 0.0 & 0.0 & 0.0 & 0.0 & 0.0 & 0.0 & 0.0 & 30.0 \\
\hline $21-31$ & 0.0 & 0.0 & 0.0 & 0.0 & 0.0 & 0.0 & 0.0 & 0.0 & 0.0 & 6.0 & 30.0 \\
\hline set. $1-10$ & 0.0 & 0.0 & 0.0 & 0.0 & 0.0 & 0.0 & 0.0 & 0.0 & 8.3 & 17.7 & 30.0 \\
\hline $11-20$ & 0.0 & 0.0 & 0.0 & 0.0 & 0.0 & 0.0 & 0.0 & 0.0 & 11.9 & 30.0 & 30.0 \\
\hline $21-30$ & 0.0 & 0.0 & 0.0 & 0.0 & 0.0 & 0.0 & 0.0 & 8.6 & 30.0 & 30.0 & 30.0 \\
\hline out. $1-10$ & 0.0 & 0.0 & 0.0 & 0.0 & 0.0 & 15.0 & 30.0 & 30.0 & 30.0 & 30.0 & 30.0 \\
\hline $11-20$ & 0,0 & 0.0 & 0.0 & 0.0 & 0.2 & 21.9 & 30.0 & 30.0 & 30.0 & 30.0 & 30.0 \\
\hline $21-31$ & 0.0 & 0.0 & 3.0 & 12.1 & 16.3 & 26.7 & 30.0 & 30.0 & 30.0 & 30.0 & 30.0 \\
\hline nov. $1-10$ & 0.0 & 0.0 & 7.8 & 19.8 & 28.4 & 30.0 & 30.0 & 30.0 & 30.0 & 30.0 & 30.0 \\
\hline $11-20$ & 0.0 & 0.0 & 3.5 & 11.5 & 24.4 & 30.0 & 30.0 & 30.0 & 30.0 & 30.0 & 30.0 \\
\hline $21-30$ & 0.0 & 0.0 & 1.0 & 9.3 & 19.3 & 30.0 & 30.0 & 30.0 & 30.0 & 30.0 & 30.0 \\
\hline dez. 1-10 & 0.0 & 10.9 & 18.5 & 27.0 & 30.0 & 30.0 & 30.0 & 30.0 & 30.0 & 30.0 & 30.0 \\
\hline $11-20$ & 0.0 & 0.0 & 19.1 & 30.0 & 30.0 & 30.0 & 30.0 & 30.0 & 30.0 & 30.0 & 30.0 \\
\hline $21-31$ & 0.0 & 30.0 & 30.0 & 30.0 & 30.0 & 30.0 & 30.0 & 30.0 & 30.0 & 30.0 & 30.0 \\
\hline
\end{tabular}


TABELA 6J - RIDEIRAO PRETO: DEFICITES (BALANCO COH AFD = 30 Aa)

DECIL

\begin{tabular}{|c|c|c|c|c|c|c|c|c|c|c|c|}
\hline DECENDID & MIN. & 1 & 2 & 3 & 4 & 5 & 6 & 7 & 8 & 9 & 10 \\
\hline jan.1-10 & 0.0 & 0.0 & 0.0 & 0.0 & 0.0 & 0.0 & 0.0 & 0.0 & 0.0 & 0.0 & 0.0 \\
\hline $11-20$ & 0.0 & 0.0 & 0.0 & 0.0 & 0.0 & 0.0 & 0.0 & 0.0 & 0.0 & 0.0 & 34.4 \\
\hline $21-31$ & 0.0 & 0.0 & 0.0 & 0.0 & 0.0 & 0.0 & 0.0 & 0.0 & 0.0 & 0.0 & 6.0 \\
\hline fev. $1-10$ & 0.0 & 0.0 & 0.0 & 0.0 & 0.0 & 0.0 & 0.0 & 0.0 & 0.0 & 0.0 & 21.1 \\
\hline $11-20$ & 0.0 & 0.0 & 0.0 & 0.0 & 0.0 & 0.0 & 0.0 & 0.0 & 0.0 & 0.0 & 3.7 \\
\hline $21-28$ & 0.0 & 0.0 & 0.0 & 0.0 & 0.0 & 0.0 & 0.0 & 0.0 & 0.0 & 0.0 & 21.5 \\
\hline tar $1-10$ & 0.0 & 0.0 & 0.0 & 0.0 & 0.0 & 0.0 & 0.0 & 0.0 & 0.0 & 0.0 & 0.0 \\
\hline $11-20$ & 0.0 & 0.0 & 0.0 & 0.0 & 0.0 & 0.0 & 0.0 & 0.0 & 0.0 & 4.0 & 26.6 \\
\hline $21-31$ & 0.0 & 0.0 & 0.0 & 0.0 & 0.0 & 0.0 & 0.0 & 0.0 & 1.5 & 5.5 & 26.1 \\
\hline abr. $1-10$ & 0.0 & 0.0 & 0.0 & 0.0 & 0.0 & 0.0 & 0.0 & 0.0 & 0.0 & 5.8 & 30.5 \\
\hline $11-20$ & 0.0 & 0.0 & 0.0 & 0.0 & 0.0 & 0.0 & 0.0 & 0.0 & 1.7 & 19.2 & 25.2 \\
\hline $21-30$ & 0.0 & 0.0 & 0.0 & 0.0 & 0.0 & 0.0 & 0.0 & 3.2 & 11.8 & 14.3 & 27.3 \\
\hline $\operatorname{mad}, 1-10$ & 0.0 & 0.0 & 0.0 & 0.0 & 0.0 & 0.0 & 0.0 & 6.5 & 10.8 & 20.3 & 25.8 \\
\hline $11-20$ & 0.0 & 0.0 & 0.0 & 0.0 & 0.0 & 0.0 & 4.5 & 13.8 & 18.0 & 20.2 & 21.8 \\
\hline $2 !-31$ & 0.0 & 0.0 & 0.0 & 0.0 & 0.0 & 0.0 & 1.1 & 12.6 & 19.4 & 22.2 & 22.8 \\
\hline jun. $1-10$ & 0.0 & 0.0 & 0.0 & 0.0 & 0.0 & 2.6 & 5.4 & 17.5 & 19.7 & 20.8 & 24.8 \\
\hline $11-20$ & 0.0 & 0.0 & 0.0 & 0.0 & 6.1 & 8.9 & 12.0 & 16.5 & 20.9 & 22.6 & 24.1 \\
\hline $21-30$ & 0.0 & 0.0 & 0.0 & 1.9 & 8.8 & 13.1 & 14.7 & 20.6 & 21.5 & 22.5 & 24.7 \\
\hline jul. $1-10$ & 0.0 & 0.0 & 0.0 & 0.0 & 12.0 & 17.8 & 21.2 & 21.8 & 22.8 & 23.8 & 26.0 \\
\hline $11-20$ & 0.0 & 0.0 & 0.0 & 4.7 & 14.3 & 19.9 & 21.6 & 22.9 & 24.0 & 25.4 & 27.0 \\
\hline $21-31$ & 0.0 & 0.0 & 0.0 & 5.6 & 14.3 & 22.9 & 24.0 & 25.6 & 27.5 & 28.5 & 30.9 \\
\hline $290.1-10$ & 0.0 & 0.0 & 4.5 & 8.0 & 17.2 & $21 \times 2$ & 24.6 & 25.7 & 27.3 & 27.8 & 29.7 \\
\hline $11-20$ & 0.0 & 0.0 & 11.6 & 20.0 & 23.0 & 24.9 & 25.9 & 26.9 & 28.4 & 29.5 & 33.6 \\
\hline $21-31$ & 0.0 & 0.0 & 5.4 & 8.9 & 24.0 & 29.8 & 31.8 & 32.6 & 35.1 & 35.4 & 38.8 \\
\hline set: $1-10$ & 0.0 & 0.0 & 0.0 & 0.0 & 8.8 & 21.1 & 26.7 & $2 \mathrm{~B} .2$ & 31.8 & 33.5 & 41.8 \\
\hline $11-20$ & 0.0 & 0.0 & 0.0 & 0.3 & 3.2 & 23.9 & 20.4 & 33.4 & 36.2 & 38.5 & 41.8 \\
\hline $21-30$ & 0.0 & 0.0 & 0.0 & 0.0 & 0.0 & 4.8 & 11.3 & 21.3 & 25.9 & 33.5 & 37.6 \\
\hline out. $1-10$ & 0.0 & 0.0 & 0.0 & 0.0 & 0.0 & 0.0 & 0.0 & 11.3 & 33.0 & 37.6 & 47.2 \\
\hline $11-20$ & 0.0 & 0.0 & 0.0 & 0.0 & 0.0 & 0.0 & 0.0 & 3.4 & 20.2 & 27.6 & 49.4 \\
\hline $21-31$ & 0.0 & 0.0 & 0.0 & 0.0 & 0.0 & 0.0 & 0.0 & 0.0 & 0.0 & 4.3 & 48.2 \\
\hline nov $1-10$ & 0.0 & 0.0 & 0.0 & 0.0 & 0.0 & 0.0 & 0.0 & 0.0 & 0.0 & 4.2 & 30.4 \\
\hline $11-20$ & 0.0 & 0.0 & 0.0 & 0.0 & 0.0 & 0.0 & 0.0 & 0.0 & 0.0 & 0.6 & 35.8 \\
\hline $21-30$ & 0.0 & 0.0 & 0.0 & 0.0 & 0.0 & 0.0 & 0.0 & 0.0 & 0.0 & 9.1 & 17.2 \\
\hline dez. $1-10$ & 0.0 & 0.0 & 0.0 & 0.0 & 0.0 & 0.0 & 0.0 & 0.0 & 0.0 & 0.0 & 9.0 \\
\hline $11-20$ & 0.0 & 0.0 & 0.0 & 0.0 & 0.0 & 0.0 & 0.0 & 0.0 & 0.0 & 0.0 & 6.2 \\
\hline $21-31$ & 0.0 & 0.0 & 0.0 & 0.0 & 0.0 & 0.0 & 0.0 & 0.0 & 0.0 & 0.0 & 42.5 \\
\hline
\end{tabular}


TABELA 64 - RIDEIRAO PRETO: EXCEDEHTES HIDRICOS (EALANCO COH AFD $=30$ 镂)

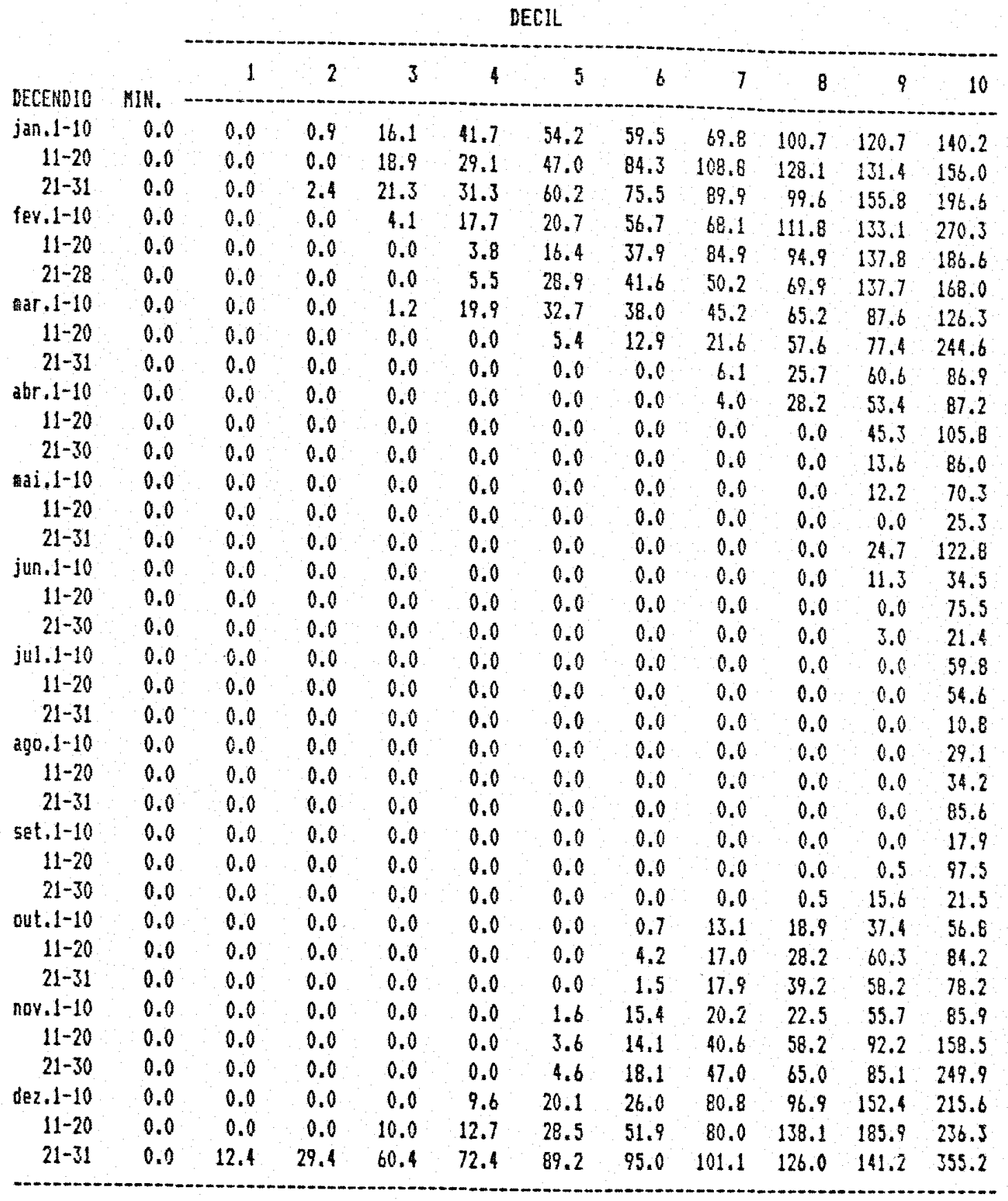


TABELA 65 - RIBEIRAO FRETO: AGUA FACILMENTE DISPONIVEL (BALANCO COM AFD $=40$ a

DECIL

\begin{tabular}{|c|c|c|c|c|c|c|c|c|c|c|c|}
\hline DECENDIO & HIN. & 1 & 2 & 3 & 4 & 5 & 6 & 7 & 8 & 9 & 10 \\
\hline jan. $1-10$ & 3.2 & 28.7 & 40.0 & 40.0 & 40.0 & 40.0 & 40.0 & 40.0 & 40.0 & 40.0 & 40.0 \\
\hline $11-20$ & 0.0 & 12.9 & 27.3 & 40.0 & 40.0 & 40.0 & 40.0 & 40.0 & 40.0 & 40.0 & 40.0 \\
\hline $21-31$ & 0.1 & 18.1 & 40.0 & 40.0 & 40.0 & 40.0 & 40.0 & 40.0 & 40.0 & 10.0 & 40.0 \\
\hline fer. $1-10$ & 0.0 & 16.5 & 35.3 & 40.0 & 40.0 & 40.0 & 40.0 & 40.0 & 40.0 & 40.0 & 40.0 \\
\hline $11-20$ & 0.0 & 6.6 & 21.3 & 32.4 & 40.0 & 40.0 & 40.0 & 40.0 & 40.0 & 40.0 & 40.0 \\
\hline $21-28$ & 0.0 & 15.4 & 28.7 & 36.5 & 40.0 & 40.0 & 40.0 & 40.0 & 40.0 & 40.0 & 40.0 \\
\hline ar $1-10$ & 12.2 & 18.6 & 22.5 & 40.0 & 40.0 & 40.0 & 40.0 & 40.0 & 40.0 & 40.0 & 40.0 \\
\hline $11-20$ & 0.0 & 0.0 & 8.4 & 28.7 & 34.5 & 40.0 & 80.0 & 40.0 & 40.0 & 40.0 & 40.0 \\
\hline $21-31$ & 0.0 & 1.7 & 5.0 & 11.8 & 19.6 & 27.2 & 29.2 & 40.0 & 80.0 & 40.0 & 40.0 \\
\hline $2 b r .1-10$ & 0.0 & 0.0 & 9.6 & 17.3 & 18.4 & 25.2 & 35.0 & 40.0 & 40.0 & 40.0 & 40.0 \\
\hline $11-20$ & 0.0 & 0.0 & 0.0 & 10.6 & 15.2 & 16.4 & 19.3 & 24.5 & 33.9 & 40.0 & 40.0 \\
\hline $21-30$ & 0.0 & 0.0 & 0.0 & 5.1 & 8.4 & 13.8 & 17.7 & 19.6 & 33.0 & 40.0 & 40.0 \\
\hline a. $1-10$ & 0.0 & 0.0 & 0.0 & 0.0 & 4.7 & 15.6 & 22.0 & 24.3 & 28.7 & 40.0 & 40.0 \\
\hline $11-20$ & 0.0 & 0.0 & 0.0 & 0.0 & 0.0 & 8.9 & 20.8 & 27.1 & 29.9 & 36.7 & 40.0 \\
\hline $21-31$ & 0.0 & 0.0 & 0.0 & 0.0 & 0.0 & 8.8 & 14.5 & 25.1 & 38.2 & 40.0 & 40.0 \\
\hline jun. 1-10 & 0.0 & 0.0 & 0.0 & 0.0 & 0.0 & 4.0 & 7.0 & 16.7 & 28.8 & 40.0 & 50.0 \\
\hline $11-20$ & 0.0 & 0.0 & 0.0 & 0.0 & 0.0 & 0.0 & 0.0 & 11.1 & 20.5 & 28.0 & 40.0 \\
\hline $21-30$ & 0.0 & 0.0 & 0.0 & 0.0 & 0.0 & 0.0 & 0.0 & 0.6 & 19.2 & 33.0 & 40.0 \\
\hline jul.1-10 & 0.0 & 0.0 & 0.0 & 0.0 & 0.0 & 0.0 & 0.0 & 7.4 & 13.8 & 19.9 & 40.0 \\
\hline $11-20$ & 0.0 & 0.0 & 0.0 & 0.0 & 0.0 & 0.0 & 0.0 & 0.0 & 18.8 & 24.6 & 60.0 \\
\hline $21-31$ & 0.0 & 0.0 & 0.0 & 0.0 & 0.0 & 0.0 & 0.0 & 0.0 & 5.8 & 19.2 & 40.0 \\
\hline ago. $1-10$ & 0.0 & 0.0 & 0.0 & 0.0 & 0.0 & 0.0 & 0.0 & 0.0 & 0.0 & 10.3 & 40.0 \\
\hline $11-20$ & 0.0 & 0.0 & 0.0 & 0.0 & 0.0 & 0.0 & 0.0 & 0.0 & 0.0 & 0.0 & 40.0 \\
\hline $21-31$ & 0.0 & 0.0 & 0.0 & 0.0 & 0.0 & 0.0 & 0.0 & 0.0 & 0.0 & 6.0 & 40.0 \\
\hline set. $1-10$ & 0.0 & 0.0 & 0.0 & 0.0 & 0.0 & 0.0 & 0.0 & 0.0 & 12.7 & 17.7 & 40.0 \\
\hline $11-20$ & 0.0 & 0.0 & 0.0 & 0.0 & 0.0 & 0.0 & 0.0 & 0.0 & 11.9 & 30.5 & 40.0 \\
\hline $21-30$ & 0.0 & 0.0 & 0.0 & 0.0 & 0.0 & 0.0 & 0.0 & 8.6 & 30.8 & 40.0 & 10.0 \\
\hline out. $1-10$ & 0.0 & 0.0 & 0.0 & 0.0 & 0.0 & 24.4 & 30.7 & 40.0 & 40.0 & 40.0 & 60.0 \\
\hline $11-20$ & 0.0 & 0.0 & 0.0 & 0.0 & 0.8 & 21.9 & 40.0 & 40.0 & 80.0 & 40.0 & 40.0 \\
\hline $21-31$ & 0.0 & 0.0 & 5.7 & 12.2 & 16.3 & 27.1 & 40.0 & 40.0 & 40.0 & 40.0 & 80.0 \\
\hline nov. $1-10$ & 0.0 & 0.0 & 17.8 & 27.8 & 36.1 & 40.0 & 40.0 & 40.0 & 40.0 & 40.0 & 40.0 \\
\hline $11-20$ & 0.0 & 8.7 & 13.5 & 21.5 & 31.2 & 40.0 & 40.0 & 40.0 & 40.0 & 40.0 & 50.0 \\
\hline $21-30$ & 0.0 & 0.0 & 11.0 & 19.3 & 29.3 & 40.0 & 40.0 & 40.0 & 40.0 & 40.0 & 40.0 \\
\hline dez. $1-10$ & 1.0 & 20.9 & 27.9 & 36.7 & 40.0 & 40.0 & 40.0 & 80.0 & 40.0 & 40.0 & 40.0 \\
\hline $11-20$ & 0.0 & 6.9 & 29.1 & 40.0 & 40.0 & 60.0 & 40.0 & 40.0 & 40.0 & 40.0 & 40.0 \\
\hline $21-31$ & 0.0 & 40.0 & 40.0 & 40.0 & 40.0 & 40.0 & 40.0 & 60.0 & 10.0 & 40.0 & 10.0 \\
\hline
\end{tabular}


TABELA 66 - RIBEIRAO FRETO: DEFICITES (BALANCO COM AFD $=40$ AR)

DECIL

\begin{tabular}{|c|c|c|c|c|c|c|c|c|c|c|c|}
\hline DECENDID & MIN. & 1 & 2 & 3 & 4 & 5 & 6 & 7 & $B$ & 9 & 10 \\
\hline$j a n \cdot 1-10$ & 0.0 & 0.0 & 0.0 & 0.0 & 0.0 & 0.0 & 0.0 & 0.0 & 0.0 & 0.0 & 0.0 \\
\hline $11-20$ & 0.0 & 0.0 & 0.0 & 0.0 & 0.0 & 0.0 & 0.0 & 0.0 & 0.0 & 0.0 & 24.4 \\
\hline $21-31$ & 0.0 & 0.0 & 0.0 & 0.0 & 0.0 & 0.0 & 0.0 & 0.0 & 0.0 & 0.0 & 0.0 \\
\hline fev.l-10 & 0.0 & 0.0 & 0.0 & 0.0 & 0.0 & 0.0 & 0.0 & 0.0 & 0.0 & 0.0 & 15.9 \\
\hline $11-20$ & 0.0 & 0.0 & 0.0 & 0.0 & 0.0 & 0.0 & 0.0 & 0.0 & 0.0 & 0.0 & 2.2 \\
\hline $21-28$ & 0.0 & 0.0 & 0.0 & 0.0 & 0.0 & 0.0 & 0.0 & 0.0 & 0.0 & 0.0 & 14.9 \\
\hline $\operatorname{mat} .1-10$ & 0.0 & 0.0 & 0.0 & 0.0 & 0.0 & 0.0 & 0.0 & 0.0 & 0.0 & 0.0 & 0.0 \\
\hline $11-20$ & 0.0 & 0.0 & 0.0 & 0.0 & 0.0 & 0.0 & 0.0 & 0.0 & 0.0 & 0.0 & 16.6 \\
\hline $21-31$ & 0.0 & 0.0 & 0.0 & 0.0 & 0.0 & 0.0 & 0.0 & 0.0 & 0.0 & 0.0 & 26.1 \\
\hline$a b r .1-10$ & 0.0 & 0.0 & 0.0 & 0.0 & 0.0 & 0.0 & 0.0 & 0.0 & 0.0 & 0.0 & 30.5 \\
\hline $11-20$ & 0.0 & 0.0 & 0.0 & 0.0 & 0.0 & 0.0 & 0.0 & 0.0 & 0.0 & 19.2 & 25.2 \\
\hline $21-30$ & 0.0 & 0.0 & 0.0 & 0.0 & 0.0 & 0.0 & 0.0 & 0.0 & 3.0 & 11.8 & 27.3 \\
\hline ai. $1-10$ & 0.0 & 0.0 & 0.0 & 0.0 & 0.0 & 0.0 & 0.0 & 0.0 & 5.9 & 18.6 & 25.8 \\
\hline $11-20$ & 0.0 & 0.0 & 0.0 & 0.0 & 0.0 & 0.0 & 0.6 & 9.2 & 12.9 & 19.8 & 21.8 \\
\hline $21-31$ & 0.0 & 0.0 & 0.0 & 0.0 & 0.0 & 0.0 & 0.0 & 10.8 & 19.3 & 22.2 & 22.8 \\
\hline jun. $1-10$ & 0.0 & 0.0 & 0.0 & 0.0 & 0.0 & 0.0 & 4.8 & 10.0 & 14.7 & 20.1 & 24.8 \\
\hline $11-20$ & 0.0 & 0.0 & 0.0 & 0.0 & 1.0 & 3.5 & 9.7 & 15.2 & 20.3 & 22.0 & 24.1 \\
\hline $21-30$ & 0.0 & 0.0 & 0.0 & 0.0 & 1.9 & 3.3 & 14.7 & 20.6 & 21.5 & 22.5 & 24.7 \\
\hline jul.1-10 & 0.0 & 0.0 & 0.0 & 0.0 & 2.0 & 16.9 & 20.5 & 21.3 & 22.8 & 23.6 & 25.6 \\
\hline $11-20$ & 0.0 & 0.0 & 0.0 & 2.4 & 14.0 & 15.5 & 20.8 & 22.5 & 24.0 & 25.4 & 27.0 \\
\hline $21-31$ & 0.0 & 0.0 & 0.0 & 0.0 & 11.3 & 22.9 & 24.0 & 25.6 & 27.5 & 28.5 & 30.9 \\
\hline $2 g 0.1-10$ & 0.0 & 0.0 & 4.5 & 6.4 & 16.3 & 21.0 & 24.6 & 25.7 & 27.3 & 27.8 & 29.7 \\
\hline $11-20$ & 0.0 & 0.0 & 11.3 & 18.1 & 23.0 & 24.9 & 25.9 & 26.9 & 28.4 & 29.5 & 33.6 \\
\hline $21-31$ & 0.0 & 0.0 & 1.9 & 8.9 & 24.0 & 29.8 & 31.8 & 32.6 & 35.1 & 35.4 & 38.8 \\
\hline set. $1-10$ & 0.0 & 0.0 & 0.0 & 0.0 & 8.8 & 18.8 & 26.7 & 28.2 & 31.8 & 33.5 & 41.8 \\
\hline $11-20$ & 0.0 & 0.0 & 0.0 & 0.0 & 3.2 & 21.0 & 28.4 & 33.4 & 36.2 & 38.5 & 41.8 \\
\hline $21-30$ & 0.0 & 0.0 & 0.0 & 0.0 & 0.0 & 3.4 & 9.8 & 21.3 & 25.9 & 33.5 & 37.6 \\
\hline out.1-10 & 0.0 & 0.0 & 0.0 & 0.0 & 0.0 & 0.0 & 0.0 & 11.3 & 32.5 & 37.6 & 47.2 \\
\hline $11-20$ & 0.0 & 0.0 & 0.0 & 0.0 & 0.0 & 0.0 & 0.0 & 3.4 & 16.7 & 27.6 & 89.4 \\
\hline $21-31$ & 0.0 & 0.0 & 0.0 & 0.0 & 0.0 & 0.0 & 0.0 & 0.0 & 0.0 & 0.0 & 47.4 \\
\hline nov. $1-10$ & 0.0 & 0.0 & 0.0 & 0.0 & 0.0 & 0.0 & 0.0 & 0.0 & 0.0 & 0.1 & 30.4 \\
\hline $11-20$ & 0.0 & 0.0 & 0.0 & 0.0 & 0.0 & 0.0 & 0.0 & 0.0 & 0.0 & 0.0 & 35.8 \\
\hline $21-30$ & 0.0 & 0.0 & 0.0 & 0.0 & 0.0 & 0.0 & 0.0 & 0.0 & 0.0 & 0.0 & 7.2 \\
\hline dez.1-10 & 0.0 & 0.0 & 0.0 & 0.0 & 0.0 & 0.0 & 0.0 & 0.0 & 0.0 & 0.0 & 0.0 \\
\hline $11-20$ & 0.0 & 0.0 & 0.0 & 0.0 & 0.0 & 0.0 & 0.0 & 0.0 & 0.0 & 0.0 & 0.8 \\
\hline $21-31$ & 0.0 & 0.0 & 0.0 & 0.0 & 0.0 & 0.0 & 0.0 & 0.0 & 0.0 & 0.0 & 36.7 \\
\hline
\end{tabular}


TABELA 67 - RIBEIRAO PRETD: EXCERENTES HIDRICOS (BALAHCO COF AFD = 40 年位)

DECIL

\begin{tabular}{|c|c|c|c|c|c|c|c|c|c|c|c|}
\hline DECENDIO & MIN. & 1 & 2 & 3 & 4 & 5 & 6 & 7 & 8 & 9 & 10 \\
\hline jan.1-10 & 0.0 & 0.0 & 0.9 & 16.1 & 41.7 & 54.2 & 59.5 & 69.8 & 100.7 & 120.7 & 140.2 \\
\hline $11-20$ & 0.0 & 0.0 & 0.0 & 18.9 & 29.1 & 47.0 & 84.3 & 100.8 & 128.1 & 131.4 & 156.0 \\
\hline $21-31$ & 0.0 & 0.0 & 2.4 & 21.3 & 31.3 & 56.3 & 75.5 & 89.9 & 99.6 & 155.8 & 186.6 \\
\hline fev. $1-10$ & 0.0 & 0.0 & 0.0 & 4.1 & 10.1 & 20.7 & 56.7 & 68.1 & 111.8 & 133.1 & 270.3 \\
\hline $11-20$ & 0.0 & 0.0 & 0.0 & 0.0 & 3.8 & 16.4 & 37.9 & 84.9 & 94.9 & 137.8 & 186.6 \\
\hline $21-28$ & 0.0 & 0.0 & 0.0 & 0.0 & 5.5 & 28.9 & 40.2 & 49.5 & 69.9 & 137.7 & 168.0 \\
\hline $\operatorname{ar} .1-10$ & 0.0 & 0.0 & 0.0 & 1.2 & 19.9 & 32.7 & 37.3 & 43.0 & 65.2 & 84.2 & 126.3 \\
\hline $11-20$ & 0.0 & 0.0 & 0.0 & 0.0 & 0.0 & 5.6 & 12.9 & 21.6 & 57.6 & 77.4 & 244.6 \\
\hline $21-31$ & 0.0 & 0.0 & 0.0 & 0.0 & 0.0 & 0.0 & 0.0 & 6.1 & 25.7 & 60.6 & 86.9 \\
\hline abr. $1-10$ & 0.0 & 0.0 & 0.0 & 0.0 & 0.0 & 0.0 & 0.0 & 4.0 & 28.2 & 50.9 & 87.2 \\
\hline $11-20$ & 0.0 & 0.0 & 0.0 & 0.0 & 0.0 & 0.0 & 0.0 & 0.0 & 0.0 & 44.6 & 105.8 \\
\hline $21-30$ & 0.0 & 0.0 & 0.0 & 0.0 & 0.0 & 0.0 & 0.0 & 0.0 & 0.0 & 3.6 & 86.0 \\
\hline a $i .1-10$ & 0.0 & 0.0 & 0.0 & 0.0 & 0.0 & 0.0 & 0.0 & 0.0 & 0.0 & 3.9 & 70.3 \\
\hline $11-20$ & 0.0 & 0.0 & 0.0 & 0.0 & 0.0 & 0.0 & 0.0 & 0.0 & 0.0 & 0.0 & 22.1 \\
\hline $21-31$ & 0.0 & 0.0 & 0.0 & 0.0 & 0.0 & 0.0 & 0.0 & 0.0 & 0.0 & 24.7 & 122.8 \\
\hline jun.1-10 & 0.0 & 0.0 & 0.0 & 0.0 & 0.0 & 0.0 & 0.0 & 0.0 & 0.0 & 11.3 & 34.5 \\
\hline $11-20$ & 0.0 & 0.0 & 0.0 & 0.0 & 0.0 & 0.0 & 0.0 & 0.0 & 0.0 & 0.0 & 65.5 \\
\hline $21-30$ & 0.0 & 0.0 & 0.0 & 0.0 & 0.0 & 0.0 & 0.0 & 0.0 & 0.0 & 0.0 & 11.4 \\
\hline jul. $1-10$ & 0.0 & 0.0 & 0.0 & 0.0 & 0.0 & 0.0 & 0.0 & 0.0 & 0.0 & 0.0 & 49.8 \\
\hline $11-20$ & 0.0 & 0.0 & 0.0 & 0.0 & 0.0 & 0.0. & 0.0 & 0.0 & 0.0 & 0.0 & 44.6 \\
\hline $21-31$ & 0.0 & 0.0 & 0.0 & 0.0 & 0.0 & 0.0 & 0.0 & 0.0 & 0.0 & 0.0 & 0.8 \\
\hline $290.1-10$ & 0.0 & 0.0 & 0.0 & 0.0 & 0.0 & 0.0 & 0.0 & 0.0 & 0.0 & 0.0 & 29.1 \\
\hline $11-20$ & 0.0 & 0.0 & 0.0 & 0.0 & 0.0 & 0.0 & 0.0 & 0.0 & 0.0 & 0.0 & 24.2 \\
\hline $21-31$ & 0.0 & 0.0 & 0.0 & 0.0 & 0.0 & 0.0 & 0.0 & 0.0 & 0.0 & 0.0 & 79.0 \\
\hline set. $1-10$ & 0.0 & 0.0 & 0.0 & 0.0 & 0.0 & 0.0 & 0.0 & 0.0 & 0.0 & 0.0 & 7.9 \\
\hline $11-20$ & 0.0 & 0.0 & 0.0 & 0.0 & 0.0 & 0.0 & 0.0 & 0.0 & 0.0 & 0.0 & 97.5 \\
\hline $21-30$ & 0.0 & 0.0 & 0.0 & 0.0 & 0.0 & 0.0 & 0.0 & 0.0 & 0.0 & 5.6 & 21.5 \\
\hline out. $1-10$ & 0.0 & 0.0 & 0.0 & 0.0 & 0.0 & 0.0 & 0.0 & 4.6 & 17.0 & 27.9 & 56.8 \\
\hline $11-20$ & 0.0 & 0.0 & 0.0 & 0.0 & 0.0 & 0.0 & 1.2 & 11.2 & 20.5 & 60.3 & 84.2 \\
\hline $21-31$ & 0.0 & 0.0 & 0.0 & 0.0 & 0.0 & 0.0 & 1.5 & 17.9 & 39.2 & 48.2 & 78.2 \\
\hline nov. $1-10$ & 0.0 & 0.0 & 0.0 & 0.0 & 0.0 & 1.6 & 12.0 & 12.6 & 18.9 & 55.7 & 75.9 \\
\hline $11-20$ & 0.0 & 0.0 & 0.0 & 0.0 & 0.0 & 3.6 & 14.1 & 30.6 & $\$ 8.2$ & 92.2 & 158.5 \\
\hline $21-30$ & 0.0 & 0.0 & 0.0 & 0.0 & 0.0 & 4.6 & 17.5 & 46.8 & 55.3 & 85.1 & 249.9 \\
\hline $\operatorname{dez} .1-10$ & 0.0 & 0.0 & 0.0 & 0.0 & 9.6 & 14.1 & 26.0 & 79.7 & 96.9 & 152.4 & 215.6 \\
\hline $11-20$ & 0.0 & 0.0 & 0.0 & 10.0 & 12.7 & 28.5 & 51.9 & 80.0 & 138.1 & 185.9 & 227.3 \\
\hline $21-31$ & 0.0 & 2.9 & 29.4 & 60.4 & 72.4 & 89.2 & 95.0 & 101.1 & 126.0 & 141.2 & 355.2 \\
\hline
\end{tabular}


TABELA 68 - RIBEIRAO PRETD: SGUA FACILHENTE DISPONIVEL (BALANCD COH AFD $=50$ an)

DECIL

\begin{tabular}{|c|c|c|c|c|c|c|c|c|c|c|c|}
\hline & & 1 & 2 & 3 & 4 & 5 & 6 & 7 & 8 & 9 & 10 \\
\hline jan. $1-10$ & 3.2 & 38.7 & 50.0 & 50.0 & 50.0 & 50.0 & 50.0 & 50.0 & 50.0 & 50.0 & 50.0 \\
\hline $11-20$ & 0.0 & 22.9 & 37.3 & 50.0 & 50.0 & 50.0 & 50.0 & 50.0 & 50.0 & 50.0 & 50.0 \\
\hline $21-31$ & 10.1 & 28.1 & 50.0 & 50.0 & 50.0 & 50.0 & 50.0 & 50.0 & 50.0 & 50.0 & 50.0 \\
\hline fev. $1-10$ & 0.0 & 26.5 & 44.3 & 50.0 & 50.0 & 50.0 & 50.0 & 50.0 & 50.0 & 50.0 & 50.0 \\
\hline $11-20$ & 0.0 & 16.3 & 31.3 & 42.4 & 50.0 & 50.0 & 50.0 & 50.0 & 50.0 & 50.0 & 50.0 \\
\hline $21-28$ & 0.0 & 25.4 & 38.7 & 46.5 & 50.0 & 50.0 & 50.0 & 50.0 & 50.0 & 50.0 & 50.0 \\
\hline tar. $1-10$ & 20.1 & 26.4 & 32.5 & 50.0 & 50.0 & 50.0 & 50.0 & 50.0 & 50.0 & 50.0 & 50.0 \\
\hline $11-20$ & 0.0 & 3.7 & 18.4 & 38.7 & 44.5 & 50.0 & 50.0 & 50.0 & 50.0 & 50.0 & 50.0 \\
\hline $21-31$ & 0.0 & 11.7 & 15.0 & 21.8 & 29.6 & 34.7 & 37.4 & 50.0 & 50.0 & 50.0 & 50.0 \\
\hline $\mathrm{abr}=1-10$ & 0.0 & 8.1 & 18.4 & 26.8 & 27.7 & 35.2 & 45.0 & 50.0 & 50.0 & 50.0 & 50.0 \\
\hline $11-20$ & 0.0 & 0.0 & 8.7 & 20.6 & 25.2 & 26.4 & 29.3 & 34.5 & 43.9 & 50.0 & 50.0 \\
\hline $21-30$ & 0.0 & 0.0 & 4.0 & 15.1 & 18.4 & 23.8 & 27.7 & 29.6 & 43.0 & 50.0 & 50.0 \\
\hline 1. $21.1-10$ & 0.0 & 0.0 & 0.0 & 9.2 & 14.7 & 22.0 & 28.1 & 34.3 & 38.7 & 50.0 & 50.0 \\
\hline $11-20$ & 0.0 & 0.0 & 0.0 & 0.0 & 6.2 & 18.9 & 29.9 & 34.9 & 39.7 & 46.7 & 50.0 \\
\hline $21-31$ & 0.0 & 0.0 & 0.0 & 0.0 & 0.0 & 16.3 & 22.3 & 35.1 & 43.8 & 50.0 & 50.0 \\
\hline jun. $1-10$ & 0.0 & 0.0 & 0.0 & 0.0 & 0.0 & 4.0 & 17.0 & 26.7 & 31.0 & 50.0 & 50.0 \\
\hline $11-20$ & 0.0 & 0.0 & 0.0 & 0.0 & 0.0 & 0.0 & 8.1 & 21.1 & 29.4 & 32.5 & 50.0 \\
\hline $21-30$ & 0.0 & 0.0 & 0.0 & 0.0 & 0.0 & 0.0 & 6.7 & 10.6 & 19.7 & 33,0 & 50.0 \\
\hline ju1.1-10 & 0.0 & 0.0 & 0.0 & 0.0 & 0.0 & 0.0 & 0.0 & 12.8 & 16.0 & 29.9 & 50.0 \\
\hline $11-20$ & 0.0 & 0.0 & 0.0 & 0.0 & 0.0 & 0.0 & 0.0 & 0.0 & 24.6 & 28.8 & 50.0 \\
\hline $21-31$ & 0.0 & 0.0 & 0.0 & 0.0 & 0.0 & 0.0 & 0.0 & 2.5 & 15.8 & 19.2 & 40.8 \\
\hline 200.1-10 & 0.0 & 0.0 & 0.0 & 0.0 & 0.0 & 0.0 & 0.0 & 0.0 & 0.0 & 10.3 & 50.0 \\
\hline $11-20$ & 0.0 & 0.0 & 0.0 & 0.0 & 0.0 & 0.0 & 0.0 & 0.0 & 0.0 & 0.0 & 50.0 \\
\hline $21-31$ & 0.0 & 0.0 & 0.0 & 0.0 & 0.0 & 0.0 & 0.0 & 0.0 & 0.0 & 16.6 & 50.0 \\
\hline set. $1-10$ & 0.0 & 0.0 & 0.0 & 0.0 & 0.0 & 0.0 & 0.0 & 0.0 & 16.4 & 26.1 & 47.9 \\
\hline $11-20$ & 0.0 & 0.0 & 0.0 & 0.0 & 0.0 & 0.0 & 0.0 & 0.0 & 11.9 & 30.5 & 50.0 \\
\hline $21-30$ & 0.0 & 0.0 & 0.0 & 0.0 & 0.0 & 0.0 & 0.0 & $B .6$ & 30.8 & 47.0 & 50.0 \\
\hline out. $1-10$ & 0.0 & 0.0 & 0.0 & 0.0 & 0.0 & 24.4 & 30.7 & 44.6 & 50.0 & 50.0 & 50.0 \\
\hline $11-20$ & 0.0 & 0.0 & 0.0 & 0.0 & 0.8 & 25.5 & 48.8 & 50.0 & 50.0 & 50.0 & 50.0 \\
\hline $2 t-31$ & 0.0 & 3.0 & 12.1 & 15.7 & 25.2 & 27.7 & 45.3 & 50.0 & 50.0 & 50.0 & 50.0 \\
\hline nov. $1-10$ & 0.0 & 0.0 & 19.8 & 33.4 & 45.4 & 50.0 & 50.0 & 50.0 & 50.0 & 50.0 & 50.0 \\
\hline $11-20$ & 0.0 & 18.7 & 23.5 & 26.3 & 41.2 & 50.0 & 50.0 & 50.0 & 50.0 & 50.0 & 50.0 \\
\hline $21-30$ & 2.8 & 5.0 & 21.0 & 29.3 & 39.3 & 50.0 & 50.0 & 50.0 & 50.0 & 50.0 & 50.0 \\
\hline dez. $1-10$ & 11.0 & 30.9 & 37.9 & 46.7 & 50.0 & 50.0 & 50.0 & 50.0 & 50.0 & 50.0 & 50.0 \\
\hline $11-20$ & 9.2 & 16.9 & 39.1 & 50.0 & 50.0 & 50.0 & 50.0 & 50.0 & 50.0 & 50.0 & 50.0 \\
\hline $21-31$ & 0.0 & 50.0 & 50.0 & 50.0 & 50.0 & 50.0 & 50.0 & 50.0 & 50.0 & 50.0 & 50.0 \\
\hline
\end{tabular}


TABELA 69 - RIBEIRAO PAETO: DEFICITES (BALANCO CON AFD = 50 ER)

\begin{tabular}{|c|c|c|c|c|c|c|c|c|c|c|c|}
\hline DECEKDIO & MIN. & 1 & 2 & 3 & 4 & 5 & 6 & 7 & 8 & 9 & 10 \\
\hline jan. 1-10 & 0.0 & 0.0 & 0.0 & 0.0 & 0.0 & 0.0 & 0.0 & 0.0 & 0.0 & 0.0 & 0.0 \\
\hline $11-20$ & 0.0 & 0.0 & 0.0 & 0.0 & 0.0 & 0.0 & 0.0 & 0.0 & 0.0 & 0.0 & 14.4 \\
\hline $21-31$ & 0.0 & 0.0 & 0.0 & 0.0 & 0.0 & 0.0 & 0.0 & 0.0 & 0.0 & 0.0 & 0.0 \\
\hline fev. $1-10$ & 0.0 & 0.0 & 0.0 & 0.0 & 0.0 & 0.0 & 0.0 & 0.0 & 0.0 & 0.0 & 5.9 \\
\hline $11-20$ & 0.0 & 0.0 & 0.0 & 0.0 & 0.0 & 0.0 & 0.0 & 0.0 & 0.0 & 0.0 & 2.2 \\
\hline $21-28$ & 0.0 & 0.0 & 0.0 & 0.0 & 0.0 & 0.0 & 0.0 & 0.0 & 0.0 & 0.0 & 4.8 \\
\hline mar. $1-10$ & 0.0 & 0.0 & 0.0 & 0.0 & 0.0 & 0.0 & 0.0 & 0.0 & 0.0 & 0.0 & 0.0 \\
\hline $11-20$ & 0.0 & 0.0 & 0.0 & 0.0 & 0.0 & 0.0 & 0.0 & 0.0 & 0.0 & 0.0 & 6.6 \\
\hline $21-31$ & 0.0 & 0.0 & 0.0 & 0.0 & 0.0 & 0.0 & 0.0 & 0.0 & 0.0 & 0.0 & 26.1 \\
\hline$a b r .1-10$ & 0.0 & 0.0 & 0.0 & 0.0 & 0.0 & 0.0 & 0.0 & 0.0 & 0.0 & 0.0 & 30.5 \\
\hline $11-20$ & 0.0 & 0.0 & 0.0 & 0.0 & 0.0 & 0.0 & 0.0 & 0.0 & 0.0 & 10.1 & 21.4 \\
\hline $21-30$ & 0.0 & 0.0 & 0.0 & 0.0 & 0.0 & 0.0 & 0.0 & 0.0 & 0.0 & 11.8 & 27.3 \\
\hline ad. $1-10$ & 0.0 & 0.0 & 0.0 & 0.0 & 0.0 & 0.0 & 0.0 & 0.0 & 3.0 & 13.0 & 25.8 \\
\hline $11-20$ & 0.0 & 0.0 & 0.0 & 0.0 & 0.0 & 0.0 & 0.0 & 0.5 & 7.2 & 18.0 & 21.8 \\
\hline $21-31$ & 0.0 & 0.0 & 0.0 & 0.0 & 0.0 & 0.0 & 0.0 & 3.2 & 18.1 & 20.3 & 22.8 \\
\hline jun. 1-10 & 0.0 & 0.0 & 0.0 & 0.0 & 0.0 & 0.0 & 0.0 & 2.0 & 5.4 & 20.1 & 24.8 \\
\hline $11-20$ & 0.0 & 0.0 & 0.0 & 0.0 & 0.0 & 0.0 & 6.5 & 11.2 & 20.3 & 22.0 & 24.1 \\
\hline $21-30$ & 0.0 & 0.0 & 0.0 & 0.0 & 0.0 & 1.9 & 8.8 & 17.0 & 20.9 & 22.5 & 24.7 \\
\hline jul.1-10 & 0.0 & 0.0 & 0.0 & 0.0 & 0.0 & 9.1 & 16.1 & 21.2 & 21.8 & 23.6 & 25.6 \\
\hline $11-20$ & 0.0 & 0.0 & 0.0 & 0.0 & 6.2 & 15.1 & 20.7 & 22.5 & 24.0 & 25.4 & 27.0 \\
\hline $21-3 \mid$ & 0.0 & 0.0 & 0.0 & 0.0 & 11.3 & .21 .4 & 23.4 & 25.1 & 27.5 & 28.5 & 30.9 \\
\hline $290.1-10$ & 0.0 & 0.0 & 1.4 & 5.1 & 16.3 & 21.0 & $24: 6$ & 25.7 & 27.3 & 27.8 & 29.7 \\
\hline $11-20$ & 0.0 & 0.0 & 11.2 & 18.1 & 23.0 & 24.9 & 25.9 & 26.9 & 28.4 & 29.5 & 33.6 \\
\hline $21-31$ & 0.0 & 0.0 & 1.9 & 8.9 & 24.0 & 29.8 & 31.8 & 32.6 & 35.1 & 35.4 & 38.8 \\
\hline set.1-10 & 0.0 & 0.0 & 0.0 & 0.0 & 8.8 & 16.9 & 26.7 & 28.2 & 31.8 & 33.5 & 41.8 \\
\hline $11-20$ & 0.0 & 0.0 & 0.0 & 0.0 & 3.2 & 21.0 & 28.4 & 33.4 & 36.2 & 38.5 & 41.8 \\
\hline $21-30$ & 0.0 & 0.0 & 0.0 & 0.0 & 0.0 & 2.8 & 9.8 & 21.3 & 25.9 & 33.5 & 37.6 \\
\hline out. $1-10$ & 0.0 & 0.0 & 0.0 & 0.0 & 0.0 & 0.0 & 0.0 & 11,3 & 32.5 & 37.6 & 47.2 \\
\hline II -20 & 0.0 & 0.0 & 0.0 & 0.0 & 0.0 & 0.0 & 0.0 & 3.4 & 16.7 & 27.6 & 49.5 \\
\hline $21-31$ & 0.0 & 0.0 & 0.0 & 0.0 & 0.0 & 0.0 & 0.0 & 0.0 & 0.0 & 0.0 & 97.6 \\
\hline nov. $1-10$ & 0.0 & 0.0 & 0.0 & 0.0 & 0.0 & 0.0 & 0.0 & 0.0 & 0.0 & 0.0 & 30.4 \\
\hline $11-20$ & 0.0 & 0.0 & 0.0 & 0.0 & 0.0 & 0.0 & 0.0 & 0.0 & 0.0 & 0.0 & 30.7 \\
\hline $21-30$ & 0.0 & 0.0 & 0.0 & 0.0 & 0.0 & 0.0 & 0.0 & 0.0 & 0.0 & 0.0 & 0.0 \\
\hline dez. $1-10$ & 0.0 & 0.0 & 0.0 & 0.0 & 0.0 & 0.0 & 0.0 & 0.0 & 0.0 & 0.0 & 0.0 \\
\hline $11-20$ & 0.0 & 0.0 & 0.0 & 0.0 & 0.0 & 0.0 & 0.0 & 0.0 & 0.0 & 0.0 & 0.0 \\
\hline $21-31$ & 0.0 & 0.0 & 0.0 & 0.0 & 0.0 & 0,0 & 0.0 & 0.0 & 0.0 & 0.0 & 26.7 \\
\hline
\end{tabular}


TABELA 70 - RIBEIRAO PRETO: EXCEDENTES HIDRICOS (BALAMCO COM AFD $=50$ aIE)

DECIL

\begin{tabular}{|c|c|c|c|c|c|c|c|c|c|c|c|}
\hline DECENDIO & MIN. & 1 & 2 & 3 & 4 & 5 & 6 & 7 & $B$ & 9 & 10 \\
\hline jan.1-10 & 0.0 & 0.0 & 0.9 & 16.1 & 41.7 & 54.2 & 59.5 & 69.8 & 100.7 & 120.7 & 140.2 \\
\hline $11-20$ & 0.0 & 0.0 & 0.0 & 18.9 & 29.1 & 47.0 & 84.3 & 108.8 & 128.1 & 131.4 & 156.0 \\
\hline $21-31$ & 0.0 & 0.0 & 2.4 & 21.3 & 31.3 & 56.3 & 75.5 & 89.9 & 99.6 & 155.8 & 176.6 \\
\hline fer. $1-10$ & 0.0 & 0.0 & 0.0 & 4.1 & 10.1 & 20.7 & 56.7 & 68.1 & 111.8 & 133.1 & 270.3 \\
\hline $11-20$ & 0.0 & 0.0 & 0.0 & 0.0 & 3.8 & 16.4 & 37.9 & 84.9 & 94.9 & 137.8 & 186.6 \\
\hline $21-28$ & 0.0 & 0.0 & 0.0 & 0.0 & 5.5 & 28.9 & 38.4 & 49.5 & 69.9 & 137.7 & 168.0 \\
\hline ar. $1-10$ & 0.0 & 0.0 & 0.0 & 1.2 & 19.9 & 27.4 & 37.3 & 43.0 & 65.2 & 84.2 & 126.3 \\
\hline $11-20$ & 0.0 & 0.0 & 0.0 & 0.0 & 0.0 & 5.4 & 12.9 & 21.6 & 49.9 & 77. & 244.6 \\
\hline $21-31$ & 0.0 & 0.0 & 0.0 & 0.0 & 0.0 & 0.0 & 0.0 & 6.1 & 25.7 & 60.6 & 86.9 \\
\hline$a b r \cdot 1-10$ & 0.0 & 0.0 & 0.0 & 0.0 & 0.0 & 0.0 & 0.0 & 4.0 & 28.2 & 50.9 & 87.2 \\
\hline $11-20$ & 0.0 & 0.0 & 0.0 & 0.0 & 0.0 & 0.0 & 0.0 & 0.0 & 0.0 & 34.6 & 105.8 \\
\hline $21-30$ & 0.0 & 0.0 & 0.0 & 0.0 & 0.0 & 0.0 & 0.0 & 0.0 & 0.0 & 2.3 & 86.0 \\
\hline aj. $1-10$ & 0.0 & 0.0 & 0.0 & 0.0 & 0.0 & 0.0 & 0.0 & 0.0 & 0.0 & 3.7 & 70.3 \\
\hline$\because 11-20$ & 0.0 & 0.0 & 0.0 & 0.0 & 0.0 & 0.0 & 0.0 & 0.0 & 0.0 & 0.0 & 22.1 \\
\hline $21-31$ & 0.0 & 0.0 & 0.0 & 0.0 & 0.0 & 0.0 & 0.0 & 0.0 & 0.0 & 24.7 & 122.6 \\
\hline jun. $1-10$ & 0.0 & 0.0 & 0.0 & 0.0 & 0.0 & 0.0 & 0.0 & 0.0 & 0.0 & 11.3 & 34.5 \\
\hline $11-20$ & 0.0 & 0.0 & 0.0 & 0.0 & 0.0 & 0.0 & 0.0 & 0.0 & 0.0 & 0.0 & 55.5 \\
\hline $21-30$ & 0.0 & 0.0 & 0.0 & 0.0 & 0.0 & 0.0 & 0.0 & 0.0 & 0.0 & 0.0 & 1.4 \\
\hline jul.1-10 & 0.0 & 0.0 & 0.0 & 0.0 & 0.0 & 0.0 & 0.0 & 0.0 & 0.0 & 0.0 & 46.6 \\
\hline $11-20$ & 0.0 & 0.0 & 0.0 & 0.0 & 0.0 & 0.0 & 0.0 & 0.0 & 0.0 & 0.0 & 34.6 \\
\hline $21-31$ & 0.0 & 0.0 & 0.0 & 0.0 & 0.0 & 0.0 & 0.0 & 0.0 & 0.0 & 0.0 & 0.0 \\
\hline ago. $1-10$ & 0.0 & 0.0 & 0.0 & 0.0 & 0.0 & 0.0 & 0.0 & 0.0 & 0.0 & 0.0 & 29.1 \\
\hline $11-20$ & 0.0 & 0.0 & 0.0 & 0.0 & 0.0 & 0.0 & 0.0 & 0.0 & 0.0 & 0.0 & 14.2 \\
\hline $21-31$ & 0.0 & 0.0 & 0.0 & 0.0 & 0.0 & 0.0 & 0.0 & 0.0 & 0.0 & 0.0 & 69.0 \\
\hline set. $1-10$ & 0.0 & 0.0 & 0.0 & 0.0 & 0.0 & 0.0 & 0.0 & 0.0 & 0.0 & 0.0 & 0.0 \\
\hline $11-20$ & 0.0 & 0.0 & 0.0 & 0.0 & 0.0 & 0.0 & 0.0 & 0.0 & 0.0 & 0.0 & 95.4 \\
\hline $21-30$ & 0.0 & 0.0 & 0.0 & 0.0 & 0.0 & 0.0 & 0.0 & 0.0 & 0.0 & 0.0 & 21.5 \\
\hline out. $1-10$ & 0.0 & 0.0 & 0.0 & 0.0 & 0.0 & 0.0 & 0.0 & 0.0 & 16.9 & 18.0 & 56.8 \\
\hline $11-20$ & 0.0 & 0.0 & 0.0 & 0.0 & 0.0 & 0.0 & 0.0 & 8.2 & 17.0 & 53.4 & 84.2 \\
\hline $21-31$ & 0.0 & 0.0 & 0.0 & 0.0 & 0.0 & 0.0 & 0.0 & 17.9 & 33.7 & 42.7 & 78.2 \\
\hline nov. $1-10$ & 0.0 & 0.0 & 0.0 & 0.0 & 0.0 & 0.2 & 2.0 & 12.6 & 18.9 & 55.7 & 73.1 \\
\hline $11-20$ & 0.0 & 0.0 & 0.0 & 0.0 & 0.0 & 3.6 & 13.5 & 20.6 & 52.7 & 92.2 & 158.5 \\
\hline $21-30$ & 0.0 & 0.0 & 0.0 & 0.0 & 0.0 & 2.5 & 17.5 & 38.6 & 55.3 & 85.1 & 248.9 \\
\hline dez. $1-10$ & 0.0 & 0.0 & 0.0 & 0.0 & 5.7 & 14.1 & 26.0 & 79.7 & 96.9 & 152.4 & 215.6 \\
\hline $11-20$ & 0.0 & 0.0 & 0.0 & 10.0 & 12.7 & 28.5 & 51.9 & 80.0 & 138.1 & 185.9 & 227.3 \\
\hline $21-31$ & 0.0 & 2.0 & 29.4 & 60.4 & 72.4 & 89.2 & 95.0 & 101.1 & 126.0 & 141.2 & 355.2 \\
\hline
\end{tabular}


TABELA 71 - RIBEIRAO PRETO: AGUA FACILHENTE DISPOMUUEL (BALANCO COM AFD $=75$ ER)

DECIL

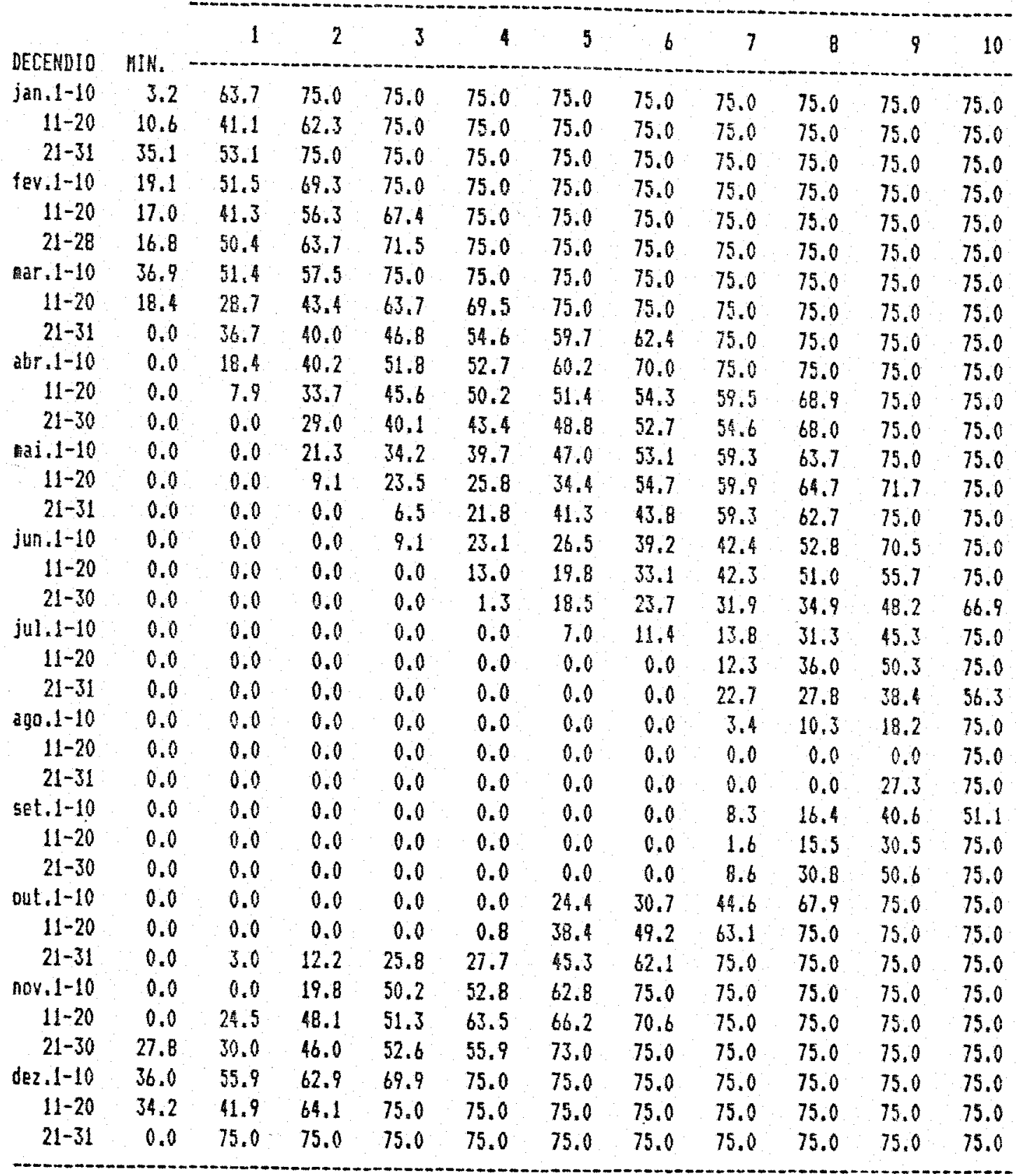


TABELA 72 - RIBEIRAO PRETO: DEFICITES (BALANCO COM AFD = 75 解)

DECIL.

\begin{tabular}{|c|c|c|c|c|c|c|c|c|c|c|c|}
\hline DECENDIO & MIN. & 1 & 2 & 3 & \begin{tabular}{c}
4 \\
- \\
\hdashline
\end{tabular} & 5 & 6 & 7 & $B$ & 9 & 10 \\
\hline jan.1-10 & 0.0 & 0.0 & 0.0 & 0.0 & 0.0 & 0.0 & 0.0 & 0.0 & 0.0 & 0.0 & 0.0 \\
\hline $11-20$ & 0.0 & 0.0 & 0.0 & 0.0 & 0.0 & 0.0 & 0.0 & 0.0 & 0.0 & 0.0 & 0.0 \\
\hline $21-31$ & 0.0 & 0.0 & 0.0 & 0.0 & 0.0 & 0.0 & 0.0 & 0.0 & 0.0 & 0.0 & 0.0 \\
\hline fev. $1-10$ & 0.0 & 0.0 & 0.0 & 0.0 & 0.0 & 0.0 & 0.0 & 0.0 & 0.0 & 0.0 & 0.0 \\
\hline $11-20$ & 0.0 & 0.0 & 0.0 & 0.0 & 0.0 & 0.0 & 0.0 & 0.0 & 0.0 & 0.0 & 0.0 \\
\hline $21-28$ & 0.0 & 0.0 & 0.0 & 0.0 & 0.0 & 0.0 & 0.0 & 0.0 & 0.0 & 0.0 & 0.0 \\
\hline var. $:-10$ & 0.0 & 0.0 & 0.0 & 0.0 & 0.0 & 0.0 & 0.0 & 0.0 & 0.0 & 0.0 & 0.0 \\
\hline $11-20$ & 0.0 & 0.0 & 0.0 & 0.0 & 0.0 & 0.0 & 0.0 & 0.0 & 0.0 & 0.0 & 0.0 \\
\hline $21-31$ & 0.0 & 0.0 & 0.0 & 0.0 & 0.0 & 0.0 & 0.0 & 0.0 & 0.0 & 0.0 & 7.7 \\
\hline abr. $1-10$ & 0.0 & 0.0 & 0.0 & 0.0 & 0.0 & 0.0 & 0.0 & 0.0 & 0.0 & 0.0 & 30.5 \\
\hline $11-20$ & 0.0 & 0.0 & 0.0 & 0.0 & 0.0 & 0.0 & 0.0 & 0.0 & 0.0 & 0.0 & 19.2 \\
\hline $21-30$ & 0.0 & 0.0 & 0.0 & 0.0 & 0.0 & 0.0 & 0.0 & 0.0 & 0.0 & 3.9 & 27.3 \\
\hline ai.1-10 & 0.0 & 0.0 & 0.0 & 0.0 & 0.0 & 0.0 & 0.0 & 0.0 & 0.0 & 5.9 & 25.8 \\
\hline $11-20$ & 0.0 & 0.0 & 0.0 & 0.0 & 0.0 & 0.0 & 0.0 & 0.0 & 0.0 & 0.0 & 20.2 \\
\hline $21-31$ & 0.0 & 0.0 & 0.0 & 0.0 & 0.0 & 0.0 & 0.0 & 0.0 & 0.0 & 7.2 & 19.6 \\
\hline jun. $1-10$ & 0.0 & 0.0 & 0.0 & 0.0 & 0.0 & 0.0 & 0.0 & 0.0 & 5.4 & 19.7 & 24.8 \\
\hline $11-20$ & 0.0 & 0.0 & 0.0 & 0.0 & 0.0 & 0.0 & 0.0 & 1.0 & 15.4 & 20.9 & 24.1 \\
\hline $21-30$ & 0.0 & 0.0 & 0.0 & 0.0 & 0.0 & 0.0 & 0.0 & 2.6 & 18.1 & 21.1 & 24.7 \\
\hline jul.1-10 & 0.0 & 0.0 & 0.0 & 0.0 & 0.0 & 0.0 & 3.2 & 14.0 & 21.3 & 23.3 & 25.6 \\
\hline $11-20$ & 0.0 & 0.0 & 0.0 & 0.0 & 0.0 & 10.3 & 17.0 & 21.6 & 23.3 & 25.4 & 27.0 \\
\hline $21-31$ & 0.0 & 0.0 & 0.0 & 0.0 & 5.6 & 17.2 & 23.3 & 24.9 & 27.5 & 28.5 & 30.9 \\
\hline $\operatorname{ago}=1-10$ & 0.0 & 0.0 & 0.0 & 0.0 & 1.7 & 19.4 & 24.6 & 25.7 & 27.3 & 27.8 & 29.7 \\
\hline $11-20$ & 0.0 & 0.0 & 10.0 & 11.2 & 17.1 & 23.0 & 25.6 & 26.5 & 27.5 & 28.9 & 33.6 \\
\hline $21-31$ & 0.0 & 0.0 & 1.9 & 8.9 & 24.0 & 29.6 & 31.8 & 32.6 & 35.1 & 35.4 & 38.8 \\
\hline set. $1-10$ & 0.0 & 0.0 & 0.0 & 0.0 & 6.8 & 16.9 & 26.7 & 26.2 & 31.8 & 33.5 & 41.8 \\
\hline $11-20$ & 0.0 & 0.0 & 0.0 & 0.0 & 0.6 & 16.5 & 28.4 & 33.4 & 36.2 & 38.5 & 41.8 \\
\hline $21-30$ & 0.0 & 0.0 & 0.0 & 0.0 & 0.0 & 2.8 & 6.9 & 12.1 & 25.9 & 33.5 & 37.6 \\
\hline out. $1-10$ & 0.0 & 0.0 & 0.0 & 0.0 & 0.0 & 0.0 & 0.0 & 11.3 & 32.5 & 37.6 & 47.2 \\
\hline $11-20$ & 0.0 & 0.0 & 0.0 & 0.0 & 0.0 & 0.0 & 0.0 & 3.4 & 16.7 & 27.6 & 89.8 \\
\hline $21-31$ & 0.0 & 0.0 & 0.0 & 0.0 & 0.0 & 0.0 & 0.0 & 0.0 & 0.0 & 0.0 & 47.4 \\
\hline nov. $1-10$ & 0.0 & 0.0 & 0.0 & 0.0 & 0.0 & 0.0 & 0.0 & 0.0 & 0.0 & 0.0 & 30.4 \\
\hline $11-20$ & 0.0 & 0.0 & 0.0 & 0.0 & 0.0 & 0.0 & 0.0 & 0.0 & 0.0 & 0.0 & 30.7 \\
\hline $21-30$ & 0.0 & 0.0 & 0.0 & 0.0 & 0.0 & 0.0 & 0.0 & 0.0 & 0.0 & 0.0 & 0.0 \\
\hline $6 e 2.1-10$ & 0.0 & 0.0 & 0.0 & 0.0 & 0.0 & 0.0 & 0.0 & 0.0 & 0.0 & 0.0 & 0.0 \\
\hline $11-20$ & 0.0 & 0.0 & 0.0 & 0.0 & 0.0 & 0.0 & 0.0 & 0.0 & 0.0 & 0.0 & 0.0 \\
\hline $21-31$ & 0.0 & 0.0 & 0.0 & 0.0 & 0.0 & 0.0 & 0.0 & 0.0 & 0.0 & 0.0 & 6.1 \\
\hline
\end{tabular}


TABELA 73 - FIBEIRAO PRETO: EXCEDENTES HIDRICOS (BALANCO COM AFD $=75$. 酷)

DECIL

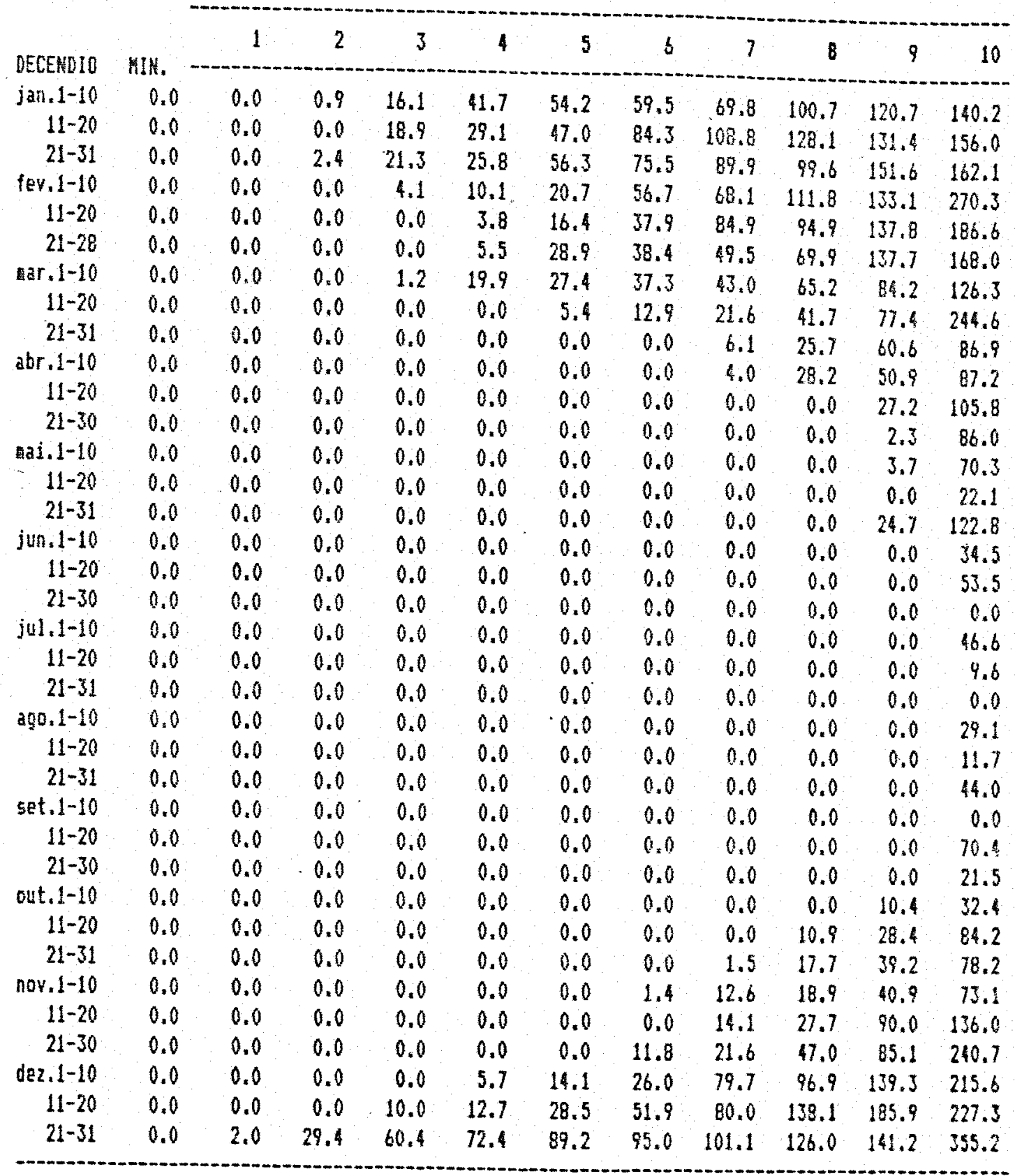

